Faculdade de Arquitetura e Urbanismo

Universidade de São Paulo

\title{
IMPACTO DA VEGETAÇÃO NOS MICROCLIMAS URBANOS EM FUNÇÃO DAS INTERAÇÕES SOLO- VEGETAÇÃO-ATMOSFERA
}

Paula Shinzato

São Paulo, 2014 


\title{
Paula Shinzato
}

\section{IMPACTO DA VEGETAÇÃO NOS MICROCLIMAS URBANOS EM FUNÇÃO DAS INTERAÇÕES SOLO- VEGETAÇÃO-ATMOSFERA}

\author{
Tese apresentada junto à Faculdade de Arquitetura e \\ Urbanismo da Universidade de São Paulo como \\ requisito parcial para obtenção do título de Doutor \\ em Arquitetura e Urbanismo. Área de Concentração: \\ Tecnologia da Arquitetura
}

Orientadora: Prof. Dra. Denise Helena Silva Duarte

\begin{abstract}
EXEMPLAR REVISADO E ALTERADO EM RELAÇÃO À VERSÃO ORIGINAL. SOB RESPONSABILIDADE DO AUTOR E ANUÊNCIA DO ORIENTADOR.
\end{abstract}

$O$ original se encontra disponível na sede do programa.

São Paulo, 29 de julho de 2014 
AUTORIZO A REPRODUÇÃO E DIVULGAÇÃO TOTAL OU PARCIAL DESTE TRABALHO, POR QUALQUER MEIO CONVENCIONAL OU ELETRÔNICO, PARA FINS DE ESTUDO E PESQUISA, DESDE QUE CITADA A FONTE.

E-MAIL: paulashinzato@yahoo.com

Shinzato, Paula

S556im Impacto da vegetação nos microclimas urbanos em função das interações solo-vegetação-atmosfera / Paula Shinzato. -- São Paulo, 2014.

205 p. : il.

Tese (Doutorado - Área de Concentração: Tecnologia da Arquitetura) - FAUUSP.

Orientadora: Denise Helena Silva Duarte

1.Microclima urbano 2.Vegetação 3.Impactos ambientais I.Título

CDU 551.584.5 


\section{Dedicatória}

Ao meu mestre da vida, pelos contínuos incentivos;

À minha família pelo apoio em todos os momentos;

Ao meu amor pelo carinho e por toda ajuda; 


\section{Agradecimentos}

À Fundação de Amparo à Pesquisa do Estado de São Paulo - FAPESP, pela concessão da bolsa de doutorado e pelo apoio financeiro para a realização desta pesquisa.

Ao Conselho Nacional de Desenvolvimento Científico e Tecnológico - CNPq, pelo suporte nos estágios iniciais da pesquisa.

À minha orientadora, Prof. Dra. Denise Helena Silva Duarte, pelo acompanhamento em todas as etapas da pesquisa e pelo direcionamento que possibilitou atingir os objetivos pretendidos no estudo sobre a vegetação urbana.

Aos professores, pesquisadores e amigos do Laboratório de Conforto Ambiental e Eficiência Energética - LABAUT, que ajudaram na discussão da pesquisa: Prof. Marcia Alucci, Prof. Joana Gonçalves, Prof. Roberta Kronka Mülfarth, Prof. Norberto Moura, Monica P. Marcondes Cavaleri e Bruna Luz.

Aos amigos e pesquisadores do LABAT que ajudaram tanto nos trabalhos de campo no Parque Trianon e como na discussão dos resultados: Carolina Gusson, Vanessa Guillon, Carolina Alves, Ranieri Higa, Leonardo Marques Monteiro.

Aos estudantes de iniciação científica pela ajuda na aplicação das metodologias de medição do índice de área foliar e uso do termovisor, assim como pela ajuda nos trabalhos de campo no Trianon: Denise Cordeiro Moreira, Fernanda Camargo Barros, Barbara Ferronato, Gabriel Alencar Novaes, Larissa Oliveira, Rosane Fukuoka, Jenniffer Liao, Angela Madeira, Camila Lacerda, Lara Goes de Andrade, Danielle Naomi Iwai.

À Carolina Gusson por compartilhar seus conhecimentos e ajudar nos estudos aplicados para o programa ENVI-met.

Ao grupo de pesquisa do Laboratório de Clima e Biosfera do IAG-USP: Prof. Dr. Humberto Ribeiro da Rocha, Dr. Tomás Domingues, Fernanda Luccas e Rafael Maia pela ajuda nos dados referentes a umidade e temperatura do solo; e plotagem dos dados de vento.

Ao grupo de pesquisa da FEC da UNICAMP Prof. Dra. Lucila Chebel Labaki, Alessandra Prata Shimomura, e à Simone pela assistência e curso do ENVI-met. 
À Secretaria do Verde e Meio Ambiente, e ao grupo de administração do Parque Trianon pela autorização e acompanhamento realização da pesquisa: Priscilla Martins Cerqueira, Rita de Cássia Ferreira Nakamura, Eliane de Andrade Azevedo, e ao atual administrador do Parque Trianon, Caio Sérgio de Oliveira Serroni. Sem esquecer a equipe de segurança no período noturno.

À pesquisadora Prof. Dra. Eleonora Sad de Assis pela ajuda no processo de calibração e dados de entrada do ENVI-met.

Ao Prof. Dr. Demóstenes Ferreira da Silva Filho e ao pesquisador Jefferson Lordello Polizel do Departamento de Ciências Florestais da Escola Superior de Agricultura "Luiz de Queiroz" - ESALq USP, pelo auxílio nas medições do Índice de Área Foliar e empréstimo do equipamento LAI-2000.

Ao Instituto de Astronomia Geofísica e Ciências Atmosféricas IAG USP, pelo fornecimento dos dados da estação meteorológica, localizado no Aeroporto de Congonhas, São Paulo. Ao pesquisador Marcos Lourenço Pereira pela assistência nos dados.

Ao grupo do Instituto de Astronomia Geofísica e Ciências Atmosféricas IAG USP no Parque de Ciência e Tecnologia da USP, no bairro da Água Funda, São Paulo, pelo fornecimento dos dados da estação meteorológica, especialmente a Sergio T. Salum.

À querida amiga Érika Mitie Umakoshi, pela cumplicidade e por poder compartilhar cada fase alcançada nesses anos de pesquisa.

Aos meus pais pelo apoio incondicional e todos os incentivos voltados ao estudo.

Aos meus irmãos, Daniela e Marcelo, por toda ajuda.

Ao meu amor, por estar sempre ao meu lado, apoiando sempre.

Às pessoas que, ao longo de todo o percurso, ofereceram contribuições na discussão sobre o tema, com sugestões e questionamentos importantes. 


\section{Sumário}

1. INTRODUÇÃO .............................................................................................. 21

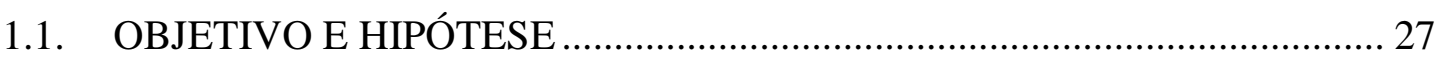

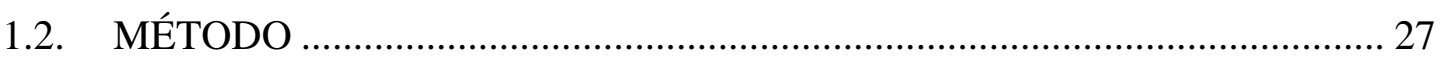

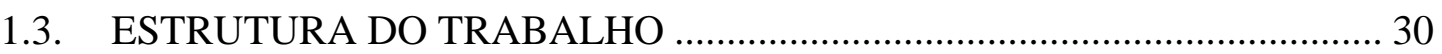

2. INTERAÇÃO SOLO-VEGETAÇÃO-ATMOSFERA .................................... 32

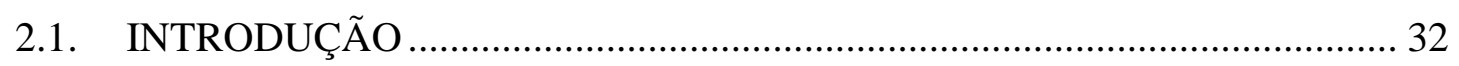

2.2. INTERAÇÃO VEGETAÇÃO-ATMOSFERA - NA ESCALA DA FOLHA. 34

2.2.1. FLUXO DE CALOR LATENTE PELA FOLHA.................................... 39

2.3. INTERAÇÃO SOLO-VEGETAÇÂO-ATMOSFERA NA ESCALA DA

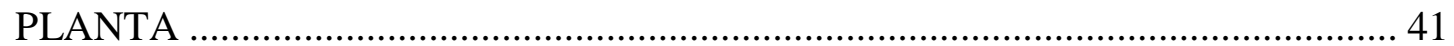

2.3.1. FLUXO DE CALOR LATENTE PELA PLANTA ................................. 41

2.3.2. FLUXO DE CALOR LATENTE PELO SOLO .................................... 45

3. CONCEITOS, APLICAÇÕES, MÉTODOS DE MEDIÇÃO E CÁLCULO DO ÍNDICE DE ÁREA FOLIAR - IAF .............................................................................. 47

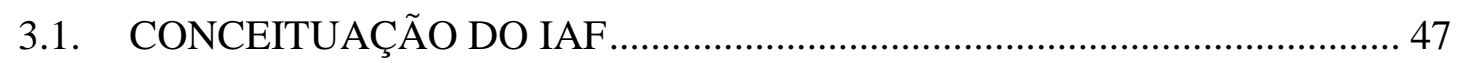

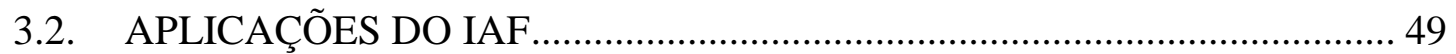

3.3. MÉTODOS DE MEDIÇÃO E CÁLCULO DO IAF........................................ 54

3.3.1. MÉTODOS DIRETOS DE MEDIÇÃO DO IAF.................................... 54

3.3.2. MÉTODOS INDIRETOS DE MEDIÇÃO DO IAF ............................... 57

3.4. COMPARAÇÕES ENTRE OS EQUIPAMENTOS E VALORES TÍPICOS

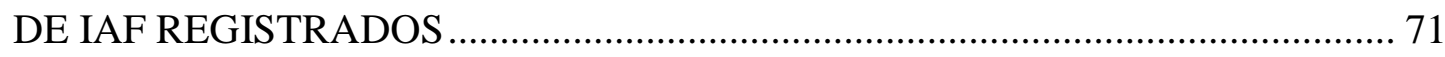

4. APLICAÇÃO DO MODELO ENVI-met PARA O ESTUDO DO IMPACTO

DA VEGETAÇÃO NOS MICROCLIMAS URBANOS............................................ 76

4.1. BREVE DESCRIÇÃO DO MODELO ENVI-met 3.1 BETA ......................... 76

4.2. MODELOS DE CÁLCULO NO ENVI-met ................................................ 78

4.2.1. MODELO ATMOSFÉRICO DE TEMPERATURA E UMIDADE........ 78

4.2.2. MODELO DE FLUXOS RADIATIVOS .............................................. 79

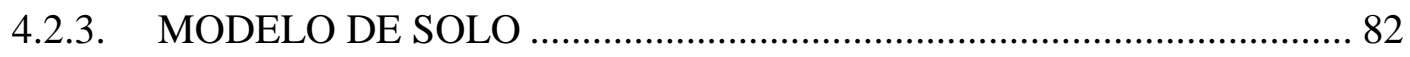

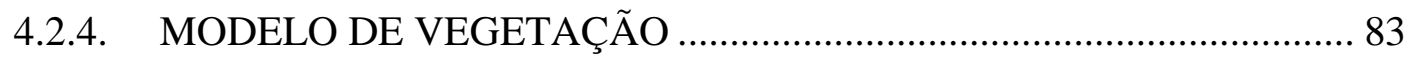

4.3. AVANÇOS DO MODELO ENVI-MET ….................................................. 86

4.4. PROCESSO DE SIMULAÇÃO NO ENVI-met v. 3.1 .................................. 89

4.4.1. CONSTRUÇÃO DA MODELAGEM ................................................ 90 
4.4.2. CONFIGURAÇÃO DOS DADOS DE ENTRADA .............................. 91

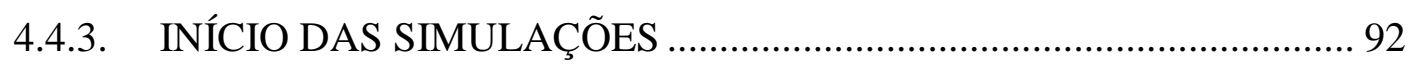

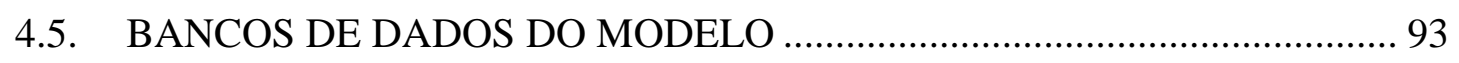

4.5.1. BANCO DE DADOS DE VEGETAÇÃO (PLANTS.DAT) ................... 93

4.5.2. BANCO DE DADOS DE SOLO/ MATERIAIS (SOILS.DAT) .............. 95

4.1.1 BANCO DE DADOS DO PERFIL DOS MATERIAS (PROFILS.DAT) 98

4.5.3. BANCO DE DADOS DE FONTES ANTROPOGÊNICAS ................... 98

5. MEDIÇÕES MICROCLIMÁTICAS NO PARQUE TRIANON ..................... 99

5.1 BREVE HISTÓRICO DO PARQUE TENENTE SIQUEIRA CAMPOS -

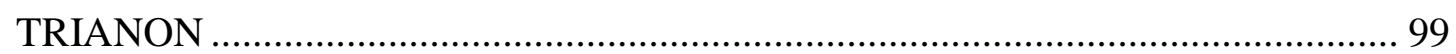

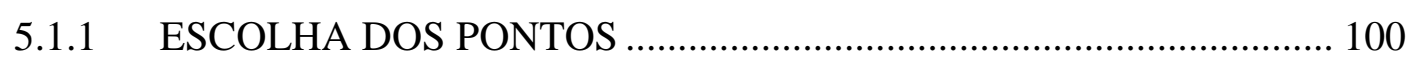

5.2 MEDIÇÕES PARA O PERÍODO DE DIAS FRIOS ..................................... 104

5.3 MEDIÇÕES PARA O PERÍODO DE DIAS QUENTES ............................. 106

5.4 TABULAÇÃO DOS DADOS ..................................................................... 107

5.5 ANÁLISE DOS RESULTADOS ….......................................................... 108

5.5.1 DADOS DE TEMPERATURA DO AR …........................................ 108

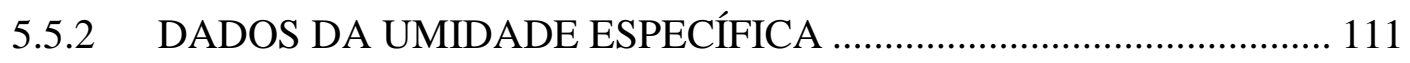

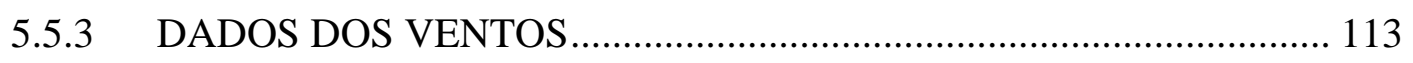

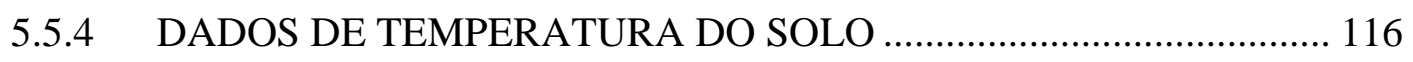

5.5.5 DADOS DE TEMPERATURA DE GLOBO E TEMPERATURA

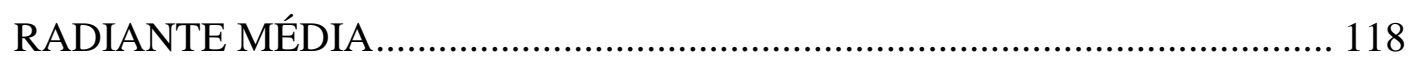

6. MEDIÇÕES DO ÍNDICE DE ÁREA FOLIAR - IAF NO PARQUE

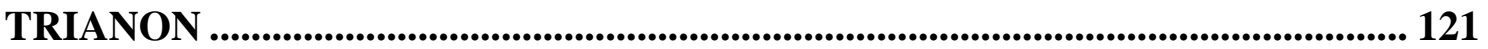

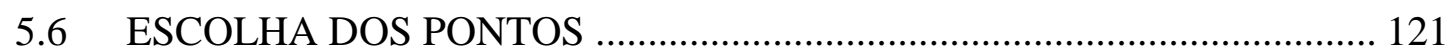

5.7 MEDIÇÕES COM O EQUIPAMENTO LAI 2000 ................................... 123

5.8 MEDIÇÕES COM FOTOS HEMISFÉRICAS .......................................... 129

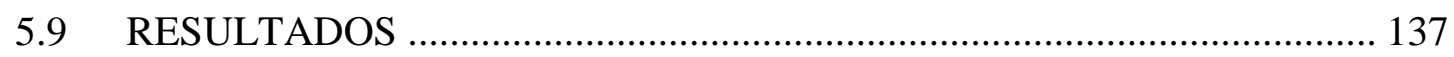

7. SIMULAÇÕES PARAMÉTRICAS NO ENVI-MET ........................................ 139

7.1 SIMULAÇÕES PRELIMINARES - PROCESSO DE CALIBRAÇÃO DO

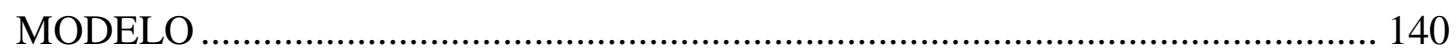

7.1.1 CONFIGURAÇÃO DOS DADOS DE ENTRADA …................................. 145

7.1.2 RESULTADO DA SIMULAÇÃO DE CALIBRAÇÃO ........................ 147

7.2 SIMULAÇÕES PARAMÉTRICAS ........................................................ 149

7.2.1 CENÁRIOS DAS SIMULAÇÕES PARAMÉTRICAS............................. 150 
7.2.2 MODELAGEM DAS ÁRVORES NO ENVI-MET . 153

8. ANÁLISE DOS RESULTADOS E COMPROVAÇÃO DA TESE 159

8.1 RESULTADOS E ANÁLISES DAS SIMULAÇÕES PARAMÉTRICAS .. 159

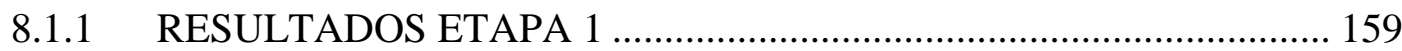

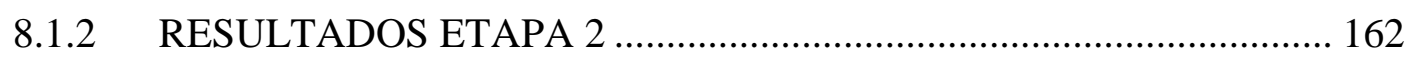

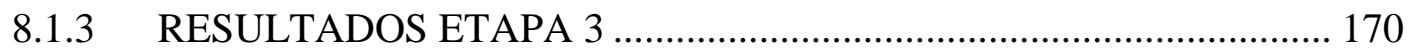

8.1.4 RESULTADOS DA ETAPA 4 …………………………………..... 173

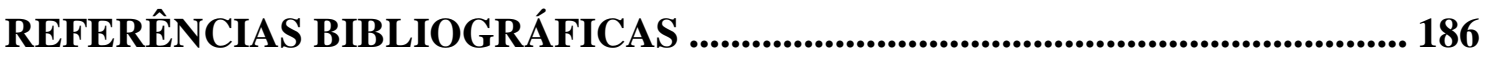




\section{Índice de Tabelas}

Tabela 1 - Diferença entre os equipamentos de análise do gap fraction no dossel

arbóreo

Tabela 2 - Diferença entre os equipamentos de análise do gap size no dossel arbóreo. 74

Tabela 3: Principais Variáveis utilizadas pelo ENVI-met................................................. 77

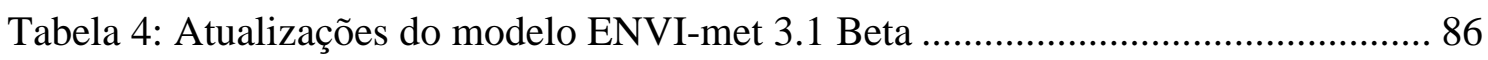

Tabela 5: Informações de cada planta no banco de dados de vegetação do ENVI-met. 93

Tabela 6: Informações sobre os tipos de solo/ materiais ............................................... 95

Tabela 7: Informações sobre o perfil dos materiais......................................................... 98

Tabela 8: Especificação dos instrumentos presentes na estação meteorológica Campbell

Tabela 9: Dados de saída das medições realizadas em 26 de julho de 2012, no campus da USP (céu aberto)

Tabela 10: Dados de saída das medições realizadas em 31 de julho de 2012, no campus

da USP (céu encoberto) 126

Tabela 11: Dados de Saída - Medições de IAF (09/09/2012) no Parque Trianon

Tabela 12: Valores das coordenadas x e y de cada imagem. 134

Tabela 13: Dados do asfalto no SOIL.DAT e PERFILS.DAT.

Tabela 14: Dados do solo no SOIL.DAT e PERFILS.DAT.

Tabela 15: Configuração dos dados climáticos

Tabela 16: Valores de DAF e IAF para os tipos de vegetação existentes no banco de dados do ENVI-met v. 3.1

Tabela 17: Principais espécies de vegetação existente no Parque Trianon 


\section{Índice de Figuras}

Figura 1: Etapas do desenvolvimento da pesquisa ................................................... 29

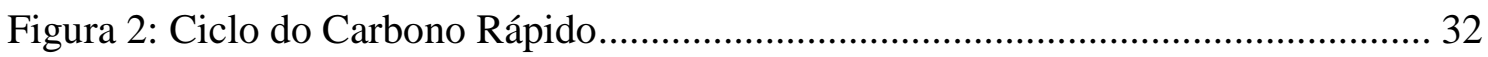

Figura 3: Efeito da Radiação nas plantas, sendo (+) significativo; (x) pouco; (o)

insignificante.

Figura 4: Coeficientes médios para absorção, reflexão e transmissão em quatro

principais bandas de comprimento de onda.

Figura 5: Emissividade da grama e do solo em relação a diferentes comprimentos de onda.

Figura 6: Resistência estomática de acordo com as condições externas e interna à folha.

Figura 7: Modelo da resistência da planta segundo a equação de Monteith (1965b)..... 43

Figura 8: Taxa de fotossíntese em relação ao aumento da concentração de $\mathrm{CO}_{2}$.......... 44

Figura 9: Taxa de fotossíntese em relação à concentração de $\mathrm{CO}_{2}$ para plantas $\mathrm{C} 3$ e $\mathrm{C} 4$.

Figura 10: Valores representativos da resistência aerodinâmica e da copa.................... 45

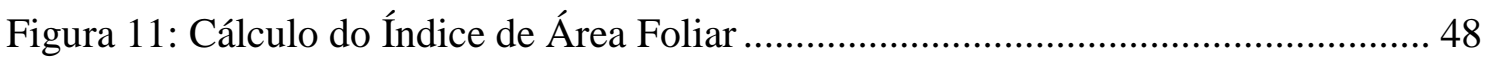

Figura 12: Relação da cobertura de folhas e o índice de área foliar.............................. 49

Figura 13: Representação dos três tipos de vegetação no indicador do Green Plot Ratio.

Figura 14: Distribuição da vegetação mantendo-se a mesma densidade foliar da Figura 16.

Figura 15: Distribuição da vegetação com diferentes valores de IAF, para um mesmo GPR.

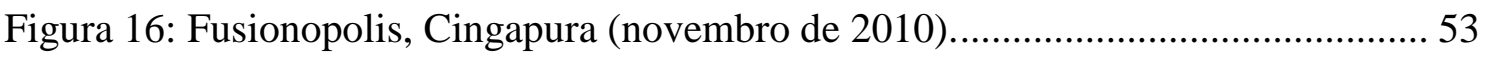

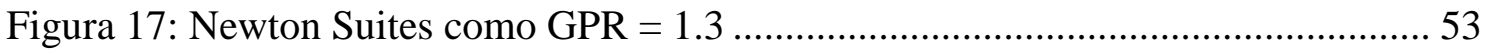

Figura 18: Empreendimento Oasia Dowtown com GPR = 7.5 …............................... 54

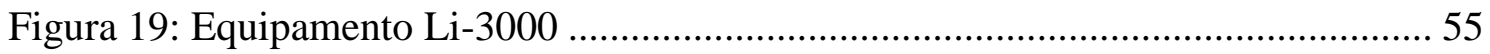

Figura 20: Equipamento Transparent Belt Conveyer ( $\mathrm{Li} 3050 \mathrm{c})$.................................... 56

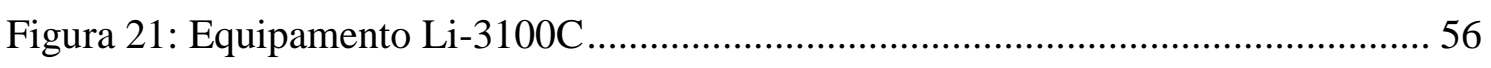

Figura 22: Diferença entre gap size e gap fraction.................................................. 58 
Figura 23: Penetração da radiação para um ângulo zenital $66^{\circ} \mathrm{em}$ uma copa com folhas

(a) horizontais

Figura 24: Equipamento LAI-2000 Plant Canopy Analyzer e a última versão, o LAI2200 .

Figura 25: Estrutura interna do equipamento LAI-2000/LAI -2200_............................ 63

Figura 26: Foto da lente grande angular com os 5 anéis concêntricos............................ 63

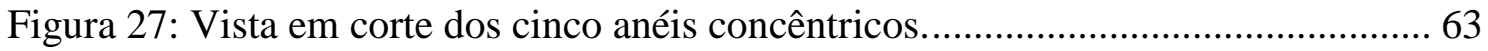

Figura 28: Tipos de capas para acoplar na lente angular (YOK; SIA, 2010)................ 64

Figura 29: Proposta de utilização das capas para áreas pequenas ou para mascarar o operador do equipamento.

Figura 30: Imagens de uma mesma copa registradas em diferentes condições de céu: céu encoberto e céu claro.

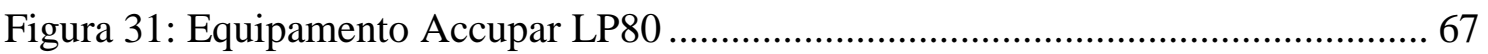

Figura 32: Funcionamento do SunScan junto com o controle PDA. .............................. 68

Figura 33: Esquema do funcionamento do equipamento SunScan. .............................. 68

Figura 34: Principais partes do instrumento óptico TRAC. Figura 35: Detalhe dos três sensores fotossensitivos do aparelho TRAC.

Figura 36: Foto hemisférica pelo software HemiView ................................................ 71

Figura 37: Foto hemisférica com a projeção da carta solar pelo software HemiView... 71

Figura 38: Foto hemisférica pelo software WinScanopy. ........................................... 71

Figura 39: Medições com o LAI-2000 em Cingapura.................................................. 75

Figura 40: Imagem da tela do novo 3D editor do ENVI-met 4.0 .............................. 87

Figura 41: Imagem da tela do novo 3D editor para vegetação no ENVI-met 4.0......... 88

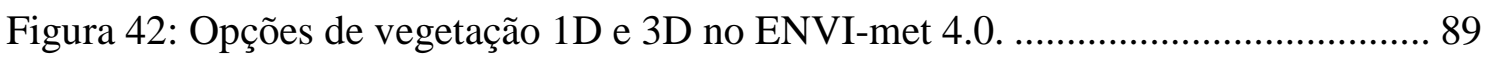

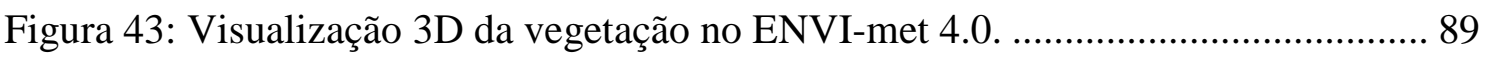

Figura 44: Estrutura geral do processo de simulação do ENVI-met............................. 90

Figura 45: Layout básico do modelo ENVI-met. ..................................................... 91

Figura 46: Distribuição das alturas: Eqüidistante (A), Telescópico com fator de

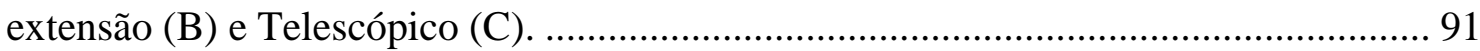

Figura 47: Opções do formato final a ser simulado no modelo ENVI-met.................... 92

Figura 48: Resultados de simulações geradas pelo Leonardo (2D).............................. 93

Figura 49: Resultados de simulações geradas pelo Leonardo (3D)............................... 93

Figura 50: Versão do triângulo de Feret com os tipos de solo. .................................... 97

Figura 51: Localização dos dois pontos de medição no Parque Trianon. ..................... 101 
Figura 52: Montagem das estações meteorológicas Campbell.

Figura 53: Ajuste na leitura dos dados medidos pela estação meteorológica. .............. 103

Figura 54: Teste das estações meteorológicas no Campus da USP.............................. 103

Figura 55: Localização do equipamento no Parque Trianon, ponto 1 (entrada do parque).

Figura 56: Localização do equipamento no Parque Trianon, ponto 2 (parte central). . 104

Figura 57: Entorno do ponto 1, próximo à entrada do Parque Trianon........................ 105

Figura 58: Entorno do ponto 2, próximo ao playground............................................. 105

Figura 59: Visão de céu no ponto 1, próximo à entrada parque Trianon (1); visão de céu no ponto 2, próximo à parte central do parque (2) (fotos: D. Moreira). 105

Figura 60: Localização dos pontos de medição no Parque Trianon e mudança do ponto 1 .

Figura 61: Localização do equipamento no Parque Trianon no ponto 1, entrada do parque (1) e ponto 2, parte central (2).

Figura 62: Visão de céu no ponto 1, próximo à entrada parque Trianon (1); visão de céu no ponto 2 , próximo à parte central do parque (2) (fotos: P. Shinzato).

Figura 63: Temperatura do ar para as estações ponto 1 e 2; Parque Água Funda e Aeroporto de Congonhas - Dados para o período de dias frios.

Figura 64: Temperatura do ar para as estações ponto 1 e 2; Parque Água Funda e

Aeroporto de Congonhas - Dados para o período de dias quentes.

Figura 65: Umidade específica para as estações ponto 1 e 2; Parque Água Funda e Aeroporto de Congonhas - Dados para o período de dias frios.

Figura 66: Umidade específica para as estações ponto 1 e 2; Parque Água Funda e Aeroporto de Congonhas - Dados para o período de dias quentes.

Figura 67: Velocidade do vento para as estações ponto 1 e 2; Parque Água Funda e Aeroporto de Congonhas - Dados para o período de dias frios.

Figura 68: Velocidade do vento para as estações ponto 1 e 2; Parque Água Funda e Aeroporto de Congonhas - Dados para o período de dias quentes.

Figura 69: Velocidade do vento para as estações ponto 1 e 2; Parque Água Funda e Aeroporto de Congonhas - Dados para o período de dias quentes.

Figura 70: Direção dos ventos para as estações ponto 1 e 2 - Dados para o período de dias frios.

Figura 71: Temperatura de solo para as estações ponto 1 e 2 - Dados para o período de dias frios. 
Figura 72: Temperatura de solo para as estações ponto 1 e 2 - Dados para o período de dias quentes.

Figura 73: Temperatura de globo para as estações ponto 1 e 2 - Dados para o período de dias frios.

Figura 74: Temperatura radiante média para as estações ponto 1 e 2 - Dados para o

período de dias frios.

Figura 75: Temperatura de globo para as estações ponto 1 e 2 - Dados para o período de dias quentes.

Figura 76: Temperatura radiante média para as estações ponto 1 e 2 - Dados para o período de dias quentes

Figura 77: Entorno da área 1 no parque Trianon..................................................... 121

Figura 78: Entorno da área 2 no parque Trianon...................................................... 121

Figura 79: Localização da área com os pontos de medição no Parque Trianon, próximo ao playground.

Figura 80: Posições das 22 fotos tiradas no Parque Trianon.

Figura 81: Capas protetoras escolhidas $\left(90^{\circ}\right.$ e $\left.180^{\circ}\right)$

Figura 82: Indicação do uso do LAI 2000 com capa $90^{\circ}$ em áreas abertas (e) e embaixo da copa (f)

Figura 83: Representação da porção da copa vista pelo sensor, utilizando a capa restritora $270^{\circ}(\mathrm{a}, \mathrm{b}), 180^{\circ}(\mathrm{c})$ e $90^{\circ}(\mathrm{d})$

Figura 84: Área escolhida para as medições-teste.

Figura 85: Medição no ponto interno à copa da árvore.

Figura 86: Valores de IAF medidos no campus da USP.

Figura 87: Valores de IAF medidos no Parque Trianon.

Figura 88: Resultados do valor de IAF para os 22 pontos no Parque Trianon.

Figura 89: Foto Hemisférica e valor de IAF do Ponto 5 (1); Foto Hemisférica e valor de IAF do Ponto 19 (2).

Figura 90: Câmera Nikon COOLPIX 4500 com lente grande angular acoplada.

Figura 91: Esquema do cálculo da extensão da imagem no plano horizontal. 130

Figura 92: Resultados das 22 imagens registradas no Parque Trianon-Medição em agosto de 2012 .

Figura 93: Resultados das 22 imagens registradas no Parque Trianon - Fevereiro de 2013

Figura 94: Tampa com três furos necessários para calibração colocada sobre a lente. 133 
Figura 95: Série de imagens registradas em diferentes rotações da lente grande angular. Neste caso, três pontos para cada foto foram considerados. (Fotos: Moreira, D.) ....... 134 Figura 96: Montagem das três réguas e posicionamento da câmera digital. (Foto:

Shinzato, P.) 135

Figura 97: Esquema de montagem para a calibragem da lente. 135

Figura 98: Foto registrada com distância de 52cm no LAME / FAUUSP. (Foto:

Moreira, D)

Figura 99: Pré-processamento da imagem. 136

Figura 100: Classificação de cores. 136

Figura 101: Estrutura do modelo para cálculo do IAF. 137

Figura 102: Valores de IAF para áreas 1 e 2 do Pq. Trianon, com os 2 métodos de medição 138

Figura 103: IAF médio para os 22 pontos considerando desvio padrão. 138

Figura 104: Estrutura geral do processo de calibração do ENVI-met. 139

Figura 105: Definição da área no entorno do Parque Trianon para modelagem no ENVImet.

Figura 106: Distribuição da malha de 10x10m sobre o modelo da SEMPLA.

Figura 107: Disposição de edifícios e áreas verdes na modelagem construída no ENVImet.

Figura 108: Distribuição dos valores de IAF = 2,5 em 10 camadas de uma arbórea... 142 Figura 109: Distribuição dos valores de IAF = 1,0 em 10 camadas de uma arbustiva. 142 Figura 110: Configuração dos tipos de solo do modelo gerado no ENVI-met. 144 Figura 111: Localização dos receptores no modelo gerado no ENVI-met.

Figura 112: Resultados de temperatura do ar simulados no ENVI-met (receptor aa) e os dados medidos nas duas estações meteorológicas - primeira fase de simulações, para os dias 13 a 15 de novembro de 2013 . 148 Figura 113: Resultados de temperatura do ar simulados no ENVI-met (receptor aa) e os dados medidos nas duas estações meteorológicas - segunda fase de simulações, para os dias 13 a 15 de novembro de 2013.

Figura 114: Resultados de temperatura do ar simulados no ENVI-met (receptor aa) e os dados medidos nas duas estações meteorológicas - terceira fase de simulações, para os dias 13 a 15 de novembro de 2013.

Figura 115: Estrutura geral do processo de simulação na primeira etapa das simulações paramétricas 
Figura 116: Estrutura geral do processo de simulação na segunda etapa das simulações paramétricas.

Figura 117: Estrutura geral do processo de simulação na terceira etapa das simulações paramétricas

Figura 118: Estrutura geral do processo de simulação na quarta etapa das simulações paramétricas. 153

Figura 119: Diferentes formatos de copas das árvores 155

Figura 120: Porcentagem de volume para diferentes formatos de copa. 156

Figura 121: Distribuição dos valores de IAF e DAF para 10 camadas de uma copa arredondada.

Figura 122: Perfil do valor de IAF=1 distribuído em 10 camadas para copa esférica. 157 Figura 123: Perfil do valor de IAF=3 distribuído em 10 camadas para copa esférica. 157 Figura 124: Perfil do valor de IAF=5 distribuído em 10 camadas para copa esférica. 157 Figura 125: Perfil do valor de IAF=1 distribuído em 10 camadas para copa elíptica.. 158 Figura 126: Perfil do valor de IAF=3 distribuído em 10 camadas para copa elíptica.. 158 Figura 127: Perfil do valor de IAF=5 distribuído em 10 camadas para copa elíptica. . 158 Figura 128: Efeito de obstrução da radiação direta para duas alturas $(13 \mathrm{~m}, 0,2 \mathrm{~m})$..... 159 Figura 129: Temperatura do ar abaixo da copa esférica, elíptica vertical e na rua. ..... 160 Figura 130: Umidade Específica abaixo da copa esférica, elíptica vertical e na rua. .. 161 Figura 131: Temperatura de superfície para esférica, elíptica vertical e na rua........... 161 Figura 132: Perfil da velocidade do vento para copas esféricas e elípticas.................. 163

Figura 133: Perfil da velocidade do vento para copa elipsoide vertical...................... 163 Figura 134: Perfil da velocidade do vento para copa esférica...................................... 164 Figura 135: Perfil da velocidade do vento para copa esférica com v=0,5m/s ............. 164 Figura 136: Perfil da velocidade do vento para copa elipsoide vertical com v=0,5m/s 165 Figura 137:Porcentagem da redução do vento para copa esférica................................. 166 Figura 138: Porcentagem da redução do vento para copa elipsoide vertical................. 166 Figura 139: Temperatura do ar para diferentes velocidades do vento para copa esférica

Figura 140: Temperatura do ar para diferentes velocidades do vento para copa elíptica

Figura 141: Umidade específica para diferentes velocidades do vento e valores de densidade para copa esférica 168 
Figura 142: Umidade específica para diferentes velocidades do vento e valores de densidade para copa elíptica

Figura 143: Temperatura de superfícies para diferentes velocidades do vento para copa esférica

Figura 144: Temperatura de superfícies para diferentes velocidades do vento para copa elíptica

Figura 145: Temperatura do ar de acordo com variação da umidade do solo para copa esférica

Figura 146: Temperatura do ar de acordo com variação da umidade do solo para copa elíptica

Figura 147: Umidade específica do ar de acordo com variação da umidade do solo para copa esférica

Figura 148: Umidade específica do ar de acordo com variação da umidade do solo para copa elíptica.

Figura 147: Temperatura de superfície de acordo com variação da umidade do solo para copa esférica

Figura 148: Temperatura de superfície de acordo com variação da umidade do solo para elipsoide vertical.

Figura 144: Tipos de malha ortogonal usada na modelagem: 10mx10m (1) e 5mx5m

Figura 152: Projeção da sombra de uma copa esférica e elipsoide vertical.

Figura 153: Projeção da sombra de uma copa esférica e elipsoide vertical. 175

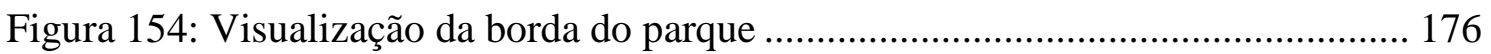

Figura 155: Corte Transversal do Parque ………......................................................... 176

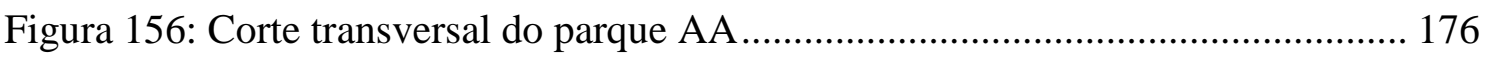

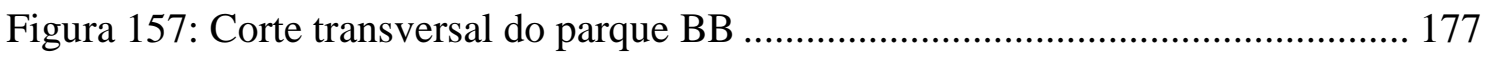

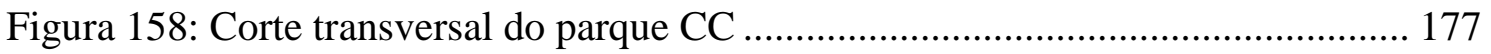

Figura 159: Projeção da sombra de uma copa esférica e elipsoide vertical. ................ 178

Figura 160: Corte transversal do parque DD ............................................................... 178

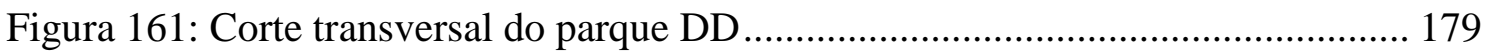

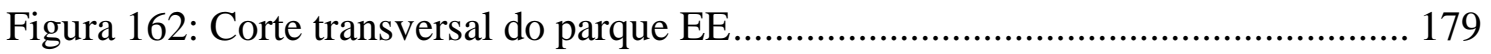

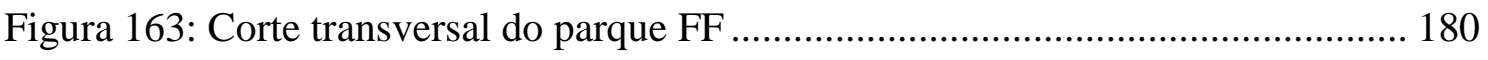

Figura 157: Resultados para TEP nos pontos 1 e 2 no Pq. Trianon. ............................ 183 


\section{Resumo}

SHINZATO, P. Impacto da Vegetação nos Microclimas Urbanos em função das Interações Solo-Vegetação-Atmosfera. 205p. Tese (Doutorado). Faculdade de Arquitetura e Urbanismo, Universidade de São Paulo, São Paulo, 2014.

Este trabalho tem por objetivo quantificar o impacto da vegetação nos microclimas urbanos abaixo do dossel, em função das interações solo-vegetação-atmosfera. Essas interações consideram os efeitos: 1) do dossel propriamente dito, expressos pelas variáveis índice de área foliar - IAF (Leaf Area Index - LAI) e distribuição geométrica das aberturas na copa (gap fraction); 2) da cobertura do solo, expressa pela composição do solo, sua temperatura e teor de umidade, e 3) das variáveis microclimáticas locais (temperatura do ar, umidade do ar, radiação solar, temperatura radiante media, temperatura superficial, direção e velocidade dos ventos). Considerando-se que o impacto da vegetação nos microclimas urbanos é função das interações solo-vegetação-atmosfera, e tendo em vista resultados de estudos anteriores, a hipótese deste trabalho é que, para o clima de São Paulo, em função dos processos de evapotranspiração e do sombreamento, a redução na temperatura do ar abaixo do dossel em parques urbanos será de cerca de $1^{\circ} \mathrm{C}$ e a redução da temperatura superficial será de cerca de $20^{\circ} \mathrm{C}$, ambas em relação às áreas não sombreadas pela vegetação, e que esses efeitos limitam-se à borda do parque sob condições de baixa velocidade do vento, de cerca de $1 \mathrm{~m} / \mathrm{s}$. O método é 1) indutivo, por meio de medições de campo durante o período de dias quentes e frios no Parque Tenente Siqueira Campos (Trianon), na cidade de São Paulo, para o registro de dados microclimáticos e para o levantamento das variáveis do dossel e do solo; e 2) dedutivo, com a calibração entre dados medidos e simulados pelo modelo ENVI-met 3.1 Beta 5 e a simulação de diferentes cenários, variando-se as características do dossel. Para se estimar a densidade foliar média das copas foram adotados dois métodos não-destrutivos indiretos: a medição do IAF com o equipamento LAI-2000 ( $L I-C O R)$ e a análise das fotos hemisféricas, utilizando-se o aplicativo Can-Eye. De acordo com os resultados das simulações, variando-se as caraterísticas do dossel, verificou-se uma redução máxima de $1^{\circ} \mathrm{C}$ na temperatura do ar e de $19^{\circ} \mathrm{C}$ na temperatura superficial, ao se comparar os valores obtidos abaixo de uma copa densa (forma elíptica e IAF $5 \mathrm{~m}^{2} / \mathrm{m}^{2}$ ) em relação às condições do entorno, fora do parque. Esse efeito se estende por, no máximo, $5 \mathrm{~m}$ de distância a partir dos limites do parque, com velocidade do ar de $1 \mathrm{~m} / \mathrm{s}$ e umidade de $40 \%$ na camada superficial do solo $(0-20 \mathrm{~cm})$. Foi feita a aplicação do TEP - Temperatura Equivalente Percebida e verificou-se que a redução de $1^{\circ} \mathrm{C}$ na temperatura do ar pode representar de $3^{\circ} \mathrm{C}$ a $5^{\circ} \mathrm{C}$ no conforto térmico das pessoas. Esses resultados comprovam a hipótese inicial e mostram não apenas a importância do tipo de vegetação escolhida (formato da copa, IAF e distribuição geométrica das aberturas na copa) como as características do meio em que ela está inserida (condições microclimáticas locais e de solo). Os resultados podem contribuir para a formulação de políticas públicas visando à mitigação dos efeitos de aquecimento urbano, particularmente diurnos, em climas tropicais.

Palavras-chave: microclima urbano, vegetação, impactos ambientais 


\begin{abstract}
SHINZATO, P. The Impact of Vegetation on Urban Microclimates as a function of Soil-Vegetation-Atmosphere Interactions. 205p. Thesis (Doctoral). Faculdade de Arquitetura e Urbanismo, Universidade de São Paulo, São Paulo, 2014.
\end{abstract}

The objective of this work is to quantify the impact of vegetation on urban microclimates, under the canopy, due to soil-vegetation-atmosphere interactions. It considers the following effects: 1 ) the canopy itself, expressed by the variable leaf area index - LAI and the geometric openness distribution in the canopy (gap fraction); 2) the soil coverage, expressed by soil composition, soil temperature and soil humidity, and 3) the local microclimatic variables (air temperature, humidity, solar radiation, mean radiant temperature, surface temperature, wind direction and wind speed). Considering the impact of vegetation on urban microclimates as a function of soil-vegetationatmosphere, and based on the outcomes of preview studies, this work starts from the hypothesis that for São Paulo climate and as a result of evapotranspiration and shadowing process, the reduction of air temperature under the canopy will be between $1{ }^{\circ} \mathrm{C}$ to $2^{\circ} \mathrm{C}$ and for surface temperature, it will be around $20^{\circ} \mathrm{C}$, both in relation to an area without tree shadowing. These effects are restricted to the borders of the park, especially under the conditions of low wind speed, approximately $1 \mathrm{~m} / \mathrm{s}$. The methods are: 1) inductive, based on field measurements in summer and winter at Tenente Siqueira Campos Park (Trianon Park), in the city of São Paulo, registering microclimatic data and collecting information for canopy and soil; and 2) deductive, with the calibration of measured and simulated data by ENVI-met 3.1 Beta 5 and the simulation for different scenarios varying the canopy characteristics. To estimate the average leaf density for trees canopy two no-destructive indirect methods were applied: measurement of LAI using the equipment LAI-2000 (LI-COR) and the analysis of hemispheric photographs, using a software application Can-Eye.

According to the simulation results, for different characteristics for canopy, it could be verified a maximum reduction of $1^{\circ} \mathrm{C}$ in air temperature and $19^{\circ} \mathrm{C}$ for surface temperature, when comparing the obtained value under a dense canopy (elliptical form and LAI of $5 \mathrm{~m}^{2} / \mathrm{m}^{2}$ ) to the conditions on the street. The maximum extension of these effects were up to $5 \mathrm{~m}$ from the limits of the park, considering $1 \mathrm{~m} / \mathrm{s}$ for wind speed and $40 \%$ for soil humidity in the upper layer $(0-20 \mathrm{~cm})$. The thermal index TEP calculated and it could be seen that the reduction of $1^{\circ} \mathrm{C}$ for air temperature can represent from $3^{\circ} \mathrm{C}$ to $5^{\circ} \mathrm{C}$ in terms of thermal comfort of people. By these results, the initial hypothesis has proven to be correct and showed not only the importance of the type of vegetation selected (canopy form, LAI values and geometric distribution of canopy openness) but also the characteristics of the surrounding environment (microclimatic and soil conditions). Furthermore, it will contribute to formulate public politics aiming to mitigate urban warming effect, mainly during daytime, in tropical cities.

Keywords: urban microclimate, vegetation, environmental impacts 


\section{INTRODUÇÃO}

O processo de urbanização mudou a relação entre a sociedade e o ambiente natural. No século XX, o crescimento das metrópoles reduziu os espaços de áreas com vegetação e o ambiente urbano criou vários obstáculos para o plantio de novas mudas como, por exemplo, a compactação do solo, o pouco espaço para crescimento das raízes, as instalações da rede elétrica e a falta do manejo adequado das árvores (KONIJNENJIJK et al., 2000).

O crescimento da urbanização impacta no clima das cidades e no desempenho ambiental dos edifícios. O aumento do número de novas construções tem reduzido as áreas com vegetação e vias arborizadas nas grandes metrópoles como, por exemplo, a cidade de Nova Iorque que perdeu cerca de 175.000 árvores ou 20\% de sua cobertura vegetal do ano de 1992 ao ano 2002 (SANTAMOURIS, 2001). No Brasil, o Município de São Paulo, entre 1990 e 1995, perdeu cerca de 668 hectares de mata atlântica, sendo que a velocidade da destruição quase dobrou na segunda metade da década passada quando foram perdidos mais 1.109 hectares de vegetação nativa (SVMA, 2000).

A ausência da vegetação influencia no aumento da temperatura do ar devido ao aquecimento das superfícies (pisos e fachadas) ao longo do dia e na redução de superfícies evaporativas que realizam trocas térmicas úmidas. Além disso, outros fatores também contribuem para esse efeito: mudança na geometria do tecido urbano (relação altura e largura do canyon), uso de materiais que armazenam grande parte do calor sensível devido às suas propriedades térmicas e emissão de calor antropogênico gerado pela queima de combustível fóssil (OKE, 1978). Dessa forma, inserir a vegetação em áreas urbanas é uma das principais estratégias para mitigar o aquecimento nas cidades, uma vez que as plantas representam um importante papel como reguladores do clima urbano (YU, 2006).

O fluxo de calor latente possibilita que a radiação solar seja absorvida na superfície terrestre, retornando para as camadas superiores da atmosfera sem contribuir no aumento da temperatura do ar. Além disso, as características do solo abaixo do dossel geram um conteúdo disponível de água (umidade do solo) para ocorrer o processo de evapotranspiração, reduzindo a temperatura das superfícies, principalmente no período do verão, assim como diminuir a quantidade de radiação de onda longa e o fluxo calor sensível emitida para atmosfera (STONE, 2012). 
Os benefícios provenientes da vegetação já foram constatados em diversos estudos, dentre os quais se destacam: o controle da temperatura e umidade (DIMOUNDI, NIKOLOPOULOU, 2003; SAILOR, 1995; OMETO, 1981), a influência na qualidade ar (NOWAK, 2004; KUTTLER; STRASSBURGER, 1999), o resfriamento passivo de uma edificação por meio do sombreamento das árvores (HEISLER, 1986; TAHA, 1997; AKBARI, 2005), o manejo das águas (BORCKE, 2003), além do valor estético e da influência na saúde das pessoas (KUO; SULLIVAN, 1998; TAHA; AKBARI, 1992; SANTAMOURIS, 2001; ULRICH, 2003).

Em relação ao microclima, a vegetação tem um importante papel devido às suas propriedades no balanço de energia. Dependendo do processo de evapotranspiração e das condições climáticas locais, a cobertura vegetal e a superfície com água diminuem os picos de temperatura durante o dia. O processo de evapotranspiração compreende a perda associada de água, que ocorre pela evaporação da superfície do solo e pela transpiração estomática e cuticular da planta.

O efeito da evapotranspiração está diretamente relacionado com a resistência estomática que relaciona a quantidade dos estômatos nas folhas com uma adequada condição no solo (disponibilidade de água) e na atmosfera (disponibilidade de luz). Assim quando maior a área de exposição das folhas, maior o efeito. Neste sentido o índice de área foliar - IAF têm uma relação direta com a quantidade de luz, energia e consumo de $\mathrm{CO}_{2}$. Segundo Chen e Black (1992) o conceito do IAF é dado por: "half the total intercepting (non-projected) area per unit ground surface area".

Sob a influência da vegetação, as diferenças na temperatura de superfície são maiores do que na temperatura do ar. Dessa forma, percebe-se que o efeito da vegetação na temperatura do ar é local e está relacionado ao balanço de energia que considera a condutividade térmica entre a superfície e a camada de ar entorno dela.

A taxa de calor físico armazenado muda os valores de absorção e emissão de calor pelo ar, solo e planta (folhas, galhos, tronco). A taxa de calor bioquímico armazenado ocorre pelo processo de fotossíntese das plantas, mudando os valores de acordo com a taxa de $\mathrm{CO}_{2}$ assimilado pela vegetação. Dependendo da natureza do ambiente de entorno podese adicionar o termo $\Delta \mathrm{Q}_{\mathrm{A}}$ sobre a ação dos ventos que considera a energia de ganhos e perdas pelo transporte horizontal do calor sensível e latente. 
Além do balanço de energia é importante considerar o balanço hídrico que contabiliza toda a água envolvida entre os sistemas solo, planta e atmosfera, podendo oferecer a qualquer instante a quantidade de água disponível contida em um perfil de solo prédeterminado (OMETO, 1981).

Em termos de distribuição da vegetação, Ong (2002) desenvolveu o conceito do Green Plot Ratio - GPR (Relação Área Verde/ Área do terreno), definido como uma média do IAF em uma determinada área arborizada. Também equivale à relação da área total de folhas existentes pela área total. O GPR é um indicador do efeito da vegetação, mais efetivo do que o cálculo da cobertura vegetal, pois está diretamente relacionado com a área foliar que realiza fotossíntese no local (ONG, 2002).

Existem outros indicadores propostos para a distribuição da vegetação nos centros urbanos como o Biotope Area Factor ${ }^{1}$ - BAF, adotado em 1994 pela cidade de Berlim, na Alemanha. Tem como objetivo estabelecer uma infra-estrutura verde em um tecido urbano de alta densidade, definindo uma pontuação de 0 a 1, de acordo com o tipo de superfície e vegetação.

A cidade de Seattle, a fim de atingir todos os requisitos de qualidade do ar, água e melhoria da temperatura do ar, criou o Green Factor ${ }^{2}$ como forma de auxiliar a inserção da vegetação pelos arquitetos e planejadores, oferecendo diversas possibilidades de estratégias de projeto incluindo: plantio de árvores, pavimento permeável, jardim de chuva, tetos e fachadas verdes (CITY OF SEATTLE, 2009).

Tanto o BAF como o Green Factor baseiam-se em aspectos ecológicos tais como a permeabilidade do solo para definir a distribuição da vegetação. Assim, a inclusão dos aspectos microclimáticos nesses indicadores poderia reforçar as estratégias de distribuição das áreas verdes e mostrar os reais efeitos da vegetação (MÜLLER, WERNER, KELCEY, 2010)

A quantidade de área verde por número de habitantes de uma região ou de um local dessa região é um indicador de qualidade de vida. Em 1997, a Organização Mundial de

\footnotetext{
${ }^{1}$ Disponível em: < http://www.stadtentwicklung.berlin.de/umwelt/landschaftsplanung/bff/index_en.shtml >. Acesso em abril de 2013.

${ }^{2}$ Disponível em: <
} http://www.seattle.gov/dpd/cms/groups/pan/@pan/@permits/documents/web_informational/dpdp016505. pdf $>$. Acesso em abril de 2013. 
Saúde OMS sugeriu o valor de $9 \mathrm{~m}^{2} / \mathrm{hab}$ para ser adotado como base para o desenvolvimento urbano na América Latina e no Caribe. No Brasil, a Sociedade Brasileira de Arborização Urbana SBAU recomenda o índice mínimo $15 \mathrm{~m}^{2}$ de áreas verdes por habitante (SBAU, 1996).

No entanto, OKE (1973) estima que um índice de área verde aproximado de 30\% seja o recomendável para proporcionar um adequado balanço térmico em áreas urbanas, sendo que áreas com índice inferior a 5\% determinam características semelhantes às de um deserto.

Segundo os estudos de Stone (2012), três principais estratégias precisam ser consideradas para mitigar o aquecimento nos grandes centros urbanos: (1) plantio de árvores ou planejar novas configurações com o uso da vegetação (teto verde, parede verde); (2) estratégia para aumento do albedo, incorporando técnicas para resfriamento das coberturas ou substituição do revestimento por materiais mais reflexivos; (3) programas de eficiência energética com o compromisso de reduzir as emissões de gases do efeito estufa.

No levantamento feito para 50 cidades americanas, todas apresentaram estratégias para melhoria da eficiência energética e redução do consumo de energia. Mas apenas 10 cidades $(20 \%)$ possuem estratégia prática voltada para aumento dos espaços com vegetação ou melhoria do albedo das superfícies (STONE, 2012).

Apesar da cidade de São Paulo apresentar mais espaços livres para implantação das áreas verdes em comparação com os centros asiáticos, percebe-se que as estruturas das calçadas não estão adequadas para o plantio de árvores. A cidade tem um dos índices mais baixos de vegetação por habitante do Brasil, apenas $4 \mathrm{~m}^{2}$ de área verde para cada habitante do município ${ }^{3}$ quando comparado com os números de outras cidades como Maringá $\left(31,5 \mathrm{~m}^{2} / \mathrm{hab}\right)$ e Curitiba ${ }^{5}\left(64,5 \mathrm{~m}^{2} / \mathrm{hab}\right)$.

Porém, quando se fala em área verde por habitante, não só em São Paulo como nas outras cidades brasileiras, dependendo da fonte, esses dados podem ser muito diversos. Segundo Nucci (2008), para se chegar a esse valor a Prefeitura Municipal de São Paulo - PMSP dividiu área da cobertura verde pública do município $\left(42,3 \mathrm{~km}^{2}\right)$ pelo número de

\footnotetext{
${ }^{3}$ Dados do Atlas Ambiental da Secretaria do Verde e Meio Ambiente do Município de São Paulo

${ }^{4}$ Dados SAMPAIO, A.; ANGELIS, B. Rev. SBAU, Piracicaba, v.3, n.1, mar. 2008, p. 37-57

${ }^{5}$ Dados Prefeitura de Curitiba - medição por fotografia aérea concluída em dezembro de 2012.
} 
habitantes (9.626.898 - IBGE, 1991). Porém, esse valor diz respeito à totalidade do município e, para se calcular o índice de área verde dever-se considerar somente as áreas com vegetação localizadas na zona urbana. Sendo assim, nos $900 \mathrm{~km} 2$ de zona urbana, apenas $26,9 \mathrm{~km}^{2}$ são de áreas verdes públicas (praças e parques públicos), ou seja, apenas 3\%. Então, na verdade, o índice de área verde pública, utilizando-se os mesmos dados coletados pela PMSP seria de $2,9 \mathrm{~m}^{2} / \mathrm{hab}\left(26,9 \mathrm{~km}^{2} \div 9.386 .225,6 \mathrm{hab}\right.$, pois $97,5 \%$ da população está na zona urbana) e não $4,4 \mathrm{~m}^{2} / \mathrm{hab}$.

Além disso, a distribuição de cobertura vegetal também é desigual. Na Sé, a taxa é de apenas $0,22 \mathrm{~m}^{2}$. O Distrito de Santa Cecília e do Brás chegam a zero. As maiores concentrações de áreas verdes estão no extremo sul, sendo Marsilac a que apresenta a maior taxa: $25.797 \mathrm{~m}^{2}$, pouco populoso e de natureza rural, o bairro fica dentro do perímetro da Área de Proteção Ambiental Capivari-Monos, que preserva uma faixa de mata atlântica (SVMA, 2000).

Givoni (1991) já havia verificado que a influência dos parques urbanos e espaços abertos no clima urbano se estendem somente a uma curta distância nos arredores densamente construídos. Santamouris (2001) avançou no sentido de realizar medições da temperatura do ar nas áreas internas e externas a um parque na cidade de Atenas, Grécia. O resultado indicou que a variação das temperaturas do ar no interior do parque foi de no máximo $1.5^{\circ} \mathrm{C}$ e a diferença entre o parque e o entorno durante o dia foi de aproximadamente $3^{\circ} \mathrm{C}$. Bruse (2004) estudou o efeito de um parque em Melbourne, Austrália, utilizando o modelo ENVI-met e demonstrou que as diferenças de temperaturas do ar entre o parque e o entorno foi de no máximo $2^{\circ} \mathrm{C}$.

No estudo de Shinzato (2009), foram realizadas medições de campo no Parque da Luz, em São Paulo, e outras áreas próximas considerando-se os seguintes parâmetros: temperatura do ar, umidade do ar, velocidade dos ventos e radiação solar. Esses valores foram colocados nos dados de entrada do modelo ENVI-met e os resultados mostraram a influência da vegetação na diminuição da temperatura superficial em $23^{\circ} \mathrm{C}$, medidos embaixo da copa das árvores, em relação a uma área descoberta com superfície em asfalto. Isso acontece pelo efeito do sombreamento das árvores com copa densa que evitam a chegada da radiação direta no solo, pelo efeito do dossel propriamente dito e pela cobertura do solo. Em relação à temperatura do ar, os resultados indicaram que houve uma redução de até $1.5^{\circ} \mathrm{C}$ nas áreas verdes, se comparadas às áreas sem 
vegetação. Esse valor está de acordo com os estudos anteriores, e os resultados não mostram uma influência muito além dos limites das áreas verdes.

Os resultados dessas simulações paramétricas indicaram que o efeito de uma área verde na temperatura do ar não ocorre principalmente devido à diferença na distribuição espacial da vegetação (parque linear, grande massa de vegetação, pequenos agrupamentos espaçados, etc.), mas sim pela densidade foliar do dossel que contribui nos processos de evapotranspiração e sombreamento e pela cobertura do solo. O dossel pode ser caracterizado por variáveis como o IAF - índice de área foliar e a distribuição geométrica das aberturas na copa, o gap fraction.

O IAF é um índice que influencia diretamente na interceptação e absorção da luz na copa, assim como no balanço das trocas de calor e taxas de evaporação com a atmosfera. À medida que a cultura vai crescendo aumenta o número de folhas e, dessa maneira, com o aumento da superfície foliar e do número de folhas utilizadas na fotossíntese, cresce a absorção de $\mathrm{CO}_{2}$, estimulando cada vez mais a evapotranspiração, resultando em acréscimo de matéria seca, que sintetiza todas as relações planta-meio (OMETO, 1981).

Desta forma, o IAF é um parâmetro-chave para se determinar uma série de processos ecológicos e fisiológicos como fotossíntese e evapotranspiração, possibilitando a previsão das taxas de trocas de energia entre vegetação e atmosfera, a curva da taxa de crescimento futuro e as diferenças na estrutura da copa devido à poluição do ar e mudança climática (ONG, 2002).

Se os valores de IAF oferecem um parâmetro médio da densidade foliar de uma copa, a informação sobre a estrutura da copa é dada pela medida da distribuição geométrica das aberturas (gap fraction). Assim gap fraction é definido como: "the fraction of view in some direction from beneath a canopy that is not blocked by foliage”. Dessa forma, representa a porcentagem de vazios existentes na copa, considerando que os raios solares atravessam a copa sem serem bloqueados ou tocados pelas folhas. (ROSS, 1981).

Entre as formas de se estimar o gap fraction tem-se que: uso de sensores lineares que medem uma direção por vez (equipamento DEMON); ou pela análise de fotos hemisféricas (ANDERSON, 1971; BONHOME e CHARTIER, 1982), usos de 
equipamentos que medem a transmissão da radiação pela copa (ROSS, 1981; LANG, McMURTRIE ,1986).

Assim uma das principais motivações da pesquisa foi investigar efeito da vegetação a partir da parametrização de tipologias arbóreas que pudessem se aproximar das espécies brasileiras existentes em parques urbanos na cidade de São Paulo, prevendo mudanças nas características das copas tanto na densidade foliar como na sua distribuição ao longo do dossel.

\subsection{OBJETIVO E HIPÓTESE}

Este trabalho tem por objetivo quantificar o impacto da vegetação nos microclimas urbanos abaixo do dossel, em função das interações solo-vegetação-atmosfera. Essas interações consideram os efeitos:

1) do dossel propriamente dito, expressos pelas variáveis índice de área foliar - IAF (Leaf Area Index - LAI) e distribuição geométrica das aberturas na copa (gap fraction);

2) da cobertura do solo, expressa pela composição do solo, sua temperatura e teor de umidade;

3) das variáveis microclimáticas locais (temperatura do ar, umidade do ar, radiação solar, temperatura radiante media, temperatura superficial, direção e velocidade dos ventos).

Considerando-se que o impacto da vegetação nos microclimas urbanos é função das interações solo-vegetação-atmosfera, e tendo em vista resultados de estudos anteriores, a hipótese deste trabalho é que, para o clima de São Paulo, em função dos processos de evapotranspiração e do sombreamento, a redução na temperatura do ar abaixo do dossel em parques urbanos será de cerca de $1^{\circ} \mathrm{C}$ e a redução da temperatura superficial será de cerca de $20^{\circ} \mathrm{C}$, ambas em relação às áreas não sombreadas pela vegetação, e que esses efeitos limitam-se à borda do parque sob condições de baixa velocidade do vento, de cerca de $1 \mathrm{~m} / \mathrm{s}$.

\subsection{MÉTODO}

O método utilizado foi indutivo por meio de medições de campo durante o período de dias quentes e frios no Parque Tenente Siqueira Campos (Trianon), na cidade de São Paulo, para o registro de dados microclimáticos e para o levantamento das variáveis do dossel e do solo; e dedutivo, com a calibração entre dados medidos e simulados pelo 
modelo ENVI-met 3.1 Beta 5 e a simulação de diferentes cenários, variando-se as características do dossel.

As fases iniciais de pesquisa bibliográfica e levantamento de dados secundários foram complementados com os fundamentos teóricos básicos levantados durante o mestrado. Essa fase incluiu o estudo dos seguintes temas:

1. Entendimentos dos fenômenos envolvidos no balanço de energia e nas alterações no clima provocadas pela urbanização.

2. Estudo do conceito do índice de área foliar e levantamento das metodologias de medição direta e indireta do IAF. Entendimento do conceito de gap fraction para realizar as estimativas do IAF usando metodologias com fotos hemisféricas.

3. Estudo de fisiologia vegetal e processos que influenciam na evapotranspiração das plantas, tais como a quantidade de luz, o tipo de clima e a presença de água. A diferença na forma de fixação do carbono entre plantas $\mathrm{C}_{3}$ (arbóreas) e $\mathrm{C}_{4}$ (gramíneas), sua influencia na taxa de transpiração das folhas e consequentemente no efeito microclimático da vegetação.

4. Domínio do modelo ENVI-met, proposto por Bruse (1999), bem como das alterações que se fizerem necessárias para as simulações sob condições tropicais.

5. Levantamento do Parque Trianon e principais espécies existentes, com a SVMA, bem como dos edifícios no entorno imediato

Em seguida, foram realizados os seguintes levantamentos de campo, a fim de verificar as condições climáticas e das características da vegetação (IAF das copas) no Parque Trianon:

6. Medição do índice de área foliar - nesta pesquisa o IAF foi medido de duas formas, utilizando-se o equipamento LAI - 2000 (empresa LI-COR, Lincoln, Nebraska) e por meio da metodologia de fotos hemisféricas (WEISS et al., 2004). As imagens foram registradas no Parque Trianon no dia 8 de fevereiro de 2014 das 7h às 10h, utilizando a câmera digital Nikon COOLPIX 4500 com uma lente angular Nikon FC-E8 acoplada. Os resultados foram comparados com as medições de IAF feitas em agosto de 2012.

7. Medição das variáveis microclimáticas no Parque Trianon: foram realizadas medições de campo com duas estações meteorológicas Campbell Scientific no Parque Tenente Siqueira Campos (Trianon) em duas etapas: no período entre os dias 28 de 
setembro e 01 de outubro de 2012, com duração de três dias e duas noites; e nos dias 13 e 16 de novembro de 2013, com duração de quatro dias e três noites. Foram levantados os dados climáticos de temperatura do ar, umidade do ar, radiação, temperatura de globo, temperatura de solo, velocidade e direção dos ventos.

Posteriormente, e tendo em mãos os dados medidos em campo e o levantamento da vegetação existente, foram feitas simulações computacionais no modelo ENVI-met para os diferentes cenários paramétricos propostos.

8. Simulações no ENVI-met Beta v.3.1: foram feitas as simulações para calibrar o modelo ENVI-met para as condições microclimáticas do parque Trianon. Em seguida foram feitas as simulações paramétricas com a variação nas características da vegetação (tipo e valores de IAF), condições microclimáticas (diferentes velocidades dos ventos) e das características do solo (variação da umidade relativa do solo). Uma vez concluídas as simulações, partiu-se para a análise dos resultados, comparando-se as medições com as simulações realizadas, na busca do estabelecimento de um parâmetro definindo os valores de intensidade e extensão/configuração espacial dos efeitos microclimáticos da vegetação.

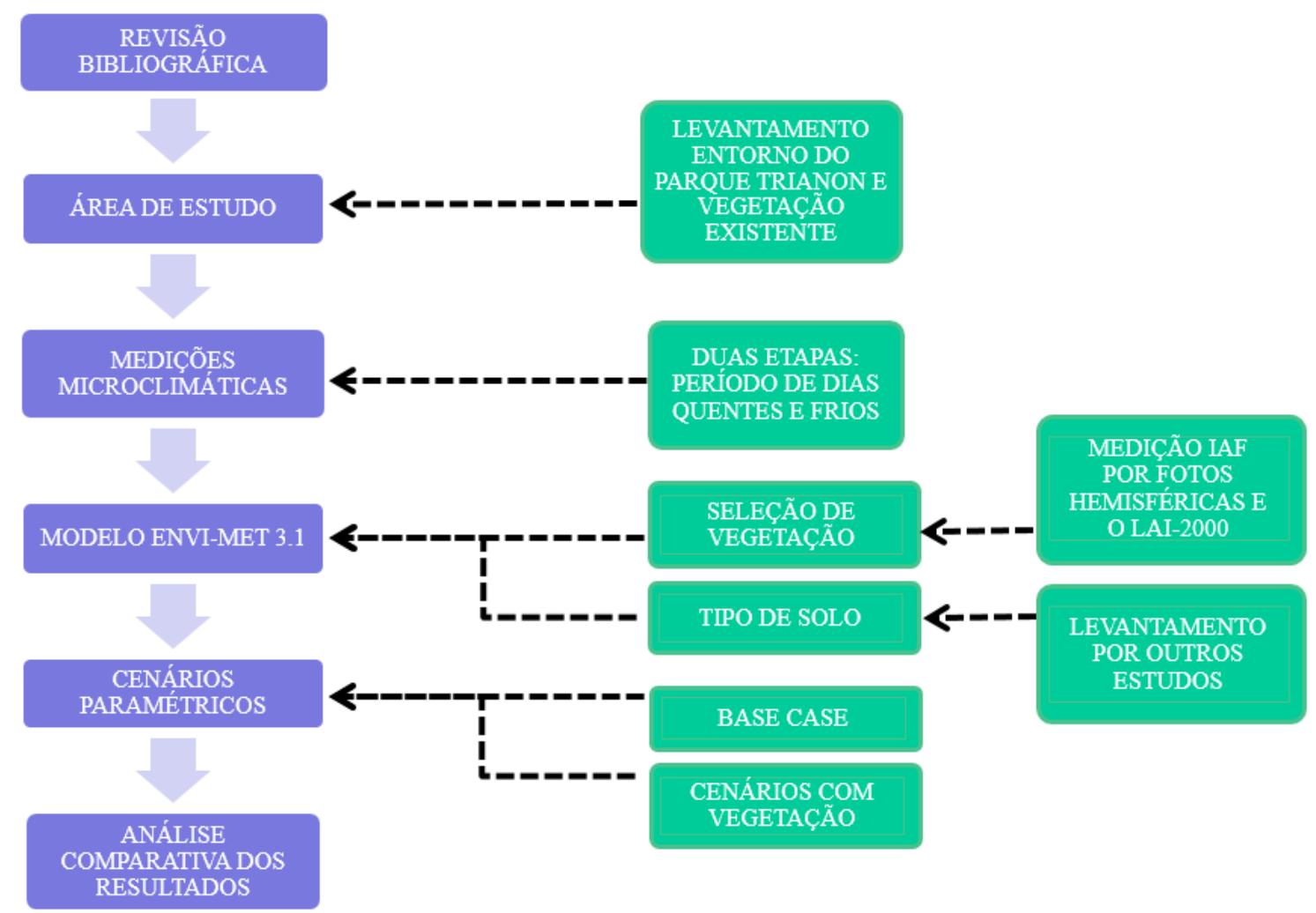

Figura 1: Etapas de trabalho do desenvolvimento da pesquisa 


\subsection{ESTRUTURA DO TRABALHO}

A tese está organizada em oito capítulos.

CAPÍTULO 1: traz a introdução e a justificativa do tema de pesquisa, bem como e descreve objeto, objetivos, hipótese, método e a estrutura da tese propriamente dita.

CAPÍTULO 2: apresenta a interação solo-vegetação-atmosfera e a influência da vegetação na atmosfera em duas escalas: na planta e na folha. Estão descritas as características e o comportamento das plantas em relação à condutância estomática, fotossíntese, taxa de evapotranspiração e balanço de energia.

CAPÍTULO 3: apresenta os conceitos, aplicações, métodos de medição e cálculo do índice de área foliar - IAF, indicando como esse índice influencia diretamente na interceptação radiação solar na copa, assim como no balanço das trocas de calor e taxas de evaporação com a atmosfera. Foram apresentadas as principais metodologias para medição do IAF, utilizados método diretos e indiretos, considerando o conceito de gap fraction.

CAPÍTULO 4: descreve o modelo ENVI-met 3.1 Beta 5, apresentando a base de cálculo para os modelos atmosféricos de fluxo de ar, fluxo radiativo, temperatura e umidade. Descreve as variáveis que compõem o banco de dados de solo, vegetação e da configuração dos dados de entrada.

CAPÍtUlO 5: apresenta os objetivos e os procedimentos das medições microclimáticas durante o período de dias quentes e frios para dois pontos localizados no interior Parque Trianon e os principais resultados.

CAPÍTULO 6: apresenta o processo de medição e resultados para a estimativa dos valores de IAF realizados no Parque Trianon, utilizando-se o equipamento LAI-2000 e a metodologia por fotos hemisféricas.

CAPÍTULO 7: Mostra o processo de calibração do modelo de acordo com as medições de campo para São Paulo. Apresenta os cenários para as simulações paramétricas que prevê a mudança nos dados relativos às condições atmosféricas, vegetação e solo. Descreve a modelagem de duas tipologias de vegetação com copas que variam no formato (elíptica e esférica), e nos valores da densidade de folhas (IAF).

CAPÍTULO 8: apresenta a análise dos resultados, usando principalmente os dados de saída de temperatura do ar, temperatura de superfície e umidade específica, para as 
simulações realizadas, a fim de se verificar o impacto da vegetação no microclima urbano com diferentes valores de IAF.

CAPÍTULO 9: Apresenta as considerações finais, comprovação da tese e conclusões da pesquisa para o impacto da vegetação no microclima urbano bem como recomendações para a arborização urbana, visando à melhoria das condições microclimáticas locais. 


\section{INTERAÇÃO SOLO-VEGETAÇÃO-ATMOSFERA}

\subsection{INTRODUÇÃO}

Em uma escala global, a vegetação tem um papel relevante no ciclo do carbono (Figura 2). Nos fluxos de ciclo lento (importantes em longas escalas de tempo), as plantas removem 0,4 $\mathrm{PgC} \mathrm{ano}^{6}$ de $\mathrm{CO}_{2}$ atmosférico, que é balanceado pelo transporte de carbono orgânico dissolvido através dos rios para os oceanos.

Esse ciclo é fundamental para equilibrar as trocas entre atmosfera, oceanos e superfície terrestre. Nos ciclos rápidos, as plantas absorvem a energia solar e $\mathrm{CO}_{2}$ da atmosfera por meio do processo da fotossíntese, produzindo oxigênio e açúcares, como a glicose, que servem de base para o crescimento das plantas. Em todo o planeta, aproximadamente $560 \times 10^{15} \mathrm{gC}$ estão estocados na vegetação e cerca de $75 \%$ deste total se encontram estocados em florestas e, mais especificamente, 50\% encontram-se em florestas tropicais. Nos solos estão estocados 1500 x $10^{15} \mathrm{gC}$, sendo que a metade desse total encontra-se em solos cobertos por florestas. O Brasil tem estocados cerca de $100 \mathrm{x}$ $10^{15} \mathrm{gC}$ em suas florestas, revelando, portanto, a sua importância no ciclo global do carbono (MOORE, 2007).

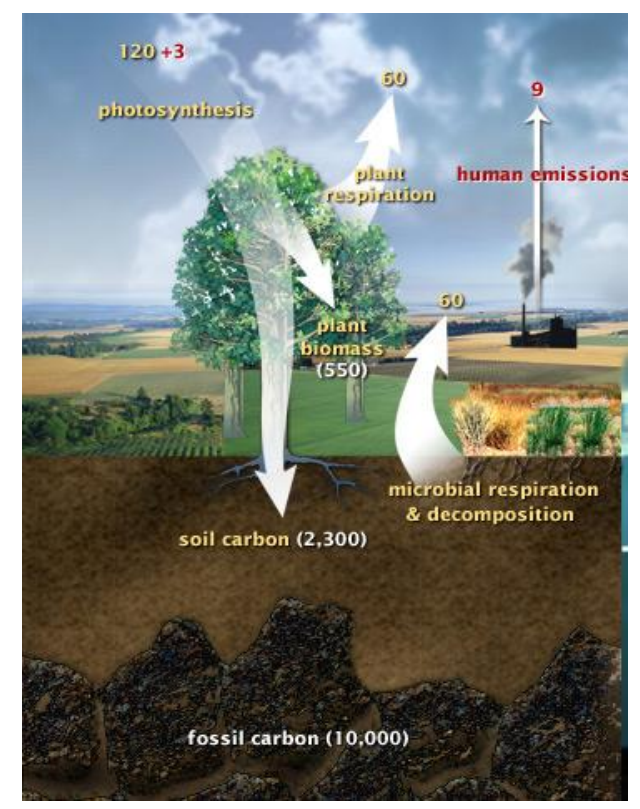

Figura 2: Ciclo do Carbono Rápido

Fonte: NASA. Disponível em: < http://earthobservatory.nasa.gov/Features/CarbonCycle/>. Acesso em setembro de 2011.

\footnotetext{
61 PgC/ano = 1 Peta grama de carbono por ano = 1 bilhão de toneladas de carbono por ano.
} 
Smith (2005) indica que desde a revolução industrial a queima de combustíveis fósseis e a devastação das florestas têm resultado em um crescimento de $26 \%$ nas concentrações de dióxido de carbono na atmosfera. Além disso, o metano é um gás muito mais poderoso do que o dióxido de carbono no efeito estufa e sua emissão dobrou desde então devido à queima de biomassa.

A partir do quarto relatório do Intergovernmental Panel on Climate Change - IPCC (AR4), foi possível afirmar que o sistema climático está em processo de aquecimento, e que este é inequívoco. Como elemento ilustrativo desta realidade, o AR4 faz referência às observações dos aumentos das temperaturas médias globais do ar e dos oceanos, derretimento generalizado da neve e do gelo e da elevação do nível global médio do mar.

A concentração de dióxido de carbono $\left(\mathrm{CO}_{2}\right)$ na atmosfera cresceu $40 \%$ desde 1750 , e esse aumento deveu-se principalmente à queima de combustíveis fósseis (petróleo, carvão e gás natural) e ao desmatamento de florestas tropicais. A concentração de metano $\left(\mathrm{CH}_{4}\right)$, que é outro gás de efeito estufa emitido pela exploração de gás natural e por emissões da agropecuária, subiu mais de $150 \%$ desde o início da Revolução Industrial (IPCC, 2007).

Outro ponto importante é que o AR4 demonstrou claramente que a maior parte do aquecimento observado nas temperaturas globais médias desde meados do século XX está relacionada às emissões antrópicas de gases de efeito estufa (IPCC, 2007).

No quinto relatório (AR5), os cenários de forçantes radiativas foram introduzidos nos modelos climáticos, que fizeram projeções de aumento de temperatura para o final o século a partir de 2005 de $1,0^{\circ} \mathrm{C}$ a $3,7^{\circ} \mathrm{C}$, dependendo do cenário de aumento de concentrações. Importante salientar que o planeta já aqueceu $0,89^{\circ} \mathrm{C}$ entre os anos de 1901 a 2012. O aumento do nível do mar foi projetado entre 40 e $62 \mathrm{~cm}$ para o período de 2005 a 2100 (IPCC, 2013).

Estudos mostram que essa elevação será desigual para as várias regiões do globo, onde áreas de altas latitudes sofrerão aquecimento mais pronunciado, e as regiões continentais sofrerão aquecimento maior do que as oceânicas. A região ártica em particular poderá se aquecer em torno de $7{ }^{\circ} \mathrm{C}$ ao longo deste século. Regiões da África também podem sofrer alterações expressivas, com aumentos de temperatura de 4 a $5{ }^{\circ} \mathrm{C}$ ao longo deste século. Na América do Sul, a temperatura pode aumentar em $5{ }^{\circ} \mathrm{C}$, 
significando provavelmente uma quebra da estabilidade climática para o ecossistema amazônico em particular (ARTAXO, 2008).

\subsection{INTERAÇÃO VEGETAÇÃO-ATMOSFERA - NA ESCALA DA FOLHA}

A biosfera recebe a radiação solar variando entre $29 \mathrm{~nm}$ e $10^{5} \mathrm{~nm}$. Nos limites da alta atmosfera a influência da radiação solar é de $1.36 \mathrm{kJm}^{-2} \mathrm{~s}^{-1}\left(1360 \mathrm{Wm}^{-2}\right) \mathrm{e}$, em média, apenas $47 \%$ da radiação solar chega na superfície terrestre. Mais da metade da radiação solar é refletida de volta para o espaço como resultado da refração e da difração na alta atmosfera, além de ser difundida e absorvida pelas nuvens e outras partículas suspensas no ar (BONAN, 2002).

A radiação total de entrada que chega na superfície horizontal é chamada de radiação global que é composta pela radiação direta (feixes de raios solares paralelos) e difusa (proveniente de cada ponto do céu) (ROSS, 1981).

Em média, $45 \%$ da entrada de energia solar está entre 380-710nm, sendo a principal faixa do comprimento de onda utilizado pelas plantas para a fotossíntese (radiação fotossinteticamente ativa - PAR, entre 400-700nm).

Segundo Ross (1981), o papel da radiação solar como fonte de energia não se restringe aos processos físicos na atmosfera e superfície terrestre, mas são também uma fonte primária de energia para vários processos biológicos que acontecem nas plantas. De acordo com a Figura 3 a interação da radiação com as plantas pode acontecer de três formas distintas:

- Efeito térmico da radiação: mais de $70 \%$ da radiação solar absorvida pelas plantas é convertida em calor e utilizada como energia para a transpiração, manutenção da temperatura da planta, etc.

- Efeito fotossintético da radiação: aproximadamente $28 \%$ da energia absorvida está na região espectral entre 380-710nm (radiação PAR-por extenso também na primeira menção), usada para o processo de fotossíntese e armazenamento químico de compostos orgânicos de alta energia

- Efeito fotomorfogênico: efeito da radiação no crescimento e desenvolvimento da planta. A região da radiação fotomorfogênica ativa inicia-se no ultravioleta, estendendo-se por toda a região do visível até o infravermelho próximo de $750 \mathrm{~nm}$. 


\begin{tabular}{|c|c|c|c|c|c|c|}
\hline \multirow[t]{2}{*}{ Spectral region } & \multirow{2}{*}{$\begin{array}{l}\text { Wavelength } \\
\text { [nm] }\end{array}$} & \multirow{2}{*}{$\begin{array}{c}\text { Percent of } \\
\text { solar } \\
\text { radiant } \\
\text { energy }\end{array}$} & \multicolumn{4}{|c|}{ Effects of radiation } \\
\hline & & & $\begin{array}{l}\text { Photo- } \\
\text { synthetic }\end{array}$ & $\begin{array}{l}\text { Photo- } \\
\text { morpho- } \\
\text { genetic }\end{array}$ & $\begin{array}{l}\text { Photo- } \\
\text { destruc- } \\
\text { tive }\end{array}$ & Thermal \\
\hline Ultraviolet & $290-380$ & $0-4$ & o & $x$ & + & o \\
\hline $\begin{array}{l}\text { Photosynthetically } \\
\text { active radiation (PhAR) }\end{array}$ & $380-710$ & $21-46^{a}$ & + & + & $x$ & + \\
\hline Infrared & $750-4000$ & $50-79^{a}$ & o & + & o & + \\
\hline $\begin{array}{l}\text { Longwave } \\
\text { radiation }\end{array}$ & $4000-100000$ & & o & o & o & + \\
\hline
\end{tabular}

${ }^{a}$ Depending on position of sun and degree of cloud cover.

Figura 3: Efeito da Radiação nas plantas, sendo (+) significativo; (x) pouco; (o) insignificante.

Fonte: Ross (1981)

No espectro visível, as folhas refletem de $6 \%$ a $10 \%$ da radiação incidente e a refletância depende da natureza de sua superfície. Em determinadas árvores de clima tropical as folhas apresentam um brilho na superfície que chega a refletir de $12 \%$ a $15 \%$ da radiação visível. Apenas uma pequena parte da radiação ultravioleta é refletida (3\%), enquanto, aproximadamente, $70 \%$ da radiação infravermelha incidente é refletida pela folha (ROSS, 1981).

A maior parte da radiação ultravioleta é retida pela cutícula e por outras camadas da epiderme, representando de $2 \%$ a $5 \%$ e menos de $1 \%$ chega nas camadas mais profundas da folha. A radiação infravermelha até $2000 \mathrm{~nm}$ é pouco absorvida pelas plantas; no entanto, acima de $7000 \mathrm{~nm}$ a radiação é praticamente toda absorvida (97\%) (LARCHER, 2006).

A Figura 4 mostra os coeficientes médios de absorção, reflexão e transmissão para quatro principais bandas de comprimento de onda: PAR, Near infra-red radiation NIR (710- 4000nm), radiação de onda curta $(350-3000 \mathrm{~nm})$ e radiação de onda longa (3000- 10.000nm). De acordo com os resultados, observa-se que a radiação solar de onda curta é absorvida pela folha em $50 \%$, sendo os valores da reflexão e da transmissão, $30 \%$ e $20 \%$, respectivamente. 


\begin{tabular}{|c|c|c|c|c|}
\hline & $\begin{array}{l}\mathrm{PAR}^{\dagger} \\
(0 \cdot 38-0.71 \\
\mu \mathrm{m}) \S\end{array}$ & $\begin{array}{l}\mathrm{NIR}^{\ddagger} \\
(0 \cdot 71-4 \cdot 0 \\
\mu \mathrm{m})\end{array}$ & $\begin{array}{l}\text { Short-wave } \\
(0.35-3.0 \\
\mu \mathrm{m}) \S\end{array}$ & $\begin{array}{l}\text { Long-wave } \\
(3 \cdot 0-100 \\
\mu \mathrm{m})\end{array}$ \\
\hline Reflection & 0.09 & 0.51 & $0 \cdot 30$ & 0.05 \\
\hline Transmission $(\Psi)$ & 0.06 & 0.34 & $0 \cdot 20$ & 0.00 \\
\hline Absorption & 0.85 & $0 \cdot 15$ & 0.50 & 0.95 \\
\hline
\end{tabular}

†AR - photosynthetically active radiation

* NIR - near infra-red radiation

$\S$ Note these wavelength limits differ slightly from those used elsewhere in this book

Figura 4: Coeficientes médios para absorção, reflexão e transmissão em quatro principais bandas de comprimento de onda.

Fonte: Ross (1975)

Em uma árvore densa e madura a absorção varia entre $60 \%$ e $99 \%$ da radiação de onda curta incidente proveniente do sol e do céu; a mesma reflete entre $10 \%$ e $30 \%$ e permite a passagem de apenas 5\% a 10\% pela copa até chegar na superfície (ROSS, 1981).

Segundo Watson (1947), a energia absorvida pelas folhas é dissipada das seguintes formas: emissão de calor para o ar, condução do calor para os tecidos internos, transpiração e reações fotoquímicas (fotossíntese e outros). Segundo a lei de StefanBoltzmann, a energia total irradiada por unidade de área superficial de um corpo negro na unidade de tempo é diretamente proporcional à quarta potência de sua temperatura.

$$
Q^{n}=\delta \varepsilon T^{4}
$$

Onde:

Q"= Energia emitida $\left[\mathrm{W} \mathrm{m}^{-2}\right]$

$\delta=$ Constante Stefan-Boltzmann $\left[5.67 \times 10^{-8} \mathrm{Wm}^{-2} \mathrm{~K}^{-1}\right]$

$\varepsilon=$ Emissividade da superfície $(0<\varepsilon<1)$

$\mathrm{T}=$ Temperatura absoluta $[\mathrm{K}]$

Assim, a quantidade de energia que sai de uma superfície sob a forma de calor é proporcional à sua emissividade e temperatura absoluta do corpo. A emissividade ( $\varepsilon$ ) é definida como a relação entre a radiação absorvida e a radiação total incidente, comparada com as propriedades teóricas de um corpo negro (JONES, 1992).

A emissividade das superfícies é influenciada por aspectos como o conteúdo de água, a composição química, a estrutura e a rugosidade. Em superfícies verdes, a emissividade depende da espécie, densidade e estado de crescimento. Nas folhas a emissividade varia entre 0.97 e 0.98 (SNYDER et al., 1998). 
A Figura 5 mostra que a emissividade muda de acordo com o comprimento de onda e as variações podem ser maiores para uma superfície apenas com substrato e menores para áreas cobertas com grama (FRENCH et al., 2000).

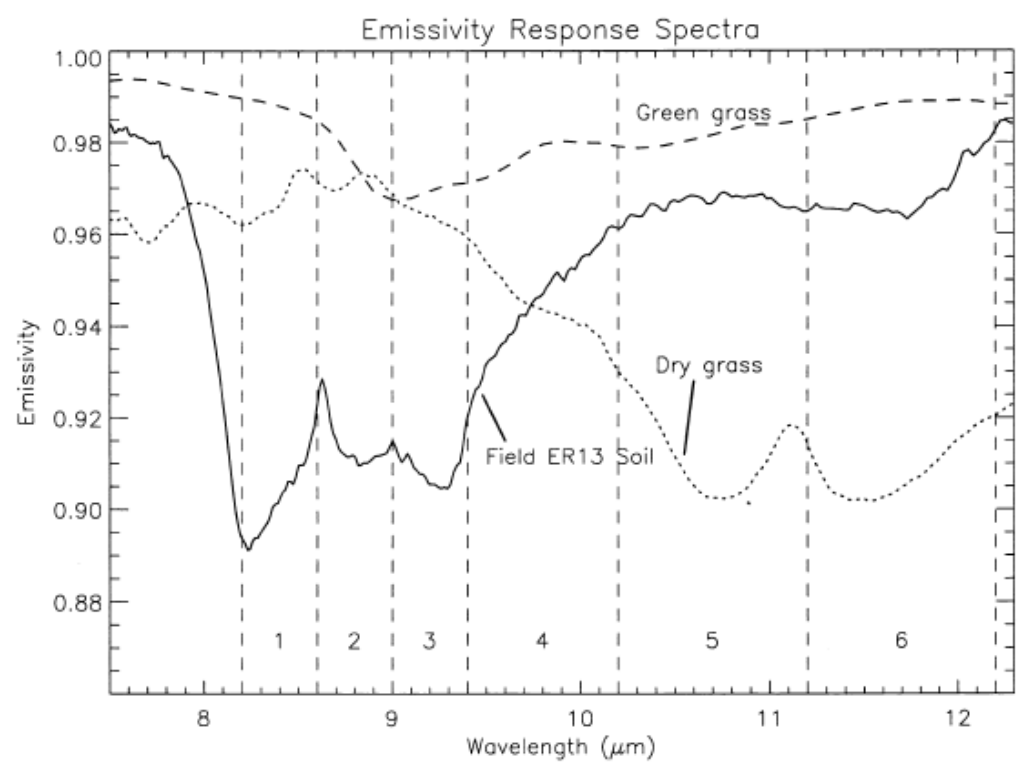

Figura 5: Emissividade da grama e do solo em relação a diferentes comprimentos de onda. Fonte: French et. al. (2000)

O albedo é a relação entre radiação solar refletida e a total incidente. Em áreas verdes, o albedo é um importante fator, sendo um mecanismo presente em muitos processos ecológicos como a evapotranspiração e a fotossíntese. O albedo da superfície é um parâmetro chave para as interações entre radiação solar, superfície e balanço energético (Yin, 1998).

Existem vários estudos sobre os fatores que determinam o albedo das plantas (ROSS, 1981; MONTEITH 1975; NORMAN 1975; GOUDRIAAN, 1977). No entanto, observam-se as alterações no albedo das superfícies nas últimas décadas devido às mudanças no uso do solo e, recentemente, esse fato tem sido colocado como um possível fator para as mudanças climáticas globais e regionais (DICKSON; HANSON, 1984).

As mudanças no albedo das superfícies influenciam na quantidade de calor absorvido e refletido. Assim, apesar da área continental representar $29 \%$ da área total da Terra, esta é a parte que mais vem sofrendo alterações nos últimos anos. Os resultados de modelos climáticos apontam que a modificação do albedo causado pela redução da área de 
vegetação resulta em diminuição de nuvens e precipitação, uma vez que existe a perda no fluxo de calor latente (SANTAMOURIS, 2001).

Os albedos das superfícies com vegetação variam tanto em função do comprimento de onda como do ângulo zenital da radiação solar incidente. Consequentemente a reflexão da radiação solar por essas áreas dependem, em parte, da forma como os raios solares são absorvidos e dispersos na atmosfera (DICKSON; HANSON, 1984).

A dificuldade em se estimar o albedo da vegetação está no fato de que a radiação difusa que incide na superfície da folha foi anteriormente refletida pela própria superfície. Assim, as múltiplas reflexões tornam-se mais significativas para condições do céu parcialmente encoberto e superfícies com altos valores de albedo (DICKSON; HANSON, 1984).

Os albedos das superfícies das folhas dependem do tipo de textura, estrutura e composição, e variam entre 0.25-0.30. No entanto, devem-se considerar algumas adaptações ecológicas para espécies em ambientes de climas quentes e secos, com baixos índices pluviométricos, que podem influenciar em albedos mais elevados. Nos estudos em Atenas por Dimoudi e Nikolopoulou (2003), o albedo utilizado para as árvores decíduas foi de 0.30 , e 0.25 para árvores que não perdem as folhas.

Segundo os estudos de Dickson e Hanson (1984), o albedo das copas das árvores difere significativamente em relação ao albedo de uma única folha e as medições indicam que os valores de albedo das copas são equivalentes, em geral, à metade dos valores de albedo para as folhas. Por exemplo, se a folha tem albedo de 0.30, a copa terá provavelmente 0.15 . Essa diferença acontece pela distribuição das folhas na copa de forma aleatória. Assim, a luz atravessa as folhas mais externas, sendo refletida pelas folhas internas, e os valores mais baixos do albedo contribuem para uma maior absorção, principalmente do espectro visível.

Quando a posição das folhas externas é suficientemente regular, podendo interceptar uma maior parte da radiação incidente, o albedo da copa pode apresentar valores mais altos do que o albedo das folhas, chegando a aproximar-se do valor individual. $\mathrm{O}$ arranjo das folhas em coníferas também tende a diminuir o albedo da copa (GOUDRIAAN, 1977). 


\subsubsection{FLUXO DE CALOR LATENTE PELA FOLHA}

A perda de água da planta para a atmosfera ocorre por meio da transpiração com a abertura dos estômatos. Essas estruturas têm aproximadamente entre 10.000-20.000nm de comprimento e largura máxima de $5.000 \mathrm{~nm}$, podendo apresentar de 100 a 500 estômatos por milímetro quadrado de área foliar e a área total dos poros representa entre $0.5 \%$ e $5 \%$ em relação à superfície total da folha (BONAN, 2002).

O papel principal dos estômatos é controlar as trocas gasosas de vapor e $\mathrm{CO}_{2}$ pela folha, sendo que o mecanismo de abertura e fechamento dos estômatos está diretamente ligado aos processos de transpiração, fotossíntese ${ }^{7}$ e respiração (JONES, 1992).

Os estômatos são formados por duas células estomáticas (células guardas) que delimitam uma fenda (ostíolo), por duas ou mais células anexas (acessórias ou subsidiárias) adjacentes e uma câmara sub-estomática, a qual está em conexão com os espaços intercelulares (BONAN, 2002).

A transpiração pode ser considerada como um processo físico de difusão, proporcional à diferença entre a concentração do vapor d'água nas superfícies e o conteúdo de água na atmosfera (LARCHER, 2006).

Assim, a água no sistema solo-planta-atmosfera é transportada de acordo com um gradiente de potencial hídrico, sempre do maior para o menor potencial. A demanda evaporativa provoca perda de água por meio da transpiração, necessitando de contínua reposição de água para manter um nível adequado de hidratação dos tecidos (OMETO, 1981).

A propriedade do estômato em controlar o fluxo de vapor d'água da folha para a atmosfera é chamada resistência estomática $\left(\mathrm{r}_{\mathrm{s}}\right)$ e o processo inverso é a condutância estomática $\left(\mathrm{g}_{\mathrm{s}}\right)(\mathrm{JONES}, 1992)$.

Oke (1978) aponta o efeito da evapotranspiração como uma relação da densidade de vapor saturado com a resistência estomática existente entre o ar e a cavidade interna dos estômatos. Assim, a equação que define essa relação tem a seguinte representação:

$$
E=\frac{(\rho * v(T o)-\rho v a)}{(r b+r s t)}
$$

\footnotetext{
${ }^{7} \mathrm{O}$ processo de fotossíntese está presente com mais detalhes no Apêndice 2.
} 
Onde:

$\rho^{*}{ }_{\mathrm{v}(\mathrm{To})}=$ Densidade de vapor saturado na superfície da folha $\left[\mathrm{Kg} \mathrm{m}^{-3}\right]$

$\rho_{\mathrm{va}}=$ Densidade do ar $\left[\mathrm{Kg} \mathrm{m}^{-3}\right]$

$\mathrm{r}_{b}=$ Resistência do Laminar Bondary Layer ${ }^{8}\left[\mathrm{~s} \mathrm{~m}^{-1}\right]$

$\mathrm{r}_{s t}=$ Resistência dos Estômatos [ $\left.\mathrm{s} \mathrm{m}^{-1}\right]$

A taxa de transpiração é proporcional à densidade de vapor saturado na superfície da folha, isto é, quanto mais saturado estiver o ar, menor será a perda de água pela superfície da folha.

A resistência estomática é diretamente influenciada por várias condições ambientais externas e outros fatores da própria planta (Figura 6) Entre os fatores externos estão: $\mathrm{CO}_{2}$, luz, temperatura (ar, solo), umidade de saturação do ar, a umidade do solo, concentração de ar no solo e poluição (ar, solo). Por sua vez, os fatores internos da planta são: temperatura da folha, quantidade de água, tipos de hormônios, idade da folha, estágio de desenvolvimento e condições de crescimento (OKE, 1978).

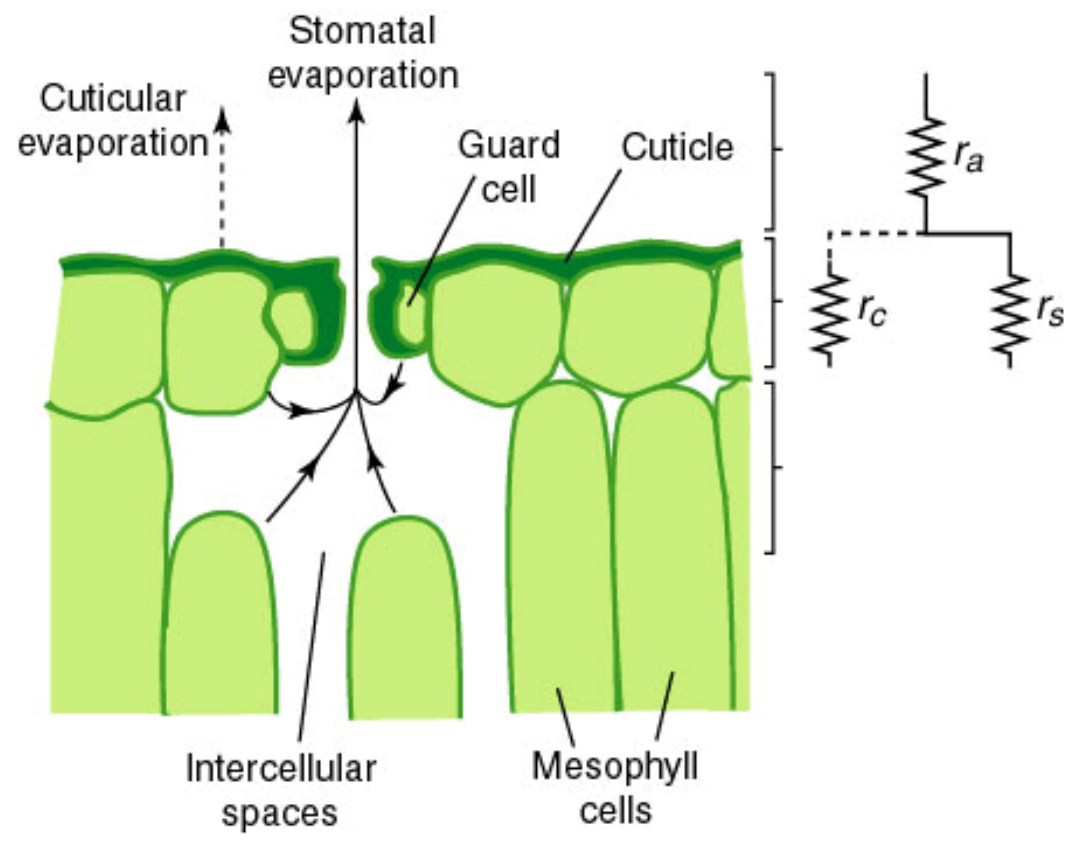

Figura 6: Resistência estomática de acordo com as condições externas e interna à folha.

Fonte: Jones (1992)

\footnotetext{
${ }^{8}$ O Laminar Boundary Layer é a camada logo acima da folha, exercendo resistência para a ação do vento. $\mathrm{O}$ valor de $\mathbf{r} b$ aumenta com o tamanho da folha, pois a camada do Lamina Boundary Layer aumenta proporcionalmente com a distância (OKE, 1978).
} 


\subsection{INTERAÇÃO SOLO-VEGETAÇÂO-ATMOSFERA NA ESCALA DA PLANTA}

A equação que define o balanço de energia do sistema solo-vegetação-atmosfera está descrita a seguir (Oke, 1978):

$$
R_{N}=H+L_{E}+G+I+\mu A
$$

Onde:

$\mathrm{Rn}=$ Saldo de Radiação [W m$\left.{ }^{-2}\right]$

$\mathrm{H}=$ Fluxo de Calor Sensível [W $\left.\mathrm{m}^{-2}\right]$

$\mathrm{L}_{\mathrm{E}}=$ Fluxo de Calor Latente $\left[\mathrm{W} \mathrm{m}^{-2}\right]$

$\mathrm{G}=$ Fluxo de Calor no solo $\left[\mathrm{W} \mathrm{m}^{-2}\right]$

$\mathrm{I}=$ Fluxo armazenado no meio biofísico $\left[\mathrm{W} \mathrm{m}^{-2}\right]$

$\mu \mathrm{A}=$ Fluxo dos processos bioquímicos $\left[\mathrm{W} \mathrm{m}^{-2}\right]$

No sistema composto apenas por vegetação, sem edifícios e outras estruturas, o fluxo de calor sensível corresponde de $5 \%$ a $25 \%$ do total, e o fluxo de calor latente, entre $80 \%$ a 95\%; já o fluxo de calor no solo é de aproximadamente 5\%. O fluxo armazenado no meio biofísico e o fluxo dos processos bioquímicos representam menos de 5\% cada um (OKE, 1978).

\subsubsection{FLUXO DE CALOR LATENTE PELA PLANTA}

A perda de água no sistema solo-vegetação (Le) pode acontecer de três formas: pela evaporação da água no solo (Es), pela evaporação da água interceptada pela copa após a chuva (Ei) e pelo processo de transpiração pela planta (Et).

$$
\boldsymbol{L e}=\underset{(10 \%-25 \%)}{\boldsymbol{E s}}+\underset{(5 \%-15 \%)}{\boldsymbol{E i}}+\underset{(60 \%-80 \%)}{\boldsymbol{E t}}
$$

O processo de evapotranspiração compreende a perda associada de água, que ocorre pela evaporação da superfície do solo e pela transpiração estomática e cuticular da planta. A equação de Penman-Monteith para o cálculo da evapotranspiração da planta é (MONTEITH, 1965):

Onde:

$$
\boldsymbol{E}=\frac{\Delta\left(R_{n}-G\right)-\rho_{a} C_{p} \frac{\left(e_{S}-e_{Q}\right)}{r_{\alpha}}}{\Delta+\gamma\left(1+\frac{r_{S}}{r_{Q}}\right)}
$$

$\mathrm{E}=$ Taxa de evapotranspiração $\left[\mathrm{g} \mathrm{s}^{-1} \mathrm{~m}^{-2}\right]$ 
$\Delta=$ Declividade da curva de pressão de saturação de vapor $\left[\mathrm{Pa} \mathrm{K}{ }^{-1}\right]$

$\mathrm{Rn}=$ Saldo de radiação $\left[\mathrm{W} \mathrm{m}^{-2}\right]$

$\mathrm{G}=$ Fluxo de calor no solo $\left[\mathrm{W} \mathrm{m}^{-2}\right]$

$\rho \mathrm{a}=$ Densidade do ar seco $\left[\mathrm{kg} \mathrm{m}^{-3}\right]$

$\mathrm{Cp}=$ Calor específico do ar seco $\left[\mathrm{J} \mathrm{kg}^{-1} \mathrm{~K}^{-1}\right]$

$\gamma=$ Constante psicrométrica $\left[\gamma \approx 66 \mathrm{~Pa} \mathrm{~K}^{-1}\right]$

(es -ea) $=$ umidade específica do ar $[\mathrm{KPa}]$

$r_{\mathrm{a}}=$ resistência aerodinâmica $\left[\mathrm{m} \mathrm{s}^{-1}\right]$

$r_{\mathrm{s}}=$ resistência estomática $\left[\mathrm{m} \mathrm{s}^{-1}\right]$

O modelo de Penman-Monteith representa a evaporação da superfície como uma grande folha (big leaf model) com dois parâmetros principais: um que é determinado pela física atmosférica, a resistência aerodinâmica; e outro que depende do comportamento fisiológico das folhas, a resistência da copa (RAUPACH; FINNINGAN, 1988). A resistência aerodinâmica para a transferência de energia da superfície para uma altura $\mathrm{z}$ é dada pela equação:

$$
\begin{gathered}
r_{a}=\frac{\ln \left[\frac{Z_{m}-d}{Z_{a m}}\right] \cdot \ln \left[Z_{h}-\frac{d}{Z_{o h}}\right]}{K^{2} \cdot U_{z}} \\
g_{a}=\frac{1}{r_{a}}
\end{gathered}
$$

Onde:

$\mathrm{r}_{\mathrm{a}}=$ Resistência aerodinâmica $\left[\mathrm{m} \mathrm{s}^{-1}\right]$

$\mathrm{Zm}=$ Altura da medição da velocidade do vento [m]

$\mathrm{d}=$ Deslocamento do plano zero do perfil do vento [m]

$\mathrm{Z}_{\mathrm{om}}=$ Parâmetro de rugosidade para momentum $[\mathrm{m}]$

$\mathrm{K}=$ Constante de Von Karman

$\mathrm{U}_{\mathrm{z}}=$ Velocidade do vento a uma altura $\mathrm{z}\left[\mathrm{m} \mathrm{s}^{-1}\right]$

$\mathrm{Zh}=$ Altura de medição da umidade do ar [m]

$\mathrm{Z}_{\mathrm{oh}}=$ Parâmetro de rugosidade para calor sensível e vapor d'água $[\mathrm{m}]$

$\mathrm{h}=$ Altura da planta $[\mathrm{m}]$

A condutância da copa é uma medida da facilidade com que a água pode se mover para fora das folhas das plantas para a atmosfera. Quando ela é baixa, surge uma resistência à difusão de vapor de água para atmosfera, representado na equação de Penman-Monteith pelo $r_{c}$. De forma contrária, quando as condições são favoráveis com a disponibilidade 
de água no solo e luz, a resistência torna-se baixa e aumentam as taxas de transpiração pelas folhas (EAMUS, 2009).

Assim, a resistência da copa é controlada pelo grau de abertura dos estômatos e, na escala da planta, essa resistência está diretamente relacionada com a quantidade de folhas no dossel. (Figura 7). Assim, Monteith (1965b) propôs o uso de uma única resistência da copa para caracterizar o controle fisiológico de toda a planta, calculado a partir da razão entre a resistência estomática de uma única folha e o índice de área foliar da árvore (OKE, 1978):

Onde:

$$
\begin{gathered}
r_{c}=\left(\frac{\rho_{v(T c)}^{*}-\rho_{w o}}{E}\right) \\
r_{c} \cong \frac{r_{s}}{I A F}
\end{gathered}
$$

$\mathrm{r}_{\mathrm{c}}=$ Resistência da copa $\left[\mathrm{s} \mathrm{m}^{-1}\right]$

$\rho^{*}{ }_{v}(\mathrm{Tc})=$ Densidade de vapor saturado a uma temperatura de superfície $\mathrm{T}_{\mathrm{c}}\left[\mathrm{kg} \mathrm{m}^{-3}\right]$

Considerando-se um dossel uniforme e denso, Allen et al. (1995) acrescentaram o valor 0.5 que multiplica o IAF na equação de Monteith e indicaram que apenas a metade superior da copa terá uma contribuição efetiva na troca de calor latente.

$$
r_{C}=\frac{r_{g}}{0,5 \text { LAF }}
$$

Onde:

$\mathrm{r}_{\mathrm{c}}=$ Resistência da copa $\left[\mathrm{s} \mathrm{m}^{-1}\right]$

$\mathrm{r}_{1}=$ Resistência estomática de uma única folha $\left[\mathrm{s} \mathrm{m}^{-1}\right]$

$\mathrm{IAF}=$ índice de área foliar da árvore $\left[\mathrm{m}^{2} \mathrm{~m}^{-2}\right]$

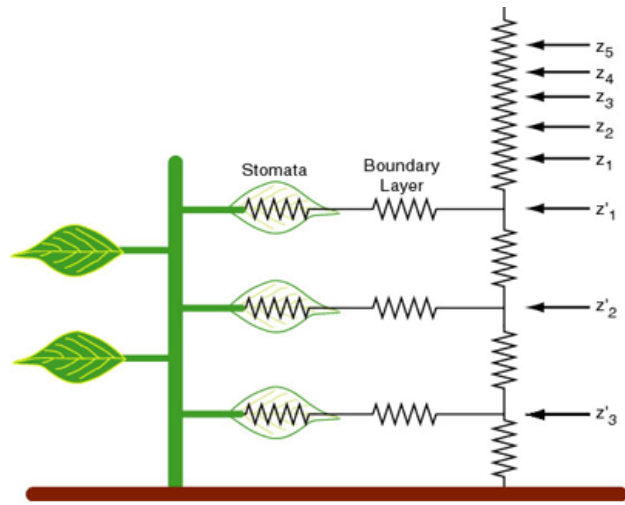

Figura 7: Modelo da resistência da planta segundo a equação de Monteith (1965b). Fonte: Jones (1992) 
Quando ocorre a abertura dos estômatos, ao mesmo tempo em que absorvem $\mathrm{CO}_{2}$ durante a fotossíntese, as plantas liberam $\mathrm{O}_{2}$ por meio da respiração. A respiração é o complemento da fotossíntese e nesse processo componentes orgânicos são oxigenados para produzir a energia necessária para manter as funções e o crescimento dos novos tecidos das plantas.

A fixação do carbono ocorre de forma diferenciada em termos bioquímicos, existindo dois principais grupos de acordo com as fases do processo da fotossíntese: as plantas $\mathrm{C}_{3}$ e $\mathrm{C}_{4}$. As espécies de soja, milho, feijão e todas as árvores são exemplos de plantas $\mathrm{C}_{3}$ e o milho, a cana de açúcar e a maior parte das gramíneas são exemplo de plantas $\mathrm{C}_{4}$.

Aparentemente, as espécies $\mathrm{C}_{4}$ parece desprender mais energia e ser menos eficiente, pois precisam de uma etapa a mais no processo de fixação do carbono. No entanto, as espécies $\mathrm{C}_{4}$ são mais eficientes do que as espécies $\mathrm{C}_{3}$ pois, no seu ciclo as plantas perdem parte do $\mathrm{CO}_{2}$ que foi fixado por meio de um processo chamado fotorespiração. Essa reação consome oxigênio e libera gás carbônico, de forma que o total de $\mathrm{CO}_{2}$ absorvido no processo de fotossíntese é reduzido de 30\% a 50\% (BONAN, 2002).

A Figura 8 mostra as diferenças entre plantas $C_{3}$ e $C_{4}$ em relação à taxa de fotossíntese e as concentrações de $\mathrm{CO}_{2}$. Nas plantas $\mathrm{C}_{3}$, existe uma forte interação fotossintética entre luz e $\mathrm{CO}_{2}$. O crescimento da energia luminosa aumenta a taxa de fotossíntese em situações de alta concentração de $\mathrm{CO}_{2}$ e a saturação do $\mathrm{CO}_{2}$ acontece em altos valores de concentração do $\mathrm{CO}_{2}$. Por outro lado, em plantas $\mathrm{C}_{4}$ a taxa de fotossíntese atinge o ponto de saturação na concentração de 440 ppm de $\mathrm{CO}_{2}$ (BONAN, 2002).
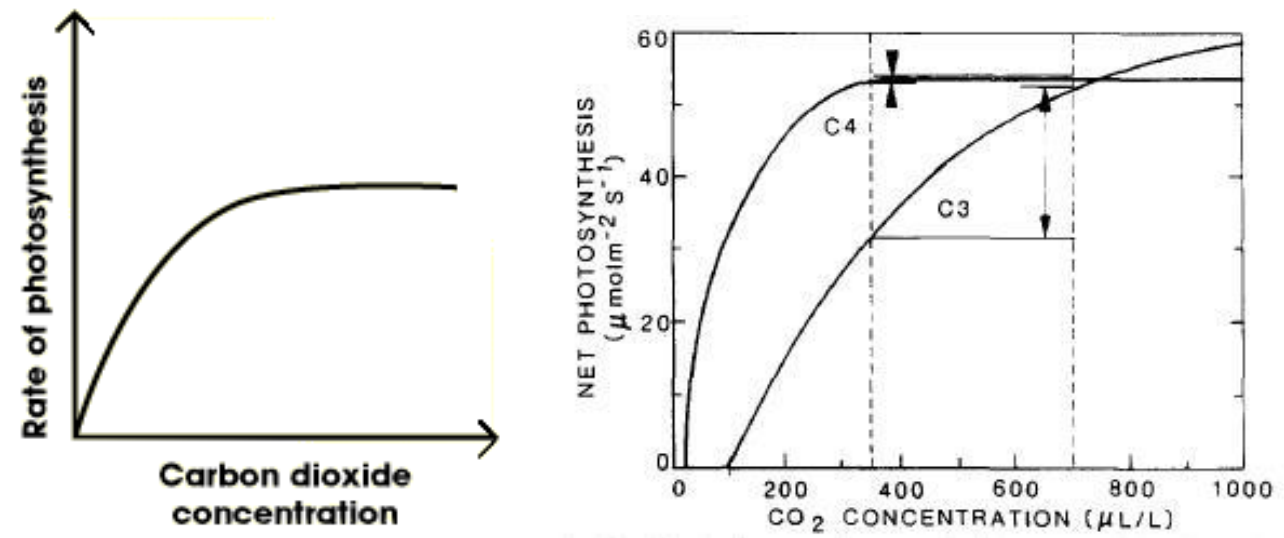

Figura 8: Taxa de fotossíntese em relação ao aumento da concentração de $\mathrm{CO}_{2}$.

Figura 9: Taxa de fotossíntese em relação à concentração de $\mathrm{CO}_{2}$ para plantas $\mathrm{C} 3$ e $\mathrm{C} 4$. Fonte: Kimball et al. (1993) 
Dessa forma, considerando-se os níveis atuais de $\mathrm{CO}_{2}$, as plantas $\mathrm{C}_{4}$ convertem a energia luminosa em energia química, tendo uma eficiência de 7\%, enquanto as plantas $\mathrm{C}_{3}$, apenas $4 \%$. Isso mostra que as gramíneas apresentam uma taxa fotossintética menor do que as arbóreas por ter um metabolismo mais eficiente. No entanto, as gramíneas, por necessitarem de uma menor absorção do $\mathrm{CO}_{2}$, perdem menos água pelos estômatos e podem ter um efeito microclimático reduzido em relação às arbóreas.

Considerando-se a resistência aerodinâmica $\left(\mathrm{r}_{\mathrm{a}}\right)$ como um indicador meteorológico do papel da turbulência atmosférica no processo de evapotranspiração e a resistência da copa $\left(\mathrm{r}_{\mathrm{c}}\right)$ como indicador da fisiologia dos estômatos pelo transporte e perda de água para a atmosfera, a Figura 10 apresenta valores representativos para $r_{a}$ e $r_{c}$ a partir de diferentes tipos de superfícies (OKE, 1978).

\begin{tabular}{llcc} 
Surface & $\begin{array}{l}r_{\mathrm{a}}^{\dagger} \\
\left(\mathrm{s} \mathrm{m}^{-1}\right)\end{array}$ & $\begin{array}{l}r_{\mathrm{c}}^{\ddagger} \\
\left(\mathrm{s} \mathrm{m}^{-1}\right)\end{array}$ & $\begin{array}{c}\text { Total } r \\
\left(\mathrm{~s} \mathrm{~m}^{-1}\right)\end{array}$ \\
\hline $\begin{array}{l}\text { Open water } \\
\text { Short grass (pasture) }\end{array}$ & 200 & 0 & 200 \\
Crops & 70 & 70 & 140 \\
Forests & $20-50$ & 50 & $70-100$ \\
\hline Calculated for $\bar{u}=3 \mathrm{~m} \mathrm{~s}^{-1}$ at a height of $2 \mathrm{~m}$ & $80-150$ & $\sim 130$ \\
\hline Average stomatal aperture, no irrigation, canopy dry
\end{tabular}

Figura 10: Valores representativos da resistência aerodinâmica e da copa. Fonte: Oke (1978)

\subsubsection{FLUXO DE CALOR LATENTE PELO SOLO}

O processo de armazenamento e emissão de calor pelo solo pode ser significativo no período de poucas horas mas, em geral, o fluxo ao longo de um dia é pequeno, pois o calor armazenado no início do dia com o aquecimento pelo sol é totalmente liberado quando o sol se põe (ALLEN et al., 2005).

A fim de se obter o fluxo do solo para pequenos períodos, é utilizada a medição por meio de sensores colocados diretamente no solo, abaixo da superfície. O cálculo do fluxo de calor no solo é feito da seguinte forma:

$$
\mathbf{G}=\mathbf{G z s}+\mathbf{C s} \int_{0}^{z s} \frac{\partial \mathrm{Ts}}{\partial \mathrm{t}} \mathbf{d z}
$$

Onde:

$\mathrm{G}=$ Fluxo de calor no solo $\left[\mathrm{W} \mathrm{m}^{-2}\right]$

Gzs = Fluxo do solo a uma profundidade $\mathrm{zs}\left[\mathrm{W} \mathrm{m}^{-2}\right]$ 
Cs = Capacidade térmica do solo $\left[\mathrm{J} \mathrm{m}^{-3} \mathrm{~K}^{-1}\right]$

$\frac{\partial T s}{\partial t}=$ Mudança de temperatura num período de tempo até a profundidade zs (K)

Segundo os estudos de Alle et al. (2005), o fluxo de calor no solo para gramíneas pode ser calculado pela equação 12 :

$$
\boldsymbol{G}=0,4^{-0,5 \cdot I A F} \cdot R_{n}
$$

Onde:

$\mathrm{G}=$ Fluxo de calor no solo $\left[\mathrm{W} \mathrm{m}^{-2}\right.$ ]

$\mathrm{IAF}=$ Índice de área foliar $\left[\mathrm{m}^{2} \mathrm{~m}^{-2}\right]$

$\mathrm{Rn}=$ Radiação total $\left[\mathrm{W} \mathrm{m}^{-2}\right]$ 


\section{CONCEITOS, APLICAÇÕES, MÉTODOS DE MEDIÇÃO E CÁLCULO DO ÍNDICE DE ÁREA FOLIAR - IAF}

\subsection{CONCEITUAÇÃO DO IAF}

O IAF é um número adimensional e expressa a relação da superfície total das folhas da copa $\left(\mathrm{m}^{2}\right)$ pela área da projeção da copa na superfície do solo $\left(\mathrm{m}^{2}\right)$ é um importante parâmetro para se para verificar a interação entre atmosfera e superfície do solo por meio da troca de energia pelas folhas das árvores (MEIR, 2000).

Segundo a definição de Watson (1947): "Leaf Area Index (LAI) is defined as the one sided green leaf area per unit ground area in broadleaf canopies, or as the projected needleleaf area per unit ground area in needle canopies".

A partir da definição de Watson, outras interpretações sobre o conceito de IAF foram propostas: Total Leaf Area Index, Projected Leaf Area Index, Silhouette Leaf Area Index, Effective Leaf Area Index e True Leaf Area Index (ZHENG, 2009).

De acordo com as diversas abordagens para o conceito de IAF, percebe-se que a definição de Watson (1947) apresenta limitações quando ocorre a variação do tipo de copa e folhas, sendo aplicável somente para árvores de folhas horizontais e lisas.

Assim, nos casos em que a tipologia das folhas (onduladas, curvadas ou irregulares) e das copas (cilíndrico, semi-cilíndrico, esférico, elipsoidal) variam, o conceito de IAF segundo Watson (1947) não é o mais adequado (JONCKHEERE, 2003).

O conceito mais aceito atualmente está baseado nos estudos de Chen e Black (1992) que definiram o IAF como sendo: "half the total intercepting (non-projected) area per unit ground surface area". Dessa forma, o IAF é calculado considerando-se metade do total da área fotossinteticamente ativa e sua área de projeção no solo.

Segundo os estudos de Zheng (2009), existem denominações específicas do conceito IAF de acordo com sua aplicação. O Total LAI (TLAI) é definido como a área total de tecido fotossintético, considerando-se apenas um dos lados da folha, por unidade de superfície projetada no solo. Essa definição de IAF é aplicada para folhas largas com formato plano, tendo a mesma área de exposição na parte superior e inferior da folha.

O Projected LAI (PLAI) é definido como a área horizontal de sombra formada logo abaixo de uma folha horizontal a partir de um feixe de luz a uma distância infinita sobre 
a folha. Este IAF é calculado pela soma das projeções das áreas com folhas de um nível a partir do solo $(\mathrm{z}=0)$ até o topo da copa $(\mathrm{z}=\mathrm{h})$ e depende do coeficiente de densidade média da superfície das folhas.

O conceito de Silhouette LAI (SLAI) é definido como a área de folhas inclinadas em relação à superfície horizontal e foi comparado ao TLAI e PLAI para se investigar o efeito da orientação das folhas como forma de interceptação de radiação. O Effective LAI (ELAI) é definido como a metade da área total da luz interceptada pelas folhas por unidade de superfície projetada no solo e está baseada na premissa de que as a distribuição das folhas no espaço é feita de forma aleatória e essa definição de IAF tentou descrever de forma mais específica as condições de radiação de onda longa e curta logo abaixo de uma floresta de coníferas.

O True LAI (TLAI) é considerado como a metade da área foliar total por unidade de superfície projetada no solo e definido a partir de análises matemáticas do coeficiente de projeção média para vários formatos de folhas.

Essas definições foram criadas em diferentes disciplinas para áreas de estudo bastante diversas como, por exemplo, a determinação da sucessão das comunidades florestais, a simulação do potencial das atividades biológicas das plantas e os regimes de radiação solar através das copas.

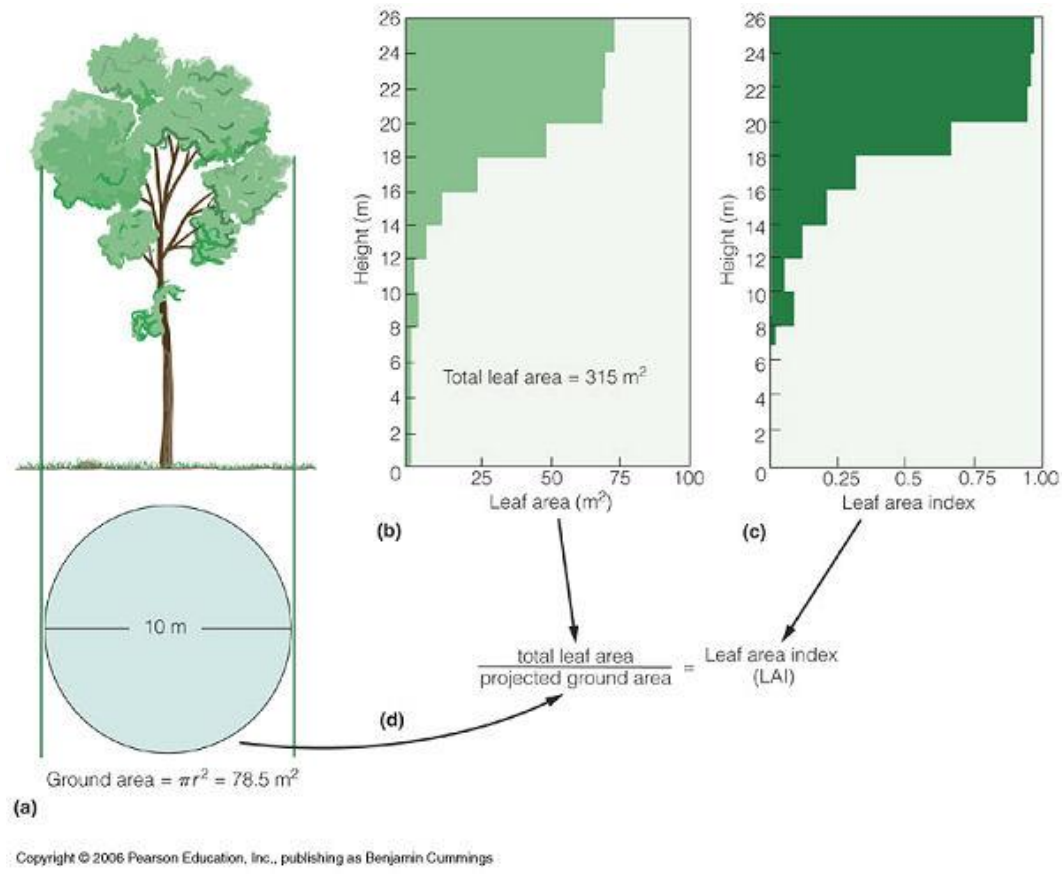

Figura 11: Cálculo do Índice de Área Foliar

Fonte: Pearson Education, Inc. Disponível em: <

http://morriscourse.com/elements_of_ecology/chapter_4.htm $>$. Acesso em junho de 2012. 
A Figura 11 mostra a aplicação do cálculo do índice de área foliar para uma determinada espécie, e considera a área total de folhas $\left(315 \mathrm{~m}^{2}\right)$ dividida pela área total de projeção máxima da copa $\left(78,5 \mathrm{~m}^{2}\right)$. Dessa forma essa árvore apresenta um IAF 4 e para se visualizar a distribuição das folhas ao longo da copa, o valor final foi separado em camadas de 2 metros cada uma.

Observando-se em planta cada camada, pode-se verificar com mais clareza o que o índice de área foliar representa. De acordo com a Figura 12, o IAF mostra a porcentagem de cobertura das folhas em relação à área máxima da copa. Somando-se os valores parciais de cada camada, tem-se no final o IAF total da copa.

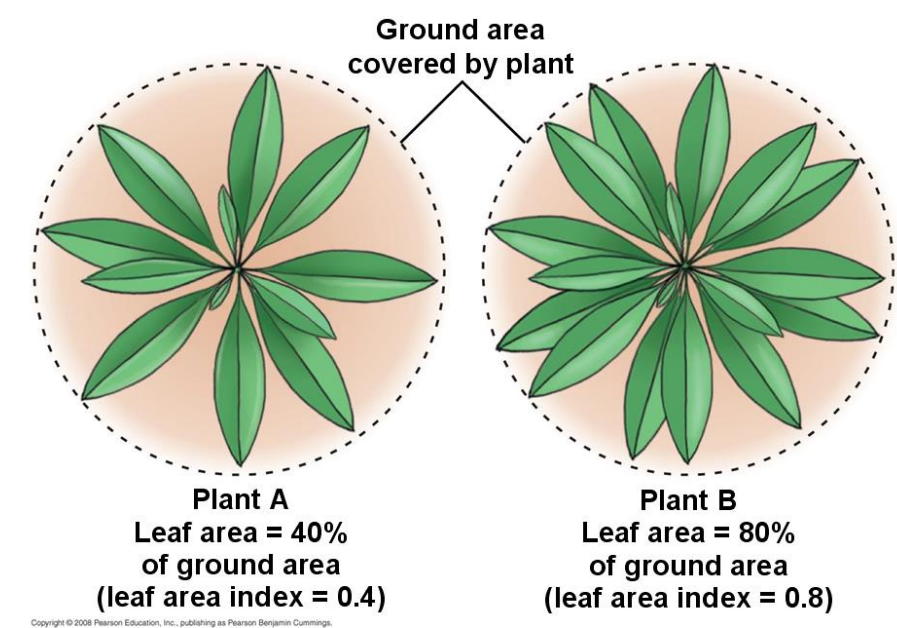

Figura 12: Relação da cobertura de folhas e $o$ índice de área foliar.

Fonte: Pearson Education, Inc. Disponível em: < http://morriscourse.com/elements_of_ecology/chapter_4.htm $>$. Acesso em junho de 2012.

Desta forma, esse índice é um parâmetro-chave para se determinar uma série de processos ecológicos e fisiológicos como fotossíntese e evapotranspiração, possibilitando a previsão das taxas de trocas de energia entre vegetação e atmosfera, a curva de crescimento futuro e as diferenças na estrutura da copa devido à poluição do ar e mudança climática (ONG, 2002).

\subsection{APLICAÇÕES DO IAF}

Muitos modelos baseiam-se nos valores de IAF para simular a interação solo-vegetaçãoatmosfera, como forma de calcular a evapotranspiração, o movimento de água no solo e a produtividade primária da vegetação como, por exemplo, o modelo Forest GBC (RUNNING; COUGHLAN, 1988) que avalia o ciclo do carbono e do nitrogênio, o 
modelo 3-PG (LANDSBERG; WARING, 1997) para o crescimento da vegetação e o modelo WAVES (ZHANG et al., 1996) que calcula o balanço hídrico e do solo.

O modelo Forest GBC - BioGeochemical Cycles (RUNNING; COUGHLAN, 1988) simula o balanço hídrico, do nitrogênio e do carbono para florestas em diferentes climas. Considera o cálculo de transpiração, evaporação, fotossíntese, alocação de carbono e crescimento das plantas. O modelo usa o IAF para quantificar a estrutura das copas e esse índice é a variável chave para o cálculo das trocas de energia e massa.

Desenvolvido por Landsberg e Waring (1997), o Physiological Principles Predicting Growth - 3PG é um modelo que verifica a alocação de carbono na floresta e o crescimento da vegetação. Nos dados de entrada são necessárias informações como: dados climáticos, localização (latitude) e características das espécies (crescimento, idade, IAF). O índice de área foliar é utilizado para descrever o dossel das árvores, influenciando no cálculo da produtividade primária bruta e intercepção das águas da chuva pela copa.

O modelo WAVES (ZHANG et al. 1996) baseia-se nos processos físico e fisiológico da planta para simular as interações dinâmicas entre solo-vegetação-atmosfera. A transpiração é determinada pela resistência da copa e calculada em função das taxas de assimilação do $\mathrm{CO}_{2}$, déficit de pressão de vapor e a concentração de $\mathrm{CO}_{2}$ na superfície da folha. O balanço hidrológico é modelado segundo a equação de Richards (1931) que descreve o movimento da água nos solos insaturados e a evapotranspiração é dada pela equação de Penman-Monteith (MONTEITH, 1965) que considera parâmetros específicos da vegetação como a resistência estomática e o IAF.

No Brasil, Soares e Almeida (2001) desenvolveram o modelo UAPE (Uso de Água em Plantações de Eucalipto) com cálculos que adaptaram o método de Penman-Monteith para estimar a transpiração e o balanço hídrico para plantações de eucalipto e o IAF é utilizado para estimar a condutância do dossel. Nos estudos de Soares et al. (1997) e Soares e Almeida (2001), a evapotranspiração do dossel, quando integrada em um dado período de tempo, pode ser utilizada para expressar o potencial de produtividade da cultura em determinado local e período (NETO, 2007).

O IAF pode ter aplicações práticas no planejamento urbano como demonstra Ong (2002) que desenvolveu o conceito do Green Plot Ratio - GPR (Relação Área Verde/ Área do terreno), definido como uma média do IAF em uma determinada área 
arborizada. Também equivale à relação da área total de folhas existentes pela área total do lote. O GPR é um indicador mais efetivo do que o cálculo da cobertura vegetal, pois está diretamente relacionado com a densidade de folhas que realizam fotossíntese no local (ONG, 2002).

O GPR pode ser calculado ao se considerar o IAF de cada espécie multiplicado pela área de projeção da copa. Esses valores são somados e divididos pela área total do lote (Equação 12).

$$
\begin{gathered}
G P R+\left(\frac{\text { área foliar total }}{\text { área total do terreno }}\right) \\
G P R=\sum \frac{\left(I A F_{1} \cdot A P C_{1}+I A F_{2} \cdot A P C_{2} \ldots \ldots+I A F_{n} \cdot A P C_{n}\right)}{A_{t}}
\end{gathered}
$$

Em relação aos valores do IAF, inicialmente o GPR assumia três categorias para representar a vegetação: gramíneas $(\mathrm{IAF}=1)$, arbustos $(\mathrm{IAF}=3)$ e árvores $(\mathrm{IAF}=6)$, definindo que o efeito de uma grama que cobre inteiramente um determinado terreno será igual a 1/3 dele forrado por arbustos ou 1/6 com árvores (Figura 15). Essas considerações sobre o GPR são válidas, pois mantém a mesma quantidade de folhas, mudando-se apenas a distribuição das mesmas.

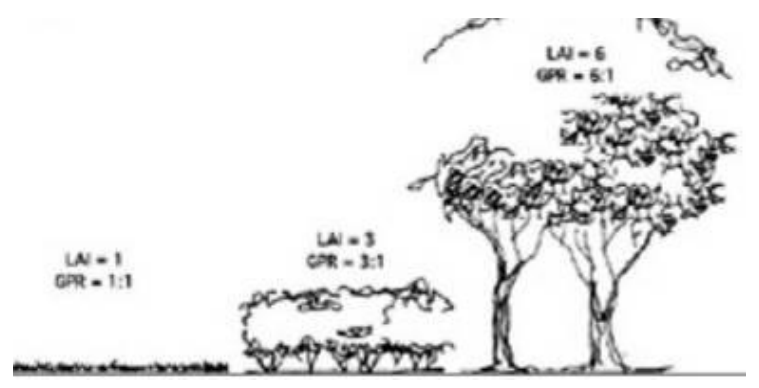

Figura 13: Representação dos três tipos de vegetação no indicador do Green Plot Ratio.

Fonte: ONG (2002).

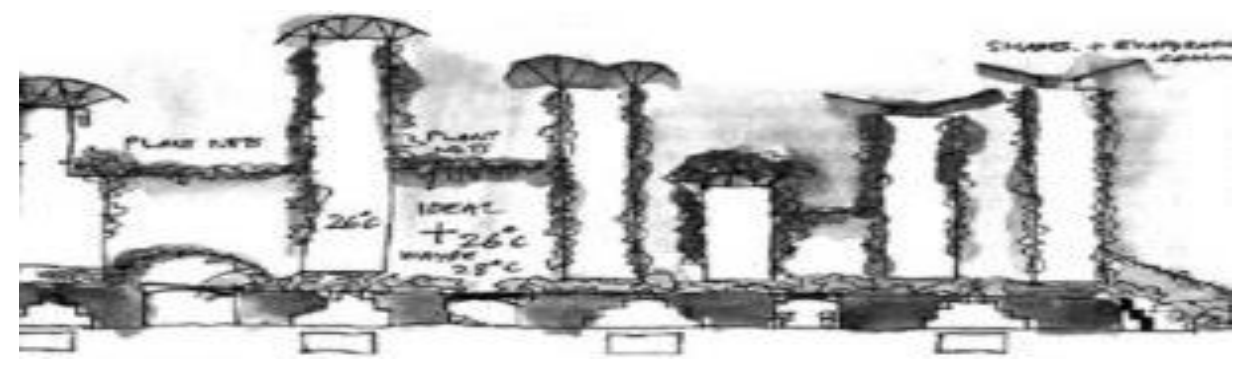

Figura 14: Distribuição da vegetação mantendo-se a mesma densidade foliar da Figura 16. Fonte: ONG (2002). 


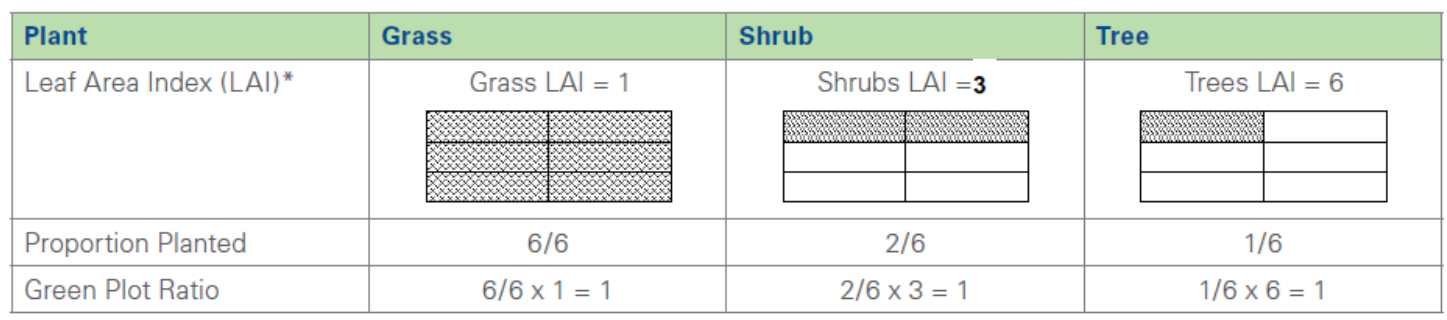

Figura 15: Distribuição da vegetação com diferentes valores de IAF, para um mesmo

GPR.

Fonte: BCA Green Mark Scheme, 2012. Disponível em: <

http://www.bca.gov.sg/GreenMark/green_mark_projects.html >. Acesso em junho de

2012.

A intenção desse indicador é expressar uma distribuição do verde mais descentralizada, criando novas áreas verdes nos centros urbanos de alta densidade e com poucos espaços disponíveis. Um modelo que se destaca são os projetos urbanos na cidade de Cingapura, com fachadas e tetos verdes para incorporar a vegetação nos edifícios de forma a se criar novos espaços que não são mais possíveis nas vias públicas.

O Centre for Urban Greenery and Ecology ${ }^{9}$ - CUGE em parceria com pesquisadores da University of Singapore criaram um banco de dados com a medição do IAF de diversas espécies existentes em Cingapura. O resultado desse levantamento divide as espécies em 4 principais grupos: arbóreas, palmáceas, arbustivas e gramíneas. Os valores de IAF estão disponíveis para consulta no site da National Parks - Nparks $^{10}$.

Desde o lançamento da certificação voluntária BCA Green Mark Scheme ${ }^{11}$ em janeiro de 2005, o cálculo do GPR é exigido como um dos itens de avaliação da sustentabilidade de todos os novos edifícios em Cingapura. A Figura 16 apresenta o edifício Fusionopolis do escritório TR Hamzah \& Yeang que obteve o GPR $=3$, mostrando que a vegetação incorporada no projeto triplicou a densidade foliar prevista para o lote.

O conjunto residencial de 63 andares no centro de Cingapura, Newton Suites, projetados pelo escritório WOHA $^{12}$ apresenta varandas com jardins suspensos (sky gardens) e paredes verdes, resultado um aumento de $30 \%$ da densidade foliar (GPR =

\footnotetext{
${ }^{9}$ Disponível em: < www.cuge.com.sg >. Acesso em junho de 2012.

${ }^{10}$ Disponível em: < http://floraweb.nparks.gov.br >. Acesso em junho de 2012.

${ }^{11}$ Disponível em: < http://www.bca.gov.sg/greenmark/green_mark_buildings.html >. Acesso em junho de 2012.

12 Disponível em: < www.woha-architects.com/ >. Acesso em junho de 2012.
} 
1.3). Após esse projeto, a secretaria de planejamento definiu o mínimo de $100 \%$ de GPR (ou GPR = 1) para novos edifícios construídos na área central da cidade. Um recente projeto comercial com 30 pavimentos, o Oasia Downtown, tem previsão de término em abril de 2014 e prevê um envelope externo com paredes verdes que devem atingir um GPR de 7.5 para o lote (Figura 18).

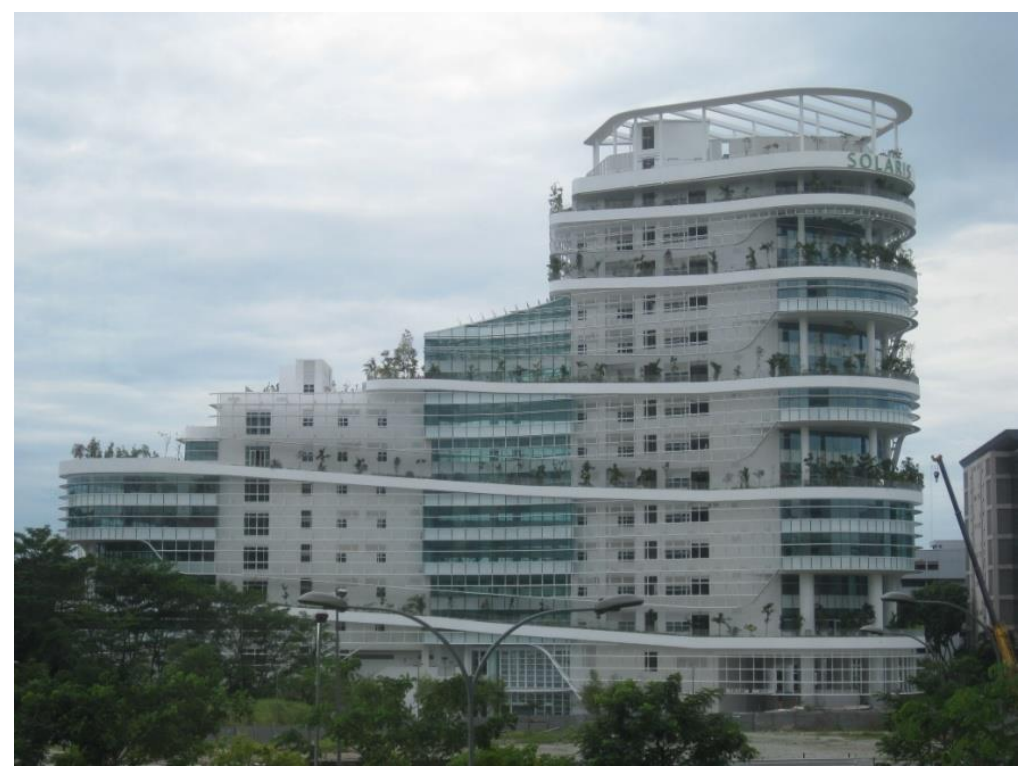

Figura 16: Fusionopolis, Cingapura (novembro de 2010).
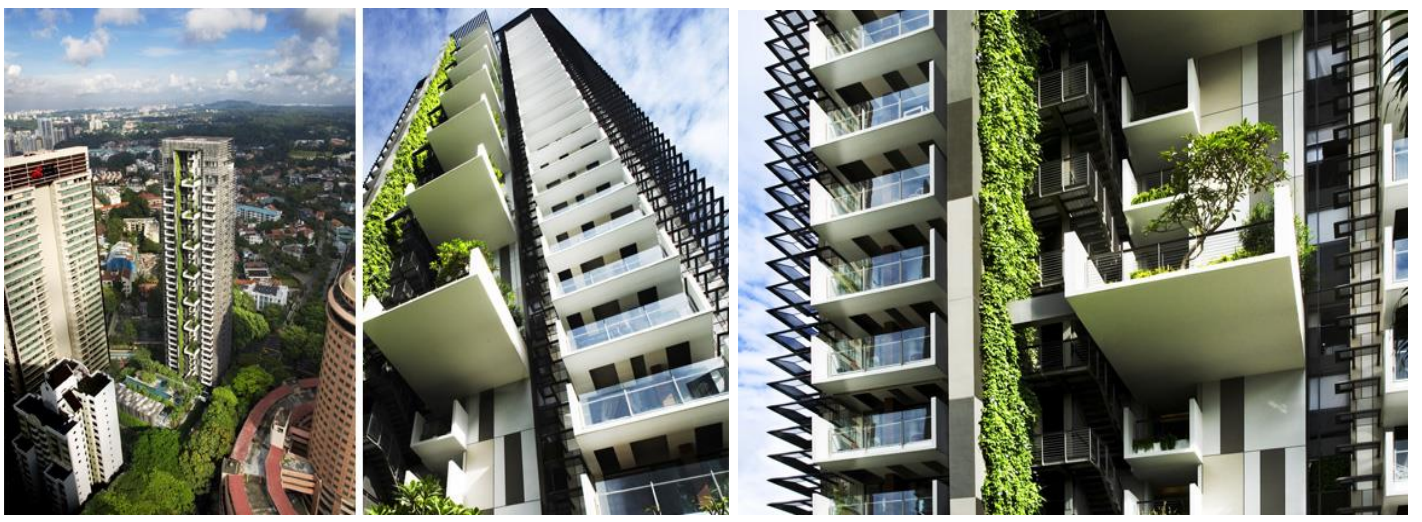

Figura 17: Newton Suites como GPR $=1.3$

Fonte: WOHA. Disponível em: < www.woha-architects.com/ >. Acesso em junho de 2012. 

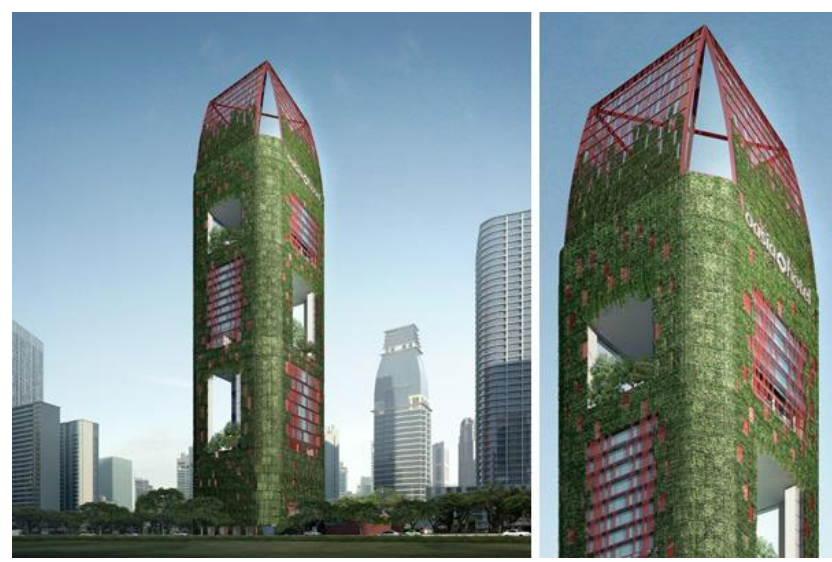

Figura 18: Empreendimento Oasia Dowtown com GPR = 7.5

Fonte: WOHA. Fonte: WOHA. Disponível em: < www.woha-architects.com/ >. Acesso em junho de 2012.Em cache - Similares

\subsection{MÉTODOS DE MEDIÇÃo E CÁLCULO DO IAF}

Os métodos de medição do IAF podem ser classificados em duas principais categorias: métodos destrutivos diretos e métodos não-destrutivos indiretos. O método direto baseia-se no cálculo da área média de folhas individuais coletadas e, a partir destes dados, estima-se o IAF para toda a copa da árvore. O método indireto envolve cálculos a partir da atenuação da radiação pelo dossel da copa, registrada de diferentes maneiras.

\subsubsection{MÉTODOS DIRETOS DE MEDIÇÃO DO IAF}

Segundo Jonckheere (2003), os métodos diretos consistem de duas etapas: coleta de folhas e determinação da área foliar. A primeira etapa apresenta as seguintes formas de coleta das folhas: coleta destrutiva, model tree; e a liteira ou serrapilheira. A segunda etapa consiste em se determinar a área foliar por meio de cálculos com planimetria ou pelo método gravimétrico.

\subsubsection{MÉTODOS DE COLETA DE FOLHAS}

A coleta destrutiva envolve a retirada de folhas de uma parte da copa, seguida da estimativa da área total do dossel e, para isso, considera-se um formato homogêneo da copa. A melhor situação para se aplicar essa metodologia é em indivíduos jovens espalhados em condições homogêneas, como as plantações de coníferas.

O model tree remove as folhas de uma pequena quantidade de árvores que podem ser representativas de toda a copa. Num estágio jovem as árvores têm uma distribuição mais regular e, nesse caso, a derrubada de 3 a 5 indivíduos pode ser suficiente. Em seguida a área foliar e a distribuição vertical são calculadas folha por folha. Esse método é 
aplicado principalmente em culturas e florestas com árvores de copas largas e baixa densidade de folhas.

A liteira ou serrapilheira é realizada no período do outono, principalmente em florestas decíduas. Bandejas são posicionadas em determinados pontos e as folhas coletadas ajudam na estimativa da área foliar da copa. Esse método não pode ser aplicado em árvores sempre verdes (evergreen), pois a perda de folhas não está relacionada ao acúmulo de biomassa, mas ao ciclo de vida das folhas e as condições climáticas do local.

\subsubsection{MÉTODOS DE DETERMINAÇÃO DE ÁREA FOLIAR}

O método da planimetria é baseado no princípio da correlação entre a área foliar individual e a quantidade de área coberta por esta área foliar individual em um plano horizontal. Para isso a folha pode ser fixada horizontalmente em uma superfície plana e seu perímetro é determinado por um planímetro e sua área calculada a partir dos dados do perímetro. Existem diferentes tipos de planímetros ópticos: o scanning planimeter Li-3000 (Li-cor, Nebraska), o Li-3100C (Li-cor, Nebraska) e Ag Vision System (Decagon devices, Inc, Washigton, USA).

O Li-3000 ${ }^{13}$ utiliza o método eletrônico rectangular approximation que gera uma resolução de $1 \mathrm{~mm}^{2}$. A medida é obtida por meio de um instrumento portátil que escaneia cada folha e pode se combinado com outro equipamento, o Transparent Belt Conveyer (LI 3050c) que permite a medição de um maior número de folhas retiradas.
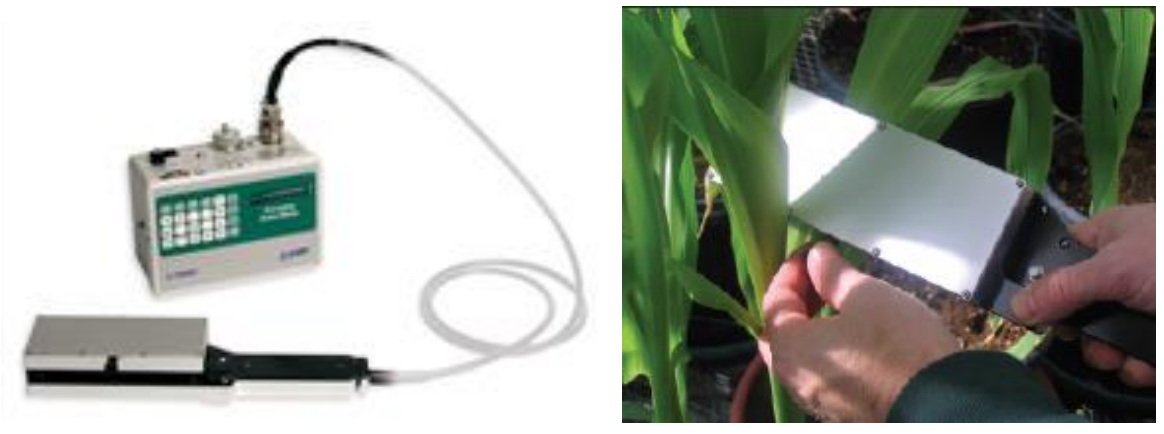

Figura 19: Equipamento Li-3000

Fonte: Li-cor. Disponível em: < www.licor.com >. Acesso em maio de 2012.

\footnotetext{
${ }^{13}$ Disponível em: < http://www.licor.com/env/products/leaf_area/LI-3000C/lit.html $>$. Acesso em maio de 2012.
} 


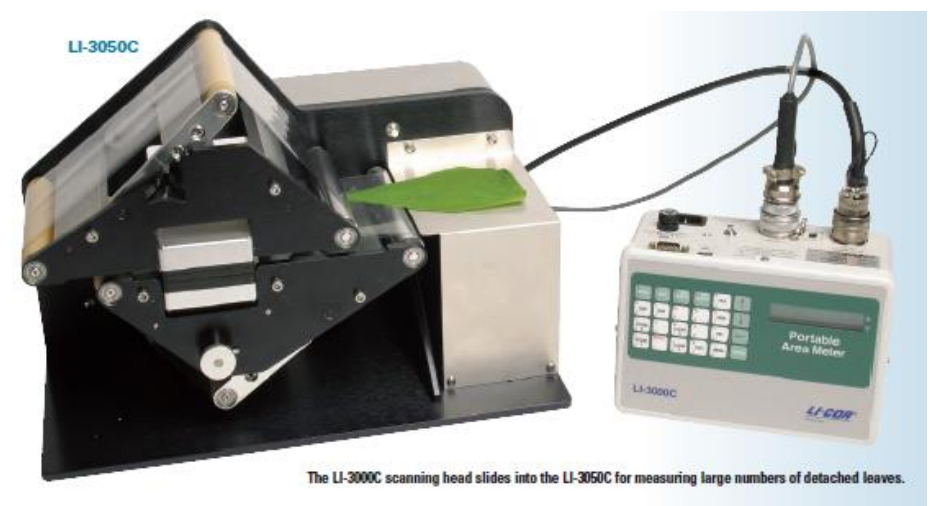

Figura 20: Equipamento Transparent Belt Conveyer (Li 3050c)

Fonte: Li-cor. Disponível em: < www.licor.com >. Acesso em maio de 2012.

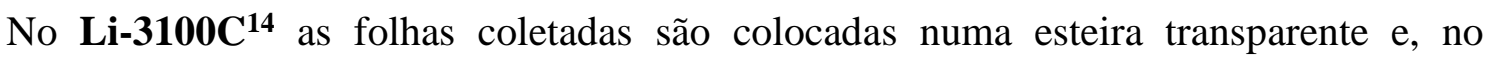
interior do equipamento, uma fonte de luz fluorescente gera a imagem projetada que é refletida por um sistema de três espelhos até uma câmera de escaneamento (Figura 21).

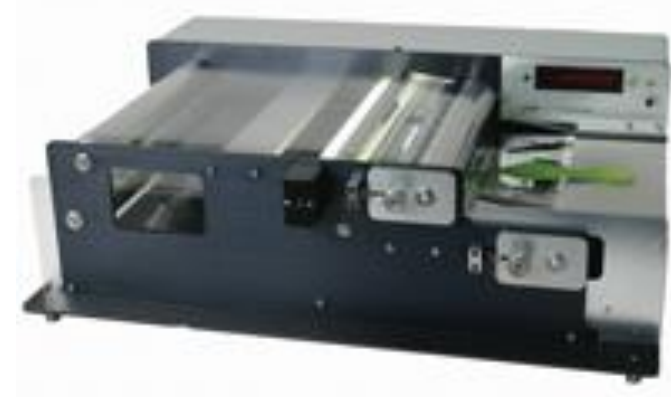

Figura 21: Equipamento Li-3100C

Fonte: Li-cor. Disponível em: < www.licor.com >. Acesso em maio de 2012.

O Ag Vision System é um sistema de análise de imagens, utilizando uma câmera de vídeo, uma moldura de digitalização e um computador com o programa apropriado para a análise dos dados. Esse equipamento digitaliza as folhas e realiza o contraste da imagem, destacando a folha em relação ao fundo.

O método gravimétrico relaciona o peso seco das folhas e a área foliar, sendo necessário encontrar o teor de umidade das folhas e uma razão pré-determinada de área foliar por peso seco. Segundo Larcher (2006), esta razão é chamada de Área Foliar Específica ou AFE $\left[\mathrm{cm}^{2}\right.$ de folha /g massa seca]. Todas as folhas selecionadas são

\footnotetext{
${ }^{14}$ Disponível em: < http://envsupport.licor.com/index.jsp?menu=Area_Meters\&spec=LI-3100C $>$. Acesso em maio de 2012.
} 
coletadas e pesadas no campo; em seguida as folhas passam por um forno de $75-105^{\circ} \mathrm{C}$ até atingirem um peso constante, e o peso seco é obtido numa balança de alta precisão. Tanto a AFE quanto o teor de umidade são calculados através de uma subamostra deste total de folhas retiradas no campo.

\subsubsection{MÉTODOS INDIRETOS DE MEDIÇÃO DO IAF}

Os métodos de medição indireta são, geralmente, baseados na medição da atenuação de radiação pelo dossel, a partir da teoria de transferência de radiação. Segundo Jonckheere (2003) os métodos indiretos podem ser de contato ou sem contato.

Os principais métodos indiretos de contato são: método inclined point quadrat e as técnicas alométricas. O primeiro consiste em colocar um longo e fino cabo em determinados ângulos da copa e contar o número de vezes que entram em contato com algumas folhas. A desvantagem é o extenso trabalho para a contagem dos pontos e o fato do método não poder ser aplicado em espécies mais altas que $1.5 \mathrm{~m}$.

Já as técnicas alométricas relacionam a área foliar com outros elementos da planta como diâmetro do tronco, altura da árvore, etc. A dificuldade é que, em geral, essas características variam de acordo com a estação do ano, a fertilidade do solo, o clima local e a estrutura da espécie.

Em relação os métodos indiretos sem contato, as medidas estão baseadas na estimativa pela frequência de contato (WARREN-WILSON, 1959) ou por meio do gap fraction (ROSS, 1981). A frequência de contato é a probabilidade dos raios que penetram no interior da copa de entrar em contato com algum elemento vegetativo. Por outro lado, termo gap fraction é a probabilidade do raio não ser bloqueado por nenhum elemento da copa e chegar até o solo. O cálculo do gap fraction é equivalente à medição de transmitância luminosa no nível do solo (WEISS et al.,2004).

Nos últimos anos, os equipamentos desenvolvidos para a medição do IAF podem ser divididos em duas categorias: um primeiro grupo que se baseia na distribuição e tamanho das aberturas da copa (Gap Size Distribution) e um segundo que considera a distribuição geométrica das aberturas (Gap Fraction Distribution). O primeiro grupo calcula o IAF por meio de fotografias hemisféricas e o segundo parte da relação entre o gap fraction e a geometria da copa para definir a penetração da radiação solar entre as folhas (JONKHEERE et al, 2003). Assim, para um mesmo gap fraction podem existir 
diferentes gap size, como mostra a Figura 22, em que ambas as figuras possuem 1/3 de gap fraction, mas a forma como estão distribuídas (geometria do gap size) é bem diferente.

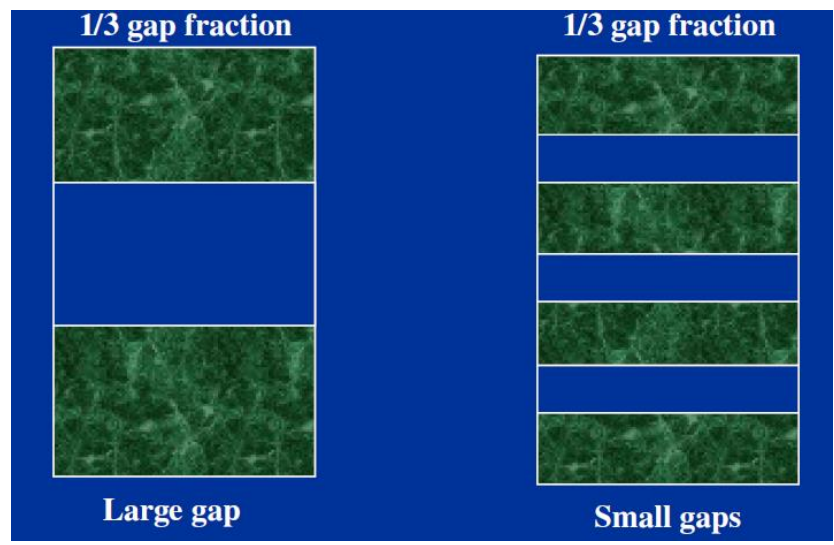

Figura 22: Diferença entre gap size e gap fraction.

Fonte: Beringer (2010).

Os equipamentos para se medir o gap fraction distribution utilizam imagens registradas acima e abaixo da copa. O valor máximo do IAF medido é geralmente baixo para esses equipamentos que medem o gap fraction, em comparação aos métodos diretos, e atingem níveis até $\mathrm{IAF}=5$.

Alguns instrumentos possibilitam o cálculo do Gap Fraction manualmente (luminous slat); outros incorporam técnicas de análise da imagem da copa (Digital Plant Canopy Analyzer CI 100, MVI), a equipamentos como o Demon (CSIRO, Canberra, Austrália), o ceptômetro Accupar LP-80 (Decagon Devices, Pullman, EUA) e o mais utilizado em pesquisa atualmente é o LAI2000 ${ }^{15}$ Plant Canopy Analyser - LICOR que calcula o IAF comparando as medidas de radiação solar na parte superior e inferior da copa (XAVIER et al., 2002).

Já para a medição do gap size distribution os instrumentos disponíveis medem a dimensão de cada superfície iluminada. Procedimentos analíticos são feitos para se converter as medidas, feitas com fotos hemisféricas, por exemplo, em valores de IAF.

\footnotetext{
${ }^{15}$ O LAI-2000 não é mais comercializado e foi substituído pelo LAI-2200. Ambos apresentam os mesmos cálculos para o IAF das plantas.
} 
Welles (1990) e Welles e Cohen (2003) descreveram uma série de instrumentos e métodos para realizar estas medições, entre os quais estão as fotografias hemisféricas, o sensor da linha DEMON e o equipamento LAI-2000 (XAVIER et al., 2002).

As medidas pelo método indireto sem contato não distinguem o tecido fotossintético ativo de outros elementos da planta como tronco, galhos, flores e, por isso, alguns ajustes e correções são necessárias. Além disso, o empilhamento das folhas leva a resultados subestimados, como verificado nos estudos de Weiss et al. (2004), Jonckheere et al. (2003).

A descrição precisa da distribuição da radiação num determinado dossel é complexa, pois leva em consideração a estrutura da copa, o ângulo de distribuição da radiação incidente e as propriedades espectrais das folhas (JONES, 1992). Os métodos indiretos utilizam as medidas de transmissão da radiação através da copa para o cálculo do IAF, baseados na teoria de transferência radiativa segundo os estudos de Anderson (1971) e Ross (1981).

Existem duas abordagens para se estimar o valor do IAF (de forma indireta sem contato): método do cálculo da radiação e o método com medições do gap fraction. $\mathrm{O}$ primeiro utiliza a analogia com os modelos de meios túrbidos (turbid media) ${ }^{16}$ e faz as seguintes considerações: as folhas são distribuídas aleatoriamente na copa e o tamanho individual das folhas é pequeno em relação à extensão da copa (BRÉDA, 2003).

O primeiro utiliza a lei da extinção da radiação dada pela Lei de Beer-Lambert, que define uma relação empírica entre a absorção da luz e as propriedades dos materiais por onde a luz passa. De acordo com a distribuição de Poisson que propõe uma adaptação na Lei de Beer-Lambert, assume que a radiação solar é atenuada exponencialmente ao atravessar a copa de uma árvore, de acordo com a seguinte equação: e segundo um coeficiente de extinção $\boldsymbol{K}$. A luz medida embaixo da copa, $Q i$, está relacionada com a luz sobre a copa, $Q o$, e o IAF é obtido pela seguinte equação:

$$
Q_{i}=Q_{0} e^{-k \cdot L A F}
$$

Onde:

\footnotetext{
${ }^{16}$ Nos modelos de meios túrbidos, assume-se que o dossel florestal ou a cobertura vegetal é uma camada contínua, homogênea e horizontalmente uniforme, possui camadas planas, paralelas e distintas sobre a superfície do terreno (MESQUITA JUNIOR, 2005).
} 
$Q i=$ Radiação total incidente $\left[\mathrm{W} \mathrm{m}^{-2}\right]$

$Q o=$ Radiação medida abaixo da copa $\left[\mathrm{W} \mathrm{m}^{-2}\right]$

$K=$ coeficiente de extinção

$\mathrm{IAF}=$ Índice de área foliar $\left[\mathrm{m}^{2} \mathrm{~m}^{-2}\right]$

Segundo Bréda (2003), existem vários estudos para se determinar o coeficiente $K$ (LEDENT, 1977; SMITH, 1993; VOSE et al., 1995). Pierce e Running (1988) propuseram o valor de 0.52 para espécies coníferas por meio das medições feitas por Jarvis e Leverenz (1983).

O coeficiente de extinção $K$ depende de fatores como a inclinação e a transmissividade da folha, o tipo (comprimento de onda) e a direção (ângulo zenital) da radiação solar (JONES, 1992; BERBIGIER; BONNEFOND, 1995).

Devido a esses fatores, o coeficiente $K$ deve ser estimado para cada espécie (BRÉDA, 2003). No entanto, analisando-se a distribuição das folhas para um modelo de copa idealizada, o coeficiente de extinção K pode assumir 4 modelos de dossel (JONES, 1992):

- Horizontal $-K=1$

- Vertical $-K=\operatorname{cotg}$ de $\beta$

- Esférica $-K=0,5 / \operatorname{sen} \beta$

- Elipsóide $-K=\left(\mathrm{x}^{2}+\operatorname{tg} \beta / \mathrm{d}\right)^{0.5}$

Sendo beta o ângulo formado pelo raio solar com a inclinação da folha
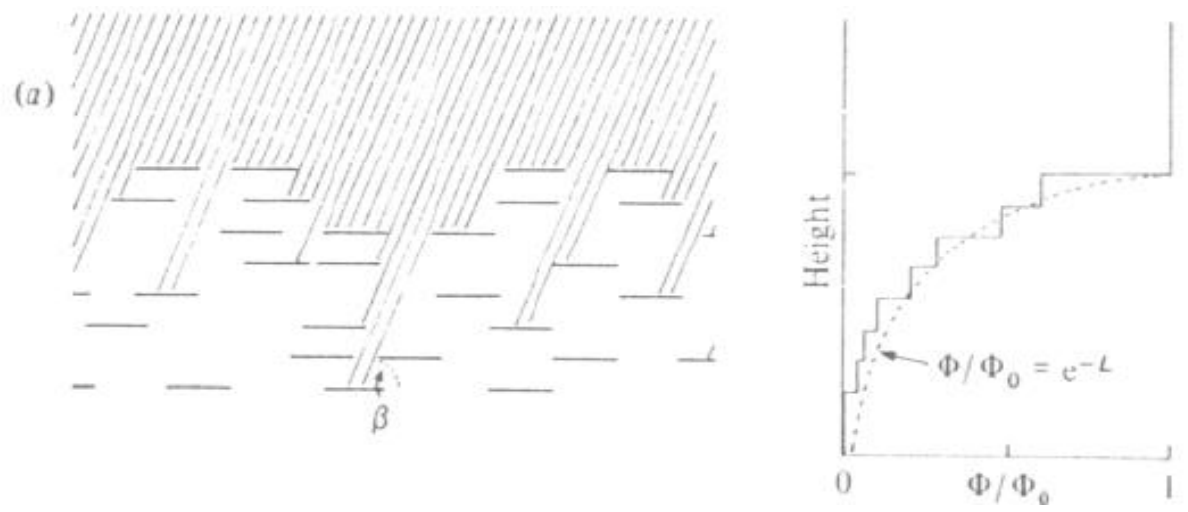

Figura 23: Penetração da radiação para um ângulo zenital $66^{\circ}$ em uma copa com folhas (a) horizontais.

Fonte: Jones (1992). 
Considerando-se que, dentre os 4 modelos de copa, a distribuição esférica das folhas é a que melhor se aproxima da situação real, e aplicando-se valores de IAF como 1, 3 e 5, observam-se os seguintes resultados:

$\mathrm{IAF}=1$

$$
\text { Qi/ } Q o=e^{-\left(\frac{0,5}{\sin 90} \times 1\right)}=0,6065
$$

$\mathrm{IAF}=3$

$$
Q i / Q o=e^{-\left(\frac{0,5}{\sin 90} \times 3\right)}=0,2231
$$

$\mathrm{IAF}=5$

$$
Q i / Q o=e^{-\left(\frac{0,5}{\sin 90} \times 5\right)}=0,0821
$$

Esses resultados indicam que, para essa distribuição de folhas, uma copa IAF $=1$ permitiria passar $60 \%$ da radiação solar incidente; IAF $=3$ permite $22 \%$ e IAF $=5$ deixa passar apenas $8 \%$.

Já pelo método de medições do gap fraction importa a distribuição do ângulo das folhas que pode ser calculado pela seguinte equação (NILSON, 1971):

$$
p(\theta)=\exp ^{\frac{-G(\theta) \Omega \mathrm{L}}{\cos (\theta)}}
$$

O IAF pode ser calculado invertendo-se a equação 18 :

$$
I A F=\frac{\ln (P(\theta)) \cos (\theta)}{G(\theta)}
$$

Onde:

$\mathrm{P}=$ distribuição geométrica das aberturas da copa, gap fraction [\%]

$(\theta)=$ ângulo zenital $\left[^{\circ}\right]$

$\mathrm{G}(\theta)=$ coeficiente de projeção caracterizado pela distribuição do ângulo das folhas

$\Omega=$ índice de sobreposição das folhas, clumping index.

Segundo Chen et al. (1997), uma importante informação na equação 18 é que o IAF pode ser calculado sem o conhecimento do ângulo de distribuição das folhas se o gap fraction for medido em diversos ângulos zenitais, cobrindo uma variação de 0 a $\pi / 2$. A medição com o equipamento LAI-2000 é uma boa opção para a aplicação dessa equação, uma vez que ele consegue medir simultaneamente 5 ângulos zenitais da luz azul difusa que passa pela copa. As fotos hemisféricas também consideram o gap 
fraction na variação dos ângulos zenitais e, dessa forma, conseguem calcular o IAF da vegetação (CHEN et al., 1997).

Foram desenvolvidos vários instrumentos de medição do IAF que podem ser divididos em duas principais categorias: os que se baseiam na distribuição do gap faction, como LAI 2000 ou LAI 2200 Canopy Analyser (LI-COR, Lincoln, Nebraska), o Demon (CSIRO, Canberra, Australia), o ceptômetro Accupar LP-80 (Decagon Devices, Pullman, EUA) e o SunScan (Delta-T Devices, Cambridge, UK) e os que utilizam o gap size como o Tracing Radiation and Architecture of Canopies - TRAC (3rd Wave Engeneering, Canada) e as fotos hemisféricas.

\subsubsection{LAI 2000 / LAI 2200, LI-COR}

O LAI-2000 foi substituído por uma nova versão do equipamento, LAI-2200. Este apresenta todas as funções do LAI- 2000 e alguns acréscimos, como uma capacidade maior para armazenar dados, uma bateria de maior duração, uma interface mais intuitiva e novas opções de saídas dos resultados.
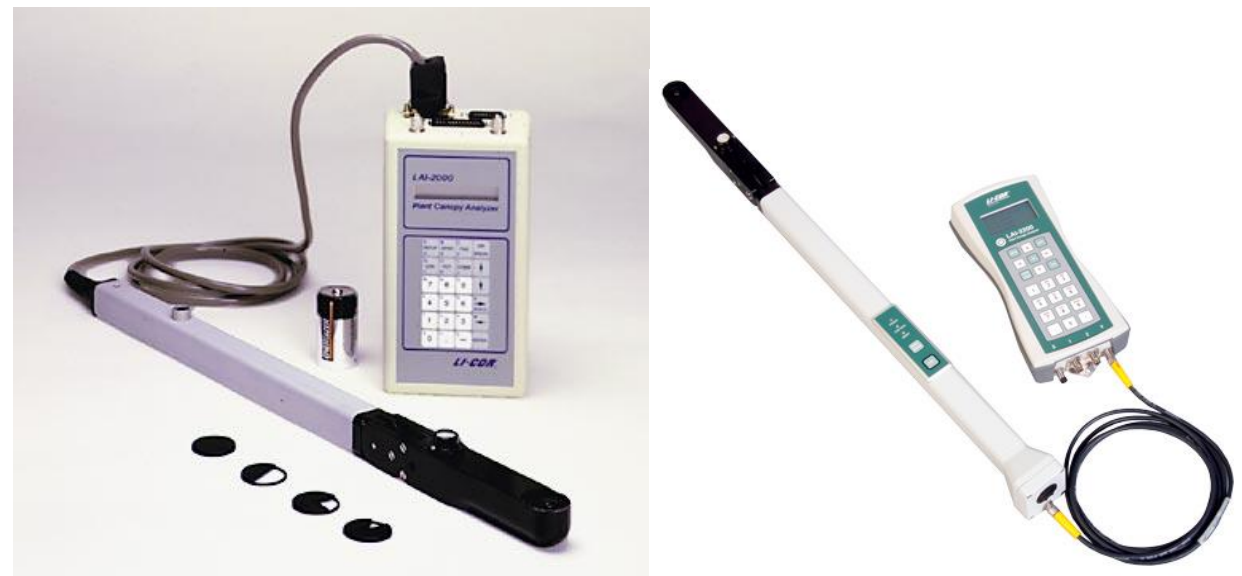

Figura 24: Equipamento LAI-2000 Plant Canopy Analyzer e a última versão, o LAI-2200. Fonte: LI-COR. Disponível em: < www.licor.com >. Acesso em maio de 2012.

O LAI-2000/LAI-2200 Plant Canopy Analyzer calcula o IAF pelas medidas de radiação feita com um sensor óptico acoplado a uma lente grande angular $\left(148^{\circ}\right)$. Esse sensor de luz mede simultaneamente a radiação difusa em cinco bandas angulares distintas $\left(7^{\circ}\right.$, $23^{\circ}, 38^{\circ}, 53^{\circ}, 68^{\circ}$ ), sendo constituído de cinco fotodiodos, cujas superfícies ativas estão arranjadas em anéis concêntricos (ZHENG, 2009). A imagem do dossel, de forma quase hemisférica, é projetada dentro desses anéis, o que permite, para cada intervalo angular, a medição da radiação na banda e no ângulo zenital conhecido. Um filtro óptico 
restringe a transmissão radiativa para comprimentos de onda menores que $490 \mathrm{~nm}$ (LICOR, 1992).
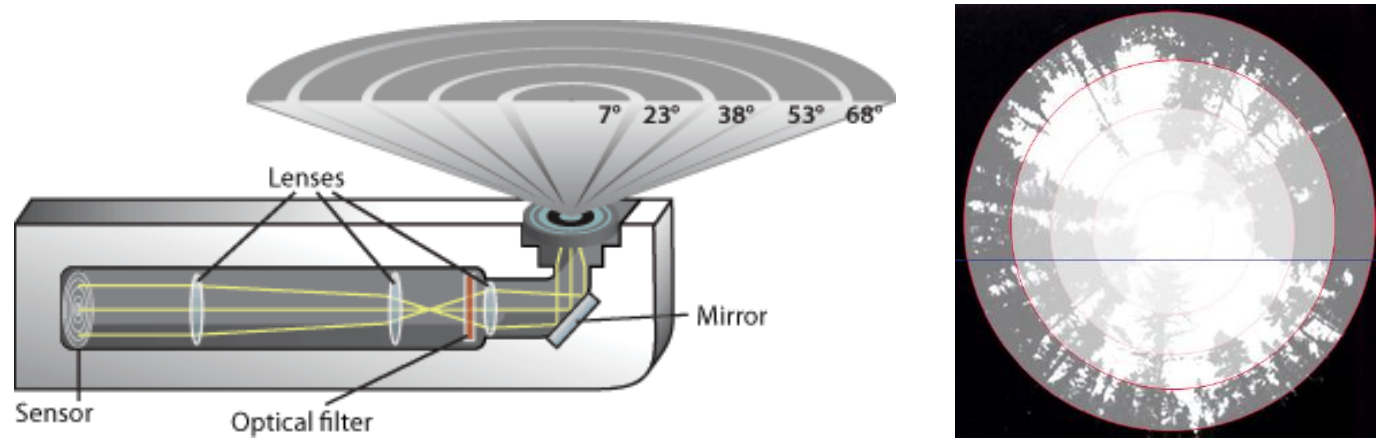

Figura 25: Estrutura interna do equipamento LAI-2000/LAI -2200.

Figura 26: Foto da lente grande angular com os 5 anéis concêntricos.

Fonte: LI-COR (1992). Disponível em: < www.licor.com >. Acesso em maio de 2012.

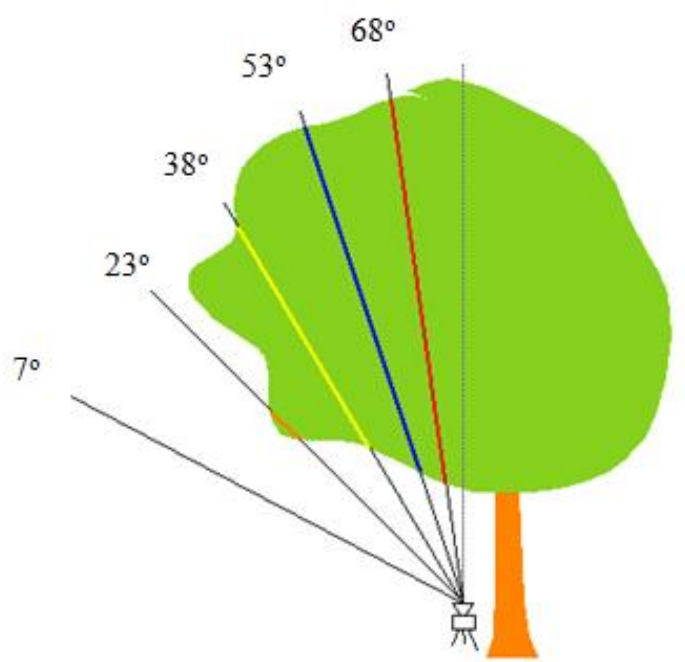

Figura 27: Vista em corte dos cinco anéis concêntricos.

Fonte: WinScanopy. Disponível em: <

http://www.regent.qc.ca/products/scanopy/winscanopymorefeatures.html >. Acesso em maio de 2012.

O equipamento LAI-2200 calcula a interceptação da luz visível de cor azul (320 490nm) em 5 ângulos zenitais, medidos abaixo e acima da copa. Os dados são direcionados para um modelo de transferência de radiação que passa pela copa da árvore. São calculados os valores de IAF, o mean tip angle (média do ângulo de inclinação) e o gap fraction (espaços entre as folhas).

O instrumento possui cinco capas para limitar o campo de visão do sensor em distintos graus de abertura: $270^{\circ} 180^{\circ} 90^{\circ} 45^{\circ}$ e $11,25^{\circ}$. As proteções são necessárias para se evitar radiação direta no sensor óptico, para remover o operador do campo de visão da 
lente quando o brilho do céu não é muito uniforme, para reduzir o tamanho da parcela exigida e para diminuir o tamanho da abertura exigida para leituras fora das copas em florestas (GIUNTI NETO, 2007).
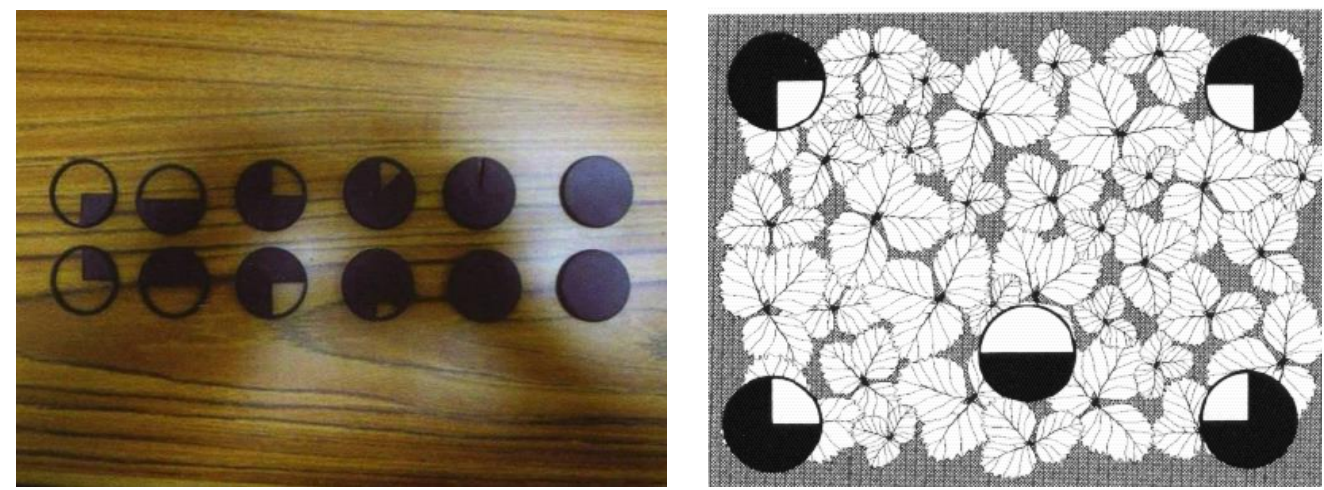

Figura 28: Tipos de capas para acoplar na lente angular (YOK; SIA, 2010).

Figura 29: Proposta de utilização das capas para áreas pequenas ou para mascarar o operador do equipamento.

Fonte: LI-COR (1992). Disponível em: < www.licor.com >. Acesso em maio de 2012.

Os dados podem ser obtidos em campo e depois processados utilizando-se o modelo computacional FV 2000 que proporciona diferentes formas de processamento dos dados e inclui 3 métodos adicionais e máscaras em anéis. $\mathrm{O}$ aplicativo pode ser baixado diretamente no site do fabricante ${ }^{17}$.

Os cálculos feitos pelo equipamento estão baseados em 4 premissas: (1) a folha funciona como um corpo negro que absorve toda a radiação que recebe, (2) os elementos de bloqueio de luz no interior da copa são feitos de forma aleatória, (3) as folhas tem a mesma projeção como elementos em formato convexo, (4) os elementos da planta são pequenos em comparação à área de cada anel concêntrico (LI-COR, 1992). O IAF é calculado para os cinco detectores do ângulo de visão, segundo a equação (JONCKHEERE et al., 2003):

$$
I A F=2 \sum i-\ln \left(T_{i}\right) \cos V_{i} W_{i}
$$

Sendo que:

$\mathrm{i}=$ corresponde aos valores de 1 a 5 .

$\mathrm{Ti}=$ transmissão média da radiação $\left[\mathrm{W} \mathrm{m}^{-2}\right]$

$V i=$ inclinação do ângulo $\left[^{\circ}\right]$

${ }^{17}$ Disponível em: < http://www.licor.com/env/newsline/2009/10/updated-lai-2000-file-viewer-software/

$>$. Acesso maio 2012. 
$W i=$ fatores relativos a cada sensor. De 1 a 5 são respectivamente: 0,$034 ; 0,104 ; 0,160 ; 0,218$; 0,484

O LAI 2000/LAI 2200 Plant Canopy Analyzer considera a distribuição das folhas de forma aleatória, o que gera uma baixa estimativa quando as folhas estiverem mais agrupadas ou sobrepostas. Além disso, os cálculos são precisos apenas para luz indireta que atravessa a copa, sendo que a luz direta induz a erros nessas estimativas (HOSSO; OMASA, 2006).

Segundo as recomendações do fabricante, o céu encoberto é a melhor condição para o uso do equipamento. Nessa situação, a contribuição da radiação indireta é significativamente maior. O sensor óptico exclui a radiação acima de 450nm, o que diminui a influência da radiação indireta pelas folhas. No entanto, se existir uma luz incidente muito forte, pode gerar problemas de brilho excessivo e causar uma baixa estimativa dos valores de IAF.

A Figura 30 mostra duas imagens registradas no mesmo dia, com condições de céu diferentes. A segunda foto mostra o efeito do brilho da luz sobre as folhas, assim a impressão é de que a árvore com condição de céu aberto é menos densa do que no céu encoberto.

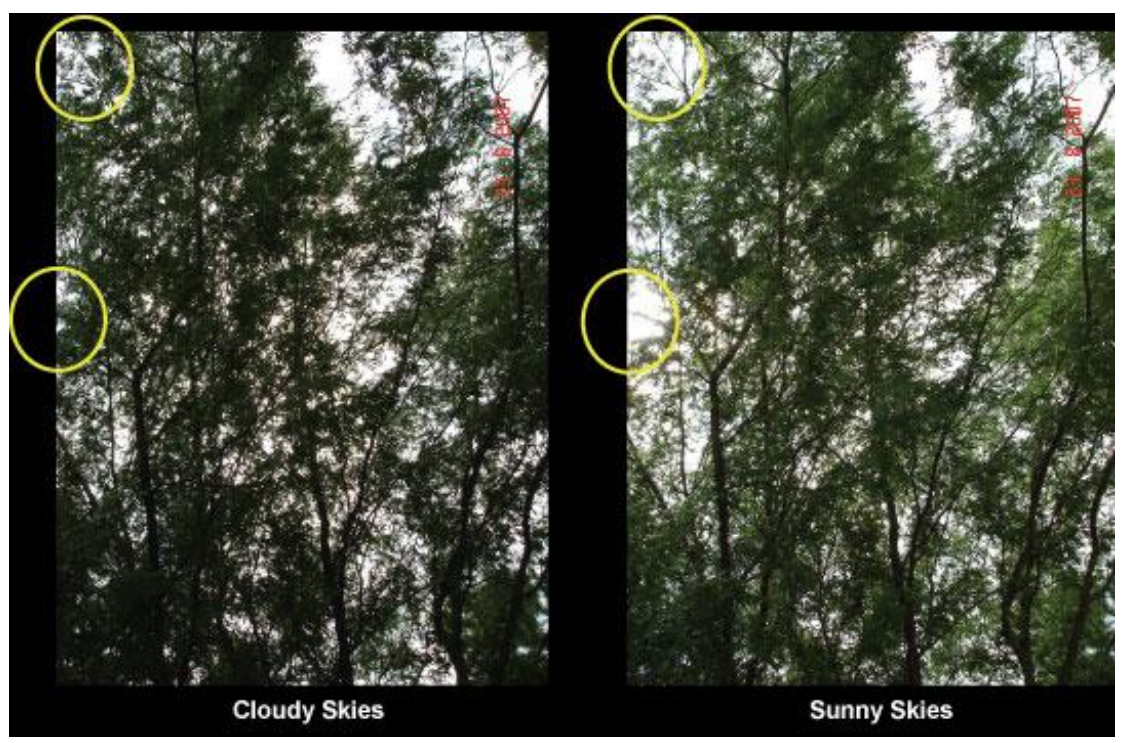

Figura 30: Imagens de uma mesma copa registradas em diferentes condições de céu: céu encoberto e céu claro.

Fonte: LI-COR. Disponível em: <http://www.licor.com/env/newsline/2008/05/appropriatesky-conditions-for-using-the-lai-2000/ >. Acesso em 28 de maio de 2012. 


\subsubsection{DEMON, CSIRO}

O DEMON (CSIRO, Canberra, Austrália) utiliza o método do inclined point quadrat que consiste em colocar um longo e fino cabo em determinados ângulos da copa e contar o número de vezes que entram em contato com algumas folhas. No caso do DEMON ao invés da difusa, utiliza-se a radiação direta solar nas medições (BRÉDA, 2003).

O equipamento mede a transmissão solar direta acima de 430nm. A influência da luz é medida acima e abaixo do dossel. Desta forma, o gap fraction é calculado usando-se uma média linear da transmitância e, posteriormente, um aplicativo do próprio fabricante calcula o IAF. Alguns filtros no detector são utilizados para limitar o espectro de luz recebido abaixo de 430nm; assim, é minimizado o efeito da luz difusa espalhada pelo dossel (JONCKHEERE, 2003).

Em copas altas, o operador do equipamento move-se abaixo da copa num trajeto linear, mantendo o sensor orientado para o sol. Para se computar a transmitância, a radiação solar direta deve ser medida numa posição fixa, podendo ser numa pequena abertura da copa, uma vez que o sensor tem um ângulo de visão reduzido. Isso se torna uma vantagem para as medições feitas em florestas, onde existem poucas áreas sem a obstrução das copas (BRÉDA, 2003). No entanto, a desvantagem é que as medidas precisam ser repetidas várias vezes ao longo do dia, pois o gap fraction é calculado por uma média logarítmica da transmitância dos dados de cada subgrupo medido e obtido em função do ângulo solar (BRÉDA, 2003; LANG, MCMURTRIE, 1986). Todas as leituras com este equipamento devem ser feitas com o céu totalmente claro, ao contrário do LAI 2000/ LAI 2200 (WHITFORD et al., 1995).

\subsubsection{CEPTÔMETRO, DECAGON}

O ceptômetro ACCUPAR LP80 (Decagon Devices Inc., Pulman, USA) é um instrumento portátil que possui uma haste com 80 sensores que medem a radiação fotossinteticamente ativa - PAR e permite a análise da intercepção do dossel em qualquer posição dentro de uma determinada cultura ou de um dossel florestal.

Os dados da radiação PAR podem ser usados com outros dados ambientais para se estimar a produção da biomassa em análises não destrutivas, sendo igualmente importantes na determinação de outras interações da planta com a atmosfera, tais como a intercepção da radiação, a conversão de energia, a troca gasosa, a intercepção da 
precipitação e a evapotranspiração. Com o uso do sensor externo que acompanha o instrumento é possível a execução das leituras acima e abaixo do dossel simultaneamente $\left(\right.$ DECAGON $\left.^{18}, 2012\right)$.

$\mathrm{O}$ equipamento mede a radiação fotossinteticamente ativa - PAR que compreende a faixa visível (400 a 700nm) do espectro de radiação, sendo esta a principal no processo de fotossíntese das plantas. Por meio da radiação PAR é possível estimar a quantidade interceptada pela copa para ser utilizada na fotossíntese e também fazer o cálculo do IAF.

No cálculo do IAF são consideradas as seguintes variáveis: a radiação PAR a pleno sol (Ro) e sob o dossel (R), o parâmetro de distribuição das folhas (descreve o formato da copa), o ângulo zenital (ângulo formado entre o zênite e os raios solares) e a fração da radiação direta. Diferente do LAI 2000/ LAI 2200, as medições devem ser feitas sob céu claro.
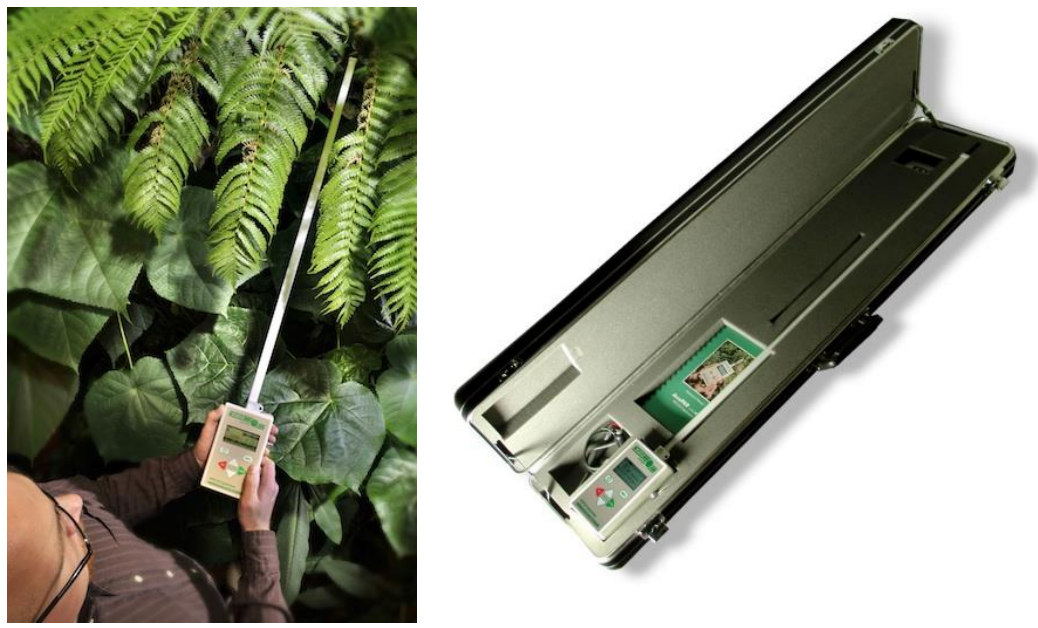

Figura 31: Equipamento Accupar LP80

Fonte: Decagon Devices Inc. Disponível em: < www.decagon.com $>$. Acesso em junho de 2012.

\subsubsection{SUNSCAN, DELTA-T}

O equipamento SunScan ${ }^{19}$ (Delta-T Devices, Cambridge, UK) faz a mesma abordagem que o Accupar LP80, medindo a radiação PAR incidente e transmitida pela copa para o

\footnotetext{
${ }^{18}$ Disponível em: < http://www.decagon.com/products/environmental-instruments/ceptometer-par-laiinstruments-2/accupar-lp-80 >. Acesso em junho de 2012.

${ }^{19}$ Manual disponível em: < ftp://ftp.dynamax.com/manuals/SS1_Manual.pdf $>$. Acesso em junho de 2012.
} 
cálculo do IAF. O equipamento é composto por três partes: um instrumento portátil com haste de $1 \mathrm{~m}$ de comprimento e 64 sensores acoplados, mais um sensor para medição de radiação direta e indireta, permitindo o uso em quase todos os tipos de céu e um controle para fazer as leituras. A Figura 33 mostra o funcionamento do equipamento.
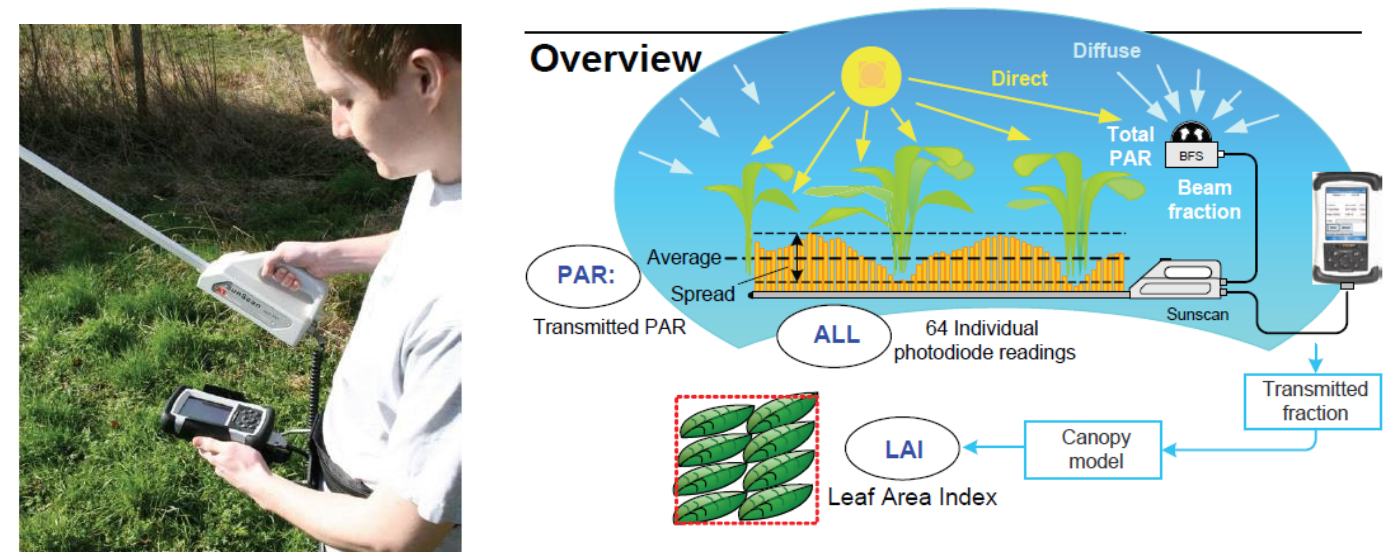

Figura 32: Funcionamento do SunScan junto com o controle PDA.

Figura 33: Esquema do funcionamento do equipamento SunScan.

Fonte: Delta-T Devices. Disponível em: < www.delta-t.co.uk $>$. Acesso em junho de 2012.

\subsubsection{TRAC, 3rd WAVE ENGINEERING}

O TRAC (Tracing Radiation and Architecture of Canopies, 3rd Wave Engineering, Ontário, Canadá) é um instrumento óptico que mede o IAF e a fração da radiação fotossinteticamente ativa (Fpar). Foi desenvolvido por Chen e Cihlar (1995) e considera as dimensões físicas das aberturas no dossel (gap size distribuition) em adição à fração de aberturas (gap fraction) (CHEN et al., 2002).

Também considera um índice de sobreposição das folhas, clumping index, $(\Omega)$, a partir do qual se quantifica os efeitos da distribuição espacial não aleatória do dossel. Todas as medidas devem ser feitas com o céu claro (JONCKHEERE, et al., 2003).

O equipamento apresenta três sensores fotossensitivos que registram a luz direta transmitida em alta frequiência $(32 \mathrm{~Hz})$ e o cálculo do gap fraction ocorre segundo a equação baseado nos estudos de Nilson (1971):

$$
P(\theta)=\exp \frac{-G(\theta) \Omega(\theta) L_{t}}{\cos (\theta)}
$$

Onde:

P $(\theta)=$ probabilidade de um raio solar que incide num ângulo $\theta$ penetrar na copa e não ser interceptado 
$\mathrm{G}(\theta)=$ coeficiente de projeção das folhas e caracteriza a distribuição angular das folhas

$\mathrm{Lt}=$ Plant Area Index - PAI, isto é, a área de projeção das folhas e outros materiais com tronco, galhos, etc. $\left[\mathrm{m}^{2} / \mathrm{m}^{-2}\right]$

$\Omega$ = índice de sobreposição, um parâmetro para se determinar o padrão da distribuição espacial das folhas na copa. Esse parâmetro é importante para ajustar o valor do IAF que tende a ser subestimado pelo agrupamento das folhas.

Os resultados do TRAC foram validados em vários estudos (CHEN; CIHLAR, 1995a; CHEN, 1996a, CHEN et al., 1997; KUCHARIK et al.,1997). Segundo as recomendações de Chen et al. (2002), o equipamento LAI 2000 ajuda nos estudos da distribuição angular das folhas, enquanto o TRAC serve para investigar os padrões da distribuição espacial das folhas. A combinação dos dois equipamentos oferece resultados mais rápidos e corretos do IAF.
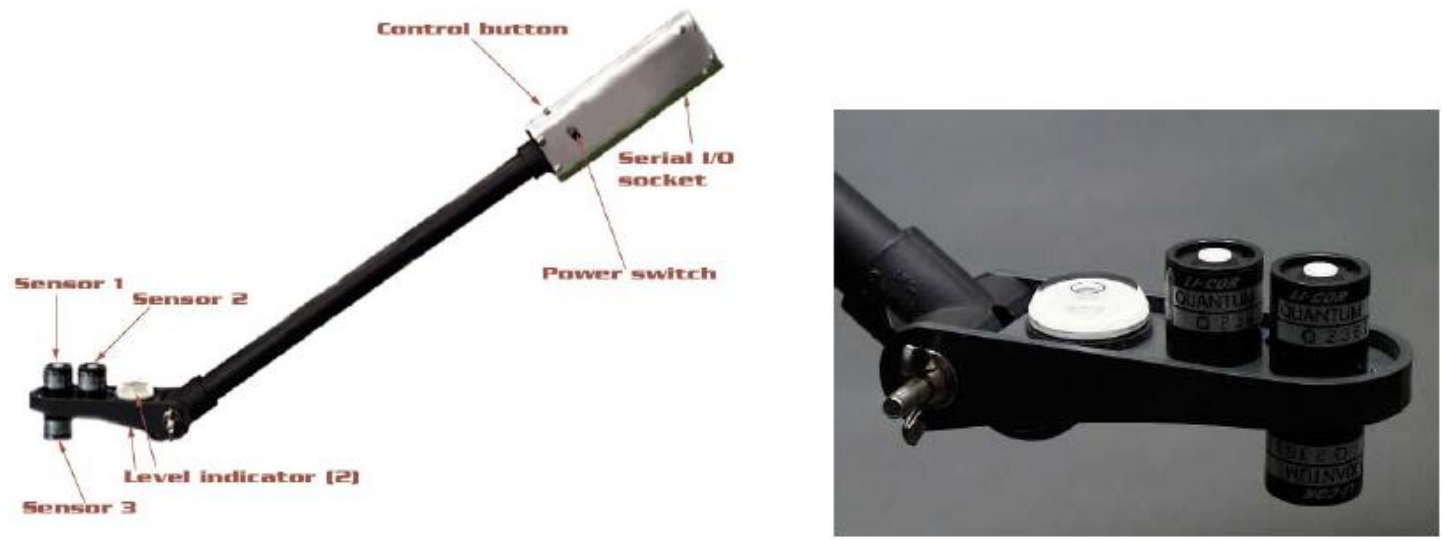

Figura 34: Principais partes do instrumento óptico TRAC.

Figura 35: Detalhe dos três sensores fotossensitivos do aparelho TRAC.

Fonte: Chen et al. 2002

\subsubsection{FOTOS HEMISFÉRICAS}

Segundo Newton (2007), as fotos hemisféricas têm uma longa história de uso na área de ecologia das plantas, nos estudos pioneiros de Anderson (1964), Becker (1971), Evan e Coombe (1959). Os principais objetivos são: descrever a estrutura do dossel, mapear, quantificar a radiação embaixo das copas e estimar o IAF das plantas, de acordo com os estudos de Bonhomme (1970), Bonhomme et al. (1974) e Rich (1990). Recentemente, como resultado do desenvolvimento das câmeras digitais de alta resolução e os avanços no processamento das imagens, outros estudos foram desenvolvidos focando em padrões mais detalhados para obtenção do IAF (CANNELL; GRACE, 1993; RICH, 1989) e novos exemplos de aplicações (RICH et al. 1993; WHITMORE et al. 1993). 
Nesse método indireto, as imagens são registradas por meio de câmeras com lentes grande angular embaixo da copa e fornecem um grande ângulo de visão, geralmente de $180^{\circ}$, resultando em uma projeção do hemisfério em um plano. Em lentes com uma perfeita projeção equi-angular (180 ${ }^{\circ}$ de campo de visão), o resultado é uma imagem circular, que mostra uma visão completa do céu em todas as direções, com o zênite no centro da imagem e o horizonte nas bordas (JONCKHEERE et al., 2003).

Dessa forma é possível se obter a distribuição das folhas e quantificar o gap fraction de acordo com diferentes ângulos zenitais e azimutais. As fotos hemisféricas também fornecem um permanente arquivo fotográfico, mantendo-se como um registro da copa com a posição, do tamanho, da densidade e da distribuição das aberturas no dossel (JONCKHEERE et al., 2003).

Para a análise das fotografias hemisféricas, há vários aplicativos como, por exemplo, o HemiView $^{20}$ (Delta-T Device), WinSCANOPY ${ }^{21}$ (Regent Intrument Inc.), Gap Light Analyser - GLA ${ }^{22}$ (Forest Renewal BC), CAN - EYE $E^{23}$ (INRA) e mais recentemente, o HEMISFER $1.53^{24}$ (Swiss Federal Institute for Forest, Snow and Landscape Research WSL).

Independente da forma de análise, as fotos hemisféricas, tanto por câmera digital como por filmes de $35 \mathrm{~mm}$, precisam ser feitas sob condições de céu encoberto, pouco antes do amanhecer ou pouco após o pôr-do-sol (BRÉDA, 2003). O momento mais crítico no processamento da imagem é ajustar o contraste, determinando as faixas de cores para distinguir entre as aberturas do céu e os elementos da copa (ANDERSON, 1964; BECKER, 1971; DUCREY, 1975a).

\footnotetext{
${ }^{20}$ Disponível em: < http://www.delta-t.co.uk $>$. Acesso em junho de 2012.

${ }^{21}$ Disponível em: < http://www.regent.qc.ca/products/Scanopy/Scanopy.html $>$. Acesso em junho de 2012.

${ }^{22}$ Disponível em: < http://www.rem.sfu.ca/forestry/publications/downloads/gaplightanalyzer.htm $>$. Acesso em junho de 2012.

${ }^{23}$ Disponível em: < https://www4.paca.inra.fr/can-eye/ >. Acesso em junho de 2012.

${ }^{24}$ Disponível em: < http://www.wsl.ch/dienstleistungen/produkte/software/hemisfer/notes_EN >. Acesso em junho de 2012.
} 

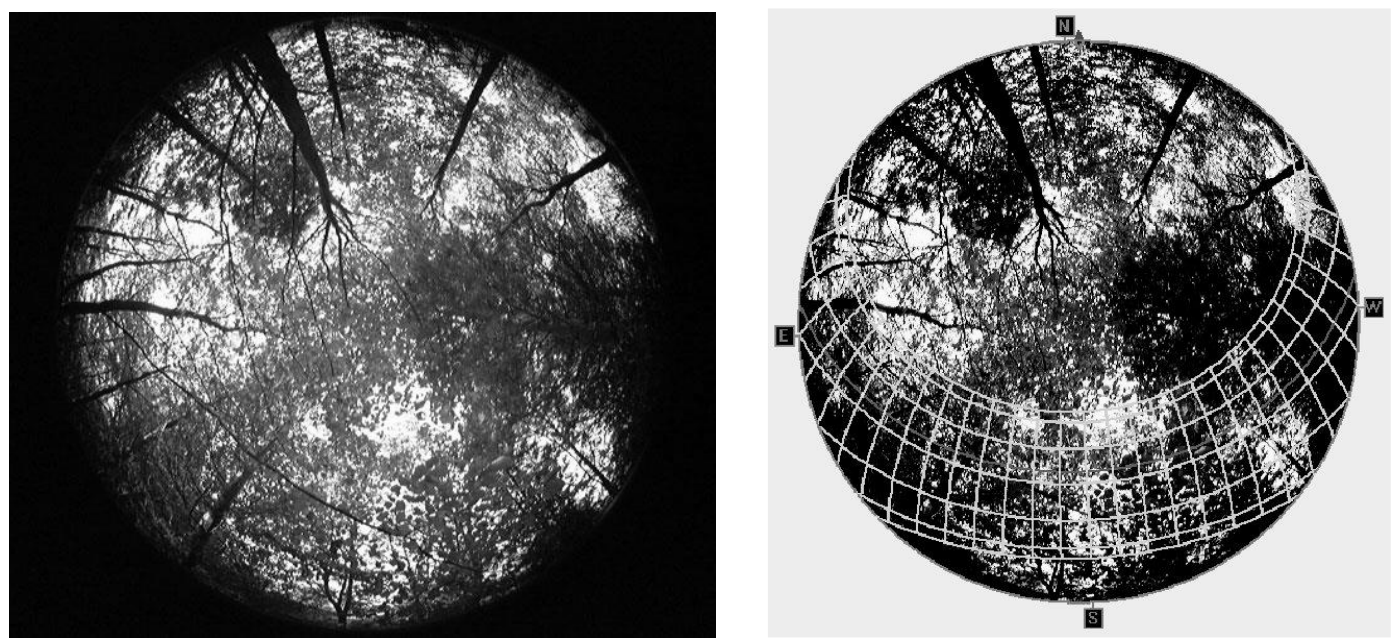

Figura 36: Foto hemisférica pelo software HemiView

Figura 37: Foto hemisférica com a projeção da carta solar pelo software HemiView

Fonte: Delta-T Devices Ltd. Disponível em: < www.delta-t.co.uk >. Acesso em junho de 2012.

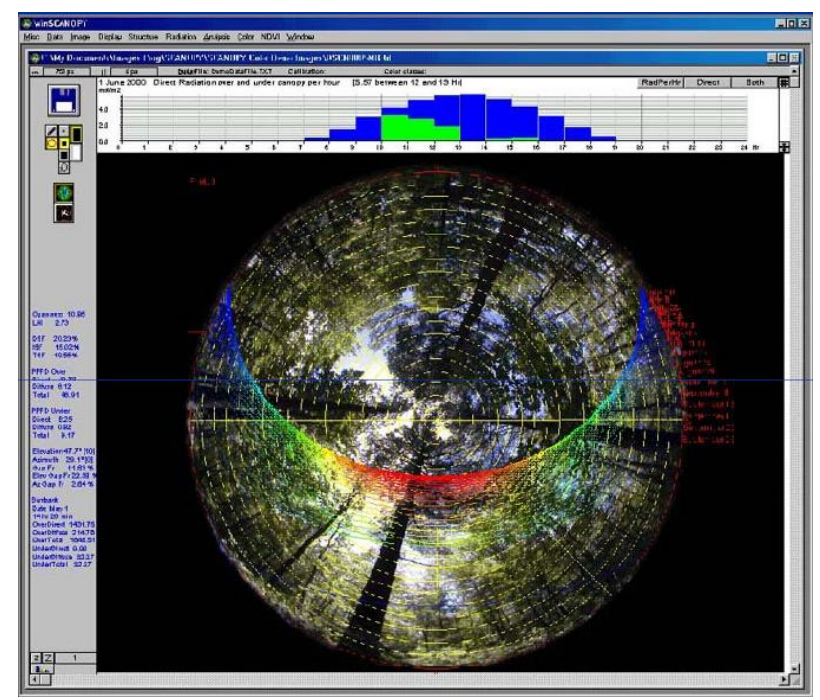

Figura 38: Foto hemisférica pelo software WinScanopy.

Fonte: Regent Instruments Inc. Disponível em: < http://www.regent.qc.ca $>$. Acesso em maio de 2012.

\subsection{COMPARAÇÕES ENTRE OS EQUIPAMENTOS E VALORES TÍPICOS DE IAF REGISTRADOS}

Considerando-se o método de medição indireta sem contato, foram levantados os principais resultados obtidos por meio de equipamentos portáteis e análise de fotos hemisféricas.

O valor do IAF depende do tipo da espécie, estágio de desenvolvimento da planta e época do ano. Além disso, esse índice é influenciado pelas condições locais e pelas 
práticas de manejo. Somado ao fato de existirem diferentes métodos de medição diretos e indiretos, os valores de IAF variam significantemente entre uma espécie e outra, conforme mostram as referências bibliográficas. As áreas florestais variam entre 0.40 para Quercus petraea (LE DANTEC et al., 2000) e 14 para Pseudotsuga menziesii (TURNER et al., 1999) e, em geral, os maiores valores registrados foram em florestas de coníferas. Em florestas decíduas foram observados valores de IAF entre 6 e 8; e em culturas, entre 2 e 4 (BEADLE, 1993).

Baseados nos estudos de Bréda (2003), as principais diferenças entre os equipamentos LAI 2000, DEMON, SunScan e Accupar estão presentes na Tabela 1.

Tabela 1 - Diferença entre os equipamentos de análise do gap fraction no dossel arbóreo

\begin{tabular}{|c|c|c|c|c|}
\hline & SUNSCAN & ACCUPAR & LAI-2000 & DEMON \\
\hline Empresa & $\begin{array}{l}\text { Delta-T Devices } \\
\text { Ltd, Cambridge, } \\
\text { UK }\end{array}$ & $\begin{array}{l}\text { Decagon Devices, } \\
\text { Pullman, USA }\end{array}$ & $\begin{array}{l}\text { Li-Cor, Lincoln, } \\
\text { Nebraska, USA }\end{array}$ & $\begin{array}{l}\text { CSIRO, Canberra, } \\
\text { Australia }\end{array}$ \\
\hline Site & $\begin{array}{l}\text { Www.delta- } \\
\underline{\text { t.co.uk }}\end{array}$ & www.decagon.com & Www.licor.com & www.cbr.clw.csiro.au \\
\hline Princípio & $\begin{array}{l}\text { Gap fraction ou } \\
\text { fachos de luz } \\
\text { direta (sunflecks) }\end{array}$ & $\begin{array}{l}\text { Gap fraction ou } \\
\text { fachos de luz } \\
\text { direta (sunflecks) }\end{array}$ & $\begin{array}{l}\text { Gap fraction para } \\
\text { cada ângulo do } \\
\text { zênite, medido } \\
\text { simultaneamente }\end{array}$ & $\begin{array}{l}\text { Gap fraction para o } \\
\text { ângulo do zênite, } \\
\text { com diferentes } \\
\text { ângulos em relação a } \\
\text { vertical }\end{array}$ \\
\hline $\begin{array}{l}\text { Tipo de } \\
\text { radiação }\end{array}$ & $\begin{array}{l}\text { Radiação PAR } \\
\text { direta e difusa }\end{array}$ & $\begin{array}{l}\text { Radiação PAR } \\
\text { total }\end{array}$ & $\begin{array}{l}\text { Radiação difusa } \\
\text { Cor azul }\end{array}$ & Radiação direta \\
\hline $\begin{array}{l}\text { Comprimento } \\
\text { de onda em } \\
\text { cima da copa }\end{array}$ & $\begin{array}{l}400-700 \mathrm{~nm} \\
\text { Rad. PAR direta } \\
\text { e difusa }\end{array}$ & $\begin{array}{l}400-700 \mathrm{~nm} \\
\text { Medida linear da } \\
\text { radiação PAR }\end{array}$ & $\begin{array}{l}\text { 320- 490nm } \\
\text { Área aberta } \\
\text { (diâmetro 7x a } \\
\text { altura da copa) }\end{array}$ & $\begin{array}{l}\text { 430nm } \\
\text { Apontado para área } \\
\text { não obstruída, } \\
\text { posição fixa }\end{array}$ \\
\hline $\begin{array}{l}\text { Medição } \\
\text { embaixo da } \\
\text { copa }\end{array}$ & $\begin{array}{l}\text { BFS1 -Sensor } \\
\text { Rad. PAR difusa/ } \\
\text { BFS2 -7 } \\
\text { fotodiodos PAR } \\
\text { direta e difusa }\end{array}$ & $\begin{array}{l}\text { Rad. PAR } \\
\text { transmitida direta e } \\
\text { difusa }\end{array}$ & Posição fixa & $\begin{array}{l}\text { Transmitância média } \\
\text { deslocando } 20 \mathrm{~m}\end{array}$ \\
\hline $\begin{array}{l}\text { Referência e } \\
\text { algoritmos }\end{array}$ & $\begin{array}{l}\text { Campbell, } 1986 \\
\text { Potter et al., } 1996\end{array}$ & $\begin{array}{l}\text { Campbell, } 1986 \\
\text { Decagon, } 2001\end{array}$ & $\begin{array}{l}\text { Welles and } \\
\text { Norman, } 1991 \\
\text { Li-Cor, } 1989\end{array}$ & $\begin{array}{l}\text { Lang, 1986, } 1987 \\
\text { Lang and Yueqin, } \\
1986\end{array}$ \\
\hline Sensor & $\begin{array}{l}64 \text { Sensores } \\
\text { PAR-distribuidos } \\
\text { em } \\
1 \mathrm{~m}\end{array}$ & $\begin{array}{l}\text { 80 Sensores PAR- } \\
\text { distribuidos em } \\
0.9 \mathrm{~m}\end{array}$ & $\begin{array}{l}\text { Sensor Fish-eye } \\
\text { com } 5 \text { aneis } \\
\text { concêntricos }\end{array}$ & $\begin{array}{l}\text { Detector do sol (cone } \\
\text { estreito - ângulo } \\
0.302 \text { ) }\end{array}$ \\
\hline Calibração & calibrado & calibrado & $\begin{array}{l}\text { Sem calibração, } \\
\text { mas possível o } \\
\text { ajuste }\end{array}$ & Sem calibração \\
\hline $\begin{array}{l}\text { Opção para } \\
\text { culturas }\end{array}$ & Sim & Sim & $\begin{array}{l}\text { Precisa de } 2 \\
\text { loggers }+2 \\
\text { sensores cruzados } \\
\text { e calibrados }\end{array}$ & $\begin{array}{l}\text { Não mas pode ser } \\
\text { adaptado }\end{array}$ \\
\hline $\begin{array}{l}\text { Opção para } \\
\text { árvores altas }\end{array}$ & $\begin{array}{l}\text { Desconectar } \\
\text { sensor, } \\
\text { transmissão de }\end{array}$ & $\begin{array}{l}\text { Precisa de larga } \\
\text { área sem } \\
\text { vegetação }\end{array}$ & $\begin{array}{l}\text { Distância mínima } \\
\text { entre sensor e } \\
\text { folhas }(4 \mathrm{x} \text { largura }\end{array}$ & $\begin{array}{l}\text { Opção para árvores } \\
\text { isoladas com trajeto } \\
\text { de } 3 \mathrm{~m} \text { embaixo da }\end{array}$ \\
\hline
\end{tabular}




\begin{tabular}{|l|l|l|l|l|}
\hline & $\begin{array}{l}\text { rádio ou data } \\
\text { logger }\end{array}$ & copa folha) & copa \\
\hline $\begin{array}{l}\text { Condição do } \\
\text { céu }\end{array}$ & Céu aberto & Céu aberto & $\begin{array}{l}\text { Céu uniforme ou } \\
\text { encoberto }\end{array}$ & $\begin{array}{l}\text { Céu aberto o dia } \\
\text { inteiro }\end{array}$ \\
\hline Software & SunDATA.exe & $\begin{array}{l}\text { DecaLink, } \\
\text { AccuPAR } \\
\text { firmware }\end{array}$ & C2000.exe & $\begin{array}{l}\text { DEMSOFT } \\
1 / \text { LONETREE }\end{array}$ \\
\hline
\end{tabular}

Fonte: Bréda (2003)

Segundo Xavier et al. (2002), o equipamento LAI 2000 (LI-COR, 1992) vem sendo amplamente utilizado em áreas florestais, devido à sua praticidade para estimar o IAF. Entre os autores que utilizaram esta técnica estão Vertessy et al. (1995), Chen e Cihlar (1996), Hingston et al. (1998), Ares e Fownes (2000), Barclay et al. (2000) e Linhares et al. (2000).

No entanto, alguns estudos mostram que o equipamento LAI-2000, quando utilizado em áreas florestais, subestima o IAF quando este está acima de 2,0, sendo indicada a calibração do equipamento para as condições de uso local com base em amostras destrutivas (CHEN et al., 1991; BATTAGLIA et al., 1998). A violação de algumas premissas para utilização do equipamento LAI-2000 seria uma das causas dessa subestimativa, como a distribuição não-aleatória das folhas no dossel (CHEN et al., 1991).

Barclay e Trofymow (2000) obtiveram valores entre 3.32 e 4.06 para florestas de coníferas em Shawnigan Lake, BC, no Canadá, por meio do equipamento LAI-2000. Comparando-se os valores medidos pelo equipamento com o método direto de coleta de folhas, foi observado que os valores do LAI-2000 foram mais baixos.

No Brasil, foram feitas medições com o equipamento LAI 2000 em floresta de eucaliptos e o IAF médio do total das 98 amostras foi de 2.86 , valor muito próximo de 2.75, obtido por Kallarackal e Somen (1997) em plantações de Eucalyptus grandis de 4 anos, e maior que a média encontrada por Hingston et al. (1998), de 2,30 em plantações de eucaliptos (Eucalyptus globulus ssp.) de 3 a 6 anos de idade, no oeste da Austrália. O maior valor do IAF observado nos estudos de Xavier et al. (2002) foi de 4.31.

Segundo Bréda (2003), os valores de IAF medidos pelos métodos indiretos podem ser subestimados entre $25 \%$ a $50 \%$ em relação aos métodos diretos. Uma das principais causas da diferença nos resultados é a distribuição irregular gerando o empilhamento 
das folhas. Assim, equipamentos como o TRAC consideram um ajuste para o cálculo do IAF por meio do índice de sobreposição das folhas $(\Omega)$.

A Tabela 2 mostra um comparativo entre o TRAC e método com fotos hemisféricas que se baseiam na análise do gap size do dossel das árvores.

Tabela 2 - Diferença entre os equipamentos de análise do gap size no dossel arbóreo

\begin{tabular}{|c|c|c|}
\hline & TRAC & FOTO HEMISFÉRICA \\
\hline Empresa & $\begin{array}{l}\text { Third-Wave Engineering, } \\
\text { Ottawa, Canada }\end{array}$ & - \\
\hline Site & mikek@3wce.com & - \\
\hline Princípio & Gap size & Gap size. \\
\hline Tipo de radiação & Radiação PAR direta & Radiação direta e difusa \\
\hline $\begin{array}{l}\text { Comprimento de onda em } \\
\text { cima da copa }\end{array}$ & $\begin{array}{l}400-700 \mathrm{~nm} \\
\text { Radiação PAR direta }\end{array}$ & A definir \\
\hline Referência e algoritmos & $\begin{array}{l}\text { Chen and Cihlar, 1995a; } \\
\text { Chen, 1996a, Chen et al., } \\
\text { 1997a; Kucharik et al., } \\
\text { 1997; Leblanc } 2002\end{array}$ & $\begin{array}{l}\text { Rich et al, 1993; Whitmore et } \\
\text { al, } 1993\end{array}$ \\
\hline Sensor & $\begin{array}{l}\text { Três sensores } \\
\text { fotossensitivos que } \\
\text { registrada a luz direta } \\
\text { transmitida em alta } \\
\text { frequiência }(32 \mathrm{~Hz})\end{array}$ & $\begin{array}{l}\text { Sensor com lente grande } \\
\text { angular de } 180^{\circ}\end{array}$ \\
\hline Opção para culturas & Sim & Sim \\
\hline Opção para árvores altas & Sim & $\begin{array}{l}\text { Sim, principalmente em } \\
\text { árvores com copas fechadas }\end{array}$ \\
\hline Condição do céu & Céu aberto & Céu aberto \\
\hline Software & TRACOMX & $\begin{array}{l}\text { WinScan, HemiView, } \\
\text { Hemisfer, Eye-can }\end{array}$ \\
\hline
\end{tabular}

Fonte: Bréda (2003); Jonckheere et al. (2004).

Dentre os diferentes métodos de estimativa de IAF (SOUDANI et al., 2001), nem todos estão adaptados para ecossistemas florestais tropicais (WASSEIGE et al., 2003). Os estudos de Sanches et al. (2008) calcularam o IAF para a floresta de transição 
Amazônica aplicando três métodos: o cálculo por Lambert-Beer, o sensoriamento remoto e o uso de fotografias hemisféricas. A estimativa por Lambert-Beer apresentou sazonalidade e uma média anual do IAF variando de 3.21 a 3.74, no período de 2001 a 2003. A média do IAF estimada pelo satélite MODIS variou entre 5.25 a 5.54 para o mesmo período. A média de IAF estimada por fotografias hemisféricas variou de 3.05 a 4.12 para o período de 2004 a 2005.

De acordo com os levantamentos feitos por Asner et al. (2003), a média do IAF para as florestas tropicais de folhas largas é de 4.9, sendo que na Amazônia foram obtidos valores entre 3.6 a 6.6 (ARAGÃO et al., 2005); nas florestas em Sumatra, na Indonésia, valores entre 3.9 e 6.1 (TRICHON et al., 1998) e valores entre 4.8 e 6.8 em Bornéu, ilha no sudeste asiático (KUMAGAI et al., 2004).

Em relação às espécies sempre verdes (evergreen) em áreas urbanas, foram realizadas medidas em Cingapura (Figura 39), onde o clima é quente e úmido e o valor máximo do IAF obtido foi 4 em espécies de copas densas como Mesua ferrea, Fillicium decipiens $e$ Minusops elengi. As medições foram feitas com o equipamento LAI 2000 para as principais espécies existentes na cidade e foram obtidos os seguintes resultados (YOK; SIA, 2010):

- arbóreas densas IAF $=4.0$

- arbóreas intermediárias IAF = 3

- arbóreas pouco densas IAF $=2.5$

- palmáceas entre 2.5 e 4

- arbustivas 3.5 e 4.5

- gramíneas IAF $=2$

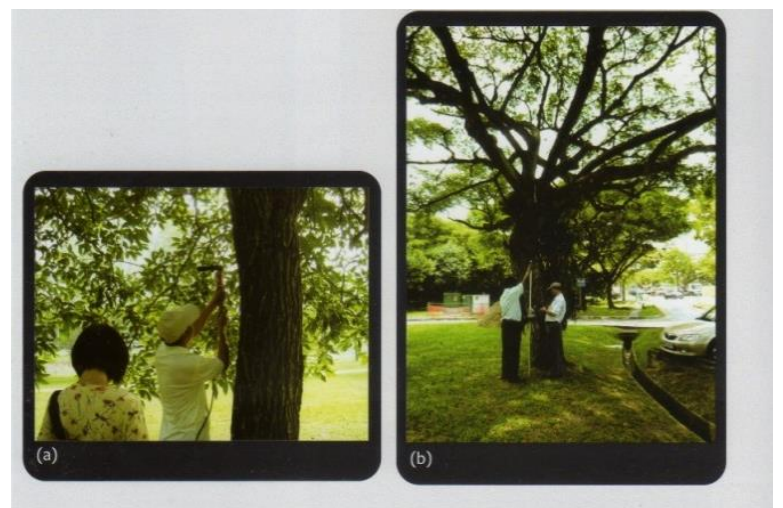

Figura 39: Medições com o LAI-2000 em Cingapura Fonte: Yok; Sia (2010) 


\section{APLICAÇÃo dO MODELO ENVI-met PARA O ESTUdO DO IMPACTO DA VEGETAÇÃO NOS MICROCLIMAS URBANOS}

\subsection{BREVE DESCRIÇÃO DO MODELO ENVI-met 3.1 BETA}

O ENVI-met ${ }^{25}$ é um modelo tridimensional para simular as interações entre superfícievegetação-atmosfera para ambientes urbanos com resoluções de $0,5 \mathrm{~m}$ a $10 \mathrm{~m}$ no espaço e até 10 segundos no tempo. Dessa forma, permite analisar, numa perspectiva de microescala, a interação entre o desenho urbano e o microclima.

Esse modelo prognóstico está baseado nas leis de dinâmica dos fluidos e da termodinâmica. Inclui simulações para: o fluxo de ar em volta e entre os edifícios; processo de troca de calor e vapor de água na superfície do piso e fachadas; turbulência local e sua taxa de dissipação; parâmetros de troca de calor com a vegetação; dispersão de partículas poluentes; e parâmetros biometeorológicos como o Predicted Mean Vote $\mathrm{PMV}^{26}$. Apresenta ferramentas adicionais como o programa Leonardo 3.0 Beta $^{27}$ para visualização e edição dos resultados gerados pelo ENVI-met.

No intuito de se avaliar os benefícios da vegetação, Bruse (1998) implementou computacionalmente esse modelo numérico para o cálculo dos principais fatores relacionados à vegetação: transpiração, evaporação, fluxo de calor sensível, fluxos turbulentos de calor e vapor; resistência dos estômatos, balanço energético da folha e balanço de água do sistema solo-vegetação. Considera não apenas o efeito de sombreamento das árvores, mas também o processo fisiológico de fotossíntese e abertura dos estômatos.

Em relação à vegetação, este modelo determina a temperatura média nas folhas por meio do cálculo do balanço térmico que considera a condição climática e fisiológica da planta. O cálculo do fluxo de radiação inclui sombreamento, absorção e re-emissão da radiação por outras partes da planta.

\footnotetext{
${ }^{25}$ Este programa é gratuito e está disponível em: < http://www.envi-met.com $>$. Acesso em fevereiro de 2014.

${ }^{26}$ Baseado no modelo de Fangers (1972) que orginalmente foi desenvolvido para ambientes internos e adaptado para o clima externo pelo modelo de Jendritzky (2003).

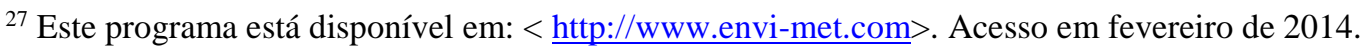


A Tabela 3 mostra os principais aspectos relacionados à arquitetura e o ambiente externo que o ENVI-met se propõe a calcular. Trata-se, portanto, de um modelo complexo que busca visualizar o comportamento de um ambiente (interno ou externo) por meio de diferentes condições climáticas e arquitetônicas.

Tabela 3: Principais Variáveis utilizadas pelo ENVI-met.

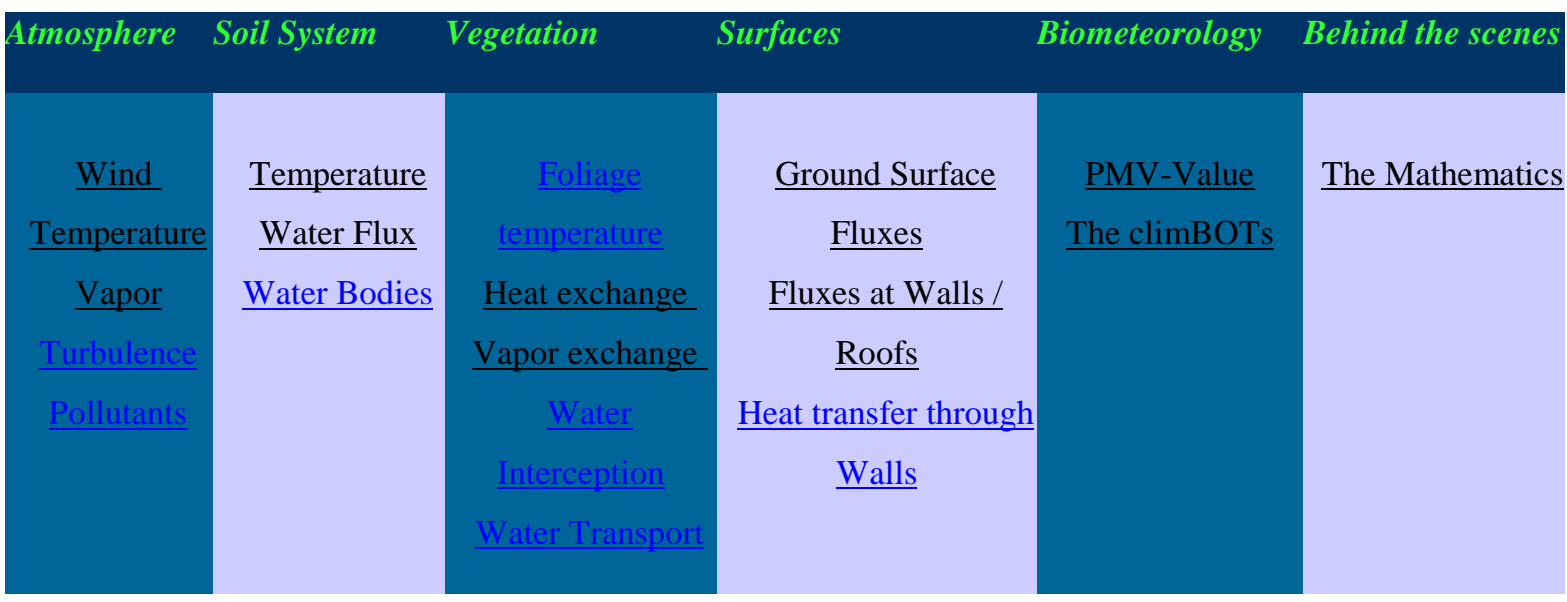

Fonte: ENVI-met 3.0 Manual. Disponível em. http://envi-met.com. Acesso em agosto de 2012.

Além dos modelos de cálculo para vegetação, o ENVI-met também aborda:

- Cálculo de radiação de onda longa e curta considerando os efeitos de sombreamento, reflexão e re-emissão dos edifícios e vegetação.

- Temperatura de superfície e paredes para cada ponto da malha do modelo.

- Trocas de calor e água dentro do sistema do solo escolhido.

- Dispersão dos gases e partículas poluentes incluindo a sedimentação de partículas nas superfícies e folhas.

O modelo ENVI-met permite avaliar o microclima de uma determinada área que sofre influência das condições climáticas como radiação solar, orientação dos ventos, umidade do ar. Possibilita também avaliar comportamento de materiais existentes em edifícios e ruas, analisa a dispersão dos poluentes e determina o fluxo de calor entre os materiais.

Chatzidimitriou et al. (2005) avaliou o uso do modelo para uma avenida muito movimentada em Thessaloniki, Grécia. A partir da situação existente foram propostas intervenções por meio da inserção de vegetação e áreas sombreadas para passagem de 
pedestres. As propostas foram sugeridas com base nas simulações feitas pelo modelo ENVI-met e comparadas com as medições locais realizadas no período de verão.

Yu e Hien (2006) aplicaram o modelo ENVI-met para avaliar os benefícios dos parques urbanos na cidade de Cingapura. As medições foram feitas para os parques e outras áreas próximas considerando os seguintes parâmetros: temperatura do ar, umidade relativa do ar, velocidade dos ventos, quantidade de chuva e radiação solar. Estes valores foram definidos nas configurações dos dados de entrada no modelo ENVI-met e os resultados mostraram a influência da vegetação no resfriamento da temperatura do ar e redução do consumo de energia pelo sistema de ar condicionado.

Existem muitos trabalhos que aplicaram o modelo ENVI-met para cidades europeias e asiáticas. Por outro lado, existe um potencial a ser explorado quanto ao uso do modelo nos trópicos. Baseando-se nas metodologias já utilizadas, foi feito um estudo do programa e foram levantadas formas de aplicação para as condições microclimáticas da cidade de São Paulo.

\subsection{MODELOS DE CÁLCULO NO ENVI-met}

\subsubsection{MODELO ATMOSFÉRICO DE TEMPERATURA E UMIDADE}

A distribuição da temperatura do ar $\theta$ e da umidade específica q é dada segundo a equação combinada de convecção-difusão:

$$
\begin{gathered}
\frac{\partial \theta}{\partial t}+u_{i} \frac{\partial \theta}{\partial x_{i}}=K_{h}\left(\frac{\partial^{2} \theta}{\partial x_{i}^{2}}\right)+\frac{1}{c_{p} \rho} \frac{\partial R_{m_{h}, w}}{\partial z}+Q_{h} \\
\frac{\partial q}{\partial t}+u_{i} \frac{\partial q}{\partial x_{i}}=K_{q}\left(\frac{\partial^{2} q}{\partial x_{i}^{2}}\right)+Q_{q}
\end{gathered}
$$

Onde:

Qh= fluxo de calor sensível entre vegetação e o entorno, de acordo com a densidade foliar [W $\left.\mathrm{m}^{-2}\right]$

$\mathrm{Qq}=$ fluxo de troca de vapor das plantas com o modelo atmosférico, de acordo com a densidade foliar $\left[\mathrm{W} \mathrm{m}^{-2}\right]$

$\frac{\partial R_{n, l} w}{\partial z}=$ divergência vertical para radiação de onda longa considerando-se o efeito de resfriamento e aquecimento dos fluxos radiativos. 


\subsubsection{MODELO DE FLUXOS RADIATIVOS}

O balanço radiativo depende dos coeficientes de absorção e emissão para diferentes camadas na atmosfera que por sua vez consideram a espessura da atmosfera, quantidade de aerossóis, a quantidade de vapor de água e outros gases do efeito estufa. No entanto, o modelo ENVI-met faz um cálculo mais simplificado a partir dos estudos de Paltridge e Platt (1976) que consideram apenas a quantidade de vapor de água na atmosfera (HUTTNER, 2012). A equação 23 mostra o cálculo da entrada de radiação de onda longa a uma altura $\mathrm{z}$ :

$$
Q_{l w}^{\downarrow}(z)=\sum_{n=1}^{N} \sigma T^{4}(n)\left[\epsilon_{n}(m+\Delta m)-\epsilon_{n}(m)\right]
$$

Onde:

$m=$ quantidade de vapor d'água entre a altura $z$ e a camada inferior $n\left[\mathrm{~kg} \mathrm{~m}^{-3}\right]$

$m+\Delta m=$ quantidade de vapor d'água entre a altura $\mathrm{z}$ e a camada superior $n\left[\mathrm{~kg} \mathrm{~m}^{-3}\right]$

$\epsilon_{\mathrm{n}}=$ emissividade

$\mathrm{T}=$ temperatura absoluta na camada $n[\mathrm{~K}]$

A entrada de radiação de onda curta na camada superior do modelo é calculada integrando-se o valor da radiação solar Io na faixa do comprimento de onda entre $\lambda=290 \mathrm{~nm}$ e $\lambda=4000 \mathrm{~nm}$, de acordo com a seguinte equação:

$$
Q_{s w}^{*}=\int_{0.29}^{4.0} I o \exp \left\{-\alpha_{R}(\lambda) m+\alpha_{M}(\lambda) m\right\} d \lambda
$$

Onde:

$\alpha_{R}(\lambda)=$ corresponde ao espalhamento de Rayleigh ${ }^{28}$

$\alpha_{M}=$ espalhamento de $\mathrm{Mie}^{29}$

${ }^{28} \mathrm{O}$ espalhamento Rayleigh é o mais comum. Ele ocorre quando o diâmetro das partículas é menor do que o comprimento da onda. Relaciona-se com as moléculas de gases presentes na atmosfera, e por isso o espalhamento Rayleigh é também denominado de espalhamento molecular. O cálculo do coeficiente de espalhamento Rayleigh depende do número de partículas por centímetro cúbico, do comprimento da radiação e dos índices refrativos das partículas e do meio, mas de forma mais simplificada, pode-se dizer que ele é proporcional ao inverso da quarta potência do comprimento de onda: $\alpha_{R}=\lambda^{-4}$ (MENEZES; ALMEIDA, 2012). 
$m$ = massa ótica da atmosfera e varia de acordo com o ângulo zenital do sol $h$, segundo a relação (HUTTNER, 2012):

$$
m= \begin{cases}\frac{1}{\operatorname{sen} h} & \text { se } h \geq 10 \\ 1.22\left(\frac{1.0144}{\operatorname{sen}(h+1.44)}\right) & \text { se } h \leq 10\end{cases}
$$

O espalhamento (difusão ou dispersão) corresponde à mudança aleatória da direção de propagação da radiação solar incidente devido à sua interação elástica com os componentes atmosféricos. A suposição comum é que a radiação espalhada não é atenuada, mas sim redirecionada (MENEZES; ALMEIDA, 2012).

Dessa forma, a quantidade absoluta de radiação de onda curta é dada por:

$$
Q_{s w, d i r}^{0}=Q_{s w}^{*}-Q_{s w_{i} a b s}
$$

Onde:

$Q_{s w_{2} \text { dir }}^{0}=$ radiação direta de onda curta $\left[\mathrm{W} \mathrm{m}^{-2}\right]$

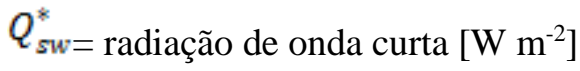

$Q_{s w, a b s}=$ radiação de onda curta absorvida pelo vapor d'água e pode ser calculado segundo os estudos de Liliequist e Cehak (2006) que relacionam a pressão de vapor de água a $2 \mathrm{~m}$ acima do solo e a massa ótica da atmosfera [W $\left.\mathrm{m}^{-2}\right]$

No interior de um modelo tridimensional, os fluxos radiativos são modificados pelas plantas e edifícios. Para estimar esse efeito, o conceito do coeficiente de obstrução do fluxo $(\sigma)$ é utilizado e descreve a influência da vegetação na radiação de onda curta direta e indireta, equação 27 e 28 , e os fluxos de onda longa descendente e ascendente, equação 29 e 30 (HUTTNER, 2012).

$$
\begin{aligned}
& \sigma_{s w_{\text {dir }}}(\mathrm{z})=\exp \left(-F, I A F^{*}(\mathrm{z})\right) \\
& \sigma_{\text {swidif }}(z)=\exp \left(-F \cdot \operatorname{IAF}\left(z_{j} z_{p}\right)\right)
\end{aligned}
$$

\footnotetext{
${ }^{29} \mathrm{O}$ espalhamento Mie ocorre quando a onda eletromagnética é de tamanho comparável ao tamanho das partículas atmosféricas. Nesse caso, o coeficiente de espalhamento é um coeficiente de área definido como a razão da frente de onda afetada pela partícula e a sessão de área transversal da própria partícula. Em analogia ao espalhamento de Rayleigh, o espalhamento de Mie tem a seguinte relação com o comprimento de onda: $\alpha_{M}=\lambda^{-1.3}$ (MENEZES; ALMEIDA, 2012).
} 


$$
\begin{gathered}
\sigma_{l w}^{\Downarrow}(z)=\exp \left(-F \cdot \operatorname{IAF}\left(z_{j} z_{p}\right)\right) \\
\sigma_{l w}^{\uparrow}(z)=\exp (-F \cdot \operatorname{IAF}(0, z))
\end{gathered}
$$

Onde:

$\mathrm{F}=$ fluxo da radiação (direta, difusa ou complementar) $\left[\mathrm{W} \mathrm{m}^{-2}\right]$

$\mathrm{IAF}=$ índice de área foliar de acordo com uma altura $\mathrm{z}\left[\mathrm{m}^{2} \mathrm{~m}^{-2}\right]$

Os valores de IAF são calculados no modelo integrando-se os valores do índice de densidade foliar $\mathrm{DAF}^{30}$ (leaf area density - LAD) para diferentes alturas $(\mathrm{z}$ ), segundo a equação abaixo:

$$
\operatorname{lAF}(z, z+\Delta z)=\int_{z^{\prime}}^{z^{\prime}+\Delta z} D A F\left(z^{\prime}\right) d z^{\prime}
$$

A redução da radiação solar direta pela vegetação considera um valor de IAF tridimensional (IAF*) ao invés do índice unidimensional de IAF, conforme a equação 33. O índice tridimensional IAF* considera o ângulo de incidência dos raios e analisa o entorno para possíves objetos que possam obstruir a passagem da radiação.

Dessa forma, no efeito do sombreamento por edifícios $\sigma_{s w_{d} d i r}$ é considerado 0 (superfícies opacas). No caso da vegetação, o sombreamento da copa varia de acordo com o coeficiente de obstrução (equação 32).

O fator de visão do céu $\left(\sigma_{s v f}\right)$ indica o total de céu visível (sem as obstruções do entorno) a partir do centro de cada célula presente na modelagem e esse coeficiente é dado por:

$$
\sigma_{s v f}=\frac{1}{360} \sum_{\pi=0}^{360} \cos w(\pi)
$$

\footnotetext{
${ }^{30}$ Segundo Weiss (2004): "DAF is defined as the total one-sided leaf area per unit of layer volume". Dessa forma, os valores de DAF expressam um índice de densidade foliar que relaciona a área total de um dos lados das folhas pelo volume da forma geométrica da copa $\left(\mathrm{m}^{2} / \mathrm{m}^{3}\right)$. Depende de diferentes microcomponentes (densidade que depende do tipo dos galhos) e microcomponentes (comprimento da copa, número de folhas pela dimensão da copa e tamanho das folhas) e o efeito de obstrução da radiação direta pela copa (LALIC; MIHAILOVIC, 2004).
} 
Assim no balanço de energia no modelo ENVI-met, o cálculo da radiação solar direta resultante pode ser definido da seguinte forma (equação 33):

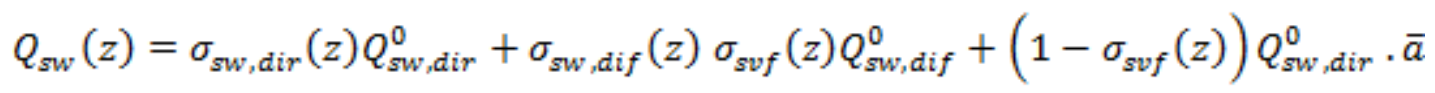

Onde:

$\bar{a}=$ albedo médio das fachadas no modelo.

$Q_{s w, d i r}^{0}=$ radiação direta no topo da área do modelo $\left[\mathrm{W} \mathrm{m}^{-2}\right]$.

$Q_{s w, \text { dif }}^{0}=$ radiação difusa no topo da área do modelo [W $\left.\mathrm{m}^{-2}\right]$.

No cálculo é considerado o efeito da vegetação pelos coeficientes $\sigma_{s w_{\imath} \text { dir }}(z)$ e $\sigma_{s w_{\imath} \text { dif }}(z)$, além do fator de visão de céu definido por $\sigma_{s v f}(z)$.

O cálculo dos fluxos de radição de onda longa é dado pelas equações 34 e 35 :

$$
\begin{array}{r}
Q_{l w}^{\downarrow}(z)=\sigma_{l w}^{\downarrow}(z, z p) Q_{l w}^{\downarrow^{\prime} 0}+\left(1-\sigma_{l w}^{\downarrow}(0, z)\right) \epsilon_{f} \sigma_{B} \overline{T_{f+}^{4}}+\left(1-\sigma_{s v f}(z)\right) Q_{l w}^{\leftrightarrow} \\
Q_{l w}^{\uparrow}(z)=\sigma_{l w}^{\uparrow}(0, z) \epsilon_{s} \sigma_{B} T_{0}^{4}+\left(1-\sigma_{l w}^{\uparrow}(0, z)\right) \epsilon_{f} \sigma_{f} \overline{T_{f-}^{4}}
\end{array}
$$

Onde:

$\overline{T_{f-}^{4}}=$ temperatura média abaixo da folha $[\mathrm{T}]$

$\overline{T_{f+}^{4}}=$ temperatura média acima da folha [T]

$\epsilon_{f}=$ emissividade da folha

$\epsilon_{s}=$ emissividade da superfície

$T_{0}=$ temperatura de superfície [T]

$Q_{l w}^{\leftrightarrow}=$ fluxo de radiação de onda longa horizontal pelas fachadas [ $\left.\mathrm{W} \mathrm{m}^{-2}\right]$

$\sigma_{B}=$ constante de Stefan-Boltzmann 5,67 $10^{-8}\left[\mathrm{Wm}^{-2} \mathrm{~K}^{-4}\right]$.

\subsubsection{MODELO DE SOLO}

O tecido urbano apresenta materiais diferenciados que variam entre o solo natural e superfícies impermeáveis como asfalto e concreto. A fim de simular situações urbanas heterogêneas, propriedades individuais podem ser especificadas para cada célula da malha na superfície do modelo.

O modelo de solo está organizado em 14 camadas desde a superfície até a profundidade de $2 \mathrm{~m}$. A resolução vertical varia em $0,01 \mathrm{~m}$ próximo da superfície e $0,5 \mathrm{~m}$ na camada mais profunda. Os processos de troca de calor e água ocorrem entre as camadas e os 
cálculos consideram uma coluna vertical unidimensional, exceto a camada de superfície, onde as trocas são calculadas tridimensionalmente com a atmosfera. A distribuição da temperatura $\mathrm{T}$ e o conteúdo de umidade no solo $\eta$ é dada nas seguintes equações prognósticas:

$$
\begin{gathered}
\frac{\partial T}{\partial t}=K_{s} \frac{\partial^{2} T}{\partial z^{2}} \\
\frac{\partial \eta}{\partial t}=D_{\eta} \frac{\partial^{2} \eta}{\partial z^{2}}+\frac{\partial K_{\eta}}{\partial z}-S_{\eta}(z)
\end{gathered}
$$

Onde:

$\mathrm{Ks}=$ difusividade térmica $\left[\mathrm{m}^{2} \mathrm{~s}^{-1}\right]$

$\mathrm{S} \eta=$ retirada de água do solo pelas raízes das plantas

$\mathrm{K}_{\eta}=$ condutividade hidráulica $\left[\mathrm{cm} \mathrm{s}^{-1}\right]$

$\mathrm{D}_{\eta}=$ difusividade hidráulica $\left[\mathrm{cm} \mathrm{s}^{-1}\right]$

$\eta=$ conteúdo de umidade no solo $\left[\mathrm{m}^{3} \mathrm{~m}^{-3}\right]$

\subsubsection{MODELO DE VEGETAÇÃO}

Os cálculos que representam as interações entre as folhas e a atmosfera como fluxo de calor sensível $\left(\mathrm{J}_{\mathrm{f}, \mathrm{h}}\right)$, fluxo de evaporação da água nas folhas $\left(\mathrm{J}_{\mathrm{f}, \text { evap }}\right)$ e o fluxo de transpiração controlado pelos estômatos $\left(\mathrm{J}_{\mathrm{f}}\right.$,trans $)$ estão expressos nas seguintes equações:

$$
\begin{gathered}
I_{f, h}=1.1 r_{a}^{-1}\left(T_{f}-T_{a}\right) \\
I_{f_{i} \text { evap }}=r_{a}^{-1} \Delta_{q} \delta_{c} f_{w}+r_{a}^{-1}\left(1-\delta_{c}\right) \Delta_{q} \\
I_{f, \text { trans }}=\delta_{c}\left(r_{a}+r_{s}\right)^{-1}\left(1-f_{w}\right) \Delta_{q}
\end{gathered}
$$

Onde:

$\mathrm{r}_{\mathrm{a}}=$ resistência aerodinâmica na folha $\left[\mathrm{m} \mathrm{s}^{-1}\right]$

$\mathrm{T}_{\mathrm{a}}=$ temperatura do ar em volta da folha $[\mathrm{K}]$

$\mathrm{q}_{\mathrm{a}}=$ umidade do ar em volta da folha [\%]

$\Delta \mathrm{q}=$ umidade específica do $\operatorname{ar}\left[\mathrm{kg} \mathrm{kg}^{-1}\right]$

$\mathrm{T}_{\mathrm{f}}=$ temperatura da folha $[\mathrm{K}]$

$\mathrm{q}^{*}=$ valor saturado de $\mathrm{q}$ na superfície da folha $\left[\mathrm{kg} \mathrm{kg}^{-1}\right]$

$\Delta \mathrm{c}=$ fator considerado 1 se a evaporação e a transpiração podem acontecer $(\Delta \mathrm{q}>0)$, caso contrário considera-se 0 . 
A abertura dos estômatos é controle vital da planta para permitir as trocas gasosas e controlar a perda de água para o ambiente. Dessa forma, quanto menor a disponibilidade de recursos como luz e água no solo, maior é a resistência dos estômatos. Esse fator expresso em $r_{s}$ pode ser calculado de duas formas no ENVI-met, sendo um primeiro método baseado em Deardorff (1978) e um segundo método de cálculo elaborado por Jacobs (1994).

A principal diferença entre os dois métodos está nas condicionantes que cada um utilizou, sendo que nas equações de Deardorff os valores e máximos estimados dependem da radiação solar e da quantidade de água, enquanto Jacobs considera o controle dos estômatos e a concentração do $\mathrm{CO}_{2}$ na atmosfera. Uma das principais desvantagens do modelo de Deardorff está no tratamento independente das variáveis, que não permite uma dinâmica adaptação a novas situações, ao mesmo tempo em que se baseia em valores estatísticos provenientes dos trabalhos experimentais.

Segundo Deardorff (1978) a resistência dos estômatos é dada pela equação:

$$
r_{s}=r_{s, \min }\left[\frac{R_{s w, \text { max }}}{0.03 R_{s w, \text { max }}+R_{s w}}+\left(\frac{\eta_{\text {willt }}}{\eta}\right)^{2}\right]
$$

Onde:

$\mathrm{r}_{\mathrm{s}}=$ resistência dos estômatos $\left[\mathrm{m} \mathrm{s}^{-1}\right]$

$\mathrm{R}_{\mathrm{sw}, \max }=$ máximo ganho de radiação solar ao meio dia $\left[\mathrm{W} \mathrm{m} \mathrm{m}^{-2}\right]$

$\mathrm{R}_{\mathrm{sw}}=$ valor de radiação solar [ $\left.\mathrm{W} \mathrm{m}^{-2}\right]$

$\eta_{\text {will }}=$ valor da umidade do solo no ponto de murcha $\left[\mathrm{m}^{3} \mathrm{~m}^{-3}\right]$

$\eta=$ valor de umidade do solo na zona de onde se encontram as raízes $\left[\mathrm{m}^{3} \mathrm{~m}^{-3}\right]$

No cálculo da resistência dos estômatos, o valor da radiação solar como variável na equação foi sugerido por Cline e Campbell (1976), Waggoner e Reifsnyder (1968) e Szeicz et. al. (1965). Numa segunda abordagem, Deardorff considera a geometria da planta, relacionando a temperatura embaixo da copa da árvore com a temperatura no topo da árvore, e a densidade das folhas que impedem a chegada da radiação de onda curta no solo. Como resultado, tem-se que:

$$
C_{H_{g}}=\left(1-\sigma_{f}\right) C_{H 0}+\sigma_{f} C_{H h}
$$

Onde:

$\mathrm{C}_{\mathrm{Hg}}=$ coeficiente de transferência de calor e umidade na superfície do solo, logo abaixo da copa da árvore 
$\sigma_{\mathrm{f}}=$ coeficiente de densidade da copa da árvore, sendo que os limites são: $0<\sigma_{\mathrm{f}}<1 ;(0$ significando árvores sem folhagem e 1 para copas muito densas)

$\mathrm{C}_{\mathrm{H} 0}=$ coeficiente de transferência de calor e umidade na superfície do solo não coberta pela copa da árvore

$\mathrm{C}_{\mathrm{Hh}}=$ coeficiente de transferência de calor e umidade na superfície do topo da copa da árvore

Por outro lado, a base do modelo de Jacobs (1994) é o processo fisiológico das plantas. O modelo Ag-s é a junção de dois modelos: um que descreve a condutância dos estômatos $\left(\mathrm{g}_{\mathrm{s}}\right)$ e outro para a taxa de fotossíntese $\left(\mathrm{A}_{\mathrm{n}}\right)$. Este modelo faz uma parametrização da resposta dos estômatos em relação à umidade e mostra como esse fato pode afetar a concentração do $\mathrm{CO}_{2}$ interno (Ci) e $\mathrm{CO}_{2}$ externo (Cs).

O modelo pode ser descrito da seguinte forma:

$$
g_{s}=1.6 \frac{A_{n}}{C_{s}-C_{i}}
$$

Onde:

$\mathrm{An}=$ taxa de fotossíntese $\left[\mathrm{mg} \mathrm{m}^{-2} \mathrm{~s}^{-1}\right]$

$\mathrm{Cs}=$ concentração de $\mathrm{CO}_{2}$ na superfície da folha $\left[\mathrm{mg} \mathrm{m}^{-3}\right]$

$\mathrm{Ci}=$ concentração de $\mathrm{CO}_{2}$ intercelular $\left[\mathrm{mg} \mathrm{m}^{-3}\right]$

A condutância estomática $\left(\mathrm{g}_{\mathrm{s}}\right)$ considera a interação entre as trocas de $\mathrm{CO}_{2}$ e $\mathrm{H}_{2} \mathrm{O}$ e para se converter em resistência dos estômatos, deve-se realizar o seguinte cálculo:

Onde:

$$
R_{s}=\frac{1}{g_{s^{*}} 1000}
$$

Rs $=$ resistência dos estômatos $\left[\mathrm{m} \mathrm{s}^{-1}\right]$

gs $=$ condutância estomática $\left[\mathrm{s} \mathrm{m}^{-1}\right]$

O modelo JS (JARVIS, 1976; STEWART, 1988), aplicado em pesquisas micrometeorológicas com modelos de mesoescala e modelos climáticos, serviu como base para se desenvolver o modelo Ag-s, pois indicava os fatores para controle do comportamento dos estômatos durante um determinado período de tempo (JACOBS, 1994).

Ainda segundo Jacobs (1994), os principais problemas apresentados pelo modelo JS são:

- Ele considera pequenos valores para concentração de $\mathrm{CO}_{2}$ na atmosfera, prejudicando os resultados e as relações entre os fatores internos da planta. 
- A maior parte dos resultados é gerada para o período noturno, quando os estômatos estão, em geral, fechados.

- Ele não considera a relação entre $\mathrm{CO}_{2}$ e o comportamento dos estômatos.

\subsection{AVANÇOS DO MODELO ENVI-MET}

Em novembro de 2008 foi lançada a versão 3.1 Beta do ENVI-met, com poucas diferenças em relação à versão anterior 3.1. A última atualização divulgada publicamente foi feita em outubro de 2010, conforme mostra a Tabela 4. Em relação ao banco de dados de vegetação, houve um acréscimo significativo nas opções para árvores, gramíneas e culturas, sendo que na versão 3.1 havia 14 tipos de plantas e, na versão mais recente, foram incluídos mais 13 novos tipos.

Tabela 4: Atualizações do modelo ENVI-met 3.1 Beta

\begin{tabular}{|c|c|}
\hline $\begin{array}{l}\text { Beta } 5 \text { V3.1 } \\
(\text { Oct/ 2010) }\end{array}$ & $\begin{array}{l}\text { - } \text { Removeu problemas de incompatibilidade } \\
\text { com o WINDOWS } 7 \text {. } \\
\text { - Removeu problemas no Xtract (falta de } \\
\text { dados nos cortes do eixo y-z) } \\
\text { - Adicionou o HTML-Help }\end{array}$ \\
\hline $\begin{array}{l}\text { Beta } 4 \text { V3.1 } \\
(\text { Jan/ 2010) }\end{array}$ & $\begin{array}{l}\text { - Removeu um problema no cálculo do } \\
\text { sombreamento que ocorria na vegetação } \\
\text { em tetos verdes. }\end{array}$ \\
\hline $\begin{array}{l}\text { Beta III } \\
\text { Dez/ } 2010\end{array}$ & $\begin{array}{l}\text { Melhorou o módulo de fluxo, agora mais } \\
\text { estável. } \\
\text { Requer a definição de arquivo de projetos } \\
\text { para armazenar os modelos. }\end{array}$ \\
\hline $\begin{array}{l}\text { Beta II V3.1 } \\
\text { Mar/ } 2009\end{array}$ & $\begin{array}{l}\text { - Removeu problemas no cálculo de } \\
\text { extinção da radiação direta pelas plantas. }\end{array}$ \\
\hline \multirow[t]{2}{*}{$\begin{array}{l}\text { Beta V3.1 } \\
\text { Nov/ } 2008\end{array}$} & $\begin{array}{l}\text { - Removeu pequenos problemas no manejo } \\
\text { dos folders }\end{array}$ \\
\hline & Acrescentou mais locais para as simulação \\
\hline
\end{tabular}

Fonte: ENVI-met. Disponível em: < www.envi-met.com>. Acesso em junho de 2013.

A versão utilizada neste trabalho foi a 3.1 Beta 5, mas já se sabe de alguns avanços da versão 4 (preview), divulgados por alguns poucos trabalhos, supervisionados pelo autor (HUTTNER et al., 2009; HUTTNER, 2012).

O modelo ENVI-met 4.0 tem como principais avanços (HUTNNER et al., 2009):

- Novas características no editor de modelagem. Na versão anterior 3.1, para se criar a área de estudo no modelo usava-se um formato $2.5 \mathrm{D}$ para construção e 
armazenagem dos dados, isto é, para cada célula na malha, apenas 1 valor acima e abaixo no valor de contorno no eixo $\mathrm{z}$ pode ser especificado em edifícios e plantas. Entre as desvantagens, não permite a construção de edifícios ou de um tecido urbano mais complexo. Na nova versão 4.0 (preview), a modelagem será construída num formato 3D de visualização, com uma maior facilidade de desenho e também permitindo ao usuário especificar as propriedades físicas em cada elemento individualmente. Assim, numa fachada de edifício é possível definir os desenhos das aberturas e especificar as características dos materiais de caixilharia, vidro e alvenaria. A figura 40 mostra que cada cor representa um material diferente na fachada.

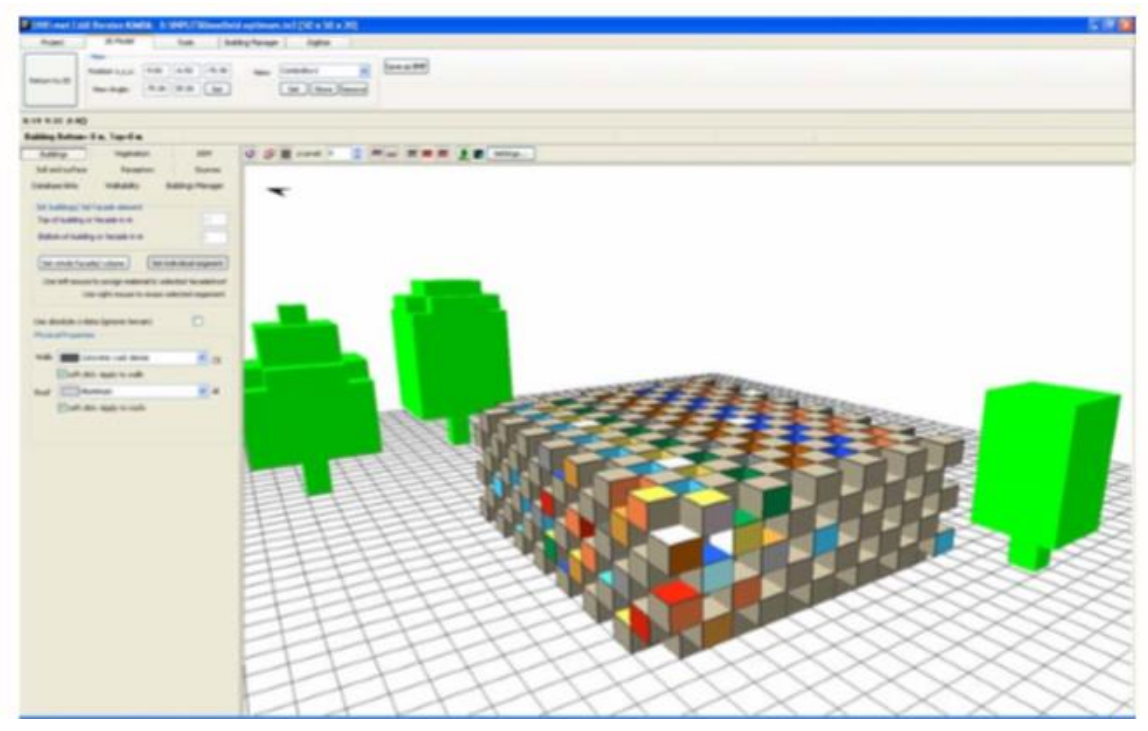

Figura 40: Imagem da tela do novo 3D editor do ENVI-met 4.0.

Fonte: Huttner et. al., 2009.

- Avanços no cálculo de temperatura da fachada e no balanço de energia dos fechamentos verticais. As versões anteriores não levam em conta a capacidade térmica das fachadas, mas os cálculos da temperatura de superfície de fachadas foram incluídos na nova versão. O cálculo está baseado em um modelo em regime transiente motivado pelos estudos de Terjung e O’Rouke (1980). As propriedades físicas da parede incluem dados de reflexão, absorção, transmissão, emissividade, coeficiente de transferência de calor, capacidade térmica específica e a espessura da parede.

- Forcing. Nas versões anteriores as condições atmosféricas de contorno da simulação só podem ser introduzidas no modelo nos valores iniciais a partir dos quais o modelo passa a deduzir direta (radiação incidente) ou indiretamente 
(ventos, temperatura do ar e umidade) a variação diurna das condições de contorno da simulação. Em outras palavras, nas versões anteriores, o modelo não assimilava dados. Já na versão 4.0 é possível informar a variação diurna das condições atmosféricas e da radiação incidente. Isso permite uma melhor comparação entre os valores medidos em campo e a simulações pelo ENVI-met.

- Vegetação 3D. O modelo de vegetação apresenta significativos avanços em relação ao modelo da versão 3.1, no que se refere à visualização do formato das árvores, de acordo as diferentes camadas de DAF. Foi implementado um banco de dados 3D para definir as árvores de uma forma mais elaborada. Segundo o editor para configuração das plantas, a estrutura da árvore segue um padrão na malha da modelagem de $11 \times 11$ células por 10 células de altura.

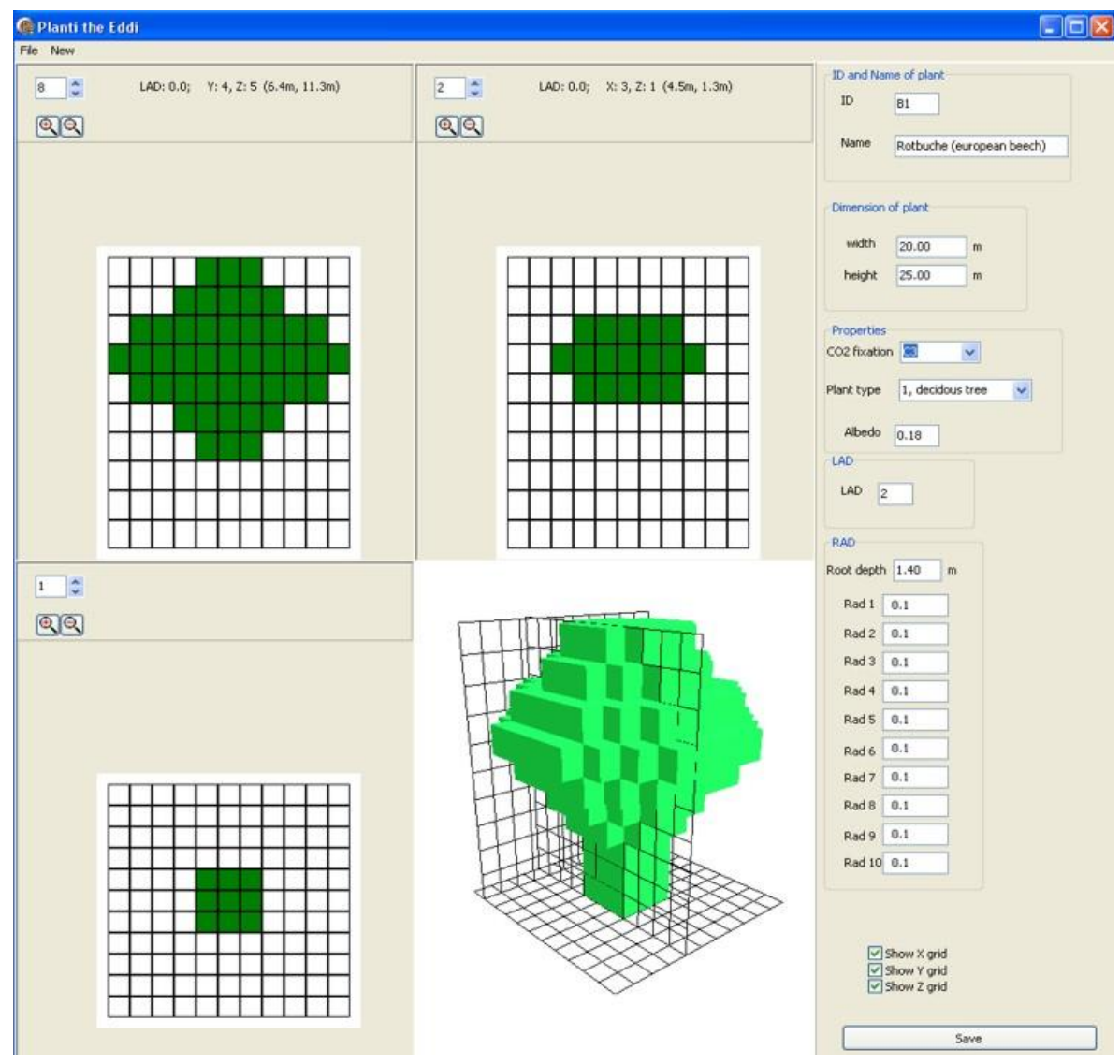

Figura 41: Imagem da tela do novo 3D editor para vegetação no ENVI-met 4.0.

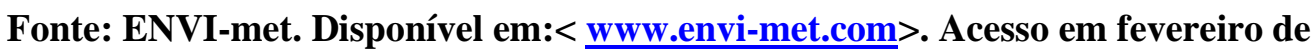
2014.

Assim existe a opção de usar tipos de vegetação no formato $1 \mathrm{D}$ e $3 \mathrm{D}$, conforme mostra a Figura 42. 


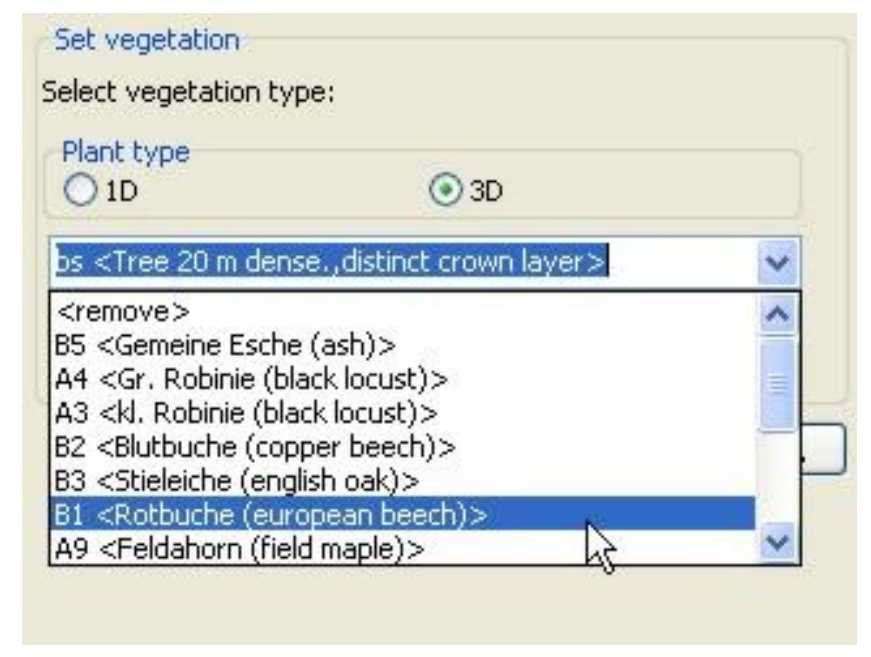

Figura 42: Opções de vegetação 1D e 3D no ENVI-met 4.0.

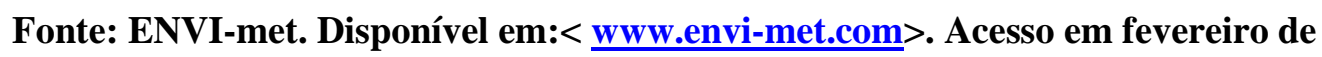
2014.

No modelo do ENVI-met v.3.1 para mudar o posicionamento da vegetação deve-se primeiro apagar a planta existente e definir um outro ponto para inseri-la novamente. No ENVI-met 4 é possível mudar posição da vegetação diretamente na modelagem com uso do mouse.

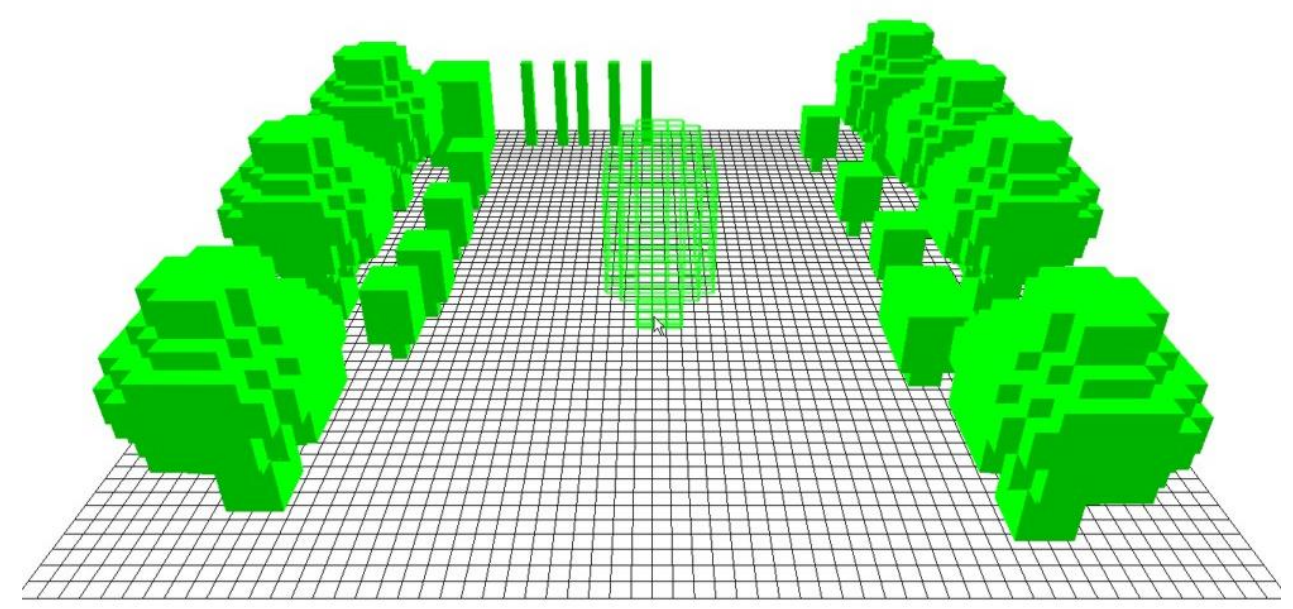

Figura 43: Visualização 3D da vegetação no ENVI-met 4.0.

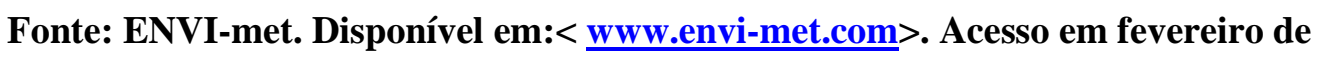
2014.

\subsection{PROCESSO DE SIMULAÇÃO NO ENVI-met v. 3.1}

O processo de simulação ocorre segundo três fases principais: construção da modelagem (area input file), definição dos dados de entrada (configuration file editor) e a fase de início da simulação (start ENVI-met). 


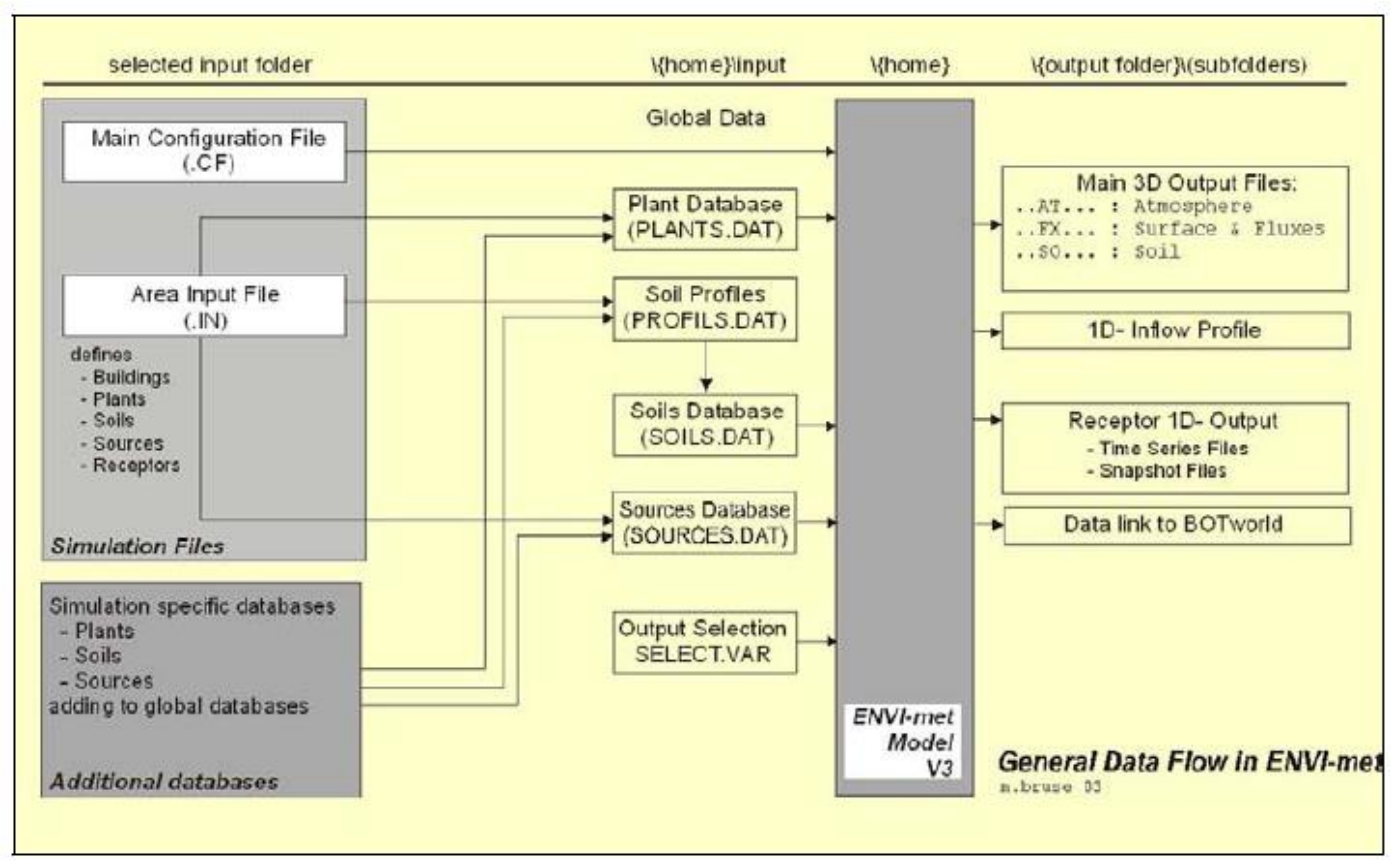

Figura 44: Estrutura geral do processo de simulação do ENVI-met.

Fonte: Bruse (1998)

\subsubsection{CONSTRUÇÃO DA MODELAGEM (Area Input File)}

O ENVI-met é um modelo 3D e está organizado de acordo com uma malha ortogonal (grid) nos eixos x, y e z. O primeiro passo é configurar a dimensão de cada célula da malha, sendo o valor mínimo de $1 \mathrm{~m}$ x $1 \mathrm{~m}$ x $1 \mathrm{~m}$. A altura máxima do modelo é de 2.500m, a partir do nível do mar, permitido uma distribuição de três formas: equidistante (células verticais de tamanho igual), telescópico e telescópico com fator de extensão (Figura 46). Nesta última opção é indicada para simulações com edifícios altos, sendo que as células estão distribuídas conforme a equação:

$$
\Delta z(k)=\left[1+\left(\frac{S}{100}\right)\right]^{k-1} \cdot \Delta z_{\text {start }}
$$

Onde,

$\mathbf{S}=$ fator de extensão [\%]

$\Delta \mathbf{z}_{\text {start }}=$ tamanho da primeira célula $[\mathrm{m}]$

Além dos limites do modelo definido, é possível acrescentar células bidimensionais (eixo $\mathrm{x}, \mathrm{y}$ ) na chamada grade de aninhamento (nesting grid). A função dessa grade é criar uma área de transição em volta do modelo para os fluxos de vento e radiação e evitar problemas nos cálculos das bordas do modelo. 


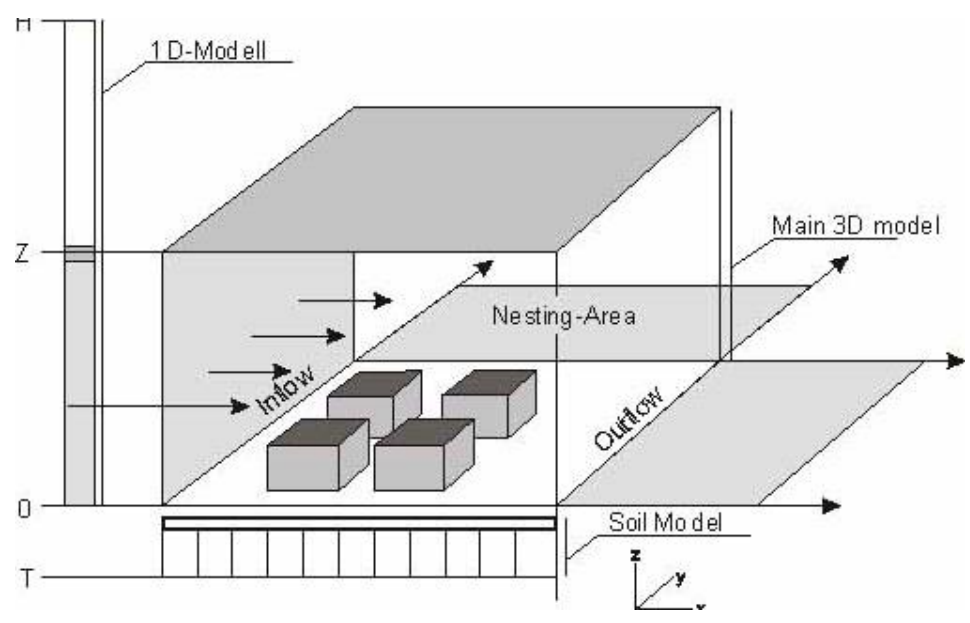

Figura 45: Layout básico do modelo ENVI-met.

Fonte: ENVI-met 3.0 Manual. Disponível em. 〈http://envi-met.com/>. Acesso em agosto de 2013.

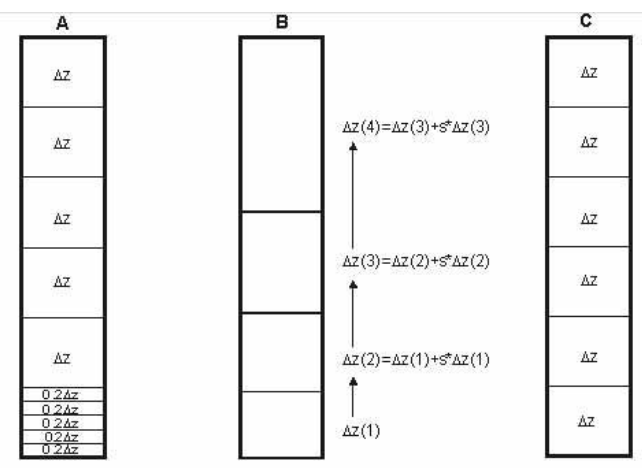

Figura 46: Distribuição das alturas: Eqüidistante (A), Telescópico com fator de extensão (B) e Telescópico (C).

Fonte: ENVI-met 3.0 Manual. Disponível em. http://envi-met.com/. Acesso em agosto de 2013.

Definidos os limites e o tamanho das células do modelo, é possível criar a geometria urbana da área de estudo utilizando-se os bancos de dados de solo, perfil dos materiais e vegetação. Esses bancos de dados do modelo apresentam vários tipos de materiais, solo e vegetação para serem aplicados no modelo de estudo. Cada material apresenta características específicas e os detalhes de cada arquivo estão presentes no item 4.5.

\subsubsection{CONFIGURAÇÃO DOS DADOS DE ENTRADA (Configuration Editor)}

Os principais parâmetros de simulação estão organizados da seguinte forma:

- Configuração dos arquivos de simulação: nome do arquivo de entrada e saída; tempo de início e término das simulações.

- Condições climáticas básicas do modelo: temperatura potencial a $2500 \mathrm{~m}$ de altitude a partir do nível do mar, umidade relativa do ar a $2 \mathrm{~m}$, umidade 
específica a $2500 \mathrm{~m}$ de altitude, a partir do nível do mar, velocidade e intensidade dos ventos a 10m, comprimento de rugosidade da superfície, posição geográfica (latitude, longitude, zonas).

- Configurações ambientais do modelo: dados do solo com temperatura e umidade em diferentes profundidades (SoilData); intervalos de atualização e armazenamento de dados simulados (Timing); modelos de turbulência (Turbulence); pontos especiais de cálculo (Receptors); dados médios de temperatura interna e albedo de paredes e coberturas (Buildings); condição de insolação da área de aninhamento (NestingArea); cálculo do índice de conforto $P M V$, adaptado para clima externo pelos estudos de Jendritzky (2003); modelo da fisiologia da vegetação e concentração do $\mathrm{CO}_{2}$ (PlantModel); tipo de fronteira lateral e variáveis de turbulência (LBC-types); tipo de poluentes emitidos (sources); tipo do céu e posicionamento das nuvens (Clouds); fator de ajuste da irradiação solar de onda curta (SolarAjust).

\subsubsection{INÍCIO DAS SIMULAÇÕES (Start ENVI-met)}

A dimensão do modelo, baseada tamanho das células que compõem a grade de aninhamento definida, determina o tamanho máximo da área de modelagem para se iniciar a simulação. O modelo apresenta seis opções de formato para processar a simulação (Figura 47). Quanto maior a resolução, maior o tempo necessário para se gerar os resultados.

\begin{tabular}{|l|l|}
\hline $60 \times 60 \times 30$ Grids & 128 Mbytes \\
\hline $80 \times 80 \times 30$ Grids & 128 Mbytes \\
\hline $120 \times 120 \times 30$ Grids & 256 Mbytes \\
\hline $130 \times 130 \times 30$ Grids & 256 Mbytes \\
\hline $200 \times 200 \times 25$ Grids & 512 Mbytes \\
\hline $250 \times 250 \times 25$ Grids & 1 GByte \\
\hline
\end{tabular}

Figura 47: Opções do formato final a ser simulado no modelo ENVI-met.

Fonte: Disponível em: <www.envi-met.com >. Acesso em agosto de 2013.

O ENVI-met oferece mais de quarenta opções de dados de saída, dentre elas: fluxo de ar, velocidade dos ventos, umidade específica, temperatura do ar, radiação direta, radiação difusa, radiação refletida, fator de visão de céu, água nas folhas, valores de 
PMV, resistência dos estômatos, fluxo de $\mathrm{CO}_{2}$ nas plantas, valor absoluto de LAD, receptores e dados de PMV.

Os arquivos do ENVI-met têm formato EDT e EDI, podendo-se exportá-los para as planilhas de cálculo, tais como o Excel. Outra forma de visualização é por meio do aplicativo do Leonardo v. $3^{31}$ no formato $2 \mathrm{D}$ e $3 \mathrm{D}$.
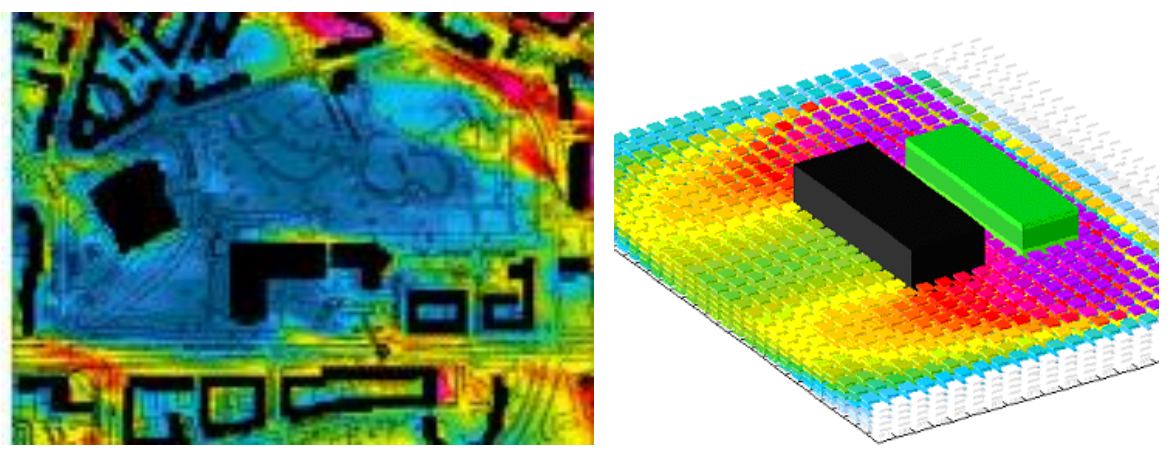

Figura 48: Resultados de simulações geradas pelo Leonardo (2D)

Figura 49: Resultados de simulações geradas pelo Leonardo (3D)

Fonte: Disponível em < http://www.envi-met.com >. Acesso em agosto de 2013.

\subsection{BANCOS DE DADOS DO MODELO}

Nas simulações, o ENVI-met utiliza 4 bancos de dados para descrever os elementos existentes na modelagem: dados para diferentes tipos de solo (SOILS.DAT), dados com as características dos materiais (PROFILS.DAT), dados de fontes antropogênicas de calor (SOURCE. DAT) e dados da vegetação (PLANTS.DAT).

\subsubsection{BANCO DE DADOS DE VEGETAÇÃO (PLANTS.DAT)}

No banco de dados de vegetação, cada planta é descrita por dez informações referentes às suas características morfológicas e fisiológicas, conforme mostra a Tabela 5.

Tabela 5: Informações de cada planta no banco de dados de vegetação do ENVI-met

\begin{tabular}{|c|l|}
\hline IC & Identificação da planta \\
\hline C? & Tipo de fixação do carbono - planta $\mathrm{C}_{3}$ ou $\mathrm{C}_{4}$ \\
\hline TY & $\begin{array}{l}\text { Tipo da planta: 01 para árvores decíduas, 02 coníferas e 03 } \\
\text { para gramíneas }\end{array}$ \\
\hline rs_min & $\begin{array}{l}\text { Resistência estomática mínima } \\
\text { Definiu-se 400 para árvores e 200 para gramíneas } \\
\text { (BRUSE, 2007) }\end{array}$ \\
\hline
\end{tabular}

Disponível em: www.envi-met.com >.Acesso em janeiro de 2014. 


\begin{tabular}{|c|l|}
\hline a_f & $\begin{array}{l}\text { Albedo para radiação de onda curta } \\
\text { Todos apresentam o valor 0.20 }\end{array}$ \\
\hline HH.HH: & Altura total (m) \\
\hline TT.TT: & Profundidade total da raiz \\
\hline LAD1 - LAD10 & $\begin{array}{l}\text { Valores da densidade de área foliar - LAD distribuídos em } \\
10 \text { camadas }\end{array}$ \\
\hline RAD1- RAD10 & $\begin{array}{l}\text { Valores da densidade da área da raiz - RAD em 10 } \\
\text { camadas }\end{array}$ \\
\hline Name & Nome da planta e tipo da copa no caso das árvores \\
\hline
\end{tabular}

Fonte: ENVI-met. Disponível em: < www.envi-met.com>. Acesso em junho de 2013.

O modelo, ao invés de utilizar diretamente os valores do IAF, utiliza como parâmetro para a quantidade de folhas na planta o valor da densidade de área foliar - DAF, distribuídos em 10 camadas de folhas.

Os valores de DAF, além de indicarem processos fisiológicos da planta (devido à quantidade de folhas), também influenciam na atenuação da radiação solar. Este fator contribui para o sombreamento e tem um efeito no conforto térmico dos pedestres, principalmente em cidades de clima tropical (YU; HIEN, 2006). A relação do IAF com DAF é dada pela equação:

$$
I A F=\int_{0}^{h} D A F d z
$$

Os estudos de Lalic e Mihailovic (2004) mostram, por meio de relações empíricas, como ocorre a distribuição vertical da DAF numa floresta heterogênea e comparam os resultados com o banco de dados de oito tipos de árvores, obtidos nos trabalhos de Kolic (1978), Shaw e Schumann (1992) e Dubov et al. (1978) sobre a distribuição do DAF. Baseados nos estudos de Levy e Jarvis (1999), eles definiram uma equação para o cálculo do valor de DAF para uma altura h com três principais fatores: a altura da árvore $h$, o valor máximo de DAF $L m$ e a altura $z m$ correspondente ao valor máximo. Bruse (2003) indica este trabalho como o método mais adequado para se chegar ao IAF de forma simplificada. Os estudos de Lalic e Mihailovic (2004) descrevem ao DAF em função da altura, como mostra a equação:

$$
D A F=\operatorname{Lm}\left(\frac{h-z m}{h-z}\right) \exp \left[n\left(1-\frac{h-z m}{h-z}\right)\right],
$$




$$
n= \begin{cases}6, & 0 \leq z \leq z m \\ \frac{1}{2}, & z m \leq z \leq h\end{cases}
$$

Onde,

$\mathrm{h}=$ altura da planta $[\mathrm{m}]$

$\mathrm{Lm}=$ valor máximo de DAF $\left[\mathrm{m}^{2} \mathrm{~m}^{-3}\right]$

$\mathrm{Zm}=$ altura onde ocorre o DAF máximo $[\mathrm{m}]$

O banco de dados de vegetação da versão 3.1 apresenta 27 tipos de vegetação, sendo 4 tipos de gramíneas, 7 tipos de culturas (milho, soja) e 16 tipos de arbóreas com alturas variando entre $10 \mathrm{~m}$ a $20 \mathrm{~m}$.

\subsubsection{BANCO DE DADOS DE SOLO/ MATERIAIS (SOILS.DAT)}

A tabela 6 apresenta as principais informações para cada material existente:

Tabela 6: Informações sobre os tipos de solo/ materiais

\begin{tabular}{|c|c|}
\hline ID & Identificação do solo \\
\hline $\mathrm{V}$ & $\begin{array}{l}\text { Tipo do solo: } 0 \text { solo aberto; } 1 \text { material selado (sem troca } \\
\text { de água); } 2 \text { corpos d'água }\end{array}$ \\
\hline ns & Conteúdo volumétrico de água na saturação $\left[\mathrm{m}^{3} \mathrm{~m}^{-3}\right]$ \\
\hline nfc & $\begin{array}{l}\text { Conteúdo volumétrico de água na capacidade de campo } \\
{\left[\mathrm{m}^{3} \mathrm{~m}^{-3}\right]}\end{array}$ \\
\hline nwilt & $\begin{array}{l}\text { Conteúdo volumétrico de água no ponto de murcha } \\
\text { permanente }\left[\mathrm{m}^{3} \mathrm{~m}^{-3}\right]\end{array}$ \\
\hline matpot & Matriz potencial na saturação [m] \\
\hline hydr & Condutividade hidráulica na saturação $\left[\mathrm{ms}^{-1}\right]$ x $10^{6}$ \\
\hline $\mathrm{CP}$ & Capacidade térmica volumétrica $\left[\mathrm{Jm}^{-3} \mathrm{k}^{-1}\right] \mathrm{x} 10^{6}$ \\
\hline $\mathrm{b}$ & Constante de Clapp e Hornberger (1978) \\
\hline $\mathrm{HCN}$ & Condutividade térmica do material $\left[\mathrm{Wm}^{-1} \mathrm{k}^{-1}\right]$ \\
\hline Name & Nome para identificação \\
\hline
\end{tabular}

Fonte: ENVI-met. Disponível em: < www.envi-met.com>. Acesso em junho de 2012.

O banco de dados apresenta: 
- 13 tipos de solo: franco (default), arenoso, franco-arenoso, franco-siltoso, franco-arenoso-argiloso, franco-siltoso-arenoso, franco-argiloso, francoargiloso, areno-argiloso, siltoso-argiloso, argiloso e a turfa.

- 3 tipos de materiais selados (concreto, asfalto com brita, asfalto basáltico).

- 2 rochas (granito e basalto ${ }^{32}$ )

- Água.

O solo é classificado em função do teor de argila, silte e areia existente em sua composição. Segundo a NBR 6502/80 (rochas e solos), os elementos que compõem o solo têm as seguintes características:

- Areia: solo não coesivo e não plástico formado por minerais ou partículas de rochas com diâmetros compreendidos entre $0,06 \mathrm{~m}$ e 2,0 m.

- Silte: solo que apresenta baixa ou nenhuma plasticidade, e que exibe baixa resistência quando seco o ar. Suas propriedades dominantes são devidas à parte constituída pela fração silte. É formado por partículas com diâmetros compreendidos entre $0,002 \mathrm{~m}$ e $0,06 \mathrm{~m}$.

- Argila: solo de granulação fina constituído por partículas com dimensões menores que $0,002 \mathrm{~m}$, apresentando coesão e plasticidade.

Conforme porcentagem de cada elemento formam-se tipos específicos de solo como os apresentados nesta versão do triângulo de Feret (Figura 50). Na parte central, existe o solo franco que apresenta uma composição equilibrada dos elementos (argila, silte, areia) e é o mais adequado para o cultivo de plantas diversificadas.

A turfa que está presente no banco de dados do ENVI-met, representa um solo com grande porcentagem de partículas fibrosas e matéria orgânica no estado coloidal, com coloração marrom escura a preta. É um material mole, altamente compressível, não plástico, combustível, e com cheiro característico.

\footnotetext{
${ }^{32}$ Basalto: rocha vulcânica escura, normalmente de granulação fina e de textura que pode ser maciça, vesicular ou amigdaloide (NBR 6502/80).
} 


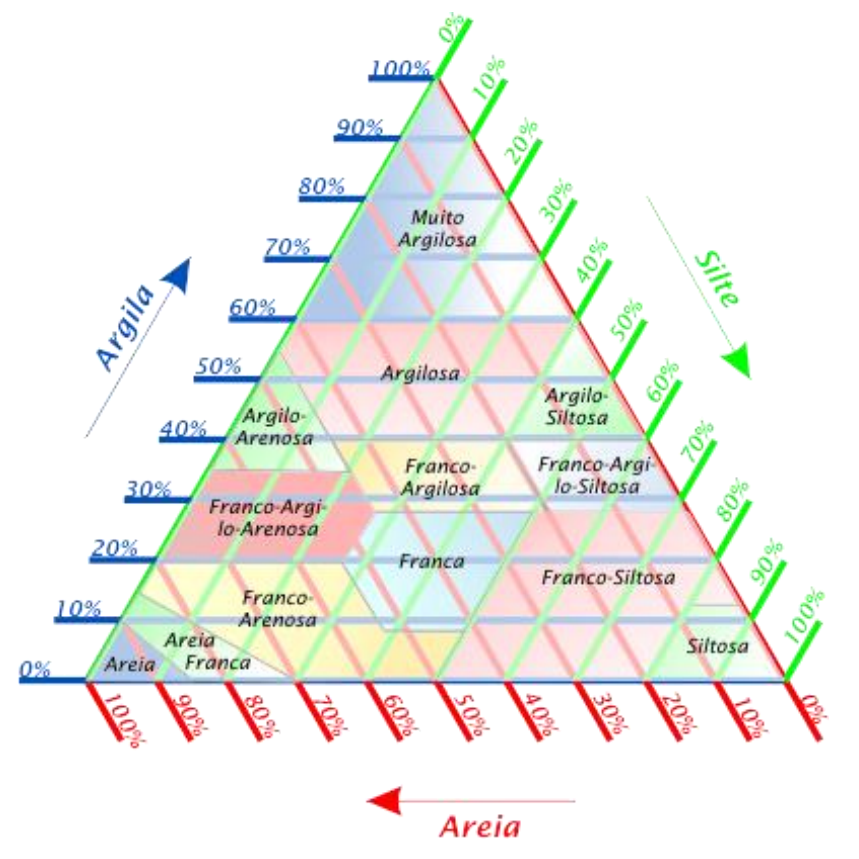

Figura 50: Versão do triângulo de Feret com os tipos de solo.

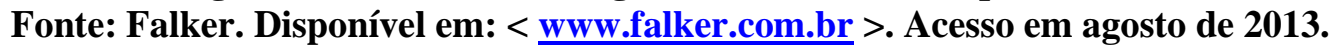

O tipo do solo determina também a capacidade de percolação e retenção da água em relação ao seu volume total. Dessa forma, a capacidade de campo (CC), e o ponto de purcha permanente (PMP) são considerados os limites máximo e mínimo de água disponível no solo.

Segundo Bruse (2004), o modelo A-gs não entra em cálculos da umidade de solo, apenas o considera com uma adequada disponibilidade de água, evitando o stress térmico da planta. Dessa forma, foi considerado um cálculo complementar para considerar o efeito da umidade do solo nas simulações do modelo ENVI-met:

$$
\xi=\frac{\left(\eta-\eta_{\text {wilt }}\right)}{\left(\eta_{f c}-\eta_{\text {wilt }}\right)}
$$

Onde,

$\eta=$ conteúdo volumétrico de água na saturação $\left[\mathrm{m}^{3} \mathrm{~m}^{-3}\right]$

$\eta$ wilt $=$ conteúdo volumétrico de água no ponto de murcha permanente $\left[\mathrm{m}^{3} \mathrm{~m}^{-3}\right]$

$\eta \mathrm{fc}=$ conteúdo volumétrico de água na capacidade de campo $\left[\mathrm{m}^{3} \mathrm{~m}^{-3}\right]$

Como as diferentes camadas do solo podem apresentar variações nas propriedades hidráulicas, o valor médio de $\xi$ é calculado na área onde se localizam as raízes, sendo que um valor mínimo de $0,1(10 \%)$ deve ser considerado a fim de se evitar erros nas simulações pelo modelo (HUTTNER, 2012). 


\subsubsection{BANCO DE DADOS DO PERFIL DOS MATERIAS (PROFILS.DAT)}

Apresenta o perfil vertical dos materiais em 14 camadas a partir da superfície, chegando no máximo a uma profundidade de $1,75 \mathrm{~m}$. Esse banco de dados está conectado ao arquivo SOIL.DAT descritos no item anterior.

A Tabela 7 mostra as principais informações para cada material e a lista é composta por: asfalto, pavimento em concreto, solo franco, solo arenoso e corpos d’água.

Tabela 7: Informações sobre o perfil dos materiais

\begin{tabular}{|c|l|}
\hline ID & Identificação do material \\
\hline-0.15 & Tipo do material/ solo em cada camada (primeira camada) \\
\hline$-1,75$ & Tipo do material/ solo em cada camada (última camada) \\
\hline zo & Comprimento de rugosidade da superfície [m] \\
\hline a & Albedo para radiação de onda curta \\
\hline em & Emissividade para radiação de onda longa na superfície \\
\hline Name & Nome para identificação \\
\hline
\end{tabular}

Fonte: ENVI-met. Disponível em: < www.envi-met.com>. Acesso em junho de 2013.

\subsubsection{BANCO DE DADOS DE FONTES ANTROPOGÊNICAS}

O ENVI-met permite a simulação da dispersão dos gases e partículas poluentes na atmosfera. Até o momento, as simulações só podem ser feitas para um tipo de partícula poluente por vez, não permitindo cenário com fontes antropogênicas que emitam, por exemplo, $\mathrm{SO}_{2}$ e $\mathrm{NO}_{2}$ ao mesmo tempo.

Esse banco de dados contém as seguintes informações:

- tipo de fonte (pontual, linear, ou uma área)

- altura da emissão em m

- taxa de emissão em 24 valores para cada hora do dia.

Os estudos de Bruse et al. (1999) utilizaram o modelo para simular o efeito de filtragem e dispersão de gases poluentes a partir de uma fachada verde com a trepadeira hera japonesa (Parthenocissus tricuspidat) em Düsseldorf, na Alemanha. 


\section{MEDIÇÕES MICROCLIMÁTICAS NO PARQUE TRIANON}

Foram realizadas medições microclimáticas nas áreas de estudo, no nível do pedestre, no período de setembro de 2012 e novembro de 2013, para configurar os dados de entrada para as simulações computacionais no ENVI-met. Para esta etapa contou-se com o apoio da equipe do LABAUT, que já tem experiência em trabalhos de campo similares (PRATA, 2005; DUARTE, GONÇALVES, 2006; SHINZATO, 2009, DUARTE 2010), e dos equipamentos existentes no laboratório, parte deles adquiridos com recursos da CAPES/CNPq ${ }^{33}$

\subsection{BREVE HISTÓRICO DO PARQUE TENENTE SIQUEIRA CAMPOS - TRIANON}

O Parque Tenente Siqueira Campos ${ }^{34}$, mais conhecido como Trianon, está localizado a $23^{\circ} 33^{\prime} 42^{\prime \prime}$ Sul e 46039'24" Oeste, segundo as coordenadas geo-espaciais. Apresenta uma área total de $48.600 \mathrm{~m}^{2}$, delimitada pelas vias: a Avenida Paulista, Rua Peixoto Gomide, Alameda Jaú e Alameda Casa Branca. O parque está dividido em duas áreas distintas pela Alameda Santos, sendo que a conexão entre as duas partes acontece por uma passarela de pedestres com 80 metros de comprimento que foi construída originalmente de madeira no início da década de 1910. Em 1968, ganhou uma estrutura de concreto, reformada no ano de 2012.

O parque foi inaugurado em abril de 1892, um ano após a abertura da Avenida Paulista. Para projetá-lo, foi convidado o francês Paul Villon, criador dos jardins do Palácio do Catete, que o elaborou em estilo inglês, com requintes românticos, preservando as espécies nativas ao lado de outras exóticas. Logo no ano seguinte à sua inauguração, o Parque foi remodelado pelo inglês Barry Parker.

Durante a administração do Barão de Duprat (1911-1914) foi construído, no local onde hoje localiza-se o Museu de Arte de São Paulo, um belvedere com projeto do arquiteto Ramos de Azevedo, que ficou conhecido como Trianon. Durante as décadas de 1920 e

\footnotetext{
${ }^{33}$ O Impacto da Vegetação nos Microclimas Urbanos, projeto de pesquisa concluído, aprovado no Edital MCT/CNPq/MEC/CAPES no 02/2010 - Ciências Humanas, Sociais e Sociais Aplicadas, processo número: 400643/2010-3, coordenado pela Profa. Dra. Denise H. S. Duarte.

${ }^{34}$ Histórico do Parque Trianon. Disponível no site:

<http://www.prefeitura.sp.gov.br/cidade/secretarias/meio_ambiente/parques $>$. Acesso em fevereiro de 2014.
} 
1930, o Parque e o belvedere transformaram-se no símbolo da riqueza da elite paulistana. Em 1924 o parque foi doado à Prefeitura e em 1931 recebeu sua denominação atual em homenagem a um dos heróis da Revolta Tenentista.

A partir dessa data, o Parque entrou em abandono até 1968, quando o prefeito Faria Lima, convidou o paisagista Burle Marx e o arquiteto Clóvis Olga para recuperá-lo. Os dois substituíram a ponte de madeira que ligava as duas áreas do parque separadas pela Alameda Santos por outra de concreto, promoveram o alargamento das alamedas internas e as pavimentaram com pedras portuguesas em forma de mosaico. O parque é tombado pelo CONDEPHAAT, ata $n^{\circ}$ 447; e pelo CONPRESP - Resolução $n^{\circ}$ 05, de 05/04/91 e seu uso é regulamentado pelas Portarias números 21 e 23/DEPAVE/78 e 88.

O Parque possui hoje uma das poucas reservas remanescente de Mata Atlântica da região com a presença de árvores antigas como Pau Brasil, Pau Ferro, Jequitibá, Embaúba, Castanha do Maranhão, Paineira, Canela, Sapucais. Além de outras espécies nativas como cedro, sapopemba, jequitibá-branco, jatobá, tapiá-guaçú, palmito, açoitacavalo, bico-de-pato, chichá, pau-de-tucano e vinheiro. Apresenta uma floresta heterogênea com espécies nativas e espécies exóticas provenientes de outros países como Figueira, Espatódea, Chorão, Tamareira e Seafórtia.

\subsubsection{ESCOLHA DOS PONTOS}

A fim de se verificar o efeito da vegetação sobre o microclima no Parque Trianon em São Paulo, foram realizadas medições microclimáticas com duas estações meteorológicas Campbell Scientific.

A primeira medição ocorreu entre os dias 28 de setembro e 01 de outubro de 2012, já no período de outono, mas com dados de temperatura do ar e umidade do ar muito mais próximas das condições de dias frios para a cidade de São Paulo.

A segunda medição foi realizada entre os dias 13 e 16 de novembro de 2013, sob condições climáticas já muito próximas dos dias quentes. O mês de novembro foi escolhido por proporcionar dias mais estáveis para a medição e menos períodos de chuva, se comparado aos meses seguintes de dezembro e janeiro.

A localização das estações aconteceu em dois pontos no parque: ponto 1, logo na entrada principal, em frente à Av. Paulista e ponto 2, na parte central, próximo à área do playground (Figura 51). 


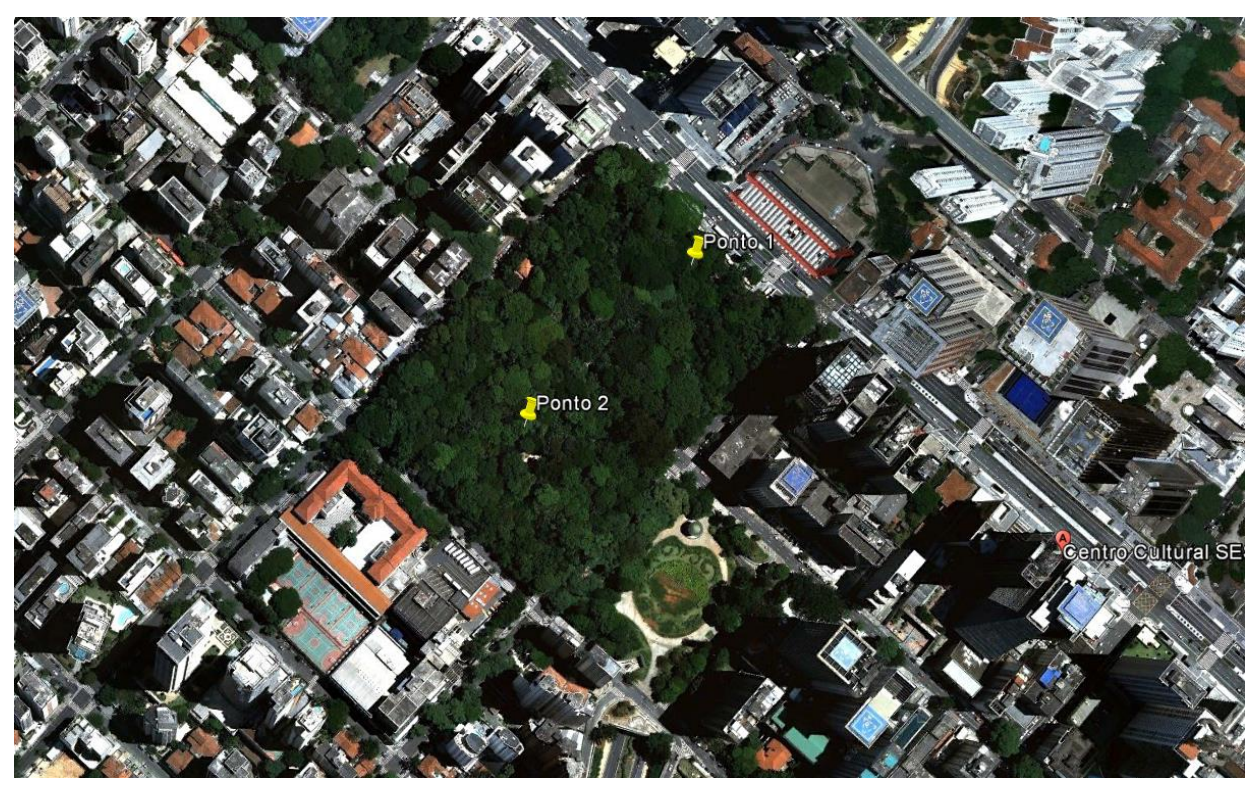

Figura 51: Localização dos dois pontos de medição no Parque Trianon.

Fonte: Google maps. Acesso em abril de 2012.

Por meio da solicitação feita à Secretaria do Verde e Meio Ambiente, foi concedida a autorização $^{35}$ ao grupo do LABAUT que permitia a realização das medições no parque ao longo de quatro dias consecutivos, incluindo o período noturno. Durante o dia houve um revezamento da equipe do LABAUT, com a participação total de 17 pessoas $^{36}$ nas duas medições, até o fechamento do parque ${ }^{37}$. Após esse horário, houve o apoio dos guardas internos do parque para a segurança dos equipamentos. As estações meteorológicas Campbell têm comunicação direta para o laptop e apresentam 6 sensores com canais para medir: temperatura do ar, umidade do ar, radiação solar global, temperatura de globo, temperatura de solo, velocidade e direção do vento. A Tabela 8 apresenta a especificação dos instrumentos presentes em cada estação meteorológica utilizada nas medições de campo do Pq. Trianon.

35 Processo administrativo 2012 - 0.226.769-2, para realizar medições no parque a partir do dia 30 de agosto de 2012 até janeiro de 2013. Uma nova autorização foi dada a partir dia 28 de agosto de 2013 até o início de fevereiro de 2014.

${ }^{36}$ Sendo que na primeira medição houve a participação de 10 pessoas ( 5 alunos de iniciação científica, 1 mestranda, 1 doutoranda, 2 voluntários e 1 professora da FAU-USP) e na segunda medição houve o apoio de 7 pessoas ( 2 alunos de iniciação científica, 2 mestrandas, 1 voluntário, 1 técnico de equipamentos e 1 professora da FAU-USP).

${ }^{37} \mathrm{Na}$ primeira medição o fechamento aconteceu às $18 \mathrm{~h}$ e na segunda o horário de fechamento do parque ocorreu às $19 \mathrm{~h}$ por conta do horário de verão. 
Tabela 8: Especificação dos instrumentos presentes na estação meteorológica Campbell

\begin{tabular}{|c|c|c|c|c|}
\hline INSTRUMENTO & MARCA/FABRICANTE & MODELO & $\begin{array}{l}\text { FAIXA DE } \\
\text { MEDIÇÃ }\end{array}$ & PRECISÃO \\
\hline \multirow{4}{*}{ globo negro } & \multirow{4}{*}{ Campbell Scientific } & \multirow{4}{*}{$\begin{array}{l}15,2 \mathrm{~cm} \\
\text { (diâmetro) }\end{array}$} & \multirow{4}{*}{$-5^{\circ} \mathrm{Ca}+95^{\circ} \mathrm{C}$} & $\begin{array}{c}\text { temp.: }-5^{\circ} \mathrm{C}--> \\
\text { tolerância: } \pm 0,14^{\circ} \mathrm{C}\end{array}$ \\
\hline & & & & $\begin{array}{l}\text { temp.: } 0^{\circ} \mathrm{C} \mathrm{a}+70^{\circ} \mathrm{C}-- \\
>\text { tolerância: } \pm 0,10^{\circ} \mathrm{C}\end{array}$ \\
\hline & & & & $\begin{array}{l}\text { temp.: }+85^{\circ} \mathrm{C}--> \\
\text { tolerância: } \pm 0,25^{\circ} \mathrm{C}\end{array}$ \\
\hline & & & & $\begin{array}{l}\text { temp.: }+95^{\circ} \mathrm{C}--> \\
\text { tolerância: } \pm 0,35^{\circ} \mathrm{C}\end{array}$ \\
\hline \multirow[t]{2}{*}{ piranômetro } & \multirow[t]{2}{*}{ Kipp \& Zonen } & \multirow[t]{2}{*}{ CMP3-L } & \multirow[t]{2}{*}{310 a $2800 \mathrm{~nm}$} & $\begin{array}{l}\text { expected accuracy for } \\
\text { daily sums: } \pm 10 \%\end{array}$ \\
\hline & & & & typical accuracy: $\pm 5 \%$ \\
\hline \multirow{3}{*}{ termohigrômetro } & \multirow{3}{*}{ Campbell Scientific } & \multirow{3}{*}{ HMP45C-L } & $\begin{array}{c}\text { temp.: }-40^{\circ} \mathrm{C} \mathrm{a} \\
+60^{\circ} \mathrm{C}\end{array}$ & $\begin{array}{c}\text { vide gráfico no campo } \\
\text { observações }\end{array}$ \\
\hline & & & --- & $\begin{array}{l}0 \text { a } 90 \%--> \pm 2 \% \\
\text { (para temp. } 20^{\circ} \mathrm{C} \text { ) }\end{array}$ \\
\hline & & & RH: 0 a $100 \%$ & $\begin{array}{c}90 \% \text { a } 100 \%--> \pm 3 \% \\
\text { (para temp. } 20^{\circ} \mathrm{C} \text { ) }\end{array}$ \\
\hline \multirow{2}{*}{$\begin{array}{c}\text { termômetro } \\
\text { (dados temp. solo } \\
\text { e globo) }\end{array}$} & \multirow{2}{*}{ CSI } & \multirow{2}{*}{108} & \multirow{2}{*}{$-5^{\circ} \mathrm{Ca}+95^{\circ} \mathrm{C}$} & $\begin{array}{c}-3^{\circ} \mathrm{C} \text { a }+90^{\circ} \mathrm{C}--> \\
\pm 0,3^{\circ} \mathrm{C}\end{array}$ \\
\hline & & & & $\begin{array}{c}-5^{\circ} \mathrm{Ca}+95^{\circ} \mathrm{C}--> \\
\pm 0,7^{\circ} \mathrm{C}\end{array}$ \\
\hline \multirow{2}{*}{$\begin{array}{l}\text { anemômetro } \\
\text { ultrasônico 2D }\end{array}$} & \multirow{2}{*}{ Gill Instruments } & \multirow{2}{*}{ WindSonic1 } & $\begin{array}{c}\text { direção: } 0^{\circ} \text { a } \\
359^{\circ}\end{array}$ & direção: $\pm 3^{\circ}$ \\
\hline & & & $\begin{array}{c}\text { velocidade: } 0 \text { a } \\
60 \mathrm{~m} / \mathrm{s}\end{array}$ & $\begin{array}{c}\text { velocidade: } \pm 2 \% \text { a } \\
12 \mathrm{~m} / \mathrm{s} \\
\end{array}$ \\
\hline \multirow{4}{*}{ datalogger } & \multirow{4}{*}{ Campbell Scientific } & \multirow{4}{*}{ CR800 } & \multirow{4}{*}{$0 \mathrm{a}+2500 \mathrm{mV}$} & $\begin{array}{c} \pm(0,06 \% \text { of reading }+ \\
\quad \text { offset }), 0^{\circ} \text { a } 40^{\circ} \mathrm{C}\end{array}$ \\
\hline & & & & $\begin{array}{c} \pm(0,12 \% \text { of reading }+ \\
\text { offset }),-25^{\circ} \text { a } 50^{\circ} \mathrm{C}\end{array}$ \\
\hline & & & & $\begin{array}{c} \pm(0,18 \% \text { of reading }+ \\
\text { offset }),-55^{\circ} \text { a } 85^{\circ} \mathrm{C}(- \\
\text { XT only) }\end{array}$ \\
\hline & & & & $\begin{array}{l}\text { **Accuracy does not } \\
\text { include sensor and } \\
\text { measurement noise }\end{array}$ \\
\hline
\end{tabular}

Fonte: LABAUT

Os sensores foram montados e instalados nos meses de julho a setembro de $2012^{38}$, realizando os ajustes necessários para a transferência dos dados do datalogger da estação para o laptop com o programa PC400 (Figuras 52 e 53). Em seguida, foram realizados testes com as estações para se verificar o funcionamento dos sensores na área externa da Faculdade de Arquitetura e Urbanismo da USP (Figura 54).

\footnotetext{
${ }^{38}$ Com o apoio da Campbell Scientific do Brasil e assistência do Eng. Agrônomo Andrea Dehó, que ajudou na configuração dos dados da estação, e da equipe de pesquisadores do LABAUT/FAUUSP.
} 

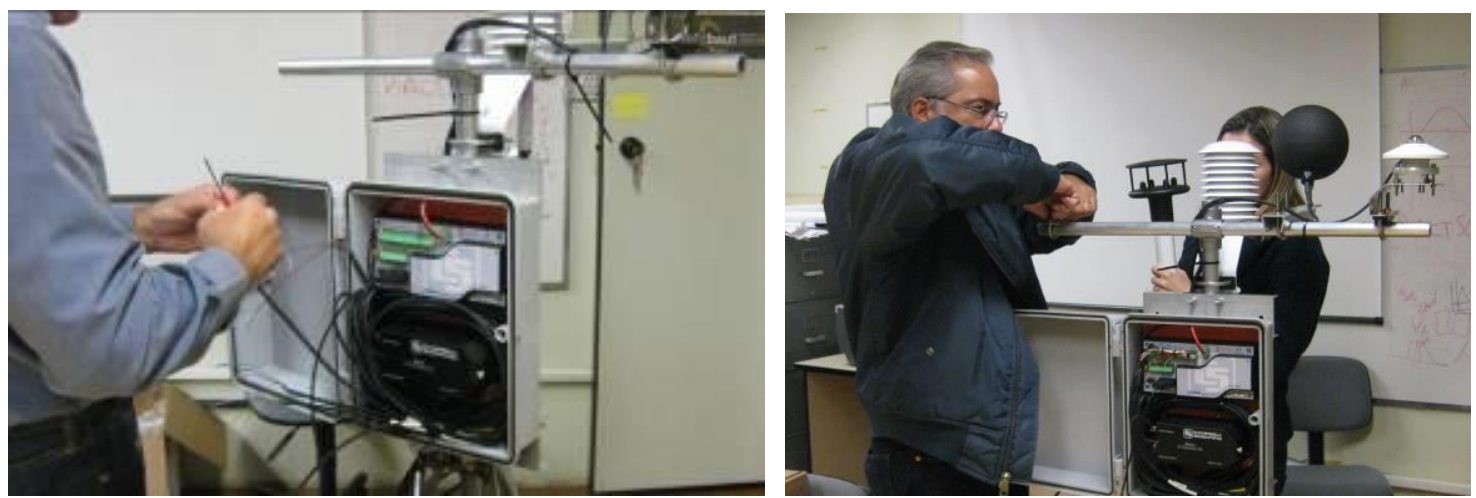

Figura 52: Montagem das estações meteorológicas Campbell.

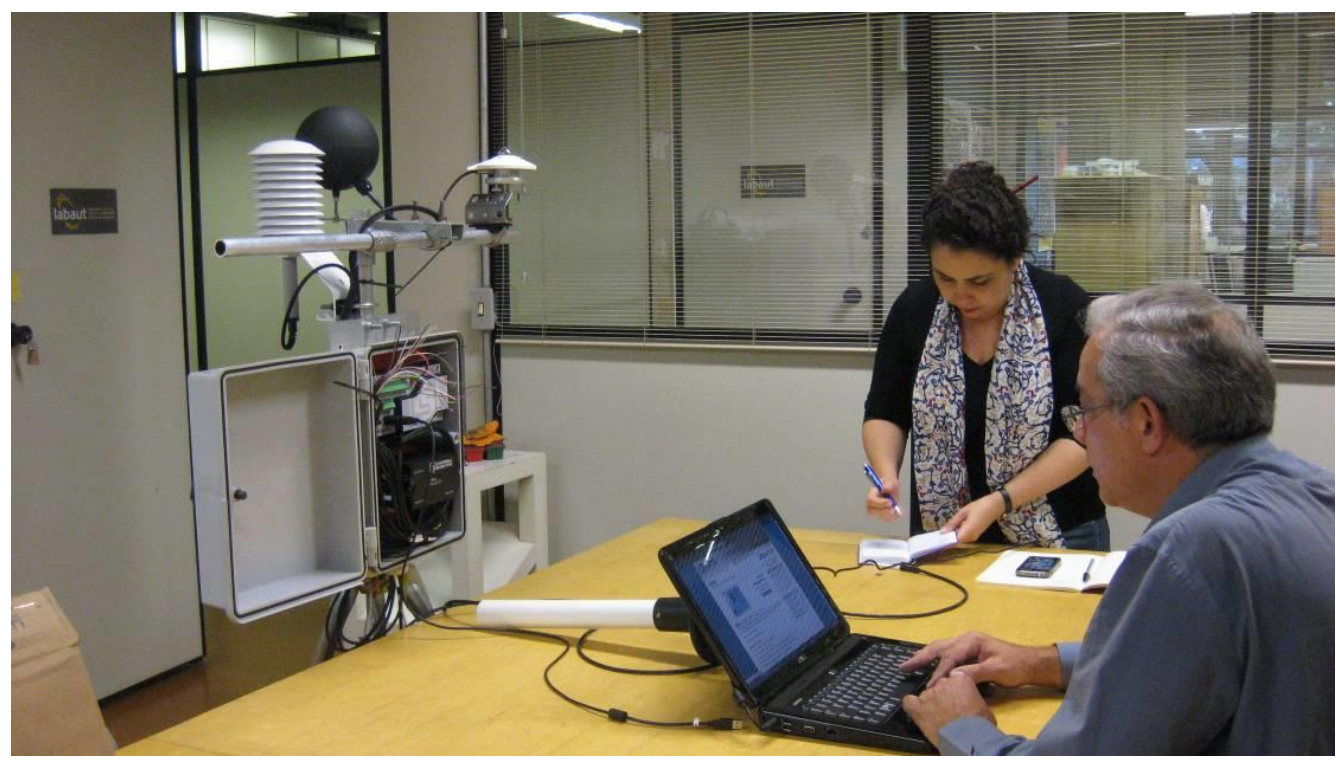

Figura 53: Ajuste na leitura dos dados medidos pela estação meteorológica.

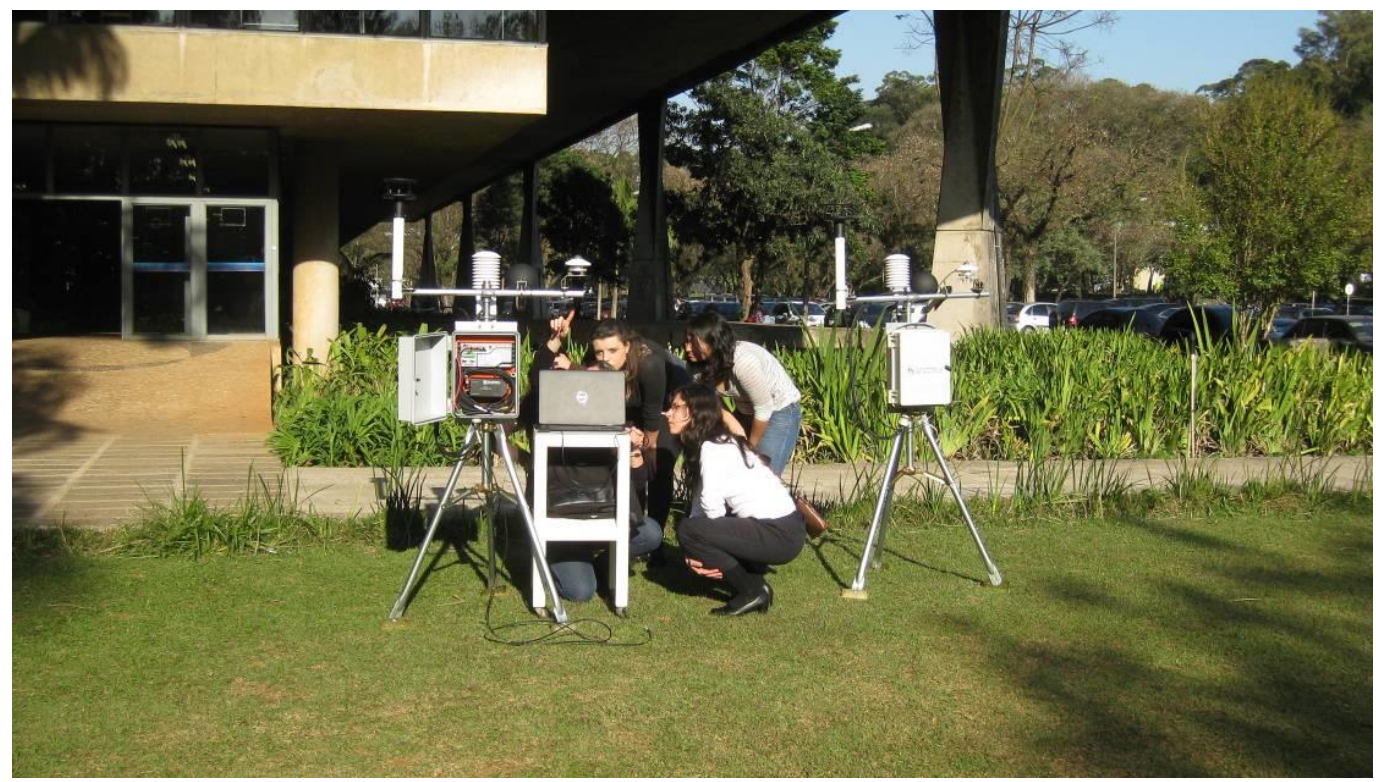

Figura 54: Teste das estações meteorológicas no Campus da USP. 


\subsection{MEDIÇÕES PARA O PERÍODO DE DIAS FRIOS}

Os equipamentos foram transportados e instalados no parque Trianon na tarde do dia 28 de setembro de 2012. Após a montagem, foram feitos alguns testes para se verificar o funcionamento dos sensores e as estações foram instaladas nos dois pontos previstos, tomando-se os cuidados com o posicionamento da estação em relação ao norte verdadeiro. $\mathrm{O}$ registro das medidas foi feito a cada 1 minuto.

A Figura 55 mostra a estação no ponto 1; esse local foi escolhido por apresentar uma vegetação pouco densa e distribuição mais espaçada, diferente da situação no ponto 2 (Figura 56), que apresenta um agrupamento maior das árvores e com copas mais densas. Os dados brutos foram armazenados em arquivos separados a cada 2 horas, e a tabulação dos dados foi feita no programa Excel, após o final de cada dia. O término das medições aconteceu às 8 h30 do dia 01 de outubro (segunda-feira) e as duas estações foram transportadas de volta até o LABAUT/FAUUSP.
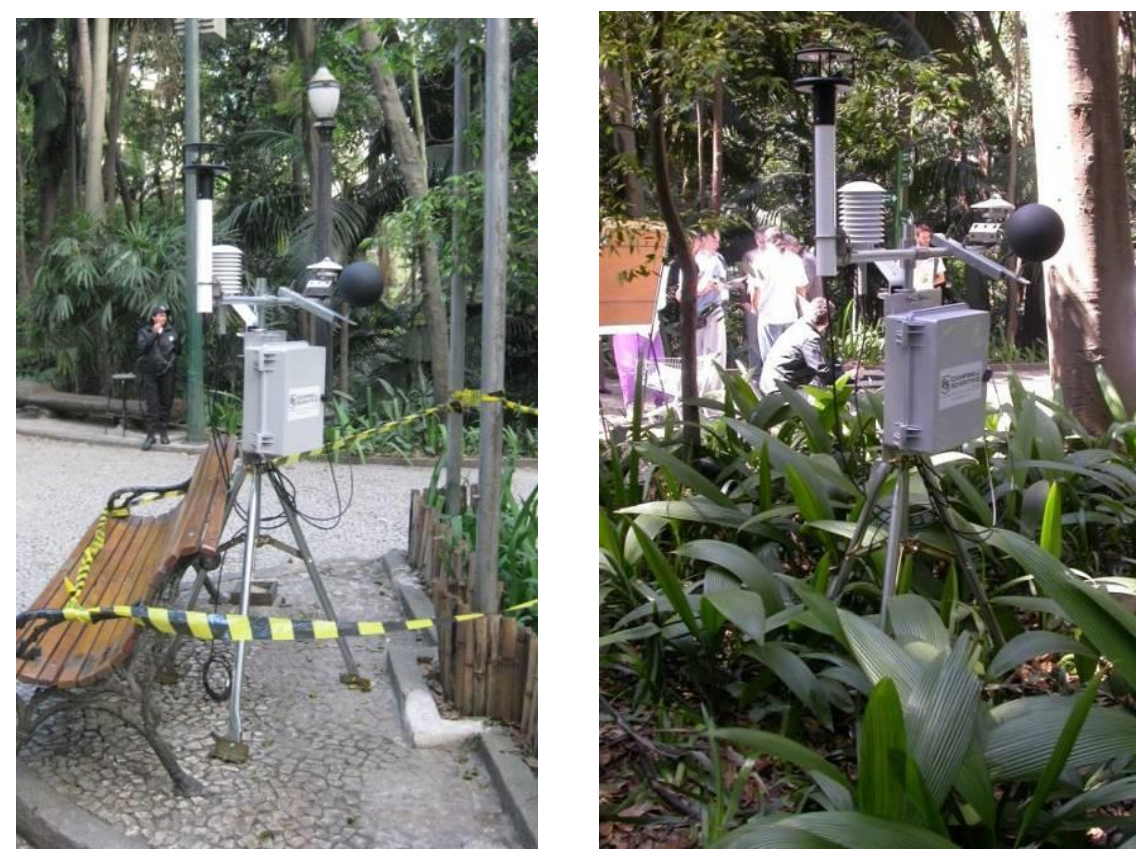

Figura 55: Localização do equipamento no Parque Trianon, ponto 1 (entrada do parque).

Figura 56: Localização do equipamento no Parque Trianon, ponto 2 (parte central). 

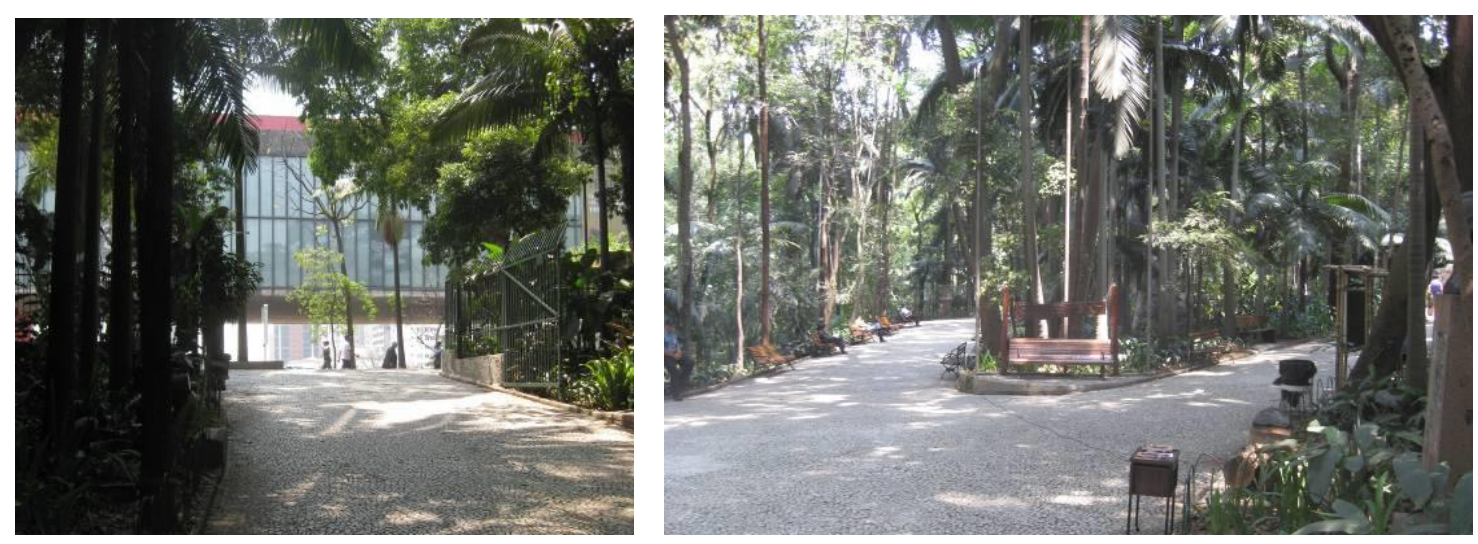

Figura 57: Entorno do ponto 1, próximo à entrada do Parque Trianon.
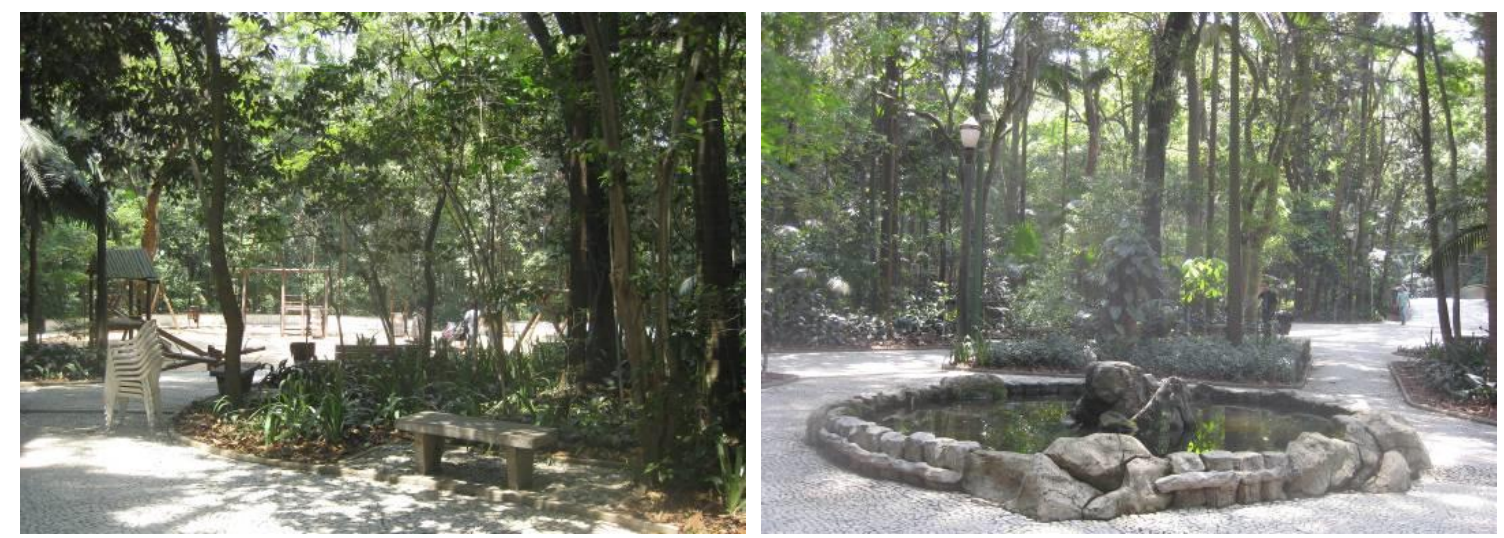

Figura 58: Entorno do ponto 2, próximo ao playground.

Ao longo dos dias de medição foram registradas fotos de fator de visão de céu para os dois pontos de medição com a câmera fotográfica digital Nikon COOLPIX 4500 com lente grande angular (olho-de-peixe) acoplada.

A Figura 59 (1) mostra o fator de visão do céu para o dia 29/09 às 8 h. O ponto onde foi colocada a estação 1, na Figura 59 (2), apresenta uma menor obstrução pela copa das árvores do Parque em relação ao ponto da estação no ponto 2 , em que a densidade e agrupamento das copas foi maior.
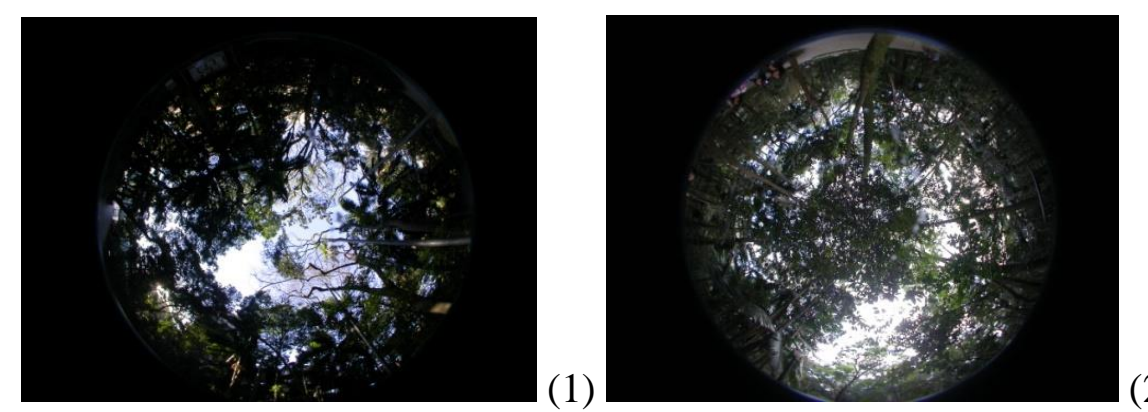

Figura 59: Visão de céu no ponto 1, próximo à entrada parque Trianon (1); visão de céu no ponto 2, próximo à parte central do parque (2) (fotos: D. Moreira). 


\subsection{MEDIÇÕES PARA O PERÍODO DE DIAS QUENTES}

Na medição feita em novembro de 2013, a estação meteorológica no ponto 1, localizada próximo à entrada principal do parque, sofreu um pequeno deslocamento em relação à posição escolhida na medição para o período de dias frios, sem mudanças significativas em relação à densidade foliar. Na época havia uma exposição e uma das peças foi posicionada no exato local da medição de agosto de 2012 (figura 60).

Manteve-se a mesma localização da estação no ponto 2, no centro do parque, em relação à medição feita em 2012. A instalação dos equipamentos aconteceu a partir das $17 \mathrm{~h}$ do dia 13 de novembro de 2013 e a intenção era medir até o dia 18 de novembro pela manhã. Porém, o término das medições aconteceu antecipadamente às $19 \mathrm{~h}$ do dia 16 de novembro devido a uma forte chuva no início da noite. Seguindo os mesmos procedimentos da medição anterior, os dados foram armazenados no datalogger a cada 1 minuto e salvos como planilha do programa Excel a cada 2 horas.

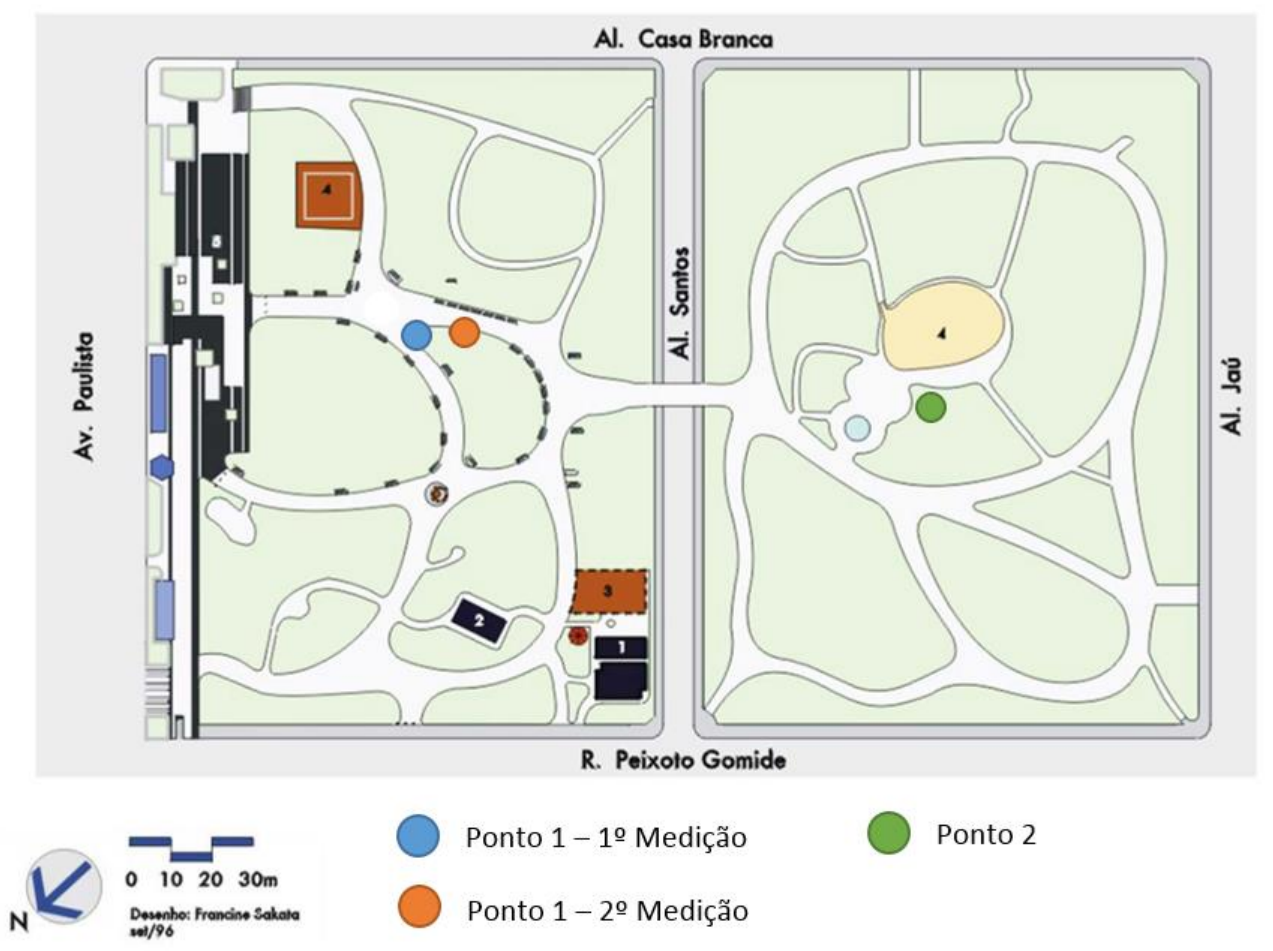

Figura 60: Localização dos pontos de medição no Parque Trianon e mudança do ponto 1. 

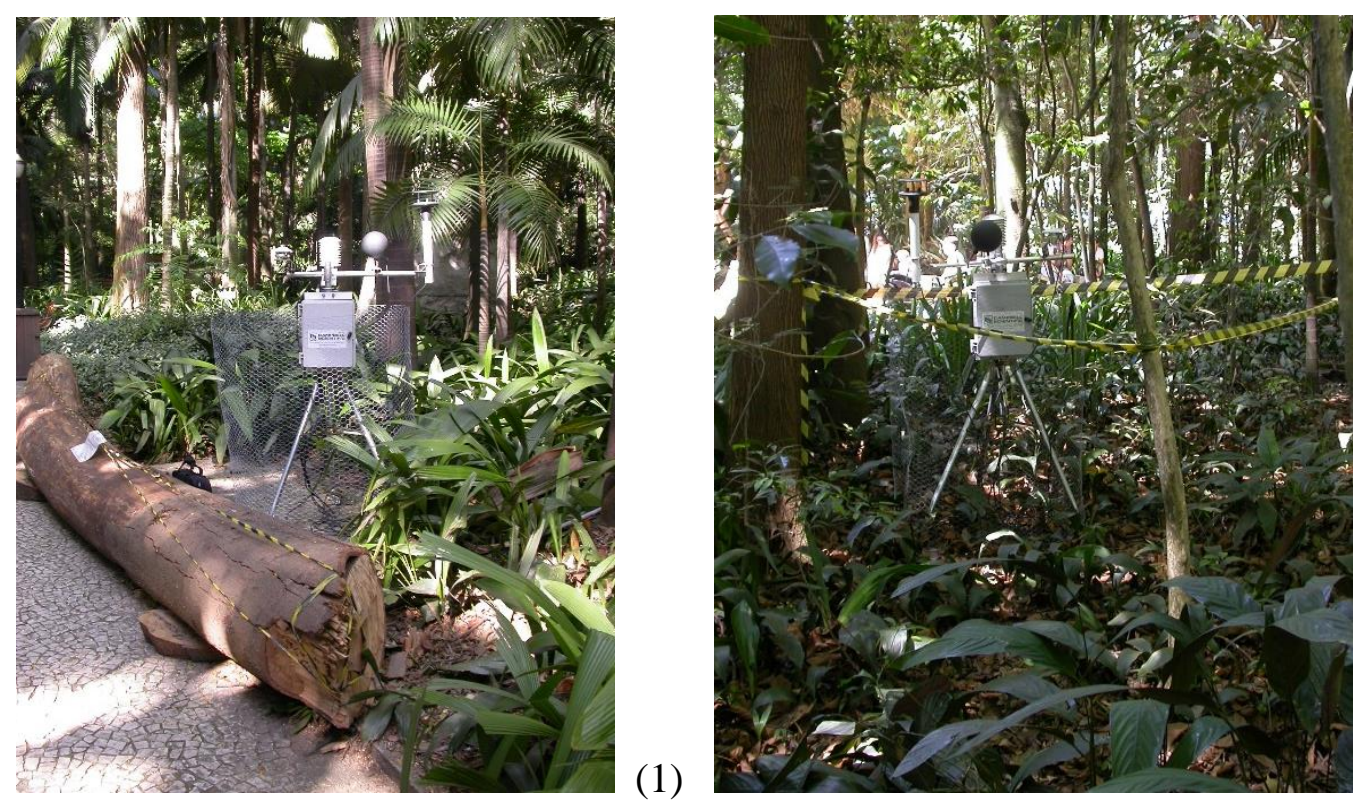

Figura 61: Localização do equipamento no Parque Trianon no ponto 1, entrada do parque (1) e ponto 2, parte central (2).

A partir das 8 h do dia 14 de novembro foi registrado o fator de visão de céu para os dois pontos de medição com câmera fotográfica digital Nikon COOLPIX 4500 com lente grande angular. Percebe-se pelo fator de visão do céu a diferença na densidade foliar entre os pontos 1 e 2 (Figura 62).
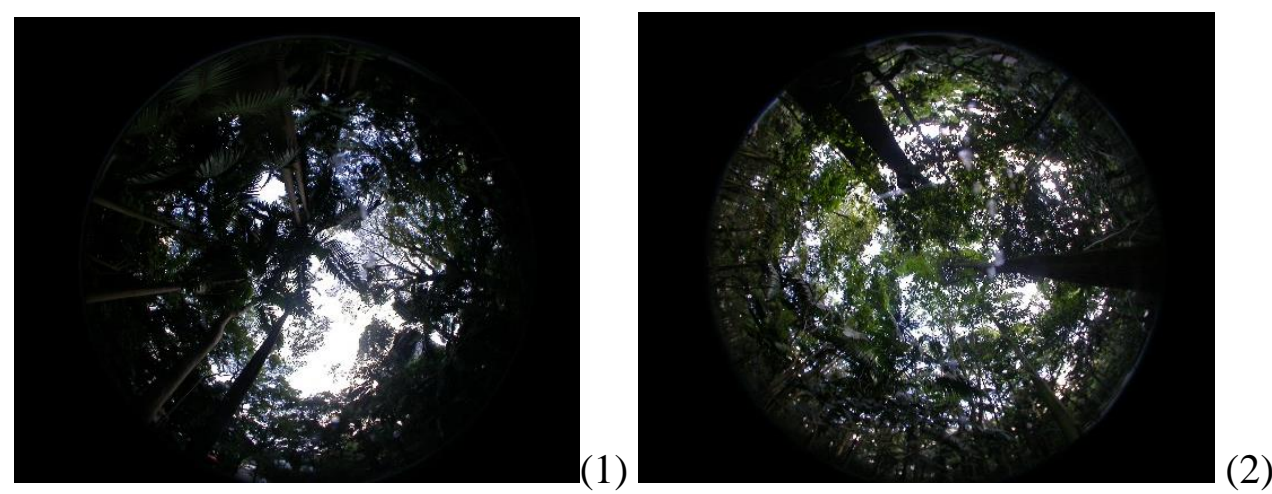

Figura 62: Visão de céu no ponto 1, próximo à entrada parque Trianon (1); visão de céu no ponto 2, próximo à parte central do parque (2) (fotos: $P$. Shinzato).

\subsection{TABULAÇÃO DOS DADOS}

Os dados obtidos foram tabulados e, a partir destes, foram gerados gráficos para cada uma das variáveis climáticas medidas e/ou calculadas: temperatura do ar, umidade 
específica $^{39}$, temperatura de solo, temperatura média radiante, velocidade e direção do vento.

A fim de se comparar os dados registrados no parque com outras estações de referência, em relação as condições de temperatura e umidade do ar, foram solicitados dados para o mesmo período a duas estações meteorológicas fixas na cidade de São Paulo:

- Estação do Instituto de Astronomia, Geofísica e Ciências Atmosferas - IAG USP. Localizada no Parque de Ciências e Tecnologia da USP, no bairro da Água Funda, zona sul de São Paulo ${ }^{40}$. Encontra-se registrada junto à Organização Meteorológica Mundial sob o número 83004. Ela é constituída de um cercado meteorológico, de um conjunto de salas no terraço do edifício da administração do parque e de uma torre no alto deste mesmo edifício. Em termos geográficos, tanto o cercado quanto o edifício encontram-se nos arredores de um marco correspondente à latitude $23^{\circ} 39^{\prime}$ Sul e à longitude $46^{\circ} 37^{\prime}$ Oeste. Foram fornecidos dados de radiação solar global, temperatura do ar, umidade relativa do ar, nebulosidade, temperatura do solo, direção e velocidade média dos ventos.

- Estação Meteorológica no Aeroporto de Congonhas, com dados fornecidos pelo Laboratório de Meteorologia Aplicada à Sistema de Tempo do Instituto de Astronomia, Geofísica e Ciências Atmosferas - IAG USP. Localizada no bairro do Campo Belo, região centro-sul de São Paulo, com as seguintes coordenadas geográficas: 23³7'34', Sul, 46³9'23', Oeste e altitude de 802 metros. Encontra-se registrada junto à Organização Meteorológica Mundial sob o número 83780. Foram fornecidos dados de temperatura do ar, temperatura no ponto de orvalho, umidade relativa do ar, pressão atmosférica, visibilidade, cobertura e altura de nuvens, direção e velocidade média dos ventos.

\subsection{ANÁLISE DOS RESULTADOS}

\subsubsection{DADOS DE TEMPERATURA DO AR}

Os dados da Figura 63 mostram valores condizentes com o período de dias frios na cidade de São Paulo, mesmo tendo sido registrados no final do mês de setembro, com

\footnotetext{
${ }^{39}$ Em grama de vapor d'agua por quilo de ar seco.

${ }^{40}$ Parque de Ciência e Tecnologia da USP - localizado na Avenida Miguel Stéfano, 4200, Água Funda, São Paulo. Informações disponíveis em:< http://www.estacao.iag.usp.br $>$. Acesso em fevereiro de 2014.
} 
temperaturas abaixo dos $11^{\circ} \mathrm{C}$ no período noturno do dia 29/09/2012. No interior do parque foi registrada uma elevação da temperatura do ar entre 6 h e $14 \mathrm{~h}$, seguida por uma diminuição da temperatura a partir desse horário, até as $6 \mathrm{~h}$ do dia seguinte. Observa-se uma amplitude térmica de $11^{\circ} \mathrm{C}$ no dia 29/09/2012 e $12^{\circ} \mathrm{C}$ no dia 30/09/2012.

Apesar das duas estações apresentarem um desenho semelhante das curvas de temperatura do ar, a estação 2 registrou, de forma consistente, temperaturas cerca de $1^{\circ} \mathrm{C}$ (margem de erro de $0,1^{\circ} \mathrm{C}$ dos sensores) mais baixas em relação à estação 1 , principalmente nos picos da temperatura máxima às $14 \mathrm{~h}$, e mínima, às $5 \mathrm{~h}$. A área onde estava localizada a estação 2 apresenta uma maior cobertura do dossel, enquanto a estação 1 estava menos protegida pela copa das árvores. Segundo as estimativas do IAF descritas no próximo capítulo, o ponto 1 apresentava um IAF médio de 1,5, enquanto no ponto 2 chegava a 3. Dessa forma, além da cobertura de solo, a densidade da vegetação também contribuiu para bloquear parte da radiação e evitar o aquecimento das superfícies.

Comparando-se com os dados do período de dias frios medidos nas duas estações de referência, a temperatura do ar registrada na estação do IAG, no Parque da Água Funda, zona sul de São Paulo, segue o perfil da curva obtida no Parque Trianon, apresentando temperaturas mais elevadas no período entre $12 \mathrm{~h}$ e $13 \mathrm{~h}$, cerca de $1,5^{\circ} \mathrm{C}$ de diferença em relação ao ponto 2, localizado na parte central do parque, densamente sombreado pela vegetação. Já os valores coletados pela estação no Aeroporto de Congonhas mostram amplitudes diárias maiores, o que é condizente com a maior exposição de Congonhas, em campo aberto, e o semi-confinamento do parque, com a vegetação dificultando as perdas de radiação noturnas. A estação de Congonhas registrou temperatura do ar de $23^{\circ} \mathrm{C}$ no dia $29 / 09$ e $26^{\circ} \mathrm{C}$ no dia $30 / 09$.

Os dados medidos no Parque Trianon para o período de dias quentes (Figura 64) mostram uma amplitude térmica de $10^{\circ} \mathrm{C}$ no dia $14 / 11 / 13$ e até $15^{\circ} \mathrm{C}$ no dia $15 / 11 \mathrm{com}$ a temperatura do ar chegando a $29^{\circ} \mathrm{C}$ no ponto 1 . As diferenças na temperatura do ar entre os pontos 1 e 2 chegou atingir $1,9^{\circ} \mathrm{C}$, no dia 15/11/13, às $11 \mathrm{~h}$. Esses dados mostram que o Aeroporto de Congonhas apresentou o maior pico da temperatura do ar registrado no período $\left(31,5^{\circ} \mathrm{C}\right.$ no dia $\left.15 / 11\right)$ e ocorreu às 15 h. Foi feita a correção do horário de verão nos dados medidos em novembro de 2013 e dos dados do Aeroporto de Congonhas (UTC+3h). 
Dados para o período de dias frios - 28/09/2012

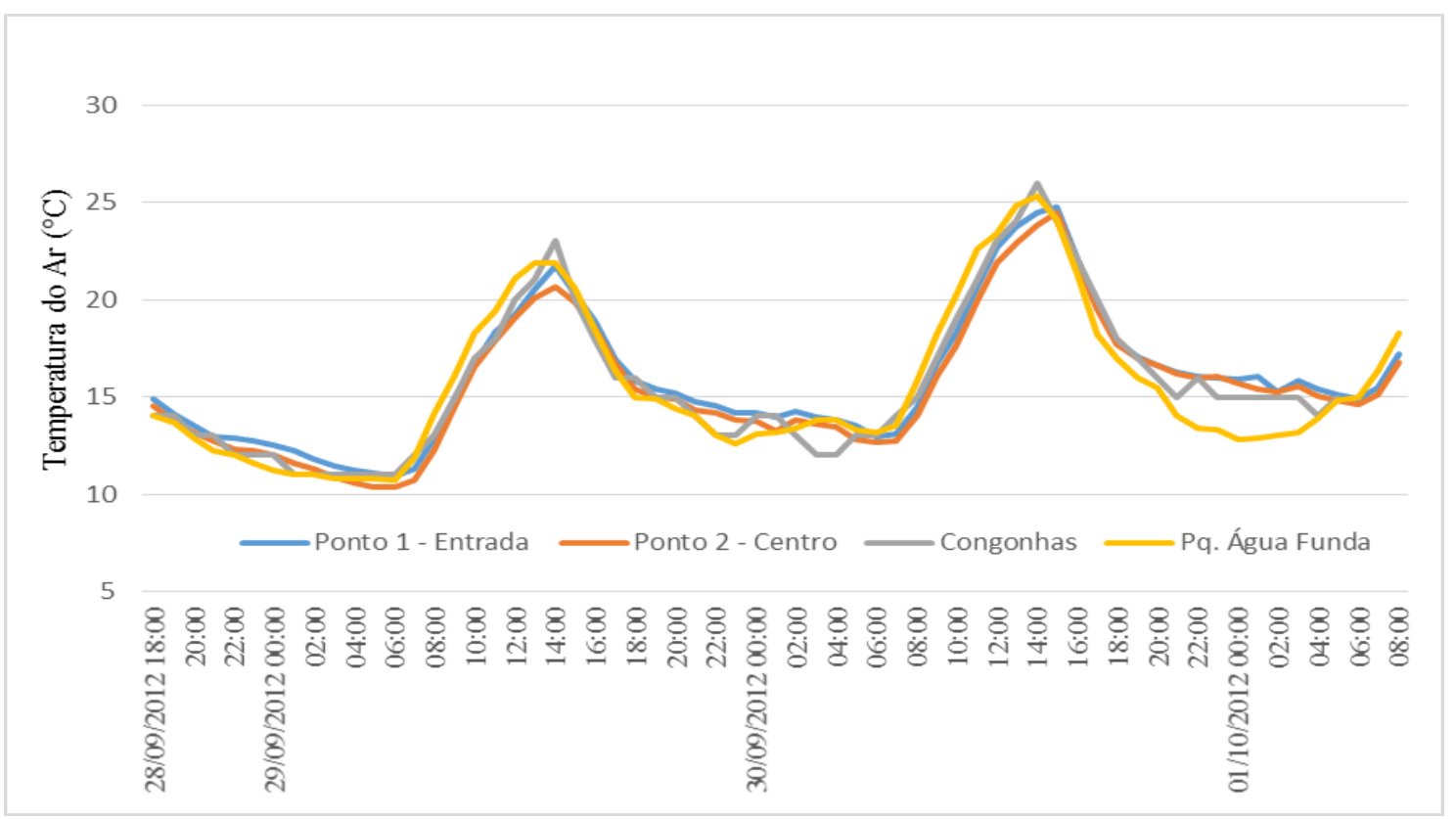

Figura 63: Temperatura do ar para as estações ponto 1 e 2; Parque Água Funda e Aeroporto de Congonhas - Dados para o período de dias frios.

Dados para o período de dias quentes- 13/11/2013

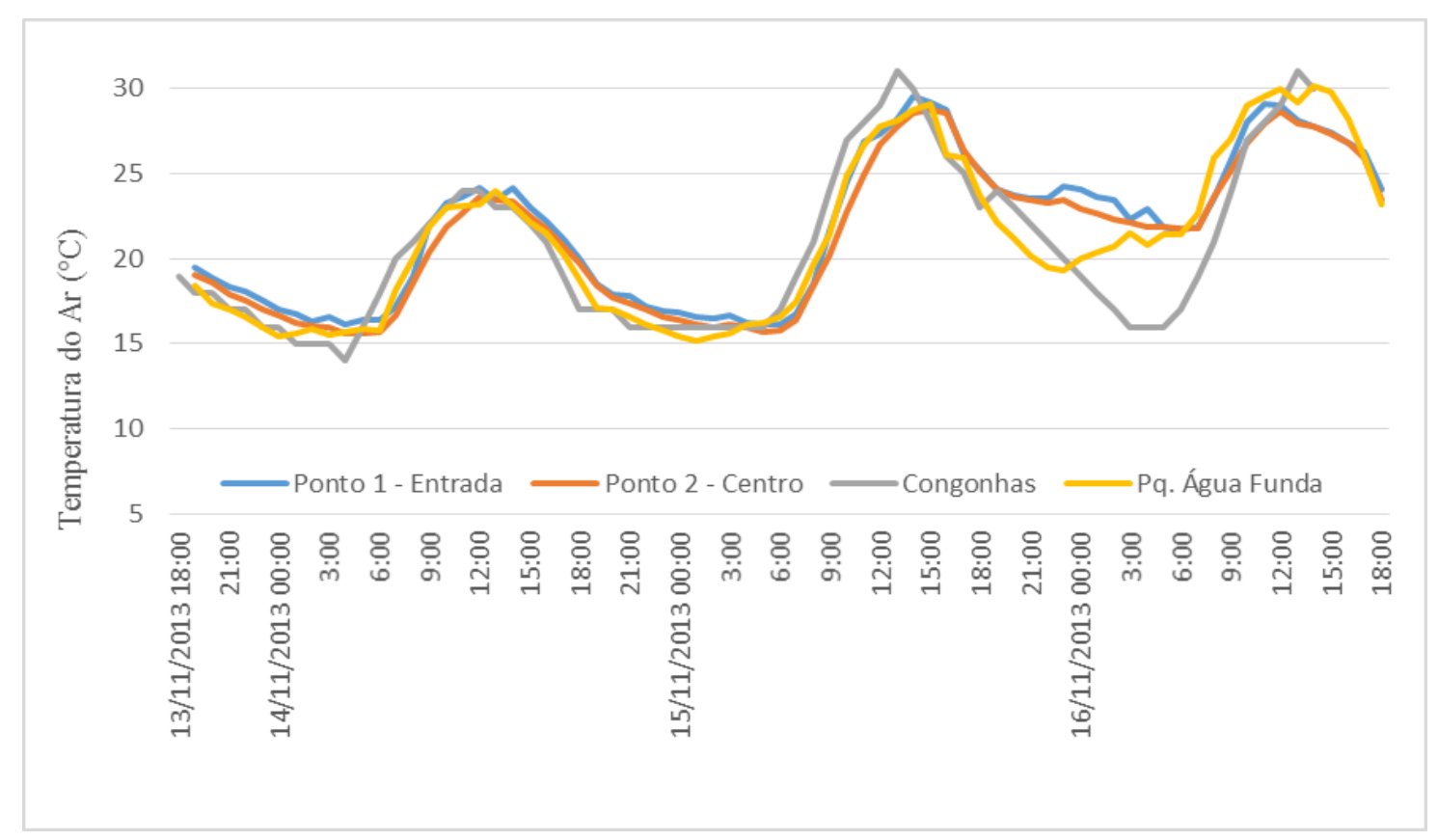

Figura 64: Temperatura do ar para as estações ponto 1 e 2; Parque Água Funda e Aeroporto de Congonhas - Dados para o período de dias quentes. 


\subsubsection{DADOS DA UMIDADE ESPECÍFICA}

Nas estações no Parque Trianon, assim como no Parque da Água Funda e Aeroporto de Congonhas, os dados medidos foram de umidade relativa do ar (\%) e para expressar melhor o conteúdo real de umidade, foram feitas conversões para umidade específica.

Os dados do período de dias frios (Figura 65) mostram poucas variações nos valores medidos nos parques e no aeroporto. No entanto, as maiores diferenças na umidade específica acontecem nos horários entre $13 \mathrm{~h}$ e $17 \mathrm{~h}$, sendo que às $14 \mathrm{~h}$ a estação no aeroporto registra o menor valor da umidade $(4,32 \mathrm{~g} / \mathrm{kg})$, enquanto as estações localizadas nos parques apresentam valores entre 7,04 e $8,62 \mathrm{~g} / \mathrm{kg}$.

Os efeitos da vegetação e da cobertura de solo na umidade são mais significativos no período dos dias quentes (Figura 66), em que as curvas medidas nos pontos 1 e 2 do Parque Trianon seguem com dados bem próximos, sendo que os valores umidade específica mais baixos aconteceram às $15 \mathrm{~h}$ no dia $15 / 11 \mathrm{com} 8 \mathrm{~g} / \mathrm{kg}$ e no dia $16 / 11$ também as $15 \mathrm{~h}$ com $7 \mathrm{~g} / \mathrm{kg}$. Durante todo período de medição o menor valor registrado da umidade foi de $5 \mathrm{~g} / \mathrm{kg}$ medido no dia $14 / 11$ às $9 \mathrm{~h}$.

Comparando as curvas de umidade nos dois parques, observamos que as estações no Parque Trianon apresentaram valores menores do que os registrados no Pq. da Água Funda, com diferenças entre $1 \mathrm{~g} / \mathrm{kg}$ e $3 \mathrm{~g} / \mathrm{kg}$, enquanto a umidade específica no aeroporto apresentou valores significativamente menores do que nos pontos do Pq. Trianon, com diferenças entre $3 \mathrm{~g} / \mathrm{kg}$ e $4 \mathrm{~g} / \mathrm{kg}$.

Segundo as informações do IAG, a umidade relativa é registrada no Parque da Água Funda a cada hora, a partir da leitura da temperatura de bulbo seco e de bulbo úmido obtida com o psicrômetro, e da pressão atmosférica observada no barômetro. O higrógrafo dotado de harpa de fios de cabelo, com rotação diária, é empregado para a estimativa da UR entre as $01 \mathrm{~h}$ e $06 \mathrm{~h}$. Ambos os instrumentos encontram-se instalados no abrigo principal do cercado meteorológico. Os valores obtidos para umidade específica no Parque Água Funda variam entre $7 \mathrm{~g} / \mathrm{kg}$ e $9 \mathrm{~g} / \mathrm{kg}$. 
Dados para o período de dias frios - 28/09/2012

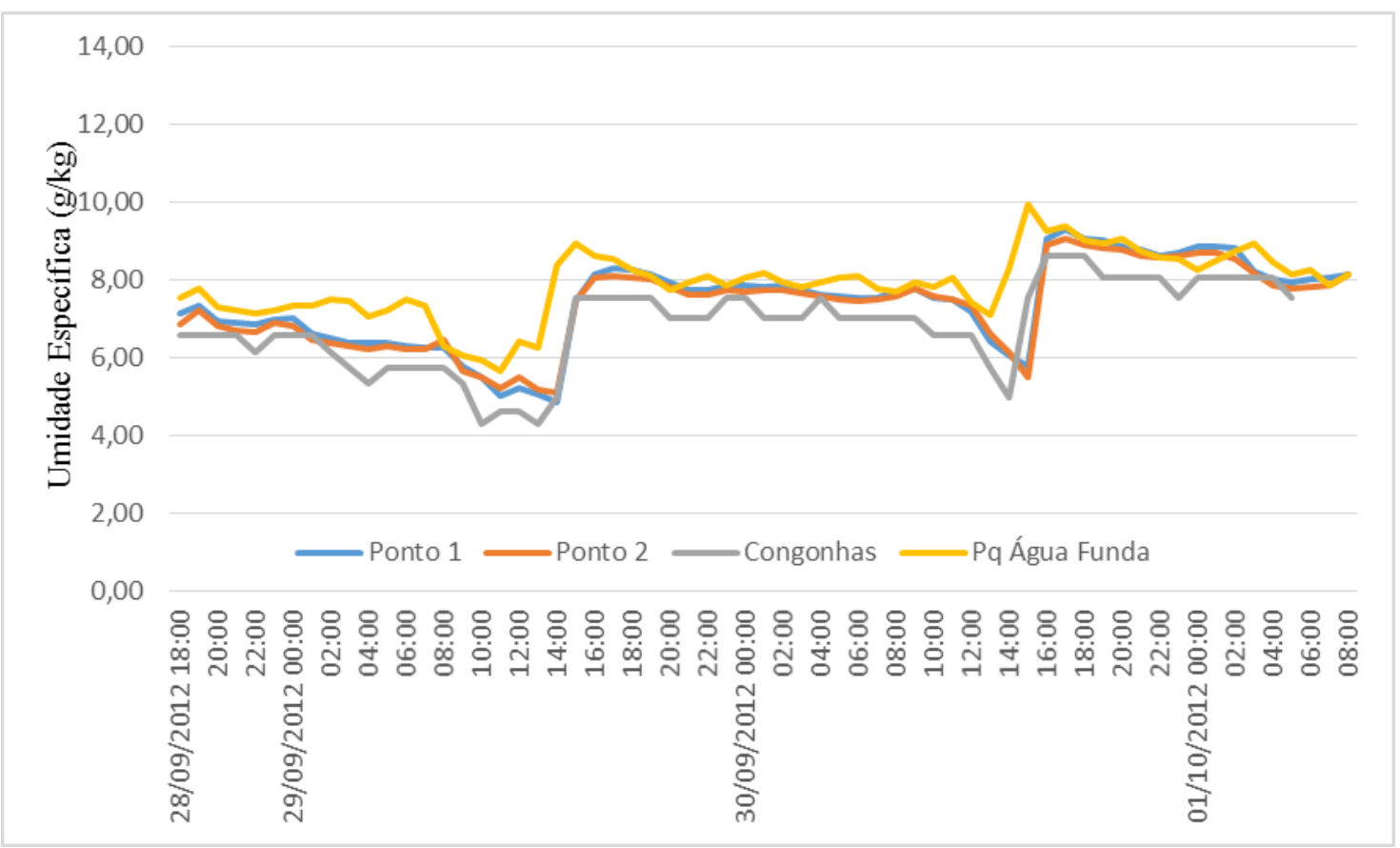

Figura 65: Umidade específica para as estações ponto 1 e 2; Parque Água Funda e Aeroporto de Congonhas - Dados para o período de dias frios.

Dados para o período de dias quentes - 13/11/2013

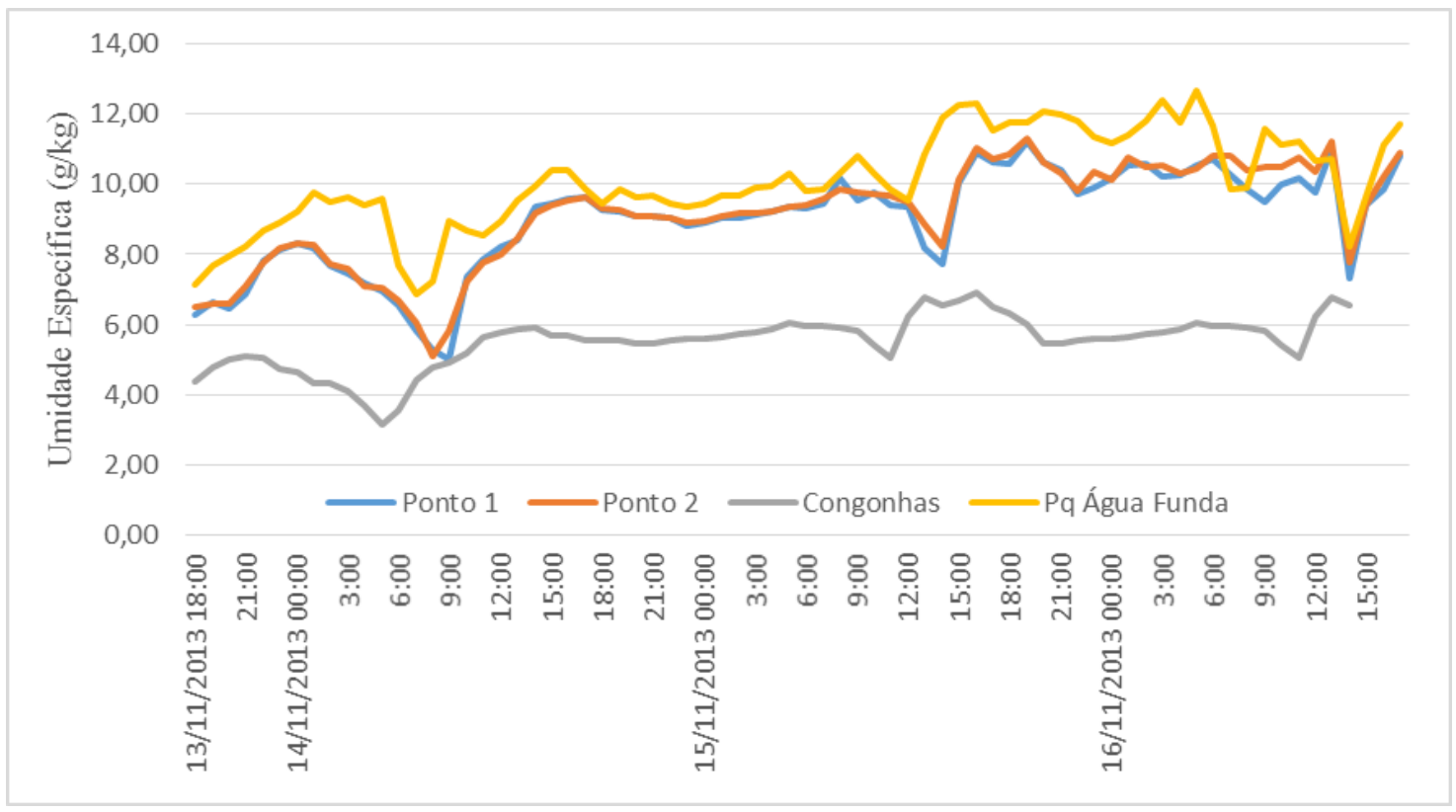

Figura 66: Umidade específica para as estações ponto 1 e 2; Parque Água Funda e Aeroporto de Congonhas - Dados para o período de dias quentes. 


\subsubsection{DADOS DOS VENTOS}

Os dados de velocidade e direção dos ventos no Parque Trianon foram obtidos a uma altura de 1,70m do piso, enquanto na estação do Parque da Água Funda e Aeroporto de Congonhas os dados foram coletados a 10m de altura.

Os dados de velocidade e direção dos ventos foram medidos no Trianon por anemômetro ultra-sônico bidimensional, modelo L24 (Campbell Scientific Inc.), a 1,7m de altura, com armazenamento de dados instantâneos da direção do vento a cada 1 minuto e registro da velocidade média nesse intervalo. $\mathrm{O}$ equipamento foi posicionado a $20^{\circ}$ à direita do norte magnético, conforme carta de declinação para São Paulo.

As Figuras 67 e 68 apresenta os dados medidos no Ponto 1, localizado próximo à entrada principal do Parque Trianon, com resultados para o período de dias frios e quentes, respectivamente. A visualização dados de direção do vento foram gerados em forma de vetor utilizando o programa Script para Plot das Componentes u e v do Vento $^{41}$ e posicionado em paralelo com os resultados para velocidade do vento para o mesmo período. Da mesma forma, as Figuras 69 e 70, mostram os resultados de para a condição do vento (velocidade e direção) para o ponto 2, localizado no miolo do parque.

De acordo com os resultados, no Ponto 1 , os valores da velocidade do vento variaram, em média, entre $0,2 \mathrm{~m} / \mathrm{s}$ e $1,2 \mathrm{~m} / \mathrm{s}$, no período de dias frios; e entre $0,1 \mathrm{~m} / \mathrm{s}$ e $1,6 \mathrm{~m} / \mathrm{s}$, no período mais quente. Em relação à orientação, houve uma predominância de ventos vindo de NE e NO, sendo que a NE está localizada a entrada do Parque pela Av. Paulista

No Ponto 2, em ambos os períodos (dias frios e quentes) a velocidade variou, em geral, entre $0,2 \mathrm{~m} / \mathrm{s}$ e $1,0 \mathrm{~m} / \mathrm{s}$. A direção do vento variou constantemente, sem uma predominância clara. A estação no ponto 1 apresenta uma velocidade média de $0,64 \mathrm{~m} / \mathrm{s}$, enquanto o ponto 2 chega a $0,54 \mathrm{~m} / \mathrm{s}$. O ponto 1 apresentou os valores mais altos do que no centro do Parque Trianon por estar menos confinado pela vegetação, mais exposto às trocas convectivas, próximo ao portão de entrada voltado à Av. Paulista.

Os dados dos ventos obtidos para as estações no Parque da Água Funda e Aeroporto de Congonhas não foram apresentados em comparação aos pontos 1 e 2 , pois a condições

\footnotetext{
${ }^{41}$ Programa em linguagem R, do autor Autor: Jonatan D. Tatsch. Os resultados forma obtido com a ajuda do Prof. Humberto Ribeiro da Rocha e pesquisador Fernando Maia, do Laboratório de Clima e Biosfera, IAG/USP.
} 
locais e posicionamento (altura) das estações são diferentes das situações encontradas nos pontos 1 e 2 .

No Parque da Água Funda, os dados são registrados por um anemógrafo instalado na torre da Estação, a 10 m de altura, sem a obstrução de edifícios ou copas das árvores no local. Dessa forma os valores foram acima dos verificados no Trianon com variações entre $1 \mathrm{~m} / \mathrm{s}$ e $9 \mathrm{~m} / \mathrm{s}$ no período de dias frios; e entre $1 \mathrm{~m} / \mathrm{s}$ e $10 \mathrm{~m} / \mathrm{s}$ nos dias quentes. No Aeroporto de Congonhas os dados de velocidade dos ventos obtidos são significativamente maiores que os medidos no Trianon, podendo chegar a $16 \mathrm{~m} / \mathrm{s}$, devido à condição de campo aberto e também pela medição a $10 \mathrm{~m}$ de altura.

Dados para o período de dias frios Pto1 - Velocidade do Vento - 28/09/2012

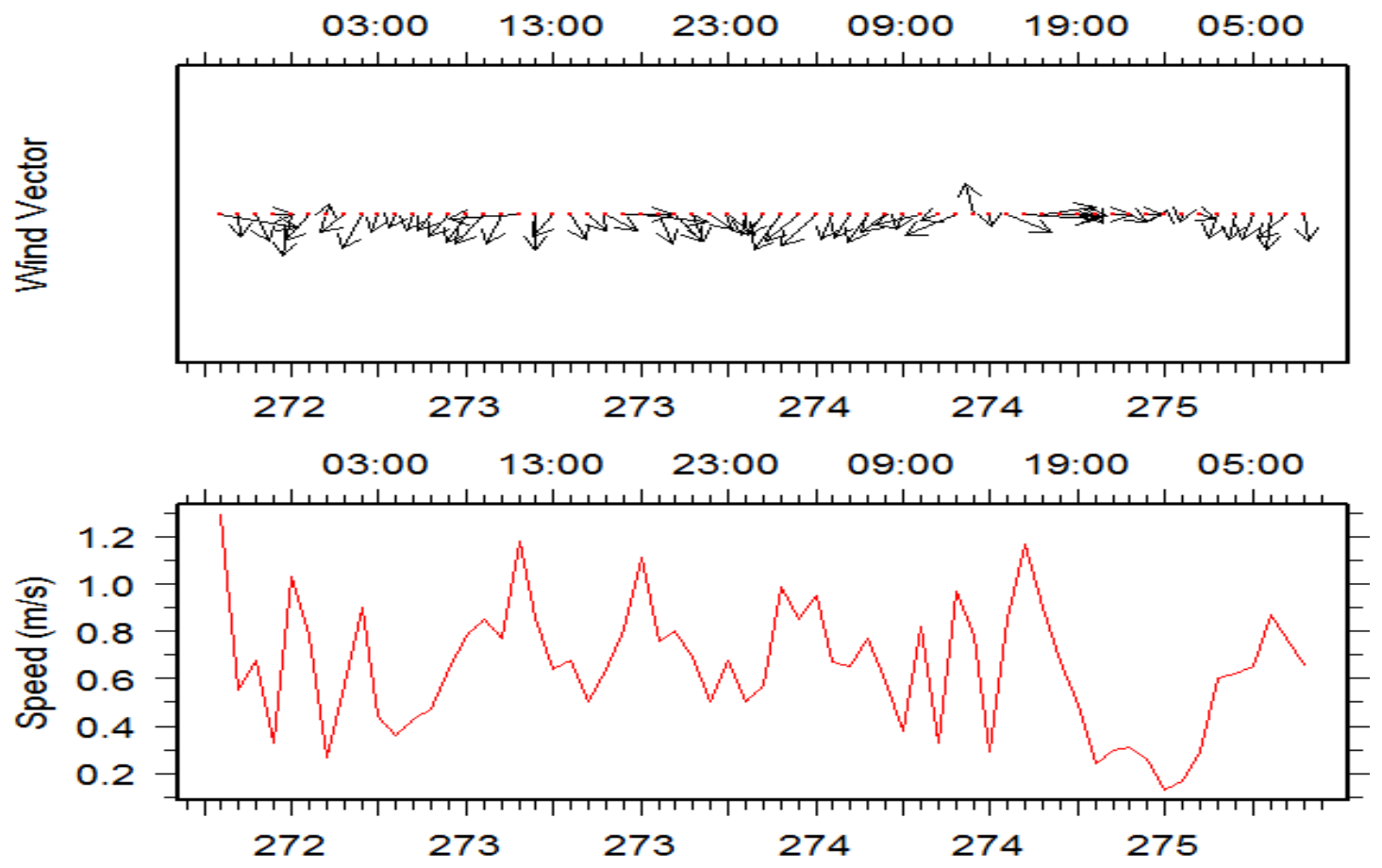

Figura 67: Velocidade do vento para as estações ponto 1 e 2; Parque Água Funda e Aeroporto de Congonhas - Dados para o período de dias frios.

Dados para o período de dias quente Pto 1 - Velocidade do Vento - 28/09/2012 

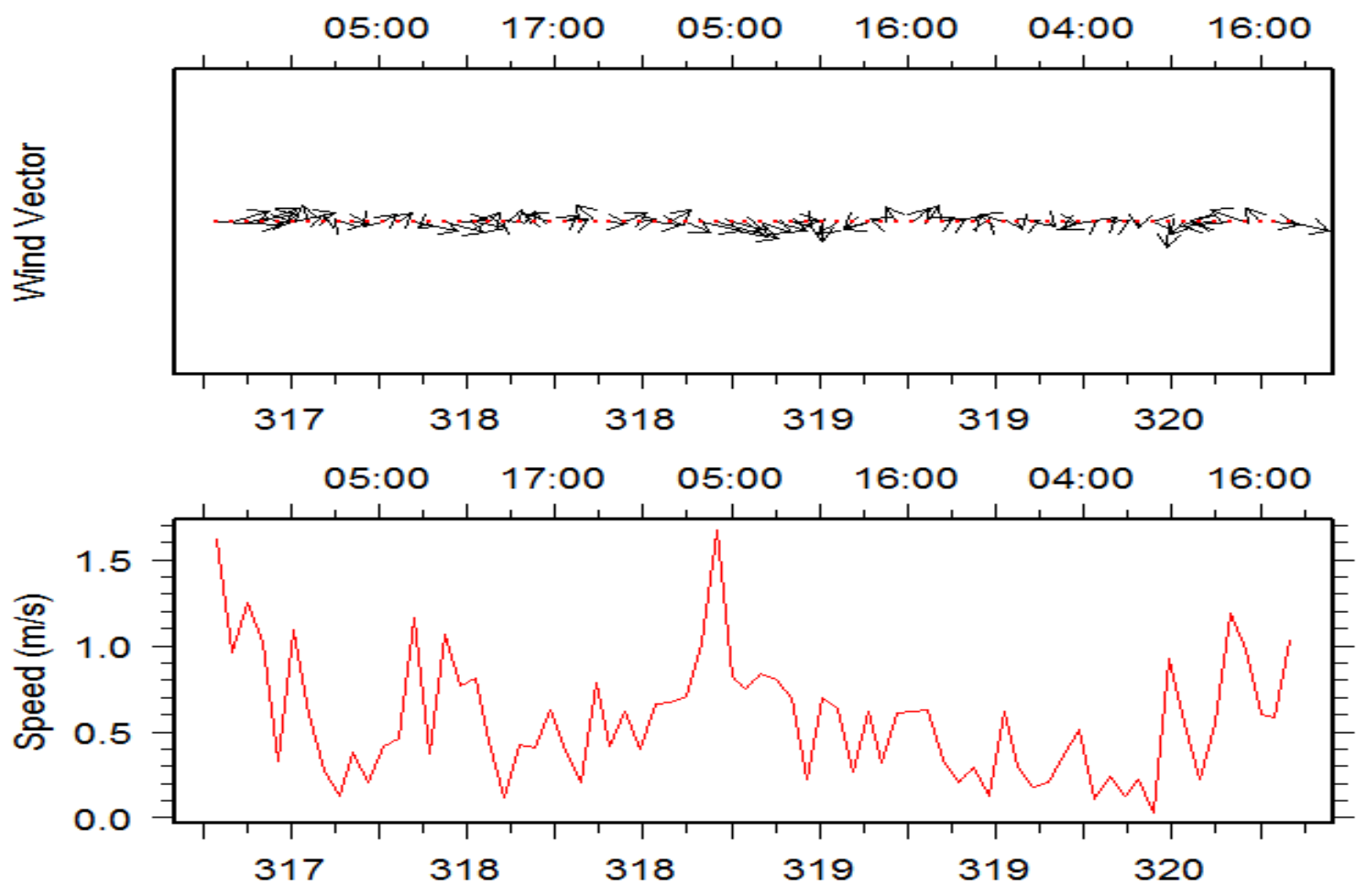

Figura 68: Velocidade do vento para as estações ponto 1 e 2; Parque Água Funda e Aeroporto de Congonhas - Dados para o período de dias quentes.

Dados para o período de dias frios Pto2 - Direção dos Ventos - 28/09/2012
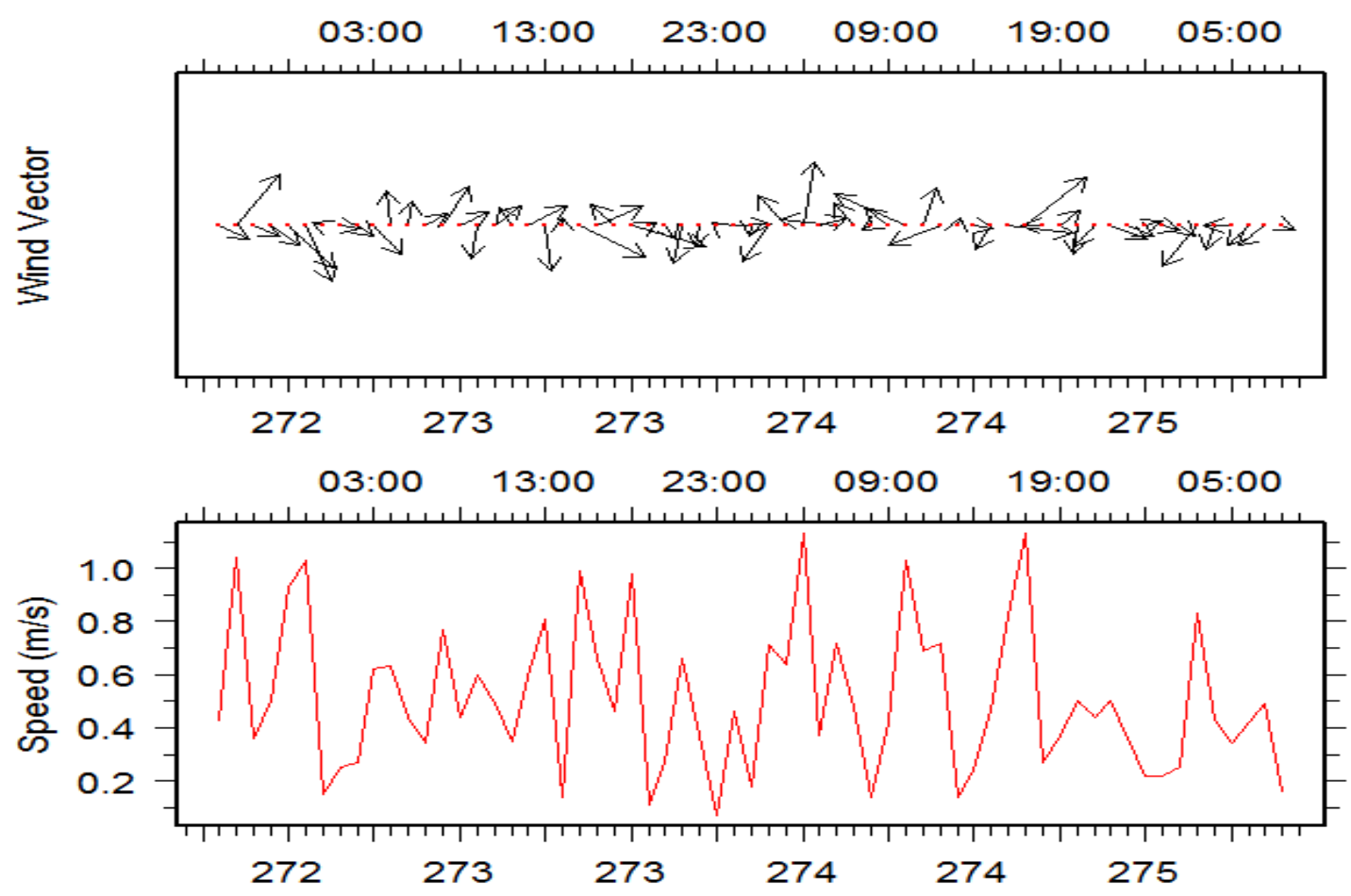

Figura 69: Velocidade do vento para as estações ponto 1 e 2; Parque Água Funda e Aeroporto de Congonhas - Dados para o período de dias quentes. 
Dados para o período de dias quentes Pto2 - Direção dos Ventos - 28/09/2012
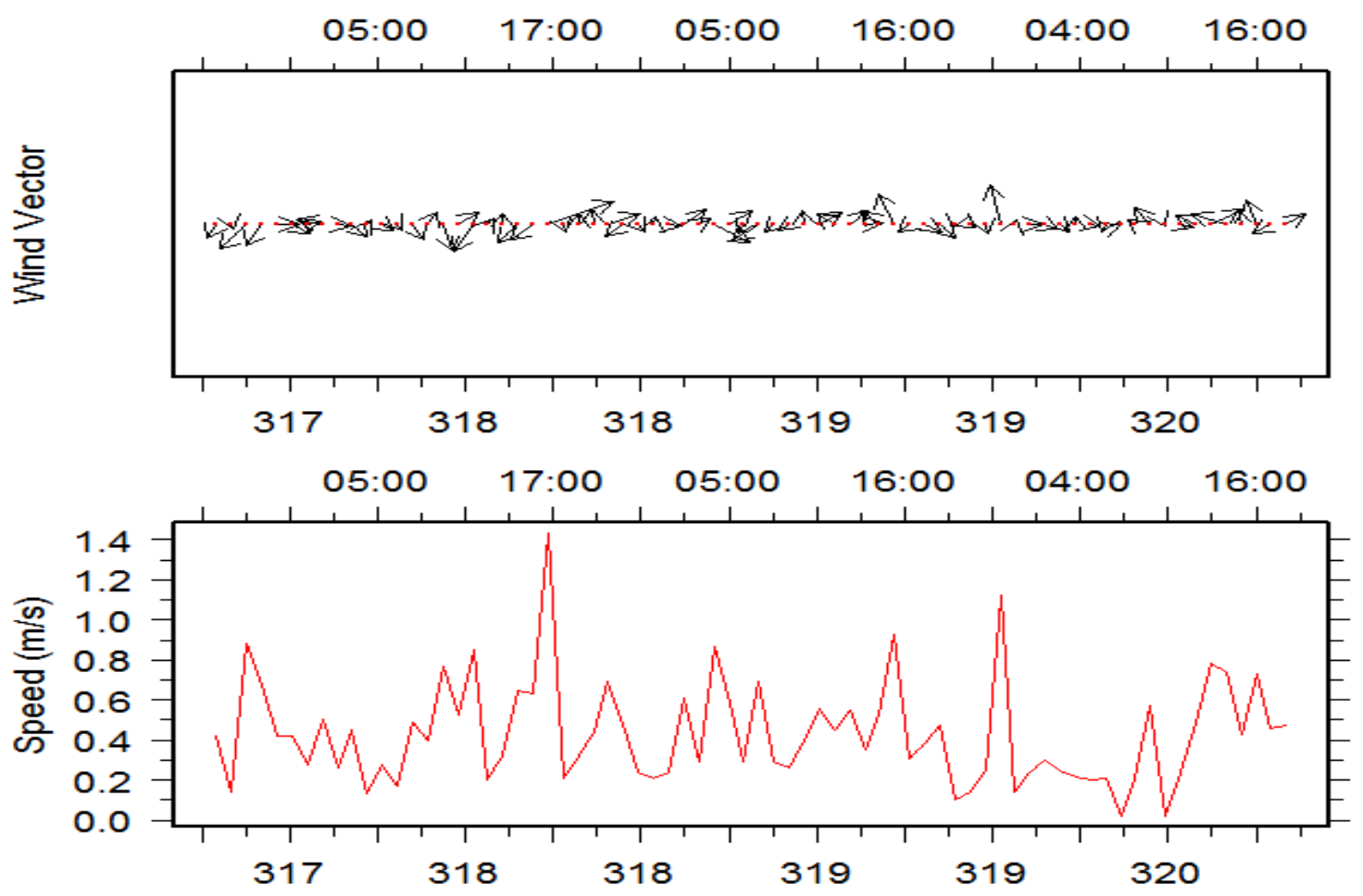

Figura 70: Direção dos ventos para as estações ponto 1 e 2 - Dados para o período de dias frios.

\subsubsection{DADOS DE TEMPERATURA DO SOLO}

O registro dos dados foi feito por um sensor posicionado no solo até uma profundidade máxima de $4 \mathrm{~cm}$ em relação à superfície. Na medição durante o período de dias frios no Pq. Trianon, as temperaturas de solo nos dois pontos tiveram poucas oscilações, variando entre $14^{\circ} \mathrm{C}$ e $17^{\circ} \mathrm{C}$.

Por outro lado, na medição no período de dias quentes (Figura 72), houve uma significativa diferença nas temperaturas medidas no ponto 1 , no intervalo entre $8 \mathrm{~h}$ e $17 \mathrm{~h}$, chegando a apresentar temperatura de até $40^{\circ} \mathrm{C}(14 \mathrm{~h}$ do dia $15 / 11)$, enquanto as temperaturas na parte central do parque variaram entre $18^{\circ} \mathrm{C}$ e $27^{\circ} \mathrm{C}$. Os dados da estação 1 para temperatura do solo mostram que houve algum erro nesse registro, uma vez que a temperatura chegou a $40^{\circ} \mathrm{C}(14 \mathrm{~h}$ do dia $15 / 11)$ e provavelmente parte do sensor ficou exposto à radiação direta. Os dados não foram considerados para configuração das simulações no modelo ENVI-met. 
Dados para o período de dias frios $-28 / 09 / 2012$

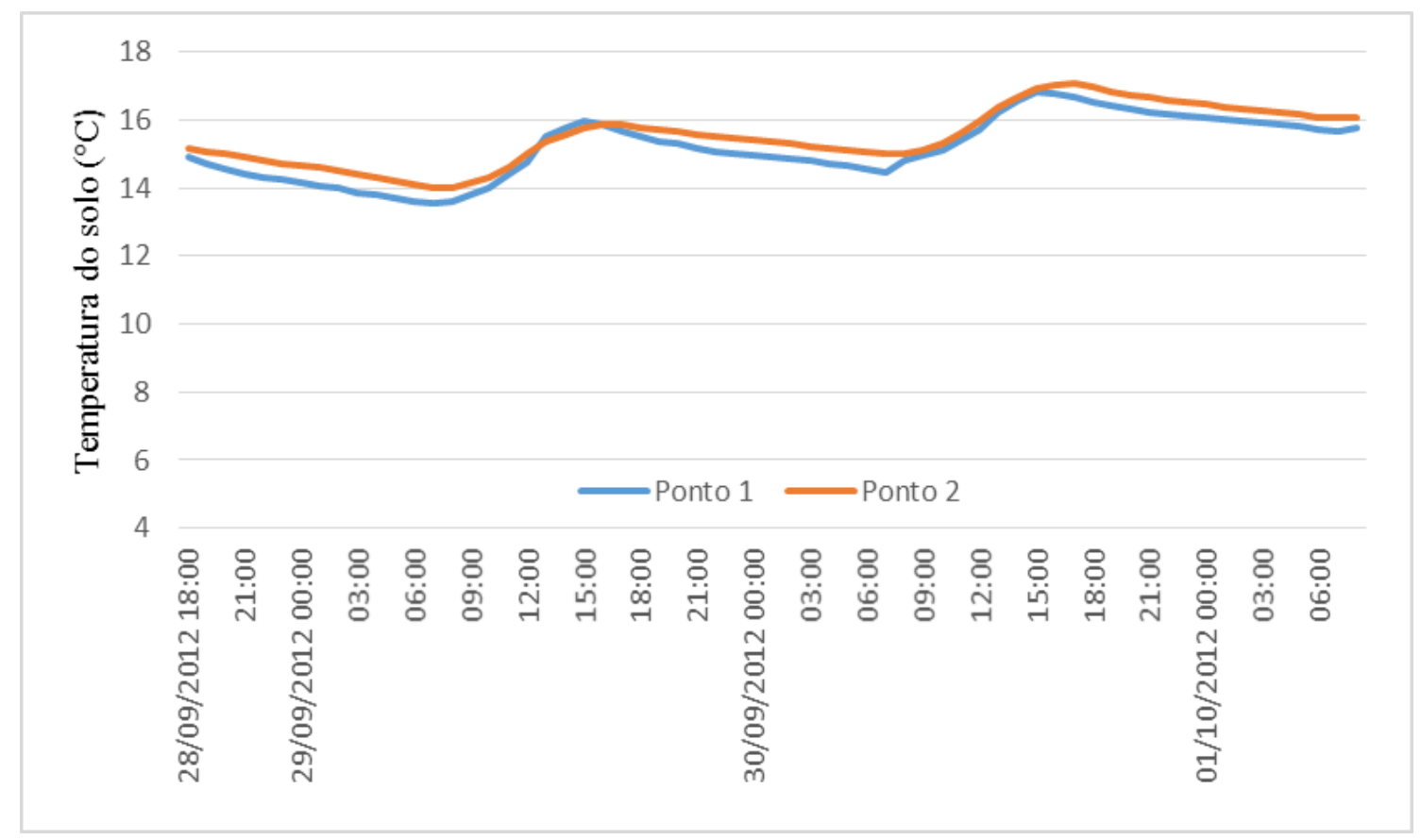

Figura 71: Temperatura de solo para as estações ponto 1 e 2 - Dados para o período de dias frios.

Dados para o período de dias quentes -13/11/2013

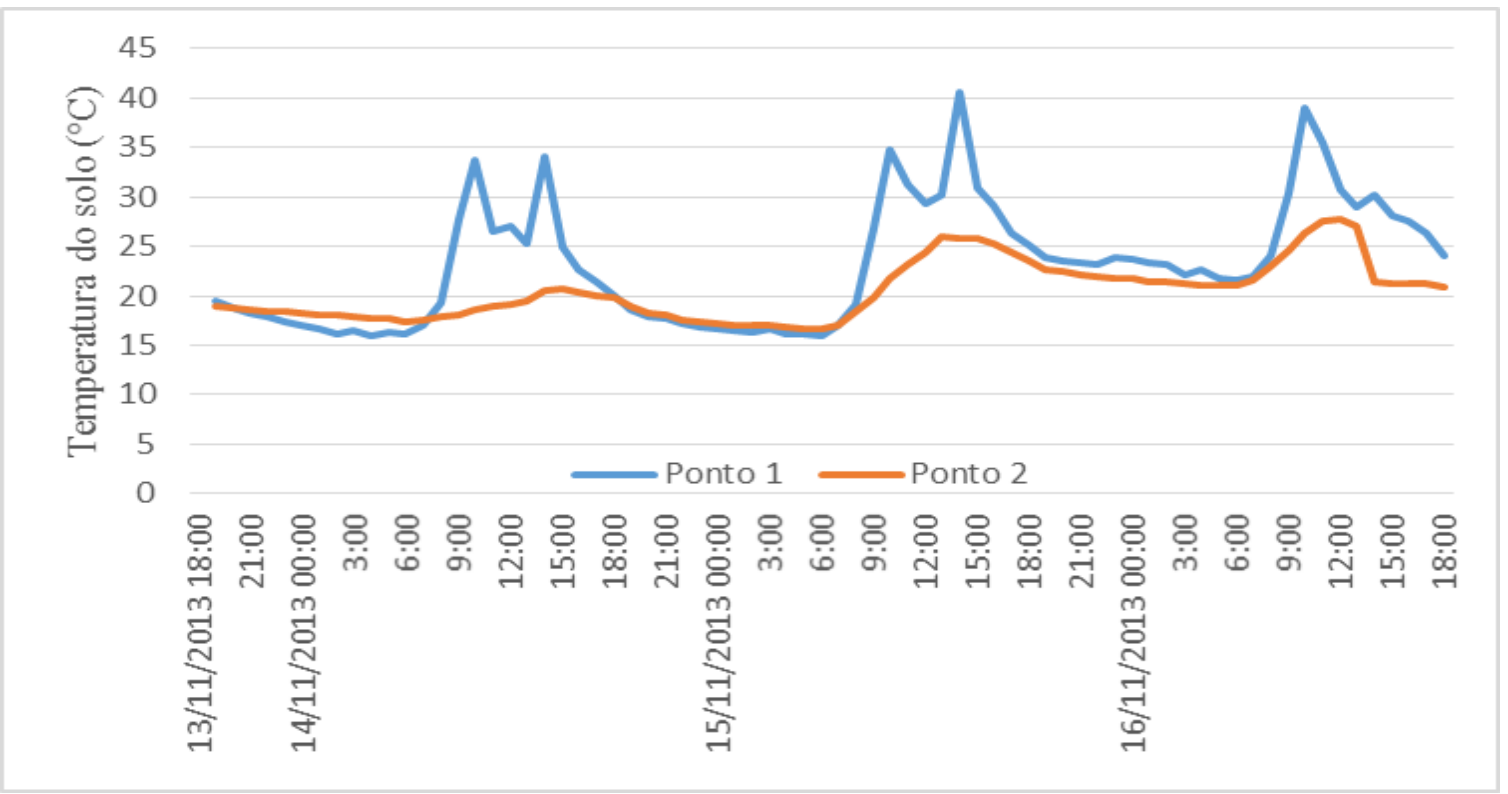

Figura 72: Temperatura de solo para as estações ponto 1 e 2 - Dados para o período de dias quentes. 


\subsubsection{DADOS DE TEMPERATURA DE GLOBO E TEMPERATURA RADIANTE MÉDIA}

A temperatura média radiante é a temperatura de um ambiente imaginário uniforme no qual a troca de calor por radiação do corpo humano é igual à troca de calor por radiação num ambiente real não uniforme. O cálculo da temperatura média radiante depende das trocas térmicas entre o globo e o ambiente, sendo expresso pelas seguintes equações de convecção natural e convecção forçada, respectivamente, (ISO 7730):

$$
\begin{gathered}
t_{r m}=\left\{\frac{\left(t_{g}+273\right)^{4}+\left[\left(0,25 \cdot 10^{8}\right)\right]}{\varepsilon_{g}} \cdot\left(\frac{\left|t_{g}-t_{a r}\right|}{D}\right)^{\frac{1}{4}} \cdot\left(t_{g}-t_{a}\right)\right\}^{\frac{1}{4}}-273 \\
t_{r m}=\left\{\left(t_{g}+273\right)^{4}-\left[\frac{\left(1,1 \cdot 10^{8} \cdot v_{a r}^{0,6}\right)}{\left(\varepsilon_{g} \cdot D^{0,4}\right)}\right] \cdot\left(t_{g}-t_{a}\right)\right\}^{\frac{1}{4}}-273
\end{gathered}
$$

Onde,

$t_{r m}=$ temperatura radiante média $\left[{ }^{\circ} \mathrm{C}\right]$

$t_{g}=$ temperatura de globo, em $\left[{ }^{\circ} \mathrm{C}\right]$

$\varepsilon_{g}=$ emissividade do globo $\left[{ }^{\circ} \mathrm{C}\right]$

$\mathrm{D}=$ diâmetro do globo em $[\mathrm{m}]$

$v_{a r}=$ velocidade dos ventos $[\mathrm{m} / \mathrm{s}]$

$\mathrm{Na}$ medição de campo foi utilizado um globo preto fosco de $15,2 \mathrm{~cm}$ de diâmetro, modelo L15 (Campbell Scientific Inc.). Os dados dos dias frios para a temperatura de globo mostram diferenças no período das $8 \mathrm{~h}$ às $14 \mathrm{~h} 30$ entre as duas estações, chegando a $5^{\circ} \mathrm{C}$ de diferença às $12 \mathrm{~h}$. $\mathrm{O}$ tipo do piso foi uma das influências, uma vez que a estação 1 foi colocada sobre a calçada de pedriscos e a estação 2 sobre o solo natural com vegetação.

Os dados dos dias quentes para a temperatura de globo mostram diferenças menores, sendo que a pequena mudança no posicionamento da estação no ponto 1 alterou o tipo do piso, passando de pedrisco (período dias frios) para cobertura com solo natural e vegetação (período dias quentes).

Os dados de temperatura radiante média apresentados foram calculados segundo a norma ISO 7726 (ISO, 1998), com a equação por convecção forçada que considera a 
velocidade dos ventos. Dessa forma, as curvas geradas tanto nos dias quente como nos dias frios para o ponto 2 (centro do parque) seguem um perfil com poucas oscilações nos valores da temperatura radiante média, enquanto no ponto 1 (entrada do parque) os dados apresentam maiores variações, principalmente no período para dias quentes.

Dados de temperatura de globo para o período de dias frios $-28 / 09 / 2012$

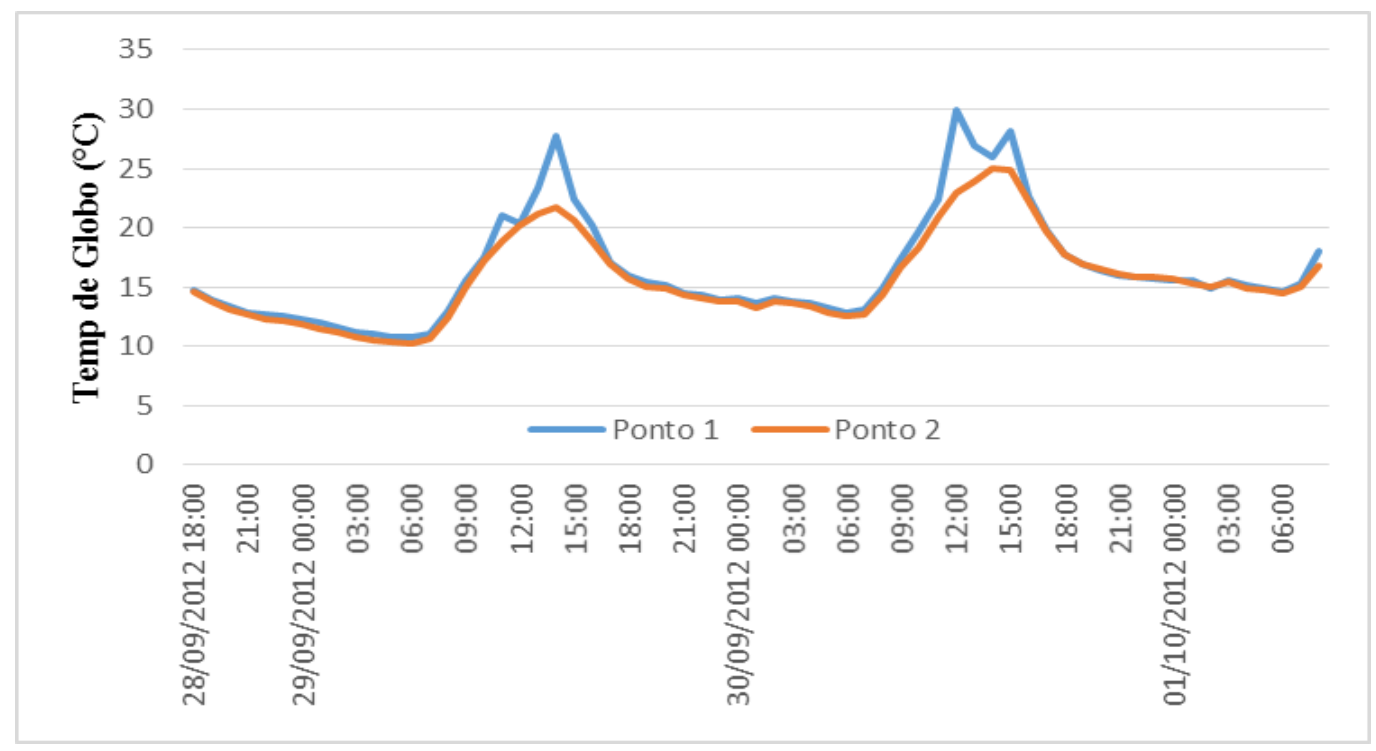

Figura 73: Temperatura de globo para as estações ponto 1 e 2 - Dados para o período de dias frios.

Dados de temperatura radiante média para o período de dias frios $-\mathbf{2 8 / 0 9 / 2 0 1 2}$

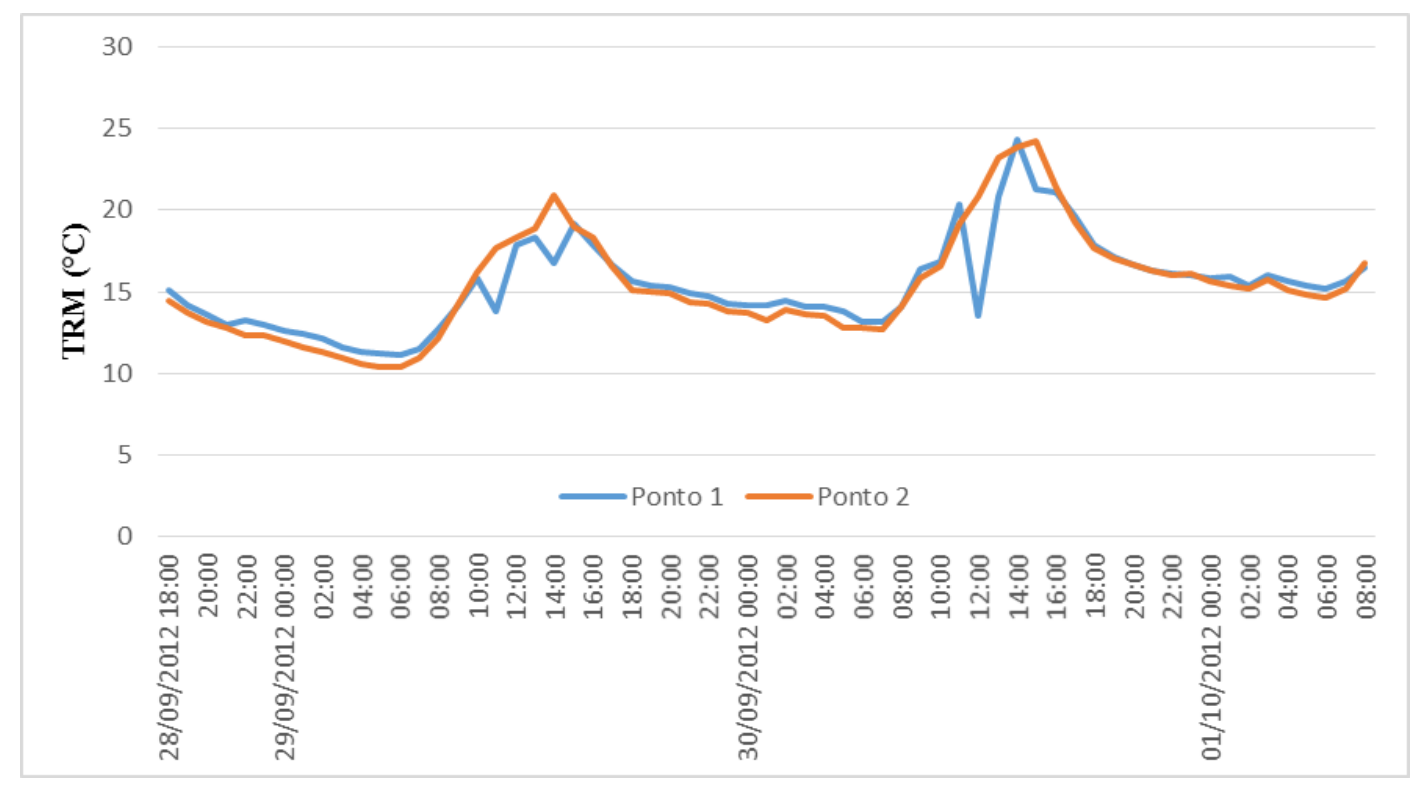

Figura 74: Temperatura radiante média para as estações ponto 1 e 2 - Dados para o período de dias frios. 
Dados de temperatura de globo para o período de dias quentes $-13 / 11 / 2013$

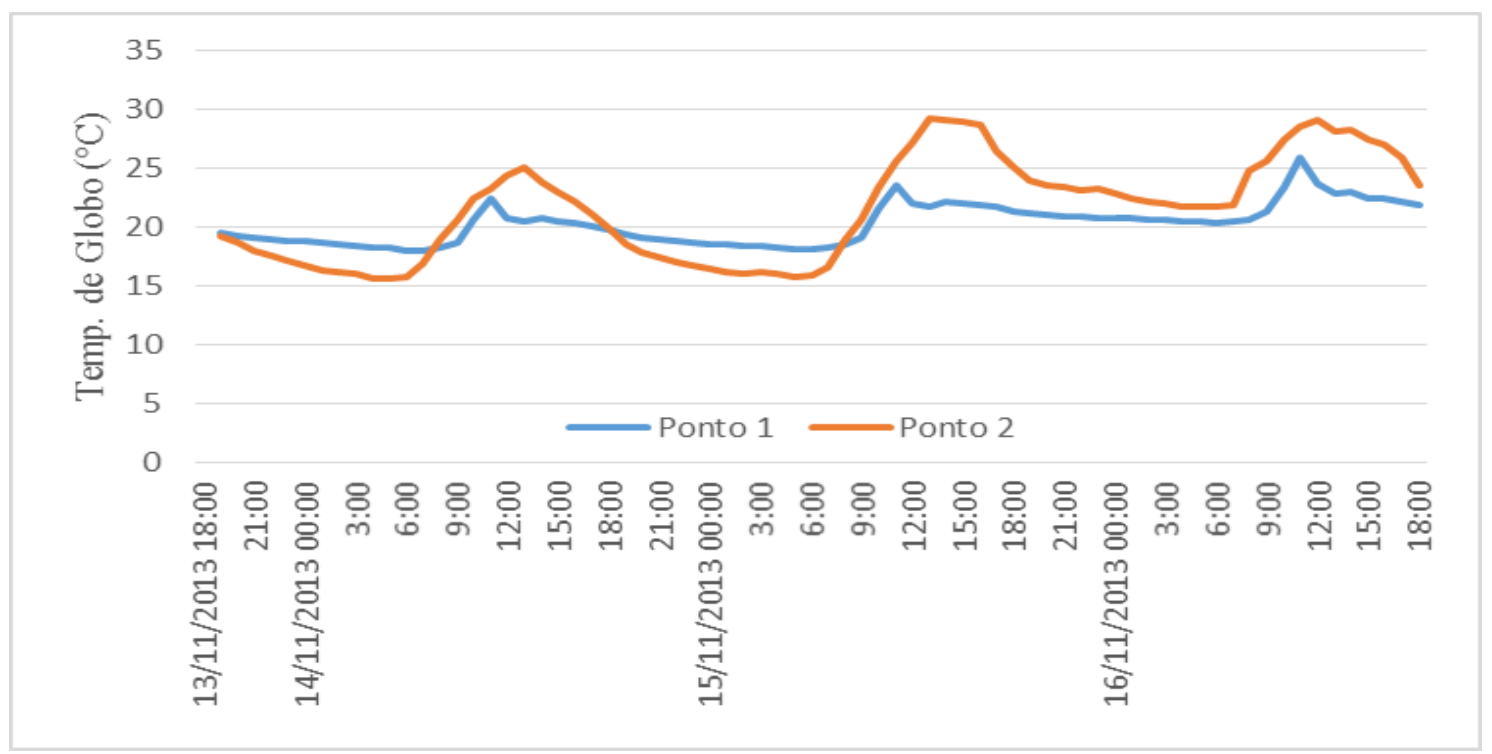

Figura 75: Temperatura de globo para as estações ponto 1 e 2 - Dados para o período de dias quentes.

Dados de temperatura radiante média para o período de dias quentes $-13 / 11 / 2013$

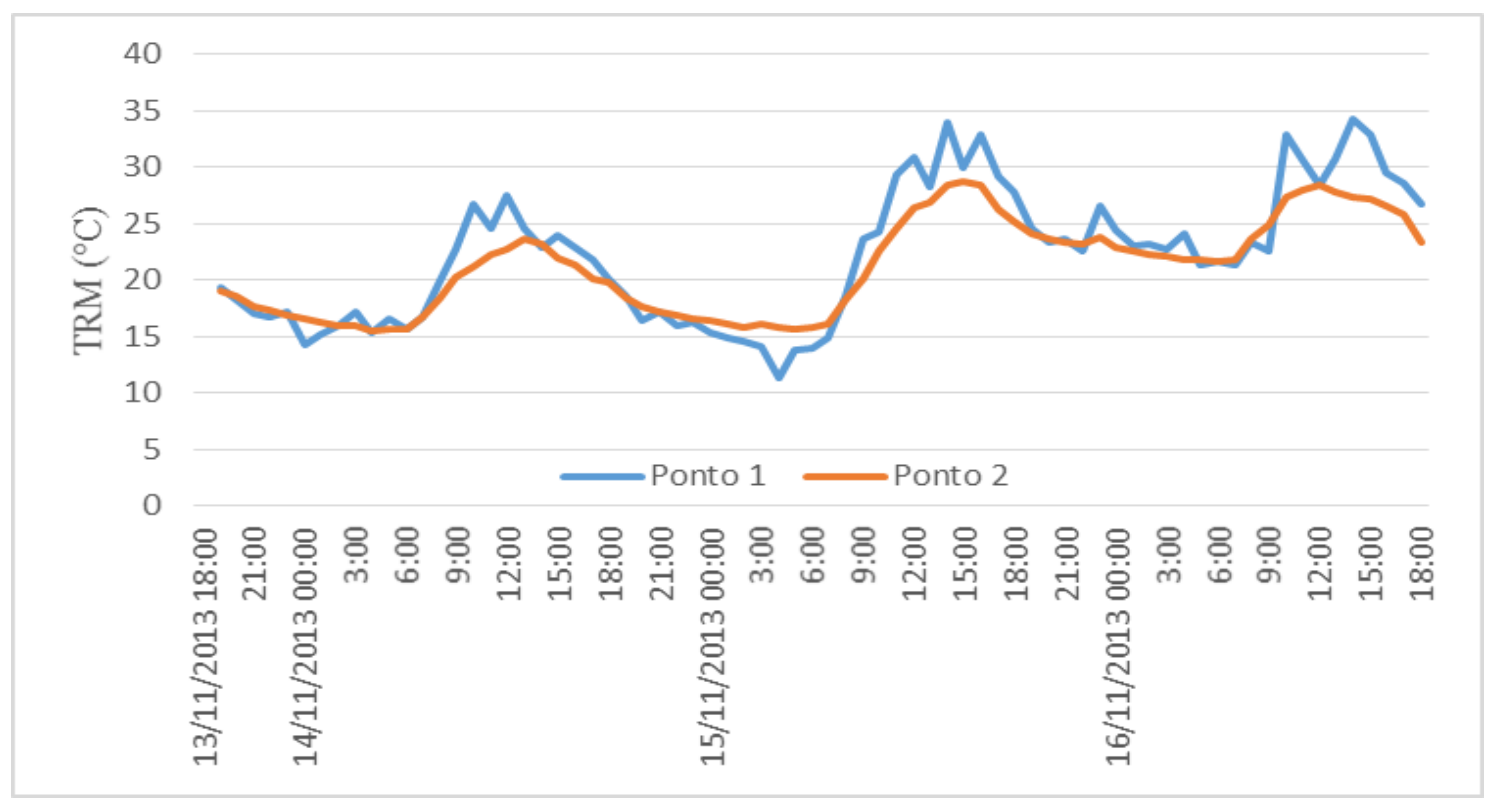

Figura 76: Temperatura radiante média para as estações ponto 1 e 2 - Dados para o período de dias quentes. 


\section{MEDIÇÕES DO ÍNDICE DE ÁREA FOLIAR - IAF NO PARQUE}

\section{TRIANON}

Conforme apresentado no Capítulo 3, os métodos de medição do índice de área foliar podem ser classificados em duas principais categorias: métodos destrutivos diretos e métodos não-destrutivos indiretos.

O método indireto considera a atenuação da radiação pelo dossel da copa, a partir da análise da distribuição geométrica das aberturas entre as folhas (Gap Fraction Distribution). Com o objetivo de estimar os valores do IAF para o Parque Trianon, foram definidas duas formas de medição: uma utilizando o equipamento LAI-2000 Plant Canopy Analyzer (LI-COR) e outra por meio da metodologia por fotos hemisféricas (WEISS et al., 2004).

A medição e levantamento dos valores de IAF serão fundamentais para complementar o banco de dados de vegetação existentes no modelo ENVI-met e contribuir para construção de modelagens mais próximas das espécies existentes no Parque Trianon.

\subsection{ESCOLHA DOS PONTOS}

No planejamento das medições, foram definidas duas áreas no parque para o levantamento do IAF (Figura 79): uma por apresentar uma massa densa de vegetação situada na parte central (Área 2) e outra em uma área pouco densa na entrada do parque (Área 1). Na parte central do parque, próximo à área do playground, a área 2 apresenta uma massa densa de vegetação, situada ao lado de uma abertura que permite a passagem livre da radiação solar. Isso possibilita a comparação dos valores medidos com o LAI2000 abaixo da copa e imediatamente ao lado desta, em local aberto, tal como recomenda o manual da LI-COR (1992).
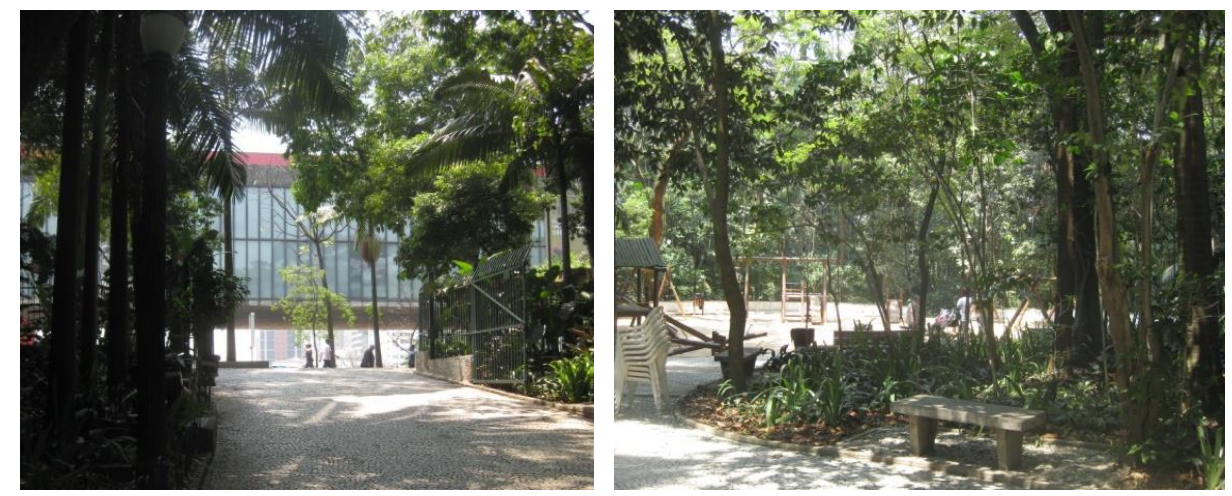

Figura 77: Entorno da área 1 no parque Trianon.

Figura 78: Entorno da área 2 no parque Trianon. 


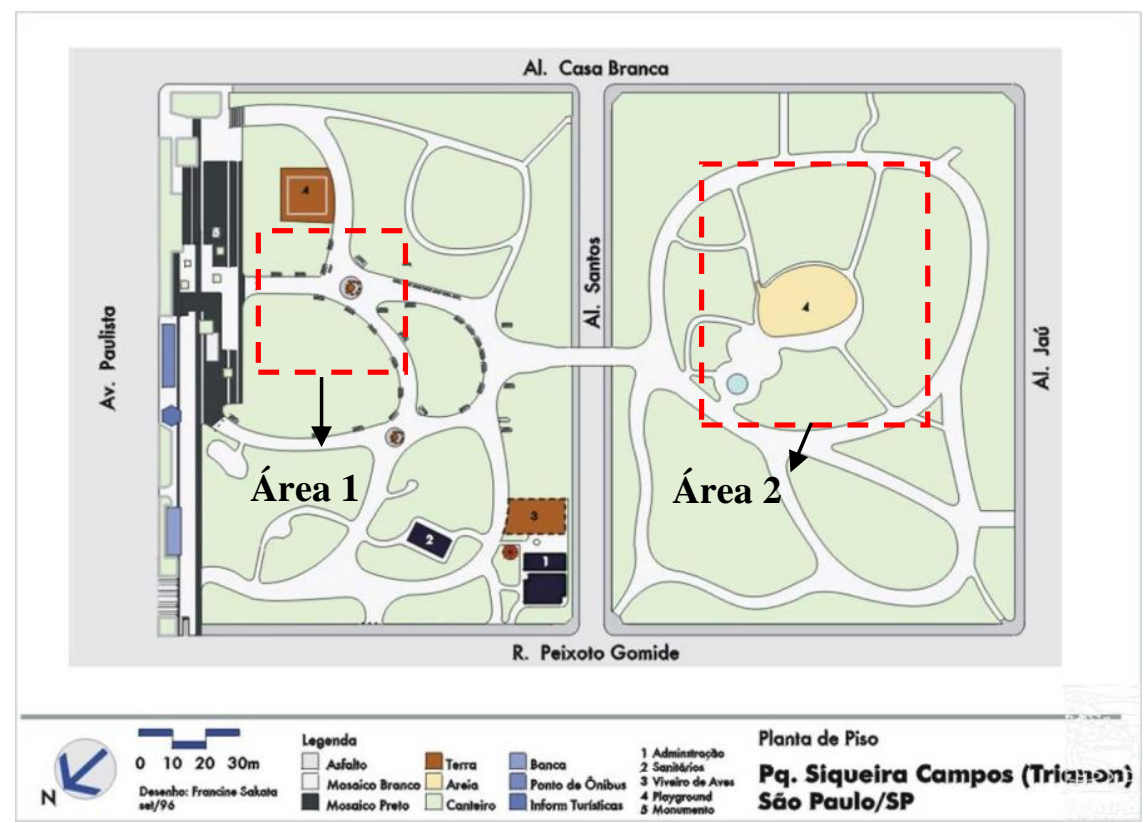

Figura 79: Localização da área com os pontos de medição no Parque Trianon, próximo ao playground.

Fonte: Mapa do Parque Trianon. ${ }^{42}$

Em seguida foi feita uma malha ortogonal dentro das áreas 1 e 2 com espaçamento de 20 x 20m para definir os 22 pontos a serem medidos no Parque Trianon, utilizando as duas metodologias (Figuras 80).

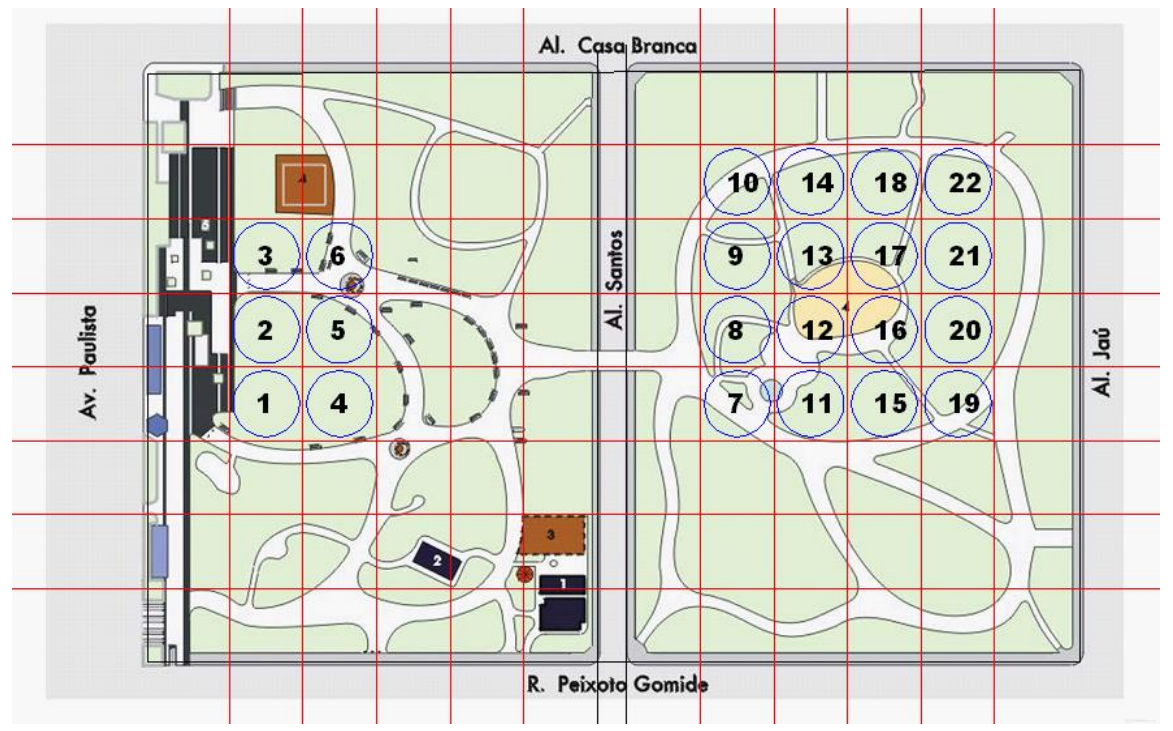

Figura 80: Posições das 22 fotos tiradas no Parque Trianon.

Fonte: Mapa do Parque Trianon. Disponível em: 〈 http://helenadegreas.wordpress.com $>$. Acesso em junho de 2012.

${ }^{42}$ Disponível em: < http://winweb.redealuno.usp.br/quapa/ > Acesso em junho de 2012. 


\subsection{MEDIÇÕES COM O EQUIPAMENTO LAI 2000}

Foram feitas medições pontuais para pré-testes de sensibilidade do equipamento LAI $2000^{43}$ no entorno da Faculdade de Arquitetura da USP, verificando o efeito das capas restritoras colocadas sob a lente do sensor. As diferentes angulações das capas restritoras permitem a visualização parcial da copa conforme os estudos de LópezSerrano et al. (2000), presentes na Figura 83.

A estimativa do IAF com o LAI 2000 foi feita utilizando-se o método do sensor único, ou seja, o mesmo sensor foi usado para coletar as leituras fora e abaixo do dossel, mantendo sempre a mesma capa restritora nas duas situações.

Segundo as instruções do manual da LI-COR (1992), em culturas e arbustos, deve-se posicionar o equipamento na parte superior e inferior da vegetação. No caso de árvores altas que não permitem medição acima do dossel, existe a possibilidade de medir em uma área descoberta, com extensões que variam de acordo com o ângulo de visão da capa restritora. Existem estudos como Nilson et al. (2011) que chegaram a construir uma torre com altura superior ao dossel para obter as medidas da radiação solar acima da copa.

Foram escolhidas para o teste as capas restritoras com ângulos de $90^{\circ}$ e $180^{\circ}$ (Figura 81). A escolha dessas capas depende do local escolhido para a medição. Como a área aberta (sem obstrução da vegetação) não tinha a extensão de 7 vezes a altura da copa, conforme recomenda LI-COR (1992), então as capas mais apropriadas foram as de $90^{\circ}$ ou $180^{\circ}$. A capa com ângulo de $90^{\circ}$ pode medir a radiação incidente em uma área de alcance de até 3 vezes e meia a altura da árvore (figura 82e), e comparar, no mínimo, com as medidas de 4 pontos abaixo da copa (figura $82 \mathrm{f}$ ).

43 O equipamento utilizado LAI-2000 Canopy Analyser foi cedido pelo Laboratório de Silvicultura Urbana, Departamento de Ciências Florestais da Escola Superior de Agricultura Luiz de Queiroz ESALq/ USP, para uso durante os meses de julho e agosto de 2012. 


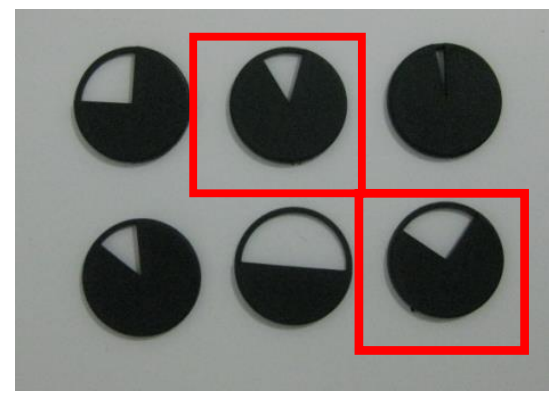

Figura 81: Capas protetoras escolhidas $\left(90^{\circ}\right.$ e $\left.180^{\circ}\right)$.
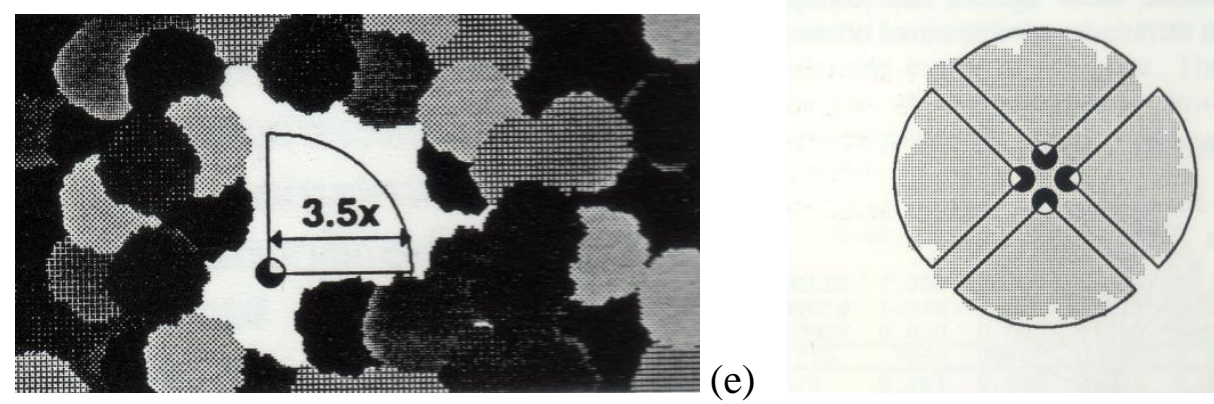

Figura 82: Indicação do uso do LAI 2000 com capa $90^{\circ}$ em áreas abertas (e) e embaixo da copa (f)

Fonte: Manual LI-COR (1992).

A: Using a $270^{\circ}$ View Cap and taking one reading

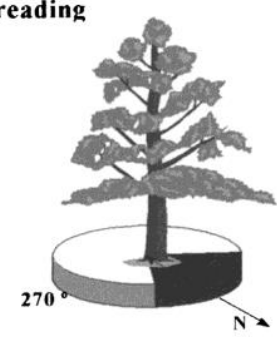

B: Using a $270^{\circ} \mathrm{View} \mathrm{C}$ ap and

taking two readings

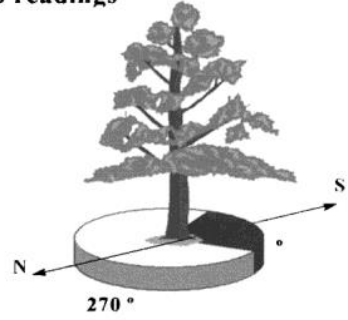

C: Using a $180^{\circ} \mathrm{View} \mathrm{Cap}$ and taking three readings

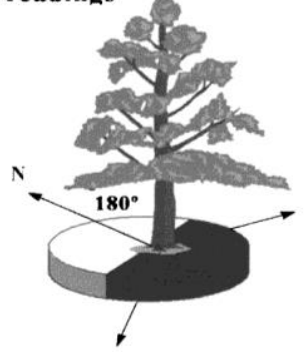

D: Using a $90^{\circ} \mathrm{View} \mathrm{C}$ ap and taking fou readings

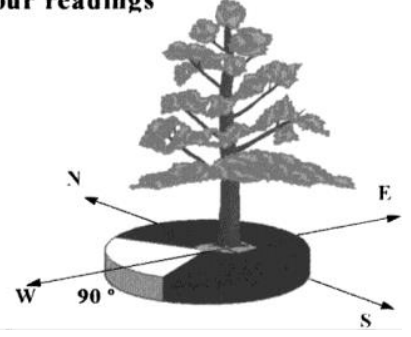

Figura 83: Representação da porção da copa vista pelo sensor, utilizando a capa restritora $270^{\circ}(\mathrm{a}, \mathrm{b}), \mathbf{1 8 0}^{\circ}$ (c) e $90^{\circ}(\mathrm{d})$.

Fonte: López-Serrano et al. (2000). 


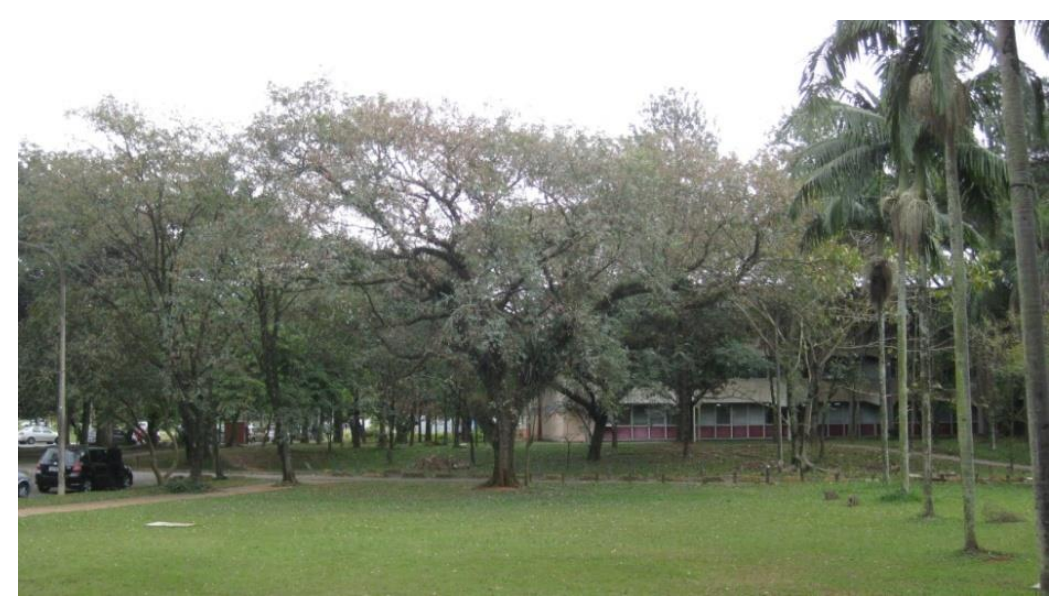

Figura 84: Área escolhida para as medições-teste.

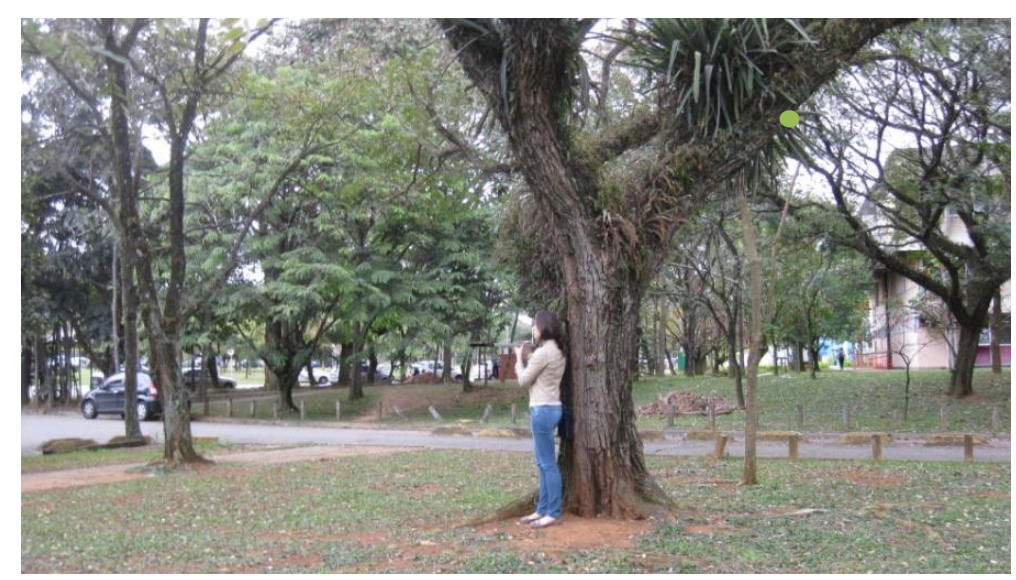

Figura 85: Medição no ponto interno à copa da árvore.

Segundo o manual da LI-COR (1992), em cada medição o equipamento disponibiliza os seguintes dados de saída:

- LAI (Leaf area index): o valor do IAF é adimensional, mas pode ser entendido como $\mathrm{m}^{2}$ de área foliar por $\mathrm{m}^{2}$ de área do solo.

- SEL (Standard error of LAI): representa o valor do erro padrão considerado para o cálculo da determinação do IAF.

- DIFN (Fraction of sky visible): o DIFN é calculado a partir do gap fraction e indica a fração de céu que não é bloqueada pela copa. O DIFN varia entre 0 (sem céu visível para o sensor) e 1 (sem folhagem visível para o sensor). O DIFN pode ser entendido como um valor único que combina os valores de IAF e de MTA, sendo representativo, portanto, da estrutura da copa. Em termos de absorção da copa, o DIFN indica apenas a absorção da radiação difusa do espectro visível $(<490 \mathrm{~nm})$. 
- MTA (Mean Tilt Angle): indica a orientação das folhas da copa. Portanto, se as folhas da copa forem horizontais, o valor de MTA será $0^{\circ}$ e se as folhas da copa forem verticais, o valor de MTA será $90^{\circ}$. Os valores típicos esperados de MTA variam entre $30^{\circ}$ (folhas predominantemente horizontal) e $60^{\circ}$ (folhas predominantemente verticais). Se forem encontrados valores de MTA muito fora dessa faixa esperada, isso indica que pode ter ocorrido algum erro de medição.

Os dados de saída do equipamento foram organizados em duas tabelas, referentes aos dias 26 e 31 de julho de 2012, com diferentes tipos de céu em cada dia (tabelas 9 e 10).

Tabela 9: Dados de saída das medições realizadas em 26 de julho de 2012, no campus da USP (céu aberto)

\begin{tabular}{lcccc}
\hline & Teste 1 & Teste 2 & Teste 3 & Teste 4 \\
\hline Horário & $14: 48$ & $14: 56$ & $15: 06$ & $15: 15$ \\
Tipo de capa & $180^{\circ}$ & $180^{\circ}$ & $90^{\circ}$ & $90^{\circ}$ \\
Sequência & 1 fora/4dentro & 1 fora/2 dentro & 1 fora/4 dentro & 1 fora/8 dentro \\
Repetições & 1 & 1 & 1 & 1 \\
IAF & 1,11 & 1,122 & 0,72 & 0,83 \\
SEL & 0,03 & 1,00 & 0,00 & 0,00 \\
DIFN & 0,378 & 1,343 & 0,3534 & 0,482 \\
MTA & 0 & 0 & 0 & 0 \\
\hline
\end{tabular}

Tabela 10: Dados de saída das medições realizadas em 31 de julho de 2012, no campus da USP (céu encoberto)

\begin{tabular}{lcccc}
\hline & Teste 1 & Teste 2 & Teste 3' & Teste 4' \\
\hline Horário & $12: 57$ & $13: 08$ & $13: 22$ & $13: 57$ \\
Tipo de capa & $180^{\circ}$ & $180^{\circ}$ & $90^{\circ}$ & $90^{\circ}$ \\
Sequência & 1 fora/4 dentro & 1 fora/2 dentro & 1 fora/4 dentro & 1 fora/8 dentro \\
Repetições & 1 & 2 & 1 & 1 \\
IAF & $\mathbf{1 , 2 0}$ & $\mathbf{1 , 2 1}$ & $\mathbf{1 , 2 5}$ & $\mathbf{1 , 2 6}$ \\
SEL & 0,03 & 0,00 & 0,00 & 0,13 \\
DIFN & 0,413 & 0,343 & 0,345 & 0,341 \\
MTA & 0 & 0 & 0 & 0 \\
\hline
\end{tabular}

Os valores do IAF obtidos para cada dia da medições-teste foram plotados e a Figura 86 mostra a diferença entre os valores de IAF obtidos em cada um dos testes realizados. Por meio da comparação entre os valores obtidos nos diferentes dias, verifica-se que os valores de IAF apresentaram maiores variações no dia 26 de julho de 2012, quando o céu estava claro, do que no dia 31 de julho de 2012, quando o céu estava encoberto. Sob 
céu claro os valores de IAF variaram de 0,72 a 1,12; enquanto que, com o céu encoberto, os valores variaram de 1,2 a 1,26.

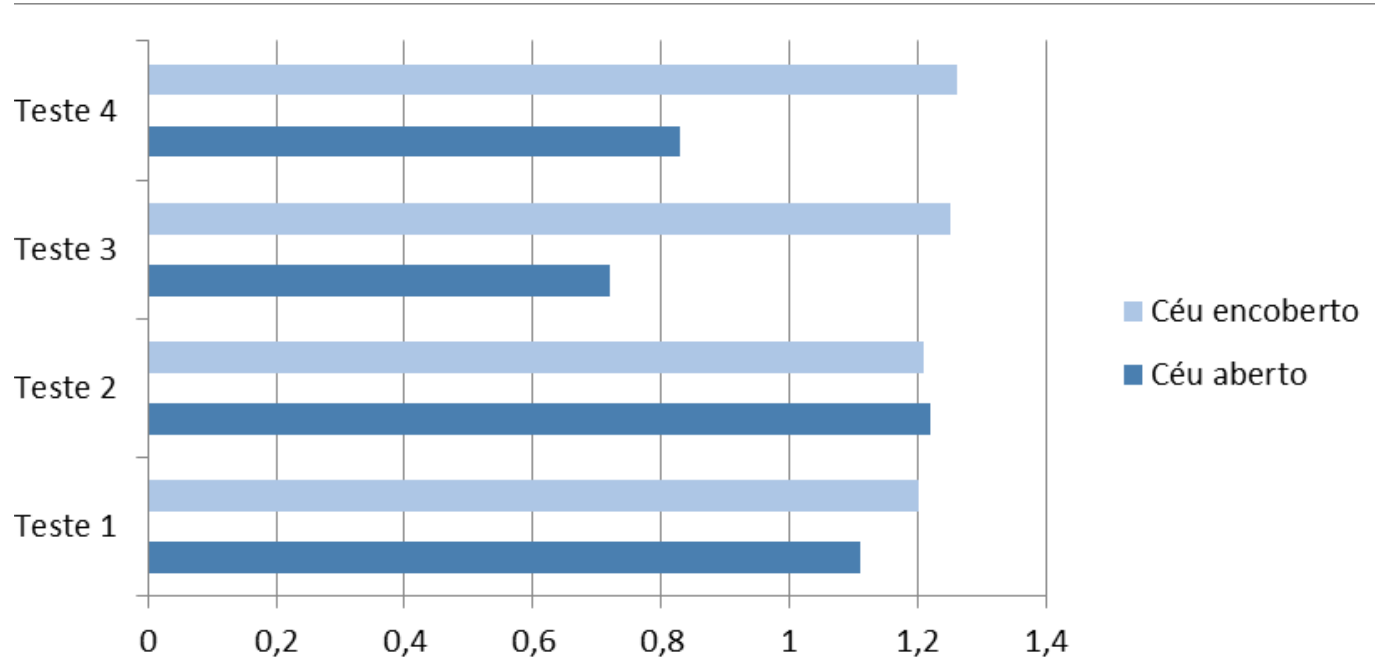

Figura 86: Valores de IAF medidos no campus da USP

Após a etapa de testes no campus da USP, foram feitas as medições propriamente ditas no Parque Trianon. Nesta etapa a capa protetora utilizada para as medições foi a de $90^{\circ}$, de forma a reduzir os erros no cálculo do IAF para áreas que possuem uma região limitada de céu totalmente desobstruído.

Foram utilizadas sequências de "1 fora/4 dentro", ou seja, para cada ponto medido no parque foi realizada 1 medição externa e 4 logo abaixo da copa.

As sequências e as repetições foram programadas de acordo com os melhores resultados obtidos nas medições-teste realizadas na Cidade Universitária, e de acordo com a análise dos resultados das Tabelas 8 e 9 .

A Tabela 11 mostra os resultados obtidos pelo equipamento LAI-2000 no dia 09 de setembro de 2012.

Tabela 11: Dados de Saída - Medições de IAF (09/09/2012) no Parque Trianon

\begin{tabular}{ccccc}
\hline Ponto & IAF & SEL & DIFN & MTA \\
\hline $\mathbf{1}$ & $\mathbf{1 , 8 6}$ & 0,52 & 0,198 & 30 \\
$\mathbf{2}$ & $\mathbf{2 , 3 6}$ & 0,00 & 0,126 & 0 \\
$\mathbf{3}$ & $\mathbf{2 , 9 8}$ & 0,00 & 0,122 & 0 \\
$\mathbf{4}$ & $\mathbf{2 , 6 1}$ & 0,00 & 0,116 & 0 \\
$\mathbf{5}$ & $\mathbf{1 , 4 6}$ & 0,38 & 0,324 & 0 \\
$\mathbf{6}$ & $\mathbf{3 , 3 3}$ & 0,38 & 0,324 & 0 \\
$\mathbf{7}$ & $\mathbf{2 , 4 2}$ & 0,02 & 0,119 & 0 \\
$\mathbf{8}$ & $\mathbf{1 , 5 2}$ & 0,02 & 0,263 & 0 \\
\hline
\end{tabular}




\begin{tabular}{ccccc}
\hline $\mathbf{9}$ & $\mathbf{2 , 2 7}$ & 0,02 & 0,138 & 0 \\
$\mathbf{1 0}$ & $\mathbf{1 , 9 8}$ & 0,00 & 0,183 & 14 \\
$\mathbf{1 1}$ & $\mathbf{3 , 1 5}$ & 0,00 & 0,065 & 22 \\
$\mathbf{1 2}$ & $\mathbf{1 , 5 1}$ & 0.02 & 0,269 & 42 \\
$\mathbf{1 3}$ & $\mathbf{1 , 5 7}$ & 0,04 & 0,278 & 0 \\
$\mathbf{1 4}$ & $\mathbf{2 , 9 2}$ & 0,04 & 0,093 & 21 \\
$\mathbf{1 5}$ & $\mathbf{2 , 8 7}$ & 0,00 & 0,084 & 22 \\
$\mathbf{1 6}$ & $\mathbf{3 , 8 4}$ & 0,00 & 0,037 & 0 \\
$\mathbf{1 7}$ & $\mathbf{3 , 3 2}$ & 0,05 & 0,060 & 25 \\
$\mathbf{1 8}$ & $\mathbf{3 , 0 6}$ & 0,06 & 0,070 & 30 \\
$\mathbf{1 9}$ & $\mathbf{3 , 8 6}$ & 0,02 & 0,037 & 0 \\
$\mathbf{2 0}$ & $\mathbf{2 , 3 1}$ & 0,03 & 0,206 & 0 \\
$\mathbf{2 1}$ & $\mathbf{2 , 1 8}$ & 0,02 & 0,153 & 41 \\
\hline $\mathbf{2 2}$ & $\mathbf{2 , 6 3}$ & 0,00 & 0,104 & 0 \\
\hline
\end{tabular}

Os valores do IAF obtidos em cada um dos 22 pontos de medição são apresentados na Figura 87 a seguir.

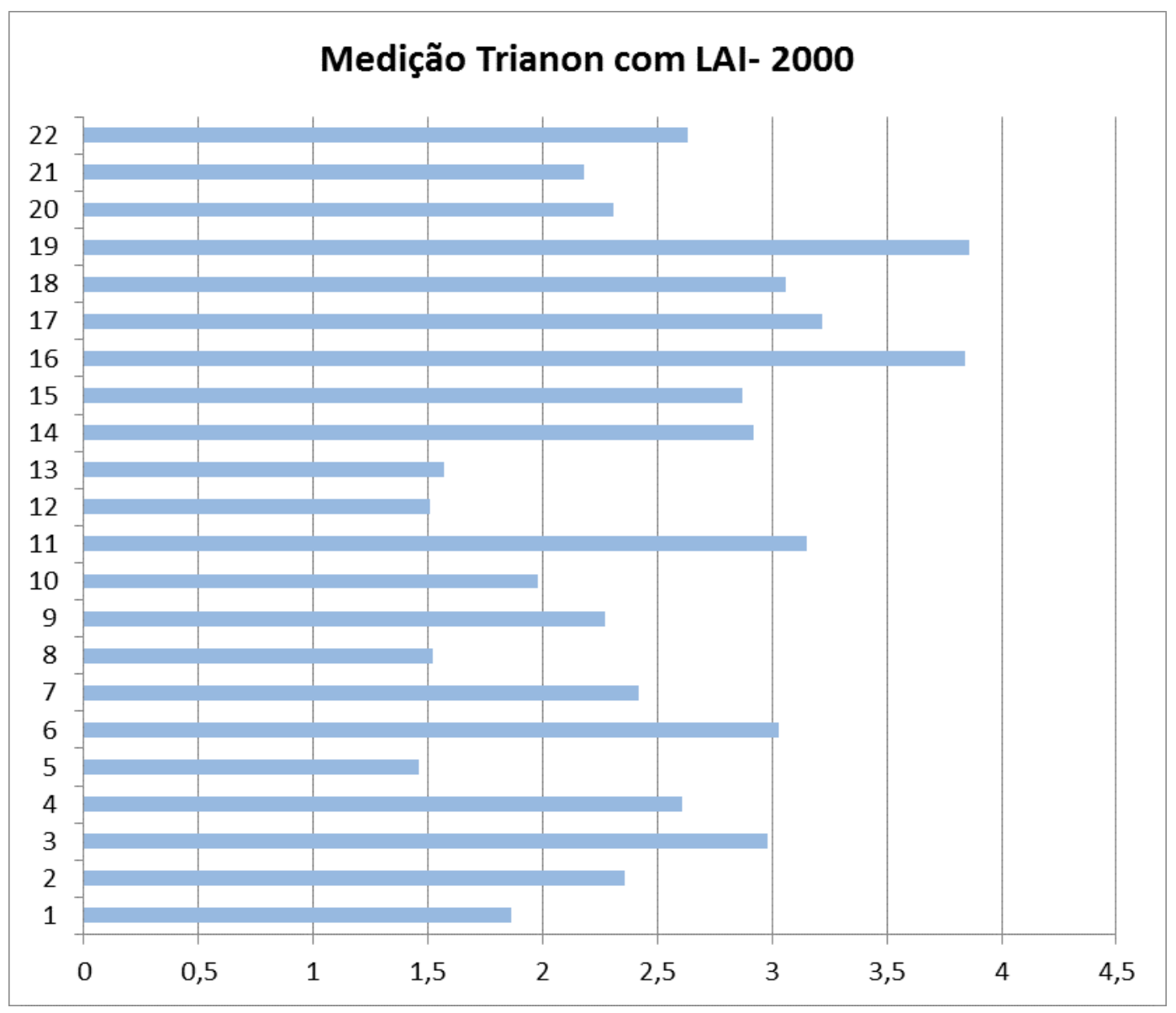

Figura 87: Valores de IAF medidos no Parque Trianon. 
Os valores de IAF variaram de 1,46 a 3,86. Os pontos 5 e 19 foram os que apresentaram o menor e o maior valor de IAF medidos com o equipamento LAI 2000, respectivamente. (Figura 88 e 89). O valor médio de IAF nos 22 pontos medidos no Parque Trianon foi de 2,52 .

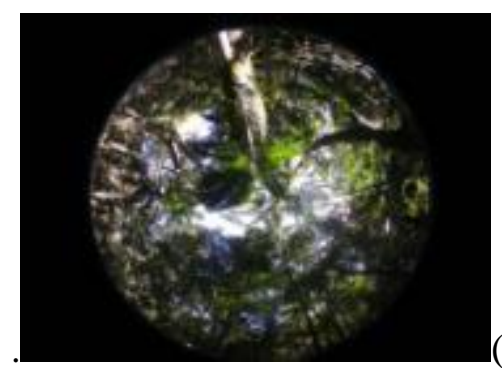

$\mathrm{IAF}=1,46$

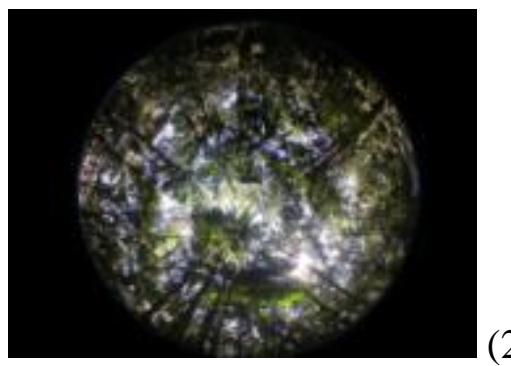

$\mathrm{IAF}=3,86$

Figura 88: Resultados do valor de IAF para os 22 pontos no Parque Trianon.

Figura 89: Foto Hemisférica e valor de IAF do Ponto 5 (1); Foto Hemisférica e valor de IAF do Ponto 19 (2).

\subsection{MEDIÇÕES COM FOTOS HEMISFÉRICAS}

As fotos hemisféricas foram feitas no Parque Trianon nos dias 15 de agosto de 2012 no período das $12 \mathrm{~h} 30$ às $14 \mathrm{~h}$ e no dia 8 de fevereiro de 2014 das $7 \mathrm{~h}$ às $10 \mathrm{~h}$. As fotos foram feitas com a câmera digital Nikon COOLPIX 4500 com uma lente grande angular Nikon FC-E8 acoplada (Figura 90).

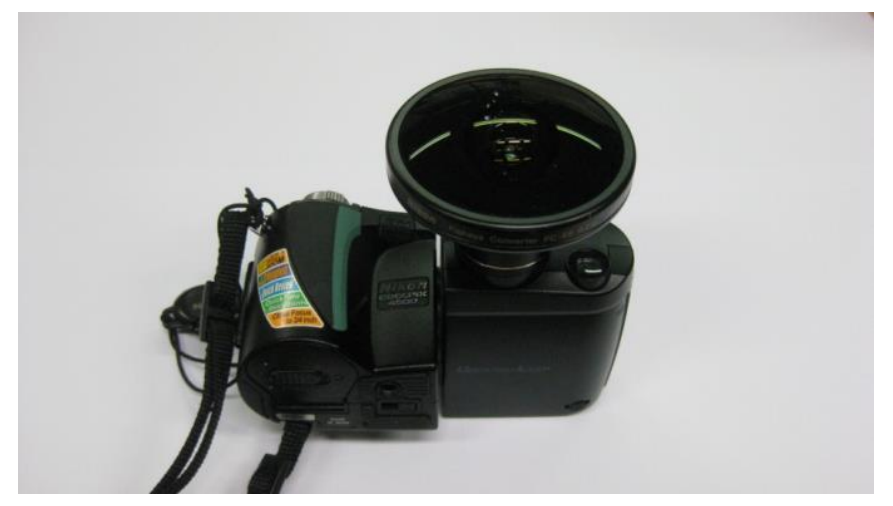

Figura 90: Câmera Nikon COOLPIX 4500 com lente grande angular acoplada.

Utilizando a mesma malha de 20 x 20m, apresentada na figura 89 , no centro de cada célula foram registradas imagens a uma distância de 1,70m e isso significa que, para uma árvore de altura 20m, a extensão da imagem no plano horizontal é de $17,07 \mathrm{~m}$ (Figura 91). Na segunda medição feita em fevereiro de 2014, além de fotos a 1,70m, também foi feito um teste com imagens registradas a $0,30 \mathrm{~m}$ do solo. A câmera estava 
apoiada num tripé e teve todo um cuidado para evitar a inclinação da câmera e a presença das pessoas na foto.

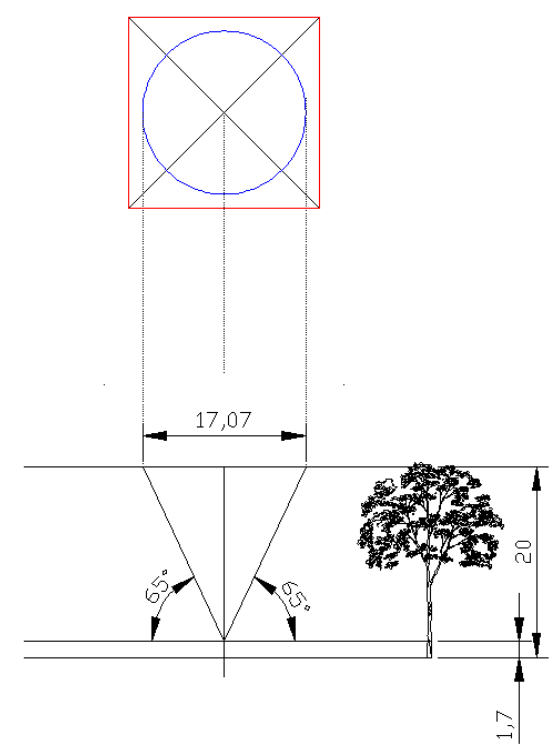

Figura 91: Esquema do cálculo da extensão da imagem no plano horizontal.

Foram registradas com lente angular $8 \mathrm{~mm}$ para os respectivos pontos definidos no Parque Trianon e os resultados para os 22 pontos estão presentes na Figura 92 e 93.

Por meio das fotos é possível se obter a distribuição das folhas e quantificar o gap fraction de acordo com diferentes ângulos zenitais e azimutais. As fotos hemisféricas também fornecem um permanente arquivo fotográfico, mantendo-se como um registro da copa com a posição, do tamanho, da densidade e da distribuição das aberturas no dossel. Para a análise das fotografias hemisférica foi utilizado o modelo computacional Can - Eye $e^{44}$, desenvolvido em 2003 pelo grupo de pesquisa francês INRA - National Institute of Agronomical Research.

A principal vantagem do modelo é que no cálculo do IAF este considera um parâmetro de dispersão $\lambda$ o (NILSON, 1971; LEMEUR e BLAD, 1974) ou também chamado de clumping index (CHEN, BLACK, 1992). Esse parâmetro considera a distribuição aleatória das folhas e dependendo de sua angulação e tamanho pode existir uma sobreposição das folhas em determinados pontos da copa, isso levaria a uma quantificação subestimada do valor de IAF real. O equipamento LAI-2000 faz a análise da distribuição geométrica das folhas (gap fraction) para calcular o IAF, mas não apresenta esse fator do index clumping para ajustar o cálculo da densidade foliar.

\footnotetext{
${ }^{44}$ Disponível gratuitamente: < http://www6.paca.inra.fr/can-eye $>$. Acesso em fevereiro de 2014.
} 

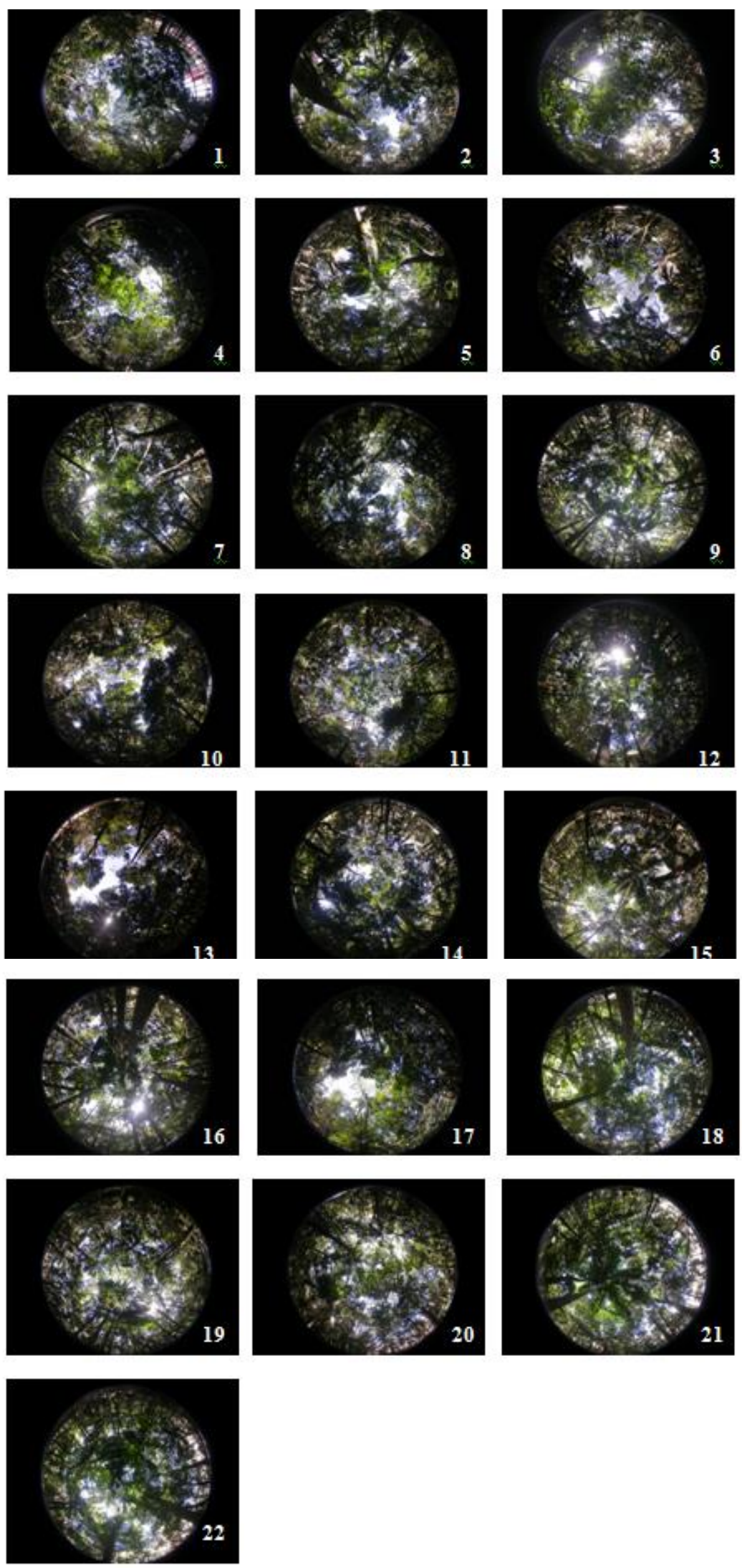

Figura 92: Resultados das 22 imagens registradas no Parque Trianon-Medição em agosto de 2012. 

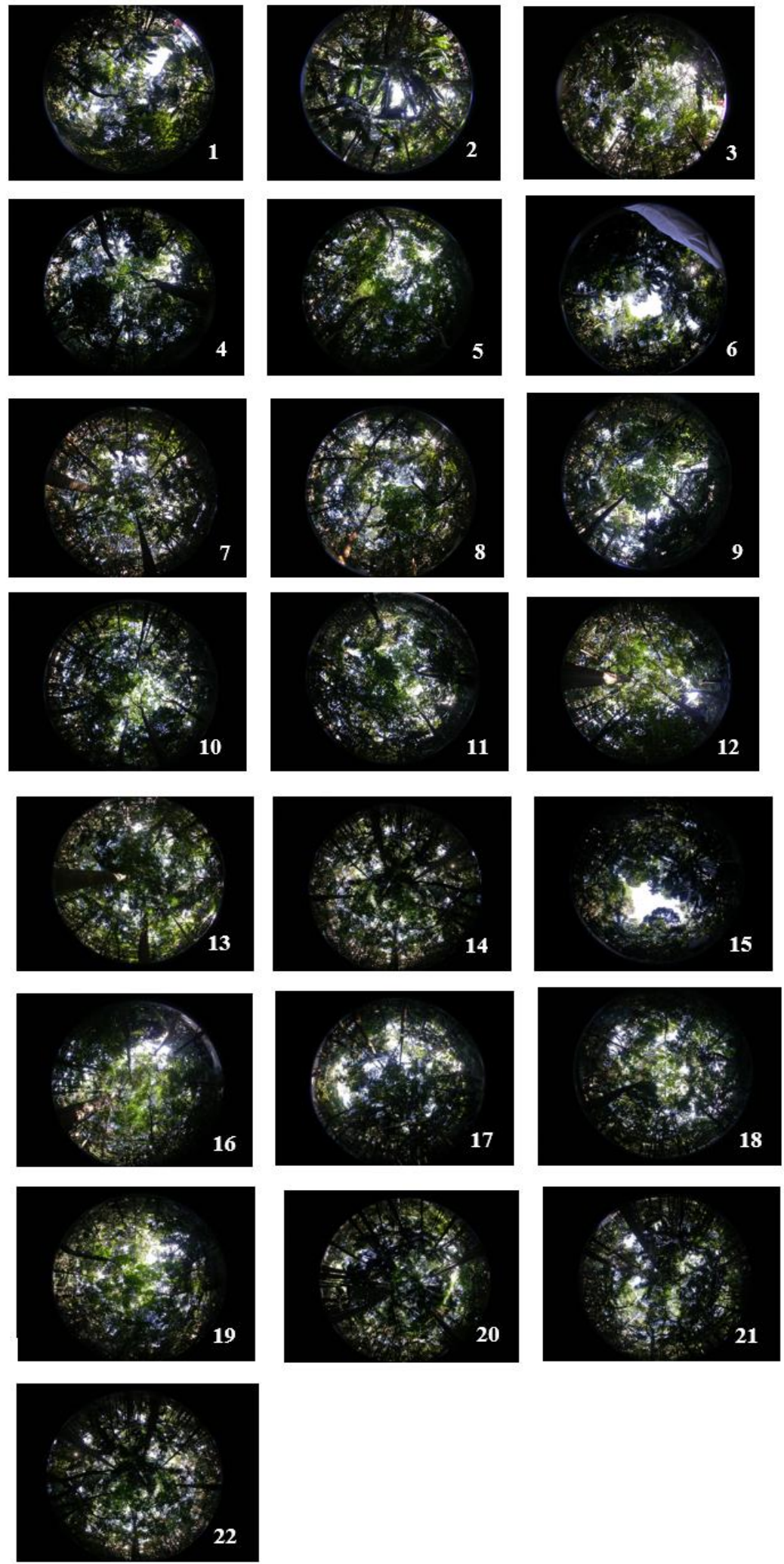

Figura 93: Resultados das 22 imagens registradas no Parque Trianon - Fevereiro de 2013. 
As imagens foram analisadas usando o modelo Can-Eye (WEISS, 2003). Porém, antes da análise das fotos, o programa pede a calibração da lente em duas etapas:

1. Identificar o centro da lente grande angular que, em muitos casos, é diferente do centro das fotos. A identificação do centro da lente é feita pela determinação das coordenadas de três pontos na tampa da câmera em diferentes rotações. Foi colocada uma tampa cobrindo a lente grande angular, de forma que apenas os três furos ficassem visíveis (Figura 94). Com um processador de imagem do CorelDraw foram identificadas as coordenadas $(\mathrm{x}, \mathrm{y})$ dos três pontos em cada foto e montou-se uma tabela com os resultados (Figura 95).

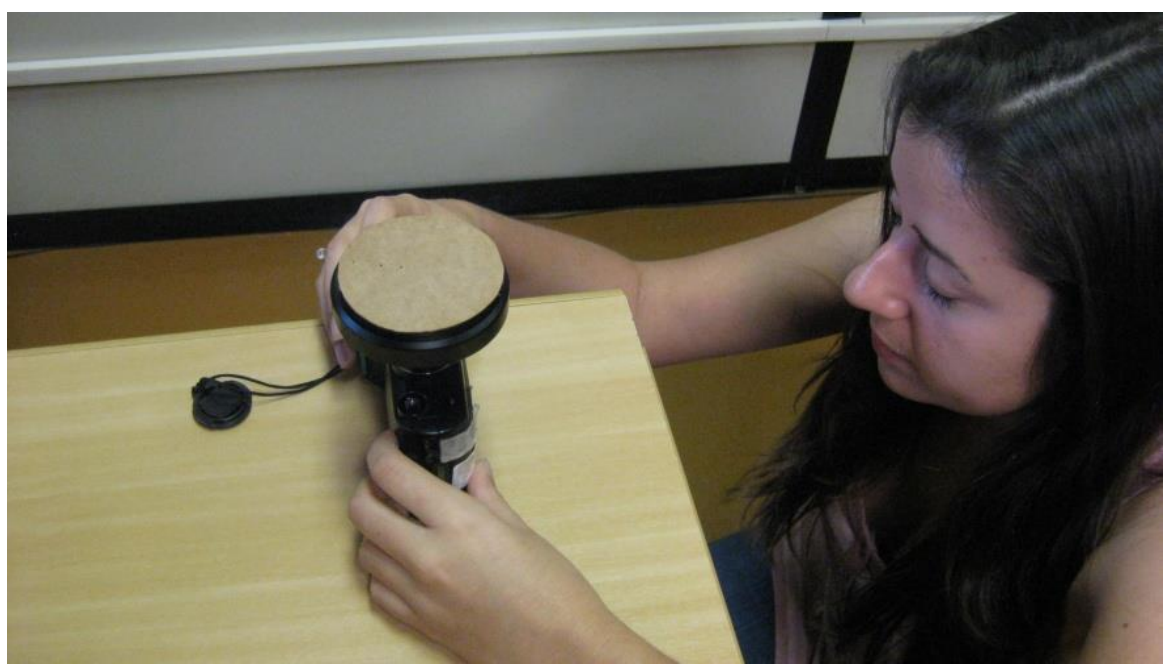

Figura 94: Tampa com três furos necessários para calibração colocada sobre a lente.

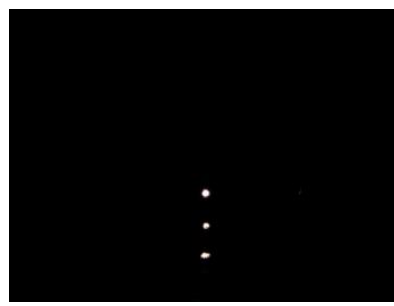

(1)
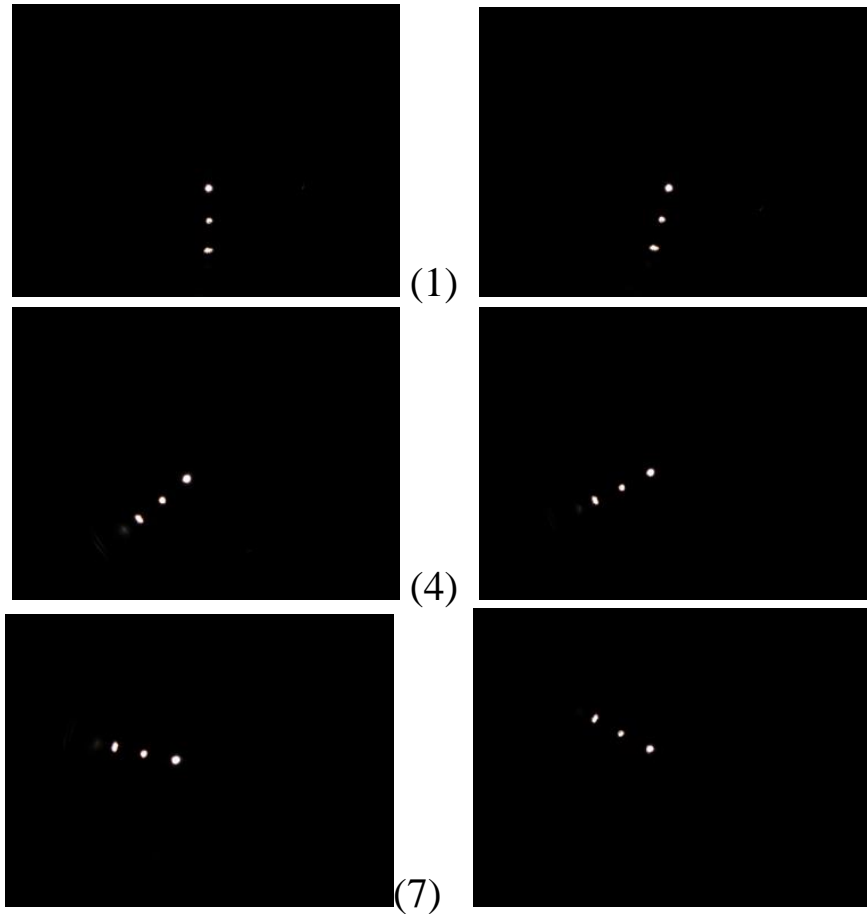

(4)

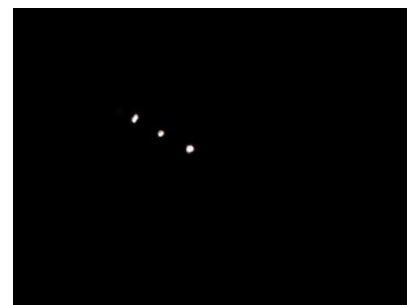

(2)

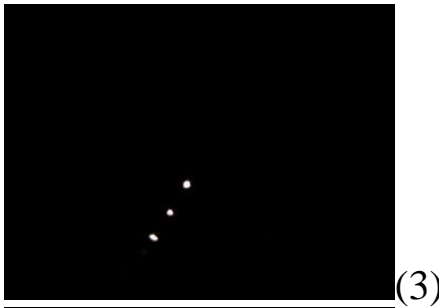

(5)

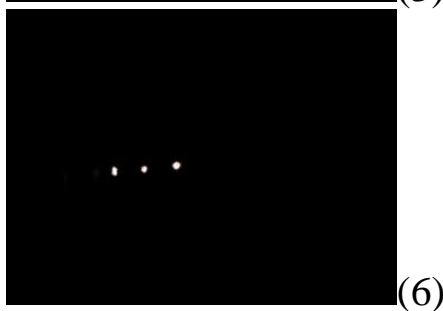

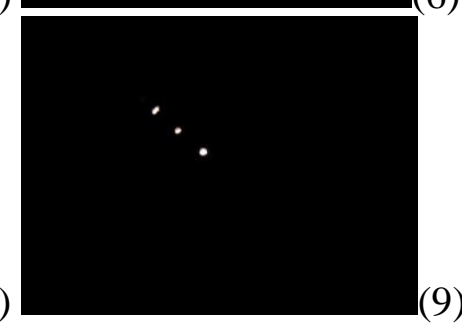




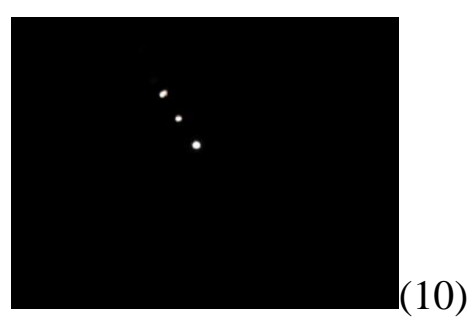

Figura 95: Série de imagens registradas em diferentes rotações da lente grande angular.

Neste caso, três pontos para cada foto foram considerados. (Fotos: Moreira, D.)

Tabela 12: Valores das coordenadas $x$ e y de cada imagem.

\begin{tabular}{|c|c|c|c|}
\hline FOTO & $\begin{array}{c}\text { Coordenada } \\
\text { Pto1 (x,y) }\end{array}$ & $\begin{array}{c}\text { Coordenada } \\
\text { Pto2 }(\mathbf{x}, \mathbf{y})\end{array}$ & $\begin{array}{c}\text { Coordenada } \\
\text { Pto3 (x,y) }\end{array}$ \\
\hline $\mathbf{1}$ & 4070,3770 & 4070,4420 & 4040,5050 \\
\hline $\mathbf{2}$ & 3900,3720 & 3770,4400 & 3600,4980 \\
\hline $\mathbf{3}$ & 1250,1220 & 1130,1420 & 1030,1590 \\
\hline $\mathbf{4}$ & 1200,1170 & 1030,1320 & 870,1440 \\
\hline $\mathbf{5}$ & 1160,1110 & 960,1200 & 770,1290 \\
\hline $\mathbf{6}$ & 880,800 & 710,820 & 560,830 \\
\hline $\mathbf{7}$ & 860,730 & 700,700 & 550,660 \\
\hline $\mathbf{8}$ & 900,700 & 750,620 & 620,550 \\
\hline $\mathbf{9}$ & 1020,760 & 880,630 & 750,520 \\
\hline $\mathbf{1 0}$ & 1020,700 & 930,560 & 830,420 \\
\hline
\end{tabular}

2. Calibração da lente. De acordo com o manual do programa, nessa calibração foi construído um gabarito com 3 réguas perpendiculares, conforme mostra a Figura 105. Nesse estudo foram utilizadas três réguas metálicas de $1 \mathrm{~m}$ colocadas numa das bancadas do LAME - Laboratório de Modelos e Ensaios da FAUUSP. A câmera foi ajustada para que nas fotos as três réguas ficassem alinhadas. As imagens registradas em duas distâncias: 52 e $57 \mathrm{~cm}$. O centro da lente fica alinhado com o meio da régua paralelo à câmera. Com o prolongamento do traçado de ângulos ( $\theta \mathrm{x}, \theta \mathrm{y}$ conforme mostra a Figura 97), a partir do centro da lente, é possível se determinar onde esses ângulos chegam nas réguas e seu posicionamento pelas coordenadas x e y. O modelo Can-Eye pede a localização de diversos pontos, em coordenadas $\mathrm{x}, \mathrm{y}$ de pixels, e a comparação desses pontos com as duas imagens registradas no LAME, permite definir o tipo da lente grande angular para o modelo. 


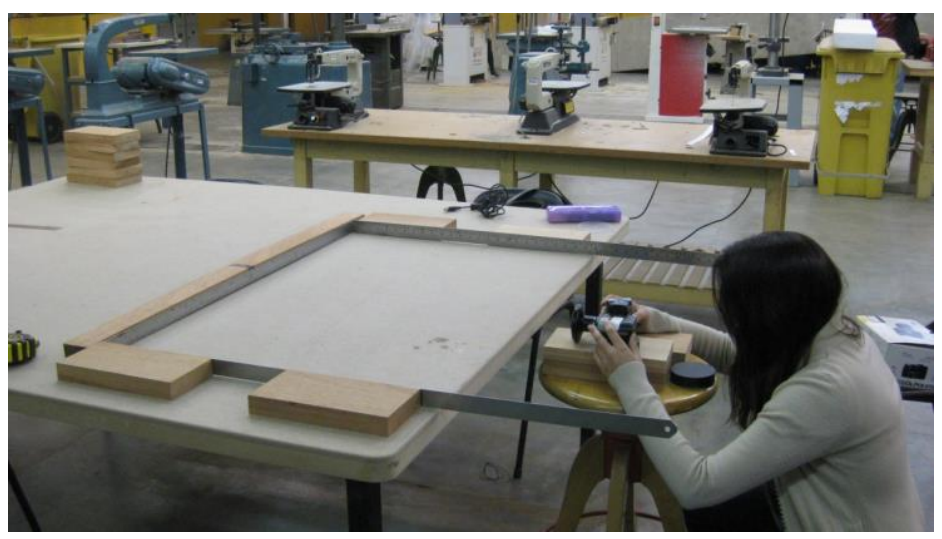

Figura 96: Montagem das três réguas e posicionamento da câmera digital. (Foto: Shinzato, P.)

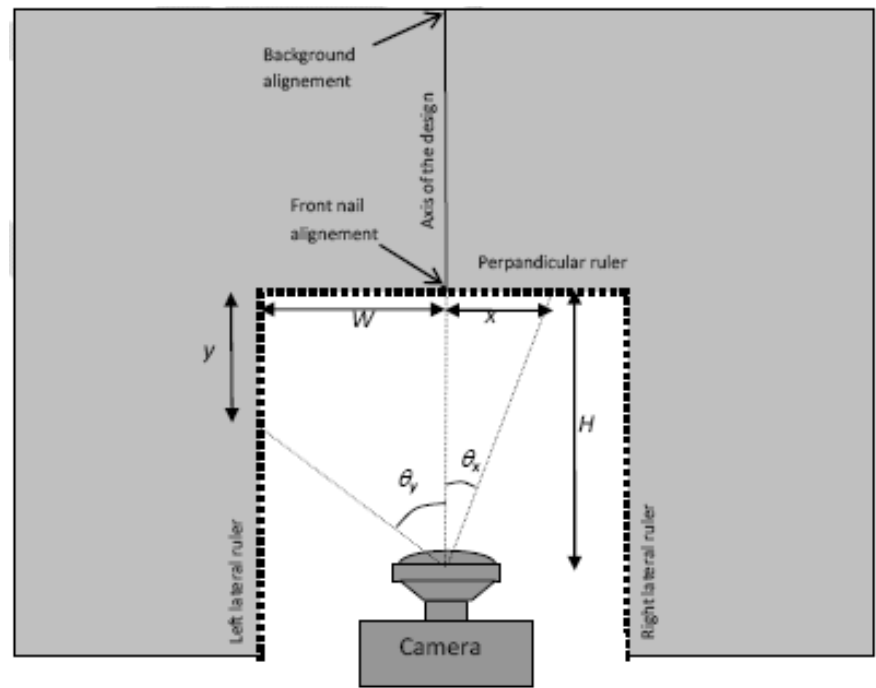

Figura 97: Esquema de montagem para a calibragem da lente.

Fonte: Manual CAN-EYE. Disponível em: < www4.paca.inra.fr/can-eye >.Acesso em agosto de 2012.

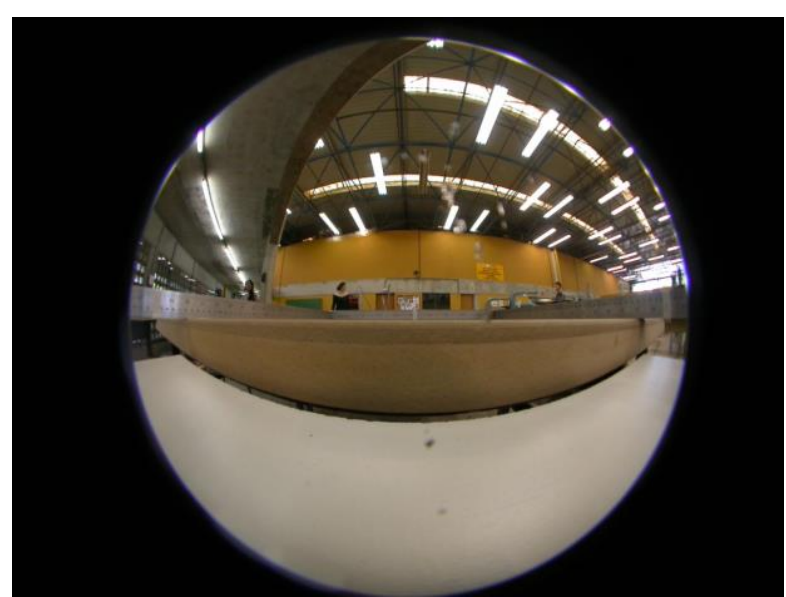

Figura 98: Foto registrada com distância de 52cm no LAME / FAUUSP. (Foto: Moreira, D). 
Após a calibração da câmera, foram feitas as seguintes etapas de ajuste das imagens:

- Pré- processamento da imagem (seleção/ correção/ mascaramento de elementos como troco, galhos, pessoas)

- Classificação de cores, definindo o que será considerado céu, elemento da árvore e folhas.

- Contraste para criar uma imagem binária, resultando no cálculo do IAF.

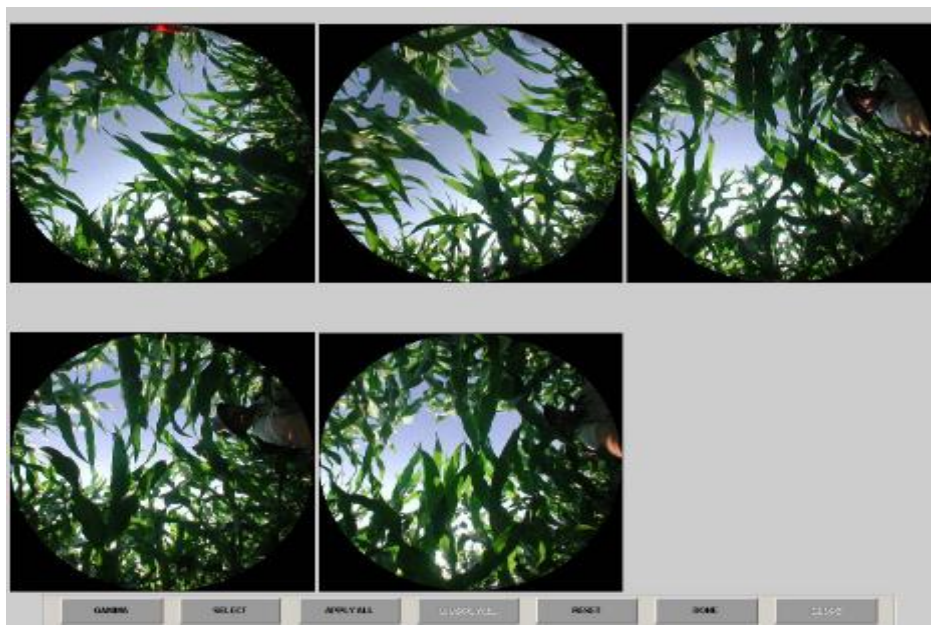

Figura 99: Pré-processamento da imagem.

Fonte: Can-Eye User Guide. Disponível em: < https://www4.paca.inra.fr/can-eye/DocumentationPublications/Documentation $>$. Acesso em dezembro de 2012

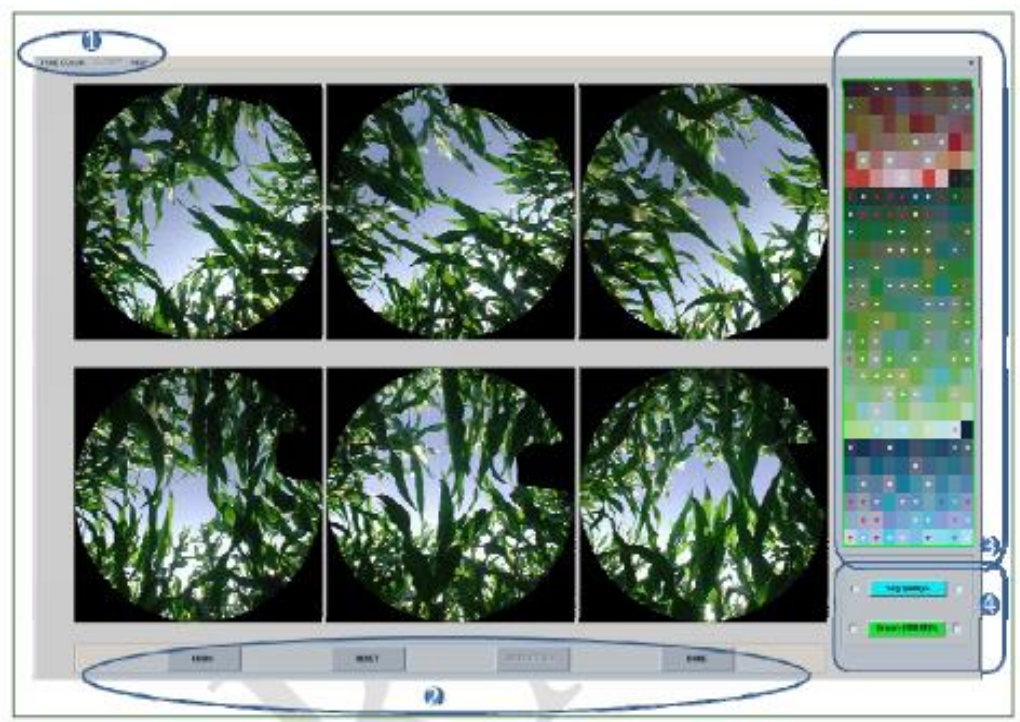

Figura 100: Classificação de cores.

Fonte: Can-Eye User Guide. Disponível em: < https://www4.paca.inra.fr/can-eye/DocumentationPublications/Documentation $>$. Acesso em dezembro de 2012 


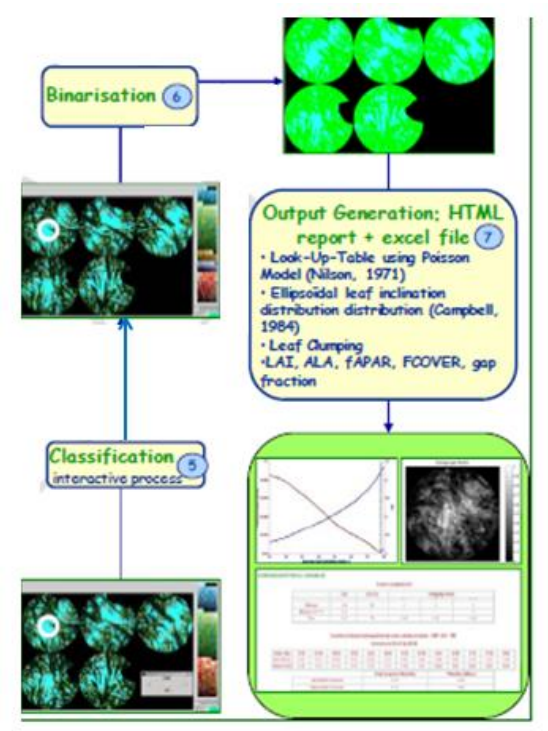

Figura 101: Estrutura do modelo para cálculo do IAF.

Fonte: Can-Eye User Guide. Disponível em: < https://www4.paca.inra.fr/can-eye/DocumentationPublications/Documentation $>$. Acesso em dezembro de 2012

\subsection{RESULTADOS}

A Figura 102 apresenta a comparação dos valores de IAF de acordo com a metodologia aplicada, indicando que o uso do LAI-2000 apresentou valores médios de IAF variando entre 2,38 (área 1) e 2,41 (área 2). Por meio das fotos hemisféricas, verificou-se que os valores médios de IAF no primeiro levantamento (agosto de 2012) variaram entre 2,05 (área 1) e 2,23 (área 2) e para o segundo levantamento (fevereiro de 2014) os valores para área 1 foram 2,17 e na área 2, IAF de 2,45. A Figura 103 mostra o resultado do IAF médio considerando os valores obtidos nos 22 pontos do Parque Trianon. Utilizando o equipamento LAI-2000 o IAF médio foi de 2,52, enquanto que para a metodologia por fotos hemisféricas em agosto de 2012 foi de 2,52 e para fevereiro de 2014, IAF médio de 2,31.

Comparando-se os resultados obtidos pelos dois sistemas de medição, verifica-se que os valores médios obtidos para os 22 pontos apresentaram pouca diferença, variando entre 2,14 e 2,52, no período de agosto de 2012. Em fevereiro de 2014, só foi aplicada a metodologia por fotos hemisférica porque o LAI-2000, pertencente ao Departamento de Ciências Florestais da ESALq, estava sendo utilizado em outra pesquisa. No entanto, mesmo sem o uso do LAI-2000 no mês de fevereiro, os valores não mudaram drasticamente, mostrando que apesar da variação das estações de ano, um valor médio de IAF a ser considerado para as simulações no Parque Trianon é por volta de 2,50 
Observa-se que cada uso tem suas especificidades e a escolha do método de medição deve considerar a condição do local de estudo. Dessa forma, observa-se que o parque Trianon tem uma distribuição mais homogênea dos grupos arbóreos e pequenos espaços entre as árvores, dificultando a medição do IAF pelo equipamento LAI-2000, uma vez que o cálculo considera medidas embaixo e fora da copa.

Além disso, o sistema por fotos hemisféricas é indicado para o cálculo médio de uma área, ficando limitado para se determinar o IAF de um único indivíduo arbóreo, mas facilmente obtido com o equipamento LAI-2000. De acordo com os resultados finais, percebe-se que o IAF medido pelo LAI- 2000 costuma ser superior em relação aos cálculos feitos pelo Can-Eye, uma vez que o equipamento acaba considerando não só as folhas, mas outros elementos da vegetação como tronco, galhos, flores. Nesse caso, o modelo computacional permite o ajuste da imagem e o mascaramento de áreas indesejadas.

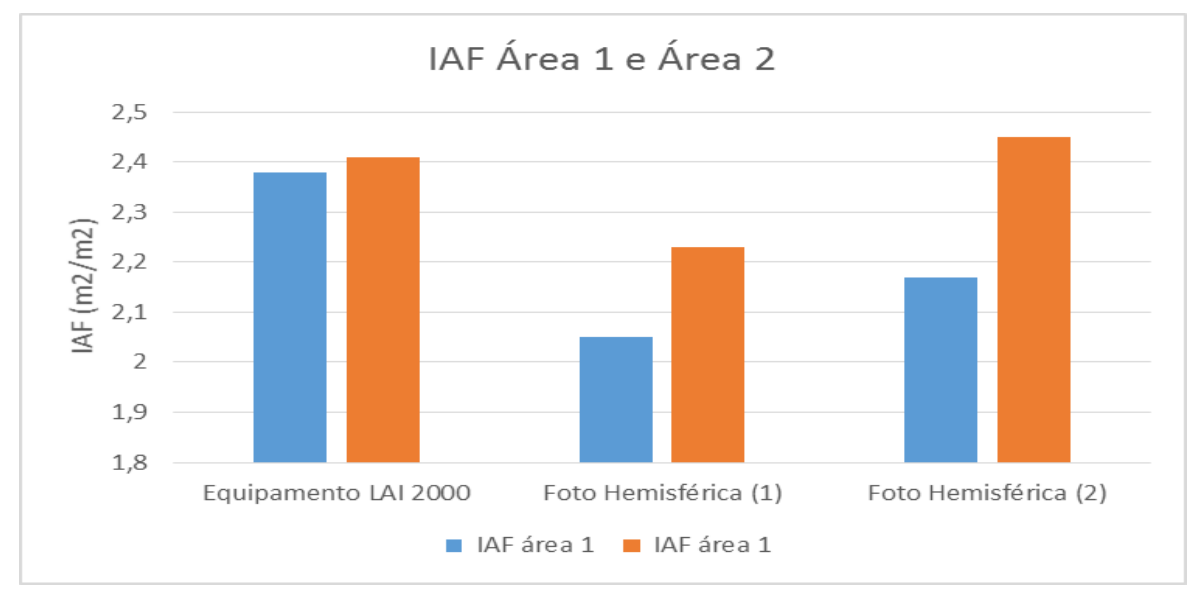

Figura 102: Valores de IAF para áreas 1 e 2 do Pq. Trianon, com os 2 métodos de medição.

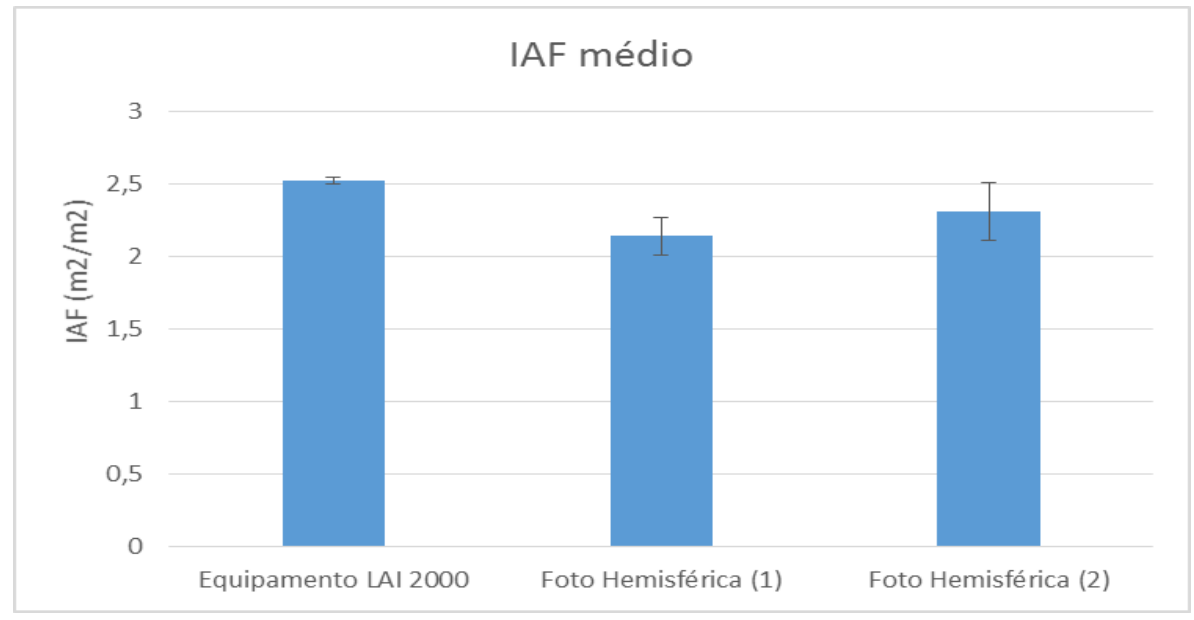

Figura 103: IAF médio para os 22 pontos considerando desvio padrão. 


\section{SIMULAÇÕES PARAMÉTRICAS NO ENVI-MET}

Conforme descrito no Capítulo 4, os resultados apresentados pelo modelo ENVI-met estão baseados nas interações entre atmosfera, vegetação/edifícios e solo. Dessa forma, a fim de se verificar os efeitos para diferentes variáveis (temperatura do ar, umidade, ventos, etc), foram feitos estudos preliminares para se calibrar as condições gerais do modelo (dados microclimáticos, características da vegetação e do solo) em relação às medições de campo (microclimáticas e valores de IAF) realizadas no Parque Trianon. $\mathrm{O}$ processo de simulação nessa fase de calibração do modelo pode ser estruturado segundo mostra a Figura 104:

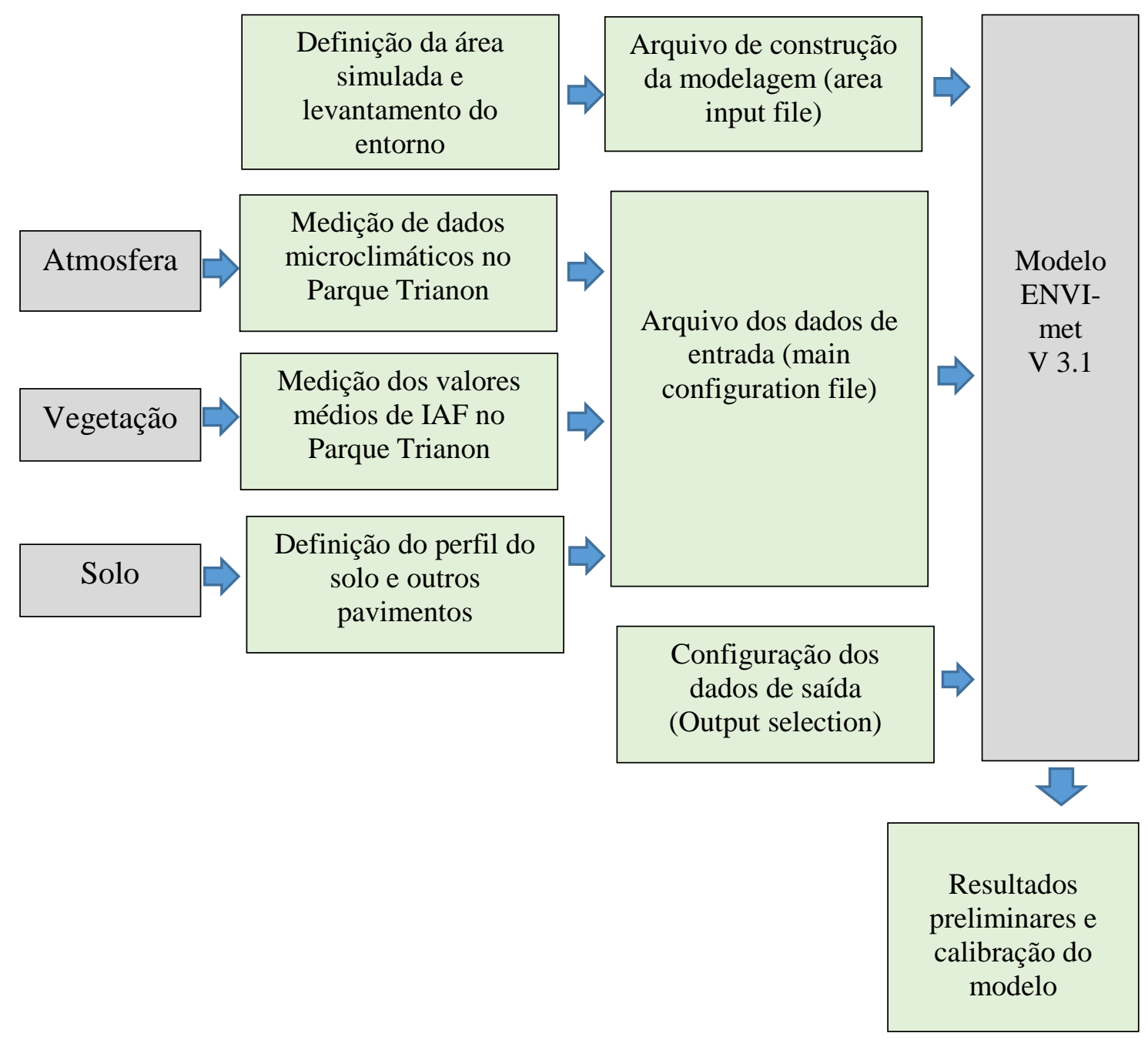

Figura 104: Estrutura geral do processo de calibração do ENVI-met. 


\subsection{SIMULAÇÕES PRELIMINARES - PROCESSO DE CALIBRAÇÃO DO MODELO}

A construção da modelagem no ENVI-met iniciou-se com a definição da área a ser considerada nas simulações, a partir de imagens de satélites com o entorno do Parque Trianon (Figura 105). Foi feito um levantamento da altura dos edifícios nas quadras adjacentes ao parque, incluindo a Praça Alexandre de Gusmão, entre a Av. Nove de Julho e a Alameda Santos, que apresenta um movimento médio de veículos, sendo a área mais exposta à radiação direta e aos ventos, uma vez que não tem obstáculos, sejam árvores ou edifícios. Esta praça tem áreas de passagem impermeáveis para a travessia dos pedestres e também área permeável coberta por gramíneas.

Para a calibragem do modelo, foi utilizado inicialmente um arquivo com extensão dwg da área do Parque Trianon, obtido da base de dados da PRODAM, da SEMPLA (Secretaria de Planejamento do Município de São Paulo). Na sequência, foram feitos alguns testes para se encontrar uma configuração do tamanho das células da malha ortogonal ( $\mathrm{grid}$ ) que apresentasse as mesmas proporções da área real e que possibilitasse uma dimensão adequada das células para reduzir o tempo de simulação computacional. A área total usada foi $32 \times 32$ células, cada uma medindo 10x10 metros, num total de $102.400 \mathrm{~m}^{2}$ (Figura 106).

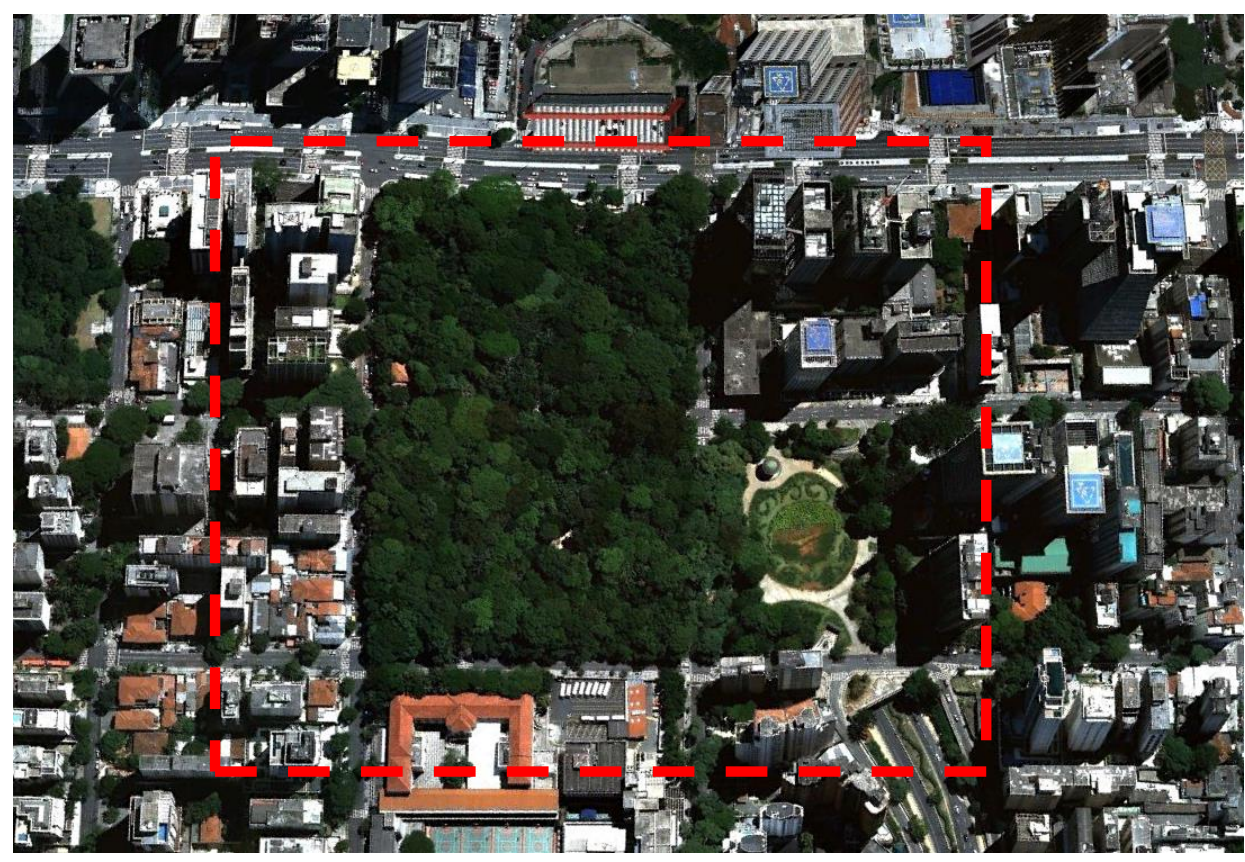

Figura 105: Definição da área no entorno do Parque Trianon para modelagem no ENVImet.

Fonte: Google Maps. Acesso em julho de 2012 


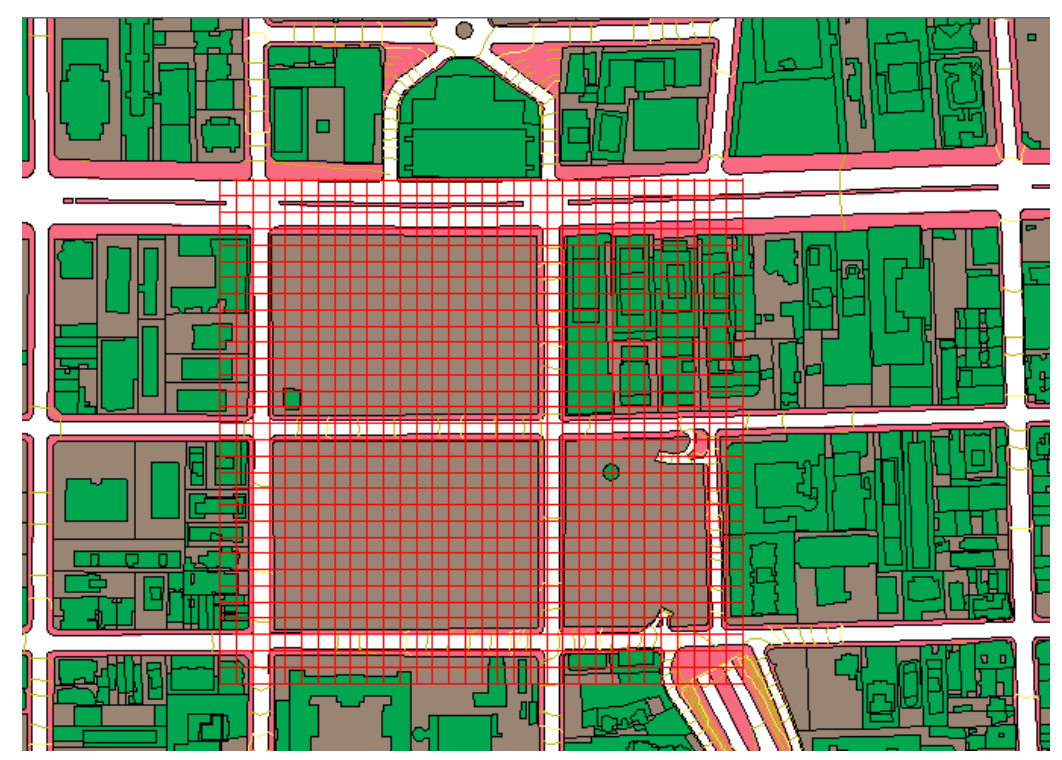

Figura 106: Distribuição da malha de 10x10m sobre o modelo da SEMPLA.

A área total do modelo no ENVI-met foi ajustada segundo a malha ortogonal feita sobre o arquivo do AutoCad. Na modelagem, em função do levantamento feito na área, cada célula teve como dimensão 10x 10m e 2m de altura e, os edifícios foram desenhados nas quadras, incluindo suas alturas correspondentes em metros, variando entre $3 \mathrm{~m}$ e $15 \mathrm{~m}$. O norte verdadeiro foi posicionado a $270^{\circ}$ à direita correspondente à orientação das quadras no local de estudo.

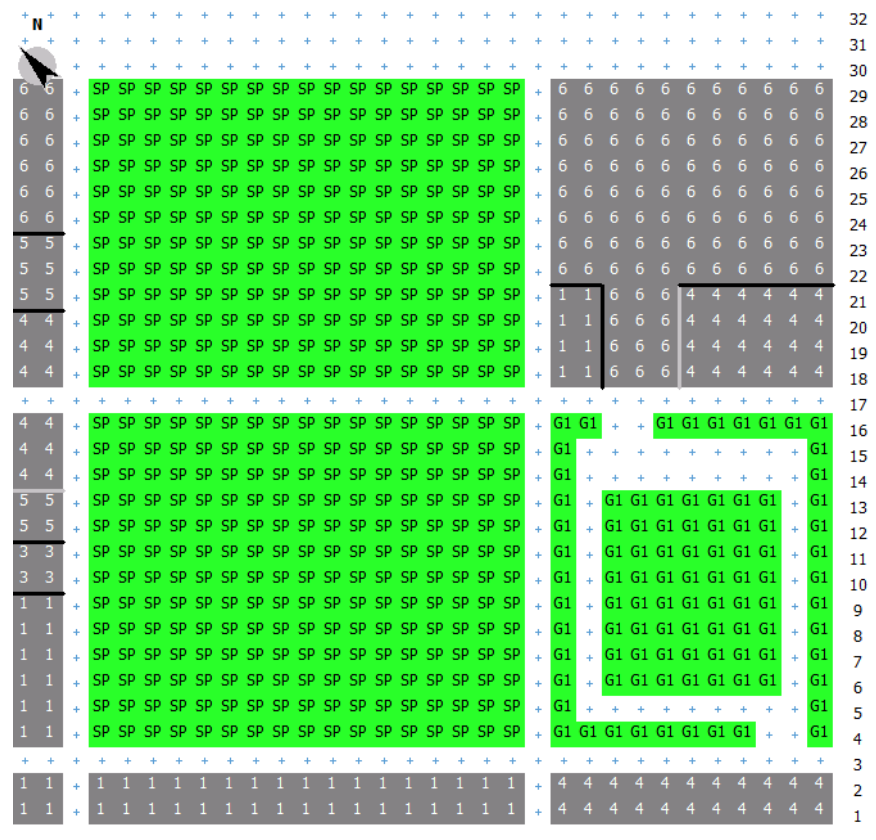

$\begin{array}{lllllllllllll}1 & 2 & 3 & 4 & 5 & 6 & 7 & 8 & 9 & 1011 & 1213141516171819202122 & 23242526272829 & 303132\end{array}$

Figura 107: Disposição de edifícios e áreas verdes na modelagem construída no ENVI-met. 
A Figura 107 mostra que no espaço do parque foi incluída uma vegetação com grupos arbóreos de $20 \mathrm{~m}$ de altura e IAF de 2,5, que é o valor médio considerado a partir dos levantamentos feitos anteriormente, conforme capítulo 6. Na área da Praça Alexandre de Gusmão foi colocada vegetação arbustiva com IAF de 1 e no máximo 0,5m de altura. A distribuição dos valores de IAF para os grupos de árvore e arbustos estão indicadas nas Figuras 108 e 109, respectivamente.

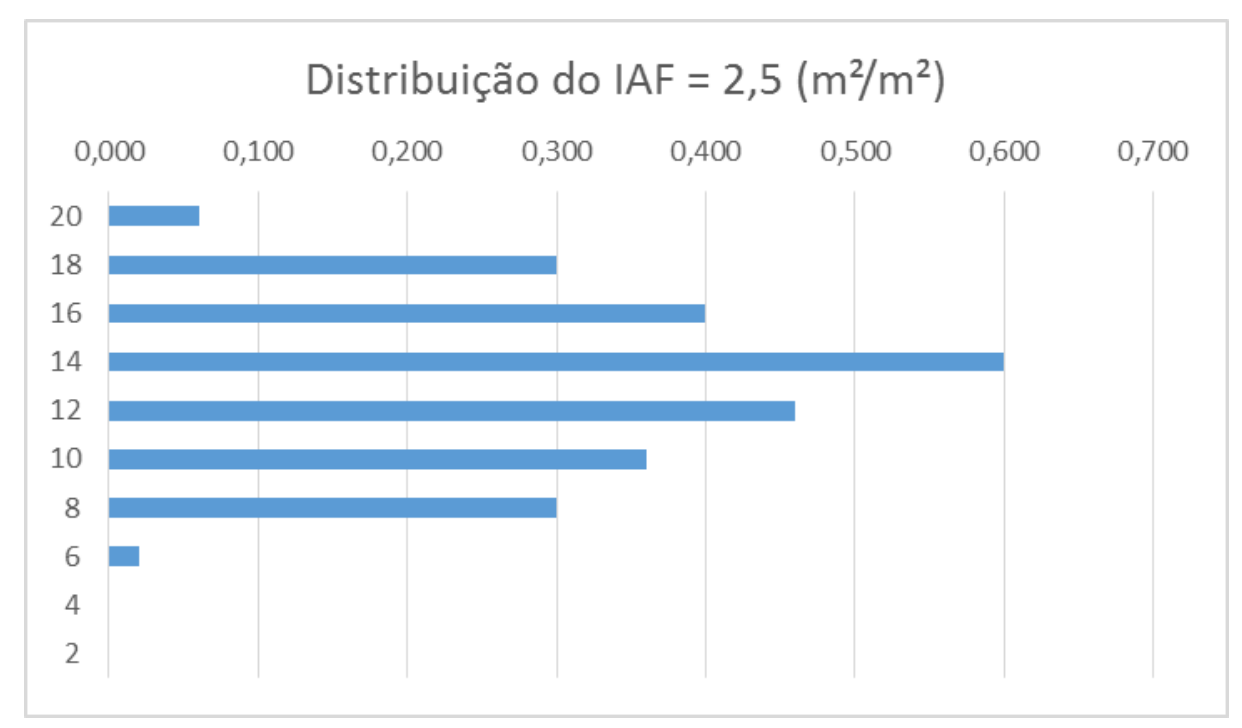

Figura 108: Distribuição dos valores de IAF = 2,5 em 10 camadas de uma arbórea.

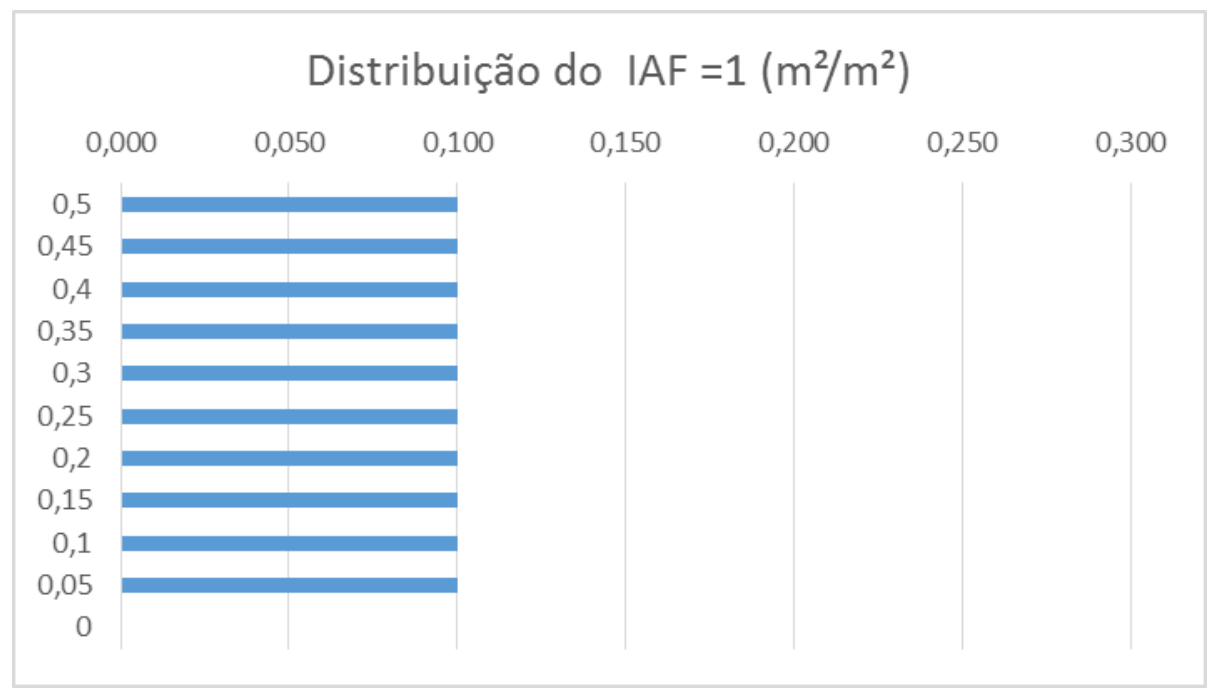

Figura 109: Distribuição dos valores de IAF = 1,0 em 10 camadas de uma arbustiva.

Em seguida foram configuradas as informações de tipo do piso e para isso foram acrescentados dois novo materiais no banco de solos (SOILS.DAT):

- as : asfalto para as vias com características da cidade de SP

- ts : solo franco-arenoso-argiloso para as áreas com vegetação 
A partir dos dados de as e ts foi criado um perfil para o solo no Parque Trianon chamado t1 e o perfil para o asfalto denominado a1. A Tabela 13 mostra as principais características do asfalto criado para a área da Av. Paulista.

Tabela 13: Dados do asfalto no SOIL.DAT e PERFILS.DAT

\begin{tabular}{|c|c|}
\hline Capacidade térmica volumétrica $\left[\mathrm{Jm}^{-3} \mathrm{k}^{-1}\right]$ & $2.1 \times 10^{6}(1)$ \\
\hline Condutividade térmica do material $\left[\mathrm{Wm}^{-1} \mathrm{k}^{-1}\right]$ & $1.15(2)$ \\
\hline Comprimento de rugosidade da superfície $[\mathrm{m}]$ & $0.010(2)$ \\
\hline Albedo para radiação de onda curta & $0.10(3)$ \\
\hline Emissividade para radiação de onda longa na superfície & $0.95(2)$ \\
\hline
\end{tabular}

Fonte: (1) Dados da ABNT (1972) / (2) Hellmann (2008) / (3) Oke (1987)

O solo franco-arenoso-argiloso considerado em toda a área do Parque Trianon apresenta as seguintes características:

Tabela 14: Dados do solo no SOIL.DAT e PERFILS.DAT

\begin{tabular}{|c|c|}
\hline Conteúdo volumétrico de água na saturação [m3m-3] & 0.42 (4) \\
\hline Conteúdo volumétrico de água na capacidade de campo [m3m-3] & 0.255 (4) \\
\hline Conteúdo volumétrico de água no ponto de murcha permanente [m3m-3] & 0.175 (4) \\
\hline Matriz potencial na saturação [m] & -0.299 (4) \\
\hline Condutividade hidráulica na saturação [ ms-1] x 106 & $6.3 \quad(4)$ \\
\hline Capacidade térmica volumétrica [Jm-3k-1] x 106 & 1.175 (4) \\
\hline Constante de Clapp e Hornberger (1978) & 7.12 (4) \\
\hline Comprimento de rugosidade da superfície [m] & 0.010 (5) \\
\hline Albedo para radiação de onda curta & 0.33 (5) \\
\hline Emissividade para radiação de onda longa na superfície & 0.95 (5) \\
\hline
\end{tabular}

Fonte: (4) Dados fornecidos pelo Prof. Dr. Humberto Ribeiro da Rocha, do IAG-USP, de acordo com seus estudos usando o modelo SIB2 - Simple Biosphere Model / (5) Estudos de Parreira et al. (1990) sobre os levantamentos do solo da cidade de São Paulo feitos para a escavação do metrô na linha Paulista. 


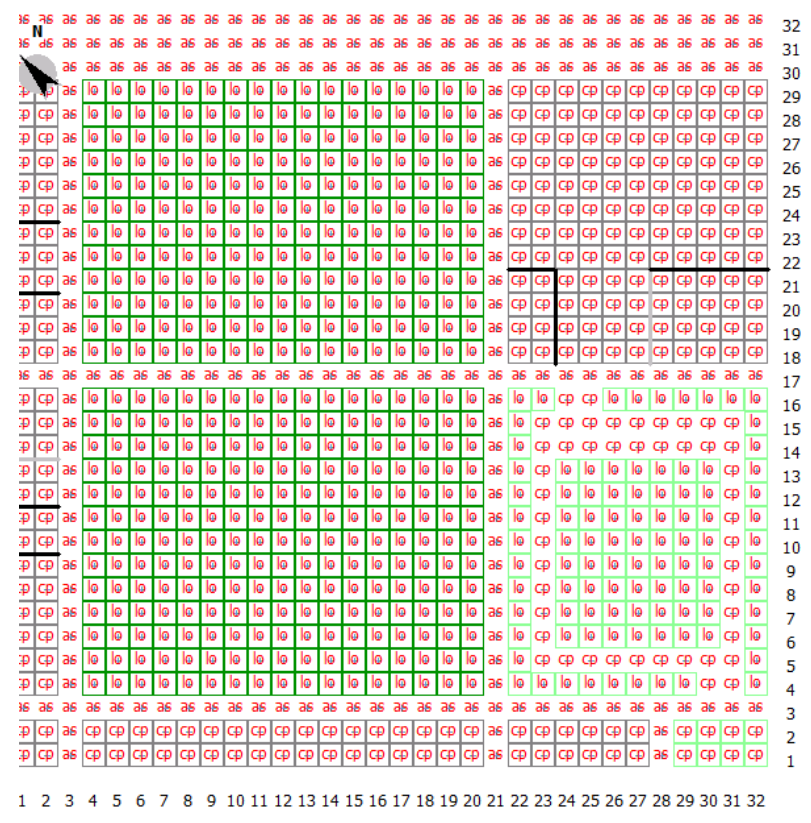

Figura 110: Configuração dos tipos de solo do modelo gerado no ENVI-met.

Também foram posicionados 3 receptores (Edit Receptors) na modelagem: dois (bb/ cc) localizados nos pontos da medição realizada entre os dias 28 de setembro a 1 de outubro de 2012; e o outro na calçada da Av. Paulista (aa), fora dos limites do Parque (Figura 111). Por falta de segurança e disponibilidade de equipamentos, não houve medição de campo na área da calçada, sendo que os resultados do ponto (aa) serão apenas para verificar o comportamento do modelo ENVI-met em um local sem vegetação e com pavimentação em concreto.

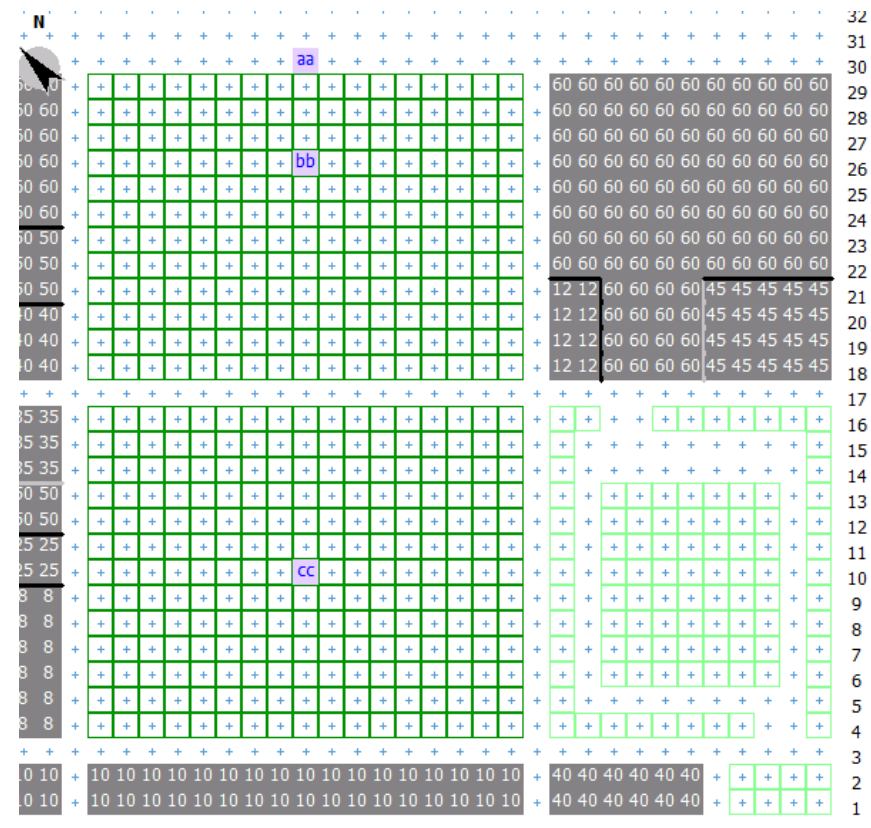

12234456678891011121314151617181920212223242526272829303132

Figura 111: Localização dos receptores no modelo gerado no ENVI-met. 


\subsubsection{CONFIGURAÇÃO DOS DADOS DE ENTRADA}

A partir da definição da modelagem, foram definidas configurações básicas para as simulações. Inicialmente são estabelecidos os seguintes parâmetros:

Tabela 15: Configuração dos dados climáticos

\begin{tabular}{|c|l|l|}
\hline 1 & Nome da simulação & $=$ MySim \\
\hline 2 & Localização do arquivo Input file & $=[$ INPUT]\MyArea.in \\
\hline 3 & Nome do arquivo gerado & $=$ MySim \\
\hline 4 & Localização do arquivo gerado & $=[$ OUTPUT $]$ \\
\hline
\end{tabular}

Os itens 1 e 2 referem-se ao nome criado para a modelagem na primeira etapa (arquivo com extensão .in) e ao local onde se encontra o arquivo, respectivamente. O item 3 indica o nome da pasta a ser criada com o início da simulação e o local onde serão armazenados os dados (item 4).

\begin{tabular}{|c|l|l|}
\hline 5 & Data do início da simulação & $=13.11 .2013$ \\
\hline 6 & Horário do início da simulação & $=21: 00: 00$ \\
\hline 7 & Tempo total da simulação (horas) & $=58.00$ \\
\hline 8 & Registro dos dados (min) & $=60$ \\
\hline 9 & Velocidade do vento a 10m [m/s] & $=1.0$ \\
\hline 10 & Direção do vento (0:N..90:E..180:S..270:W..) & $=250$ \\
\hline 11 & Comprimento de rugosidade zo & $=0.1$ \\
\hline 12 & Temperatura potencial inicial [K] & $=291\left(18^{\circ} \mathrm{C}\right)$ \\
\hline 13 & Umidade específica a 2500m [g Water/kg air] & $=11.25$ \\
\hline 14 & Umidade relativa a 2m [\%] & $=52.5$ \\
\hline 15 & Banco de dados de vegetação & $=[$ input] Plants.dat \\
\hline
\end{tabular}

Item 5 - apresenta a data do início da simulação do Parque Trianon que aconteceu no período de 28 de setembro a 1 de outubro de 2012.

Item 6 - o horário de início das simulações deve acontecer às $24 \mathrm{~h}$, com a atmosfera neutra e o que representa para São Paulo 21h segundo o Greenwitch Mean Time GMT.

Item 7 - o tempo total foi de $58 \mathrm{~h}$ para poder ter dois dias e duas noites simuladas. Item 8 - os dados foram salvos pelo modelo a cada 60min de simulação. 
Item 9 - o valor médio dos ventos medidos no Parque Trianon pela estação no ponto 2 (árvores mais densas) foi de $0,43 \mathrm{~m} / \mathrm{s}$. Mas para maior de estabilidade do programa, foi considerada a velocidade inicial de $1 \mathrm{~m} / \mathrm{s}$. Verificou-se em estudos anteriores que, quanto mais próxima de 0 a velocidade, maior a chance de problemas de convergência da simulação.

Item 10 - segundo os resultados medidos para o ponto 2, não foi identificada uma direção predominante. Assim foi considerado o valor medido às $21 \mathrm{~h}$ do dia 13 de novembro de 2013.

Item 11 - está relacionado com a rugosidade do tecido urbano. Os cálculos do ENVImet são gerados a 2500m a partir do nível do mar e, a partir dessa altura, os dados são calculados até se chegar à superfície. Assim, pela escala, a rugosidade acaba não tendo muita influência e por isso foi mantida no default de 0.1 .

Item 12 - temperatura inicial medida às $21 \mathrm{~h}$ do dia 13 de novembro de 2013, em Kelvin.

Item 13 - umidade específica obtida nos dados da Universidade de Wyoming ${ }^{45}$, dados referentes à estação do Aeroporto Campo de Marte (código da estação: WMO 83779)

Item 14 - dado registrado na medida de campo no Parque Trianon para o horário das $21 \mathrm{~h}$ do dia 13 de novembro de 2013.

Item 15 - sem alteração

\begin{tabular}{|c|l|c|}
\hline 16 & Temperatura inicial do solo na primeira camada $(0-20 \mathrm{~cm})[\mathrm{K}]$ & $=291.5$ \\
\hline 17 & Temperatura inicial do solo na segunda camada $(20-50 \mathrm{~cm})[\mathrm{K}]$ & $=293$ \\
\hline 18 & $\begin{array}{l}\text { Temperatura inicial do solo na terceira camada }(\text { abaixo } 50 \mathrm{~cm}) \\
{[\mathrm{K}]}\end{array}$ & $=296$ \\
\hline 19 & Umidade relativa do solo na primeira camada $(0-20 \mathrm{~cm})$ & $=50$ \\
\hline 20 & Umidade relativa do solo na segunda camada $(20-50 \mathrm{~cm})$ & $=60$ \\
\hline 21 & Umidade relativa do solo na terceira camada $($ abaixo $50 \mathrm{~cm})$ & \\
\hline
\end{tabular}

Item 16 - dados do sensor para temperatura do solo medido de $18,5^{\circ} \mathrm{C}$ no Parque Trianon, em Kelvin.

Itens 17 e 18 - dados estimados em função das medições feitas no Parque Trianon.

${ }^{45}$ Disponível em: < http://weather.uwyo.edu/upperair/sounding.html >. Acesso em março de 2013. 
Itens 19, 20 e 21 - dados estimados pelo Prof. Dr. Humberto Ribeiro da Rocha do IAGUSP para o período de setembro sem chuvas (10 dias antes das medições).

\begin{tabular}{|c|l|c|}
\hline 22 & Calculo de resistência estomática (1=Deardorff, 2=A-gs) & $=2$ \\
\hline 23 & Concentração de $\mathrm{CO}_{2}[\mathrm{ppm}]$ & $=400 \mathrm{ppm}$ \\
\hline 24 & Cobertura de nuvens - céu médio (x/8) & $=4 / 8$ \\
\hline 25 & Fator de ajuste da radiação solar $(0.5-1.5)$ & $=0.9$ \\
\hline
\end{tabular}

Item 22 - escolha pelo modelo de Jacobs (1994) para o cálculo da fisiologia da vegetação.

Item 23 - atualização do dado de concentração de $\mathrm{CO}_{2}$ pelos estudos de Wolf (2000).

Item 24 - de acordo com os dados de nebulosidade fornecido pelo Laboratório MASTER do IAG-USP ${ }^{46}$.

Item 25 - fator de ajuste da radiação solar do modelo com os dados fornecidos pela estação meteorológica do IAG-USP localizado no Parque de Ciência e Tecnologia na Água Funda ${ }^{47}$.

\subsubsection{RESULTADO DA SIMULAÇÃO DE CALIBRAÇÃO}

Inicialmente foi feito o processo de calibração do modelo, considerando-se os dados da medição no período de dias frios. No entanto, para uma condição de clima tropical, o principal benefício da vegetação que é o sombreamento, será sentido principalmente no período de dias quentes. Assim, o modelo também foi ajustado de acordo com os dados medidos no mês de novembro de 2013.

A maior dificuldade nessa fase de estudo foi encontrar dados representativos de materiais como solo ${ }^{48}$ (composição, conteúdo de água no ponto de murcha, saturação e capacidade de campo) e asfalto ${ }^{49}$ (espessura, albedo, condutividade térmica) do local de estudo. Para a obtenção desses dados, foram feitos contatos com orgão públicos

\footnotetext{
${ }^{46}$ Disponível em:< http://www.iag.usp.br/meteo/labmicro/Data $>$. Acesso em março de 2013.

${ }^{47}$ Disponível em: < http://www.estacao.iag.usp.br/ >. Acesso em março de 2013.

48 Informação verbal dos dados de solo foram obtidos com o Prof. Humberto Ribeiro da Rocha do Laboratório de Clima e Biosferada, área de ciências atmosféricas que estão avaliando modelos de balanço de energia em áreas urbanas e em florestas.

${ }^{49}$ Estudo de Hellmann (2008) apresenta dados sobre as propriedades térmicas do asfalto.
} 
(Secretaria do Verde, Embrapa, Instituto Biológico) e verificou-se que faltam estudos voltados para o levantamento dessa informações. Na primeira fase de simulações foram considerados dados específicos das condições climáticas da cidade de São Paulo e dados das características da envoltória e da cobertura dos edifícios. Os resultados estão indicados na Figura 112. Buscando melhor correspondência entre dados medidos e simulados, numa segunda fase de simulações foi feita, com alterações nas características do solo e asfalto, assim como o ajuste na curva de radiação considerada pelo modelo (Figura 113). Os demais dados de entrada foram mantidos em relação à primeira fase de simulação.

Deve-se ter cuidado com a mudanças na configuração de entrada do modelo, pois como toda ferramenta complexa, pode gerar resultados equivocados dependendo dos ajustes feitos e também deve-se verificar o que é necessário como resposta, para não gerar simulações com uma malha excessivamente fina, o que acarreta muito tempo para rodar a simulação.

$\mathrm{Na}$ terceira fase de simulações foram feitas mudanças no fator de ajuste da curva de radiação solar de onda curta por meio de dados do Laboratório MASTER do IAG-USP e aumento da cobertura de nuvens médias no valor de 4/8. A Figura 114 mostra o resultado mais satisfatório da curva de temperatura do ar medida em relação à simulada. A configuração dos dados de entrada da terceira fase foi a calibração adotada para os estudos paramétricos no modelo ENVI-met.

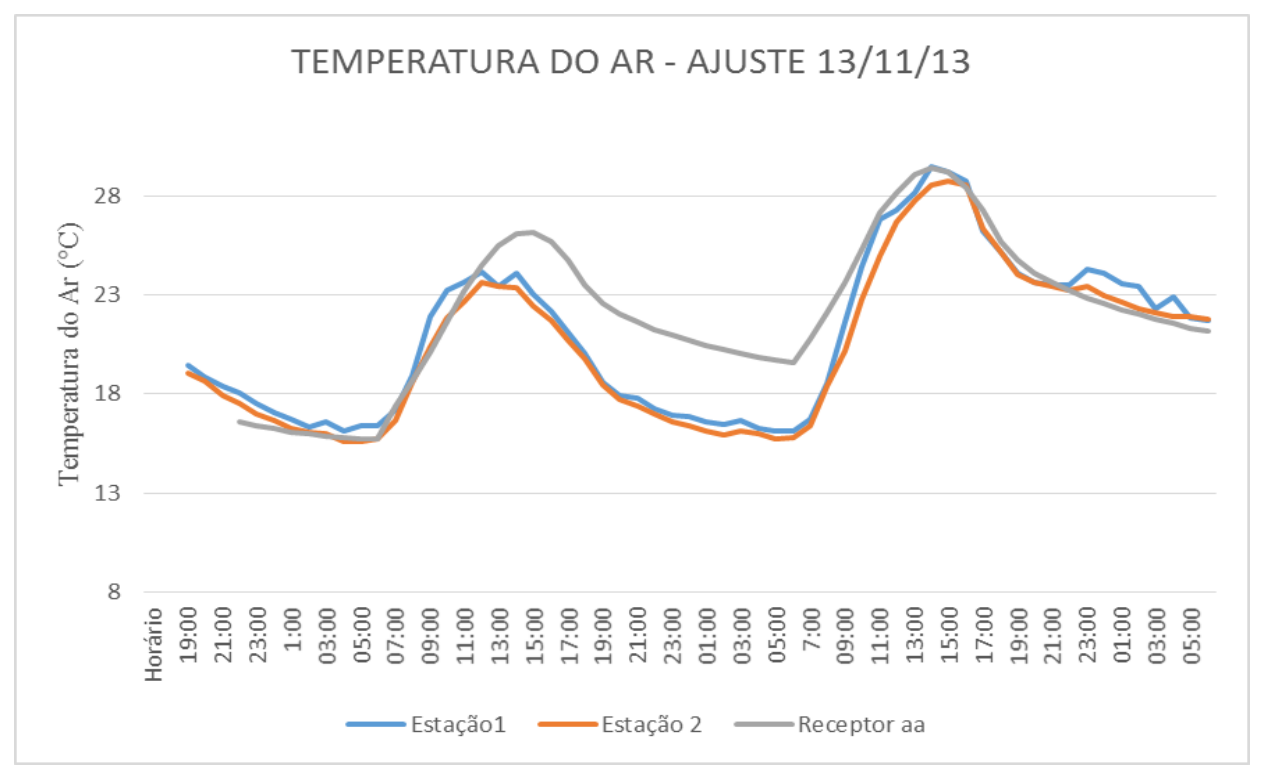

Figura 112: Resultados de temperatura do ar simulados no ENVI-met (receptor aa) e os dados medidos nas duas estações meteorológicas - primeira fase de simulações, para os dias 13 a 15 de novembro de 2013. 


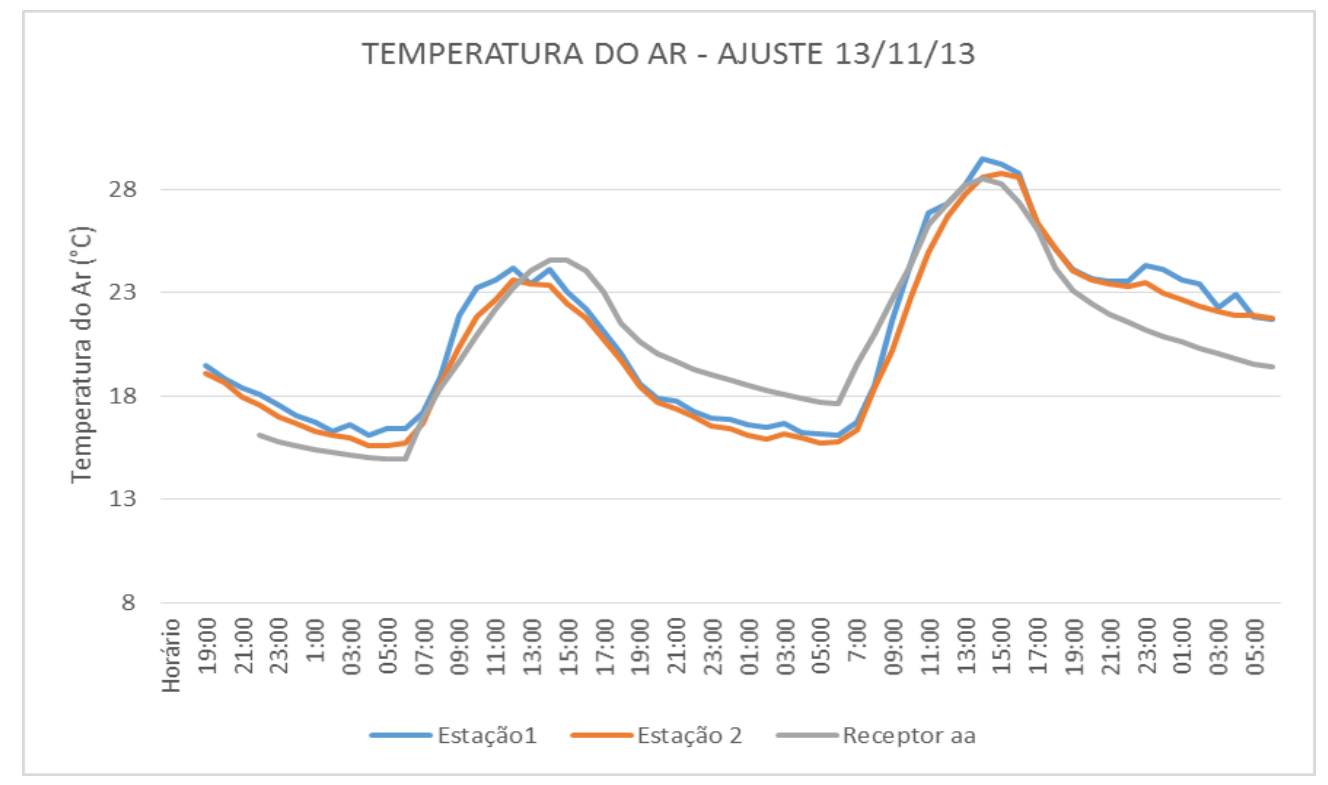

Figura 113: Resultados de temperatura do ar simulados no ENVI-met (receptor aa) e os dados medidos nas duas estações meteorológicas - segunda fase de simulações, para os dias 13 a 15 de novembro de 2013.

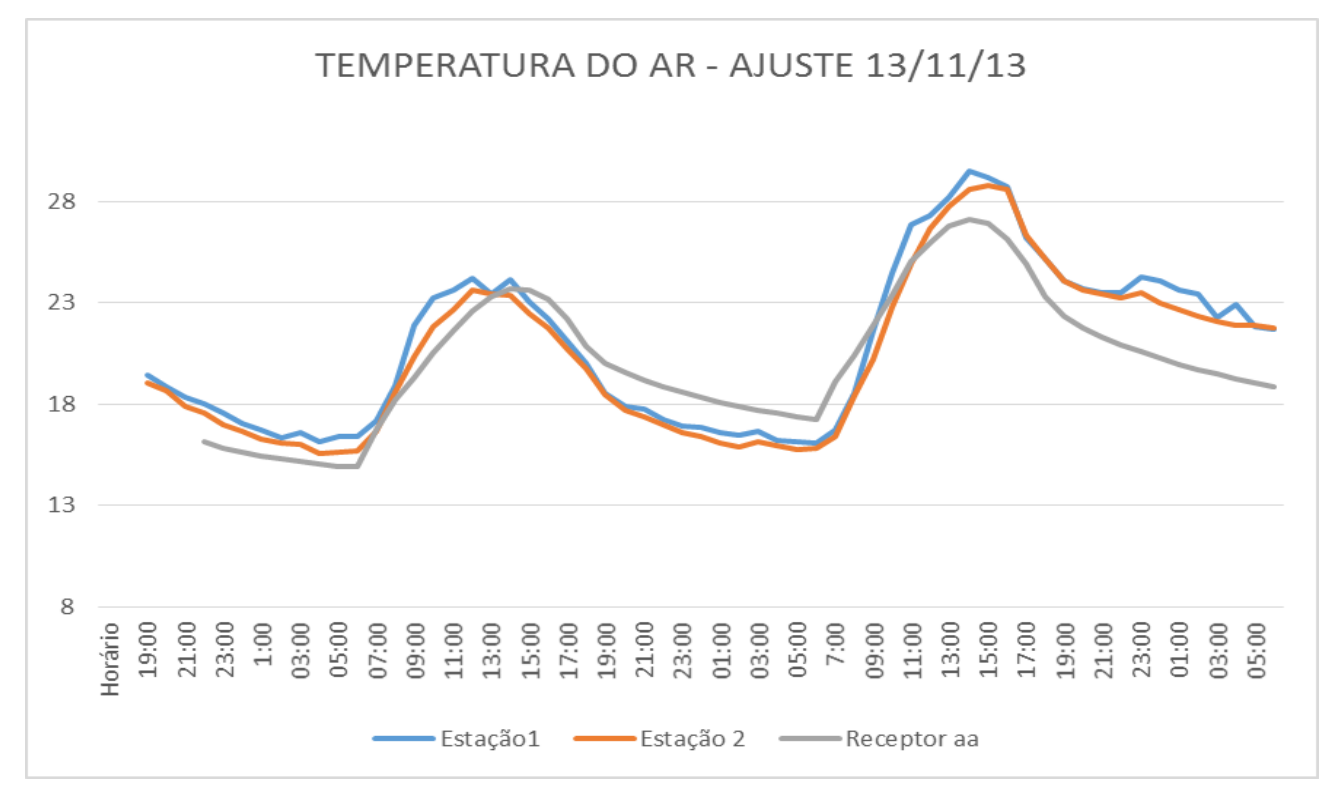

Figura 114: Resultados de temperatura do ar simulados no ENVI-met (receptor aa) e os dados medidos nas duas estações meteorológicas - terceira fase de simulações, para os dias 13 a 15 de novembro de 2013.

\subsection{SIMULAÇÕES PARAMÉTRICAS}

Após a calibração do ENVI-met para as condições locais do Parque Trianon, foram estruturadas quatro etapas de simulações, a fim de se verificar o efeito da vegetação a partir da interação solo-vegetação-atmosfera no modelo e a comparação de resultados a partir das variáveis climáticas (umidade específica, temperatura do ar e da superfície). 
Foram construídos cenários paramétricos em que um único parâmetro era alterado por vez, mantendo-se os demais valores com a mesma configuração definida na calibração do modelo.

\subsubsection{CENÁRIOS DAS SIMULAÇÕES PARAMÉTRICAS}

Considerando-se que a influência da vegetação na temperatura do ar ocorre principalmente em grande parte devido à densidade foliar que contribui nos processos de evapotranspiração e sombreamento, buscou-se realizar a primeira etapa dos estudos paramétricos testando duas tipologias de árvores: uma com a copa no formato arredondado e outra alongada (elipse vertical), ambas com 20 metros de altura e com IAF 1, 3 e 5 (Figura 115).

Buscou-se verificar nesses estudos o entendimento do modelo em relação ao IAF e à distribuição geométrica das aberturas na copa (gap fraction), assim como o efeito de obstrução pela copa em relação à radiação solar.

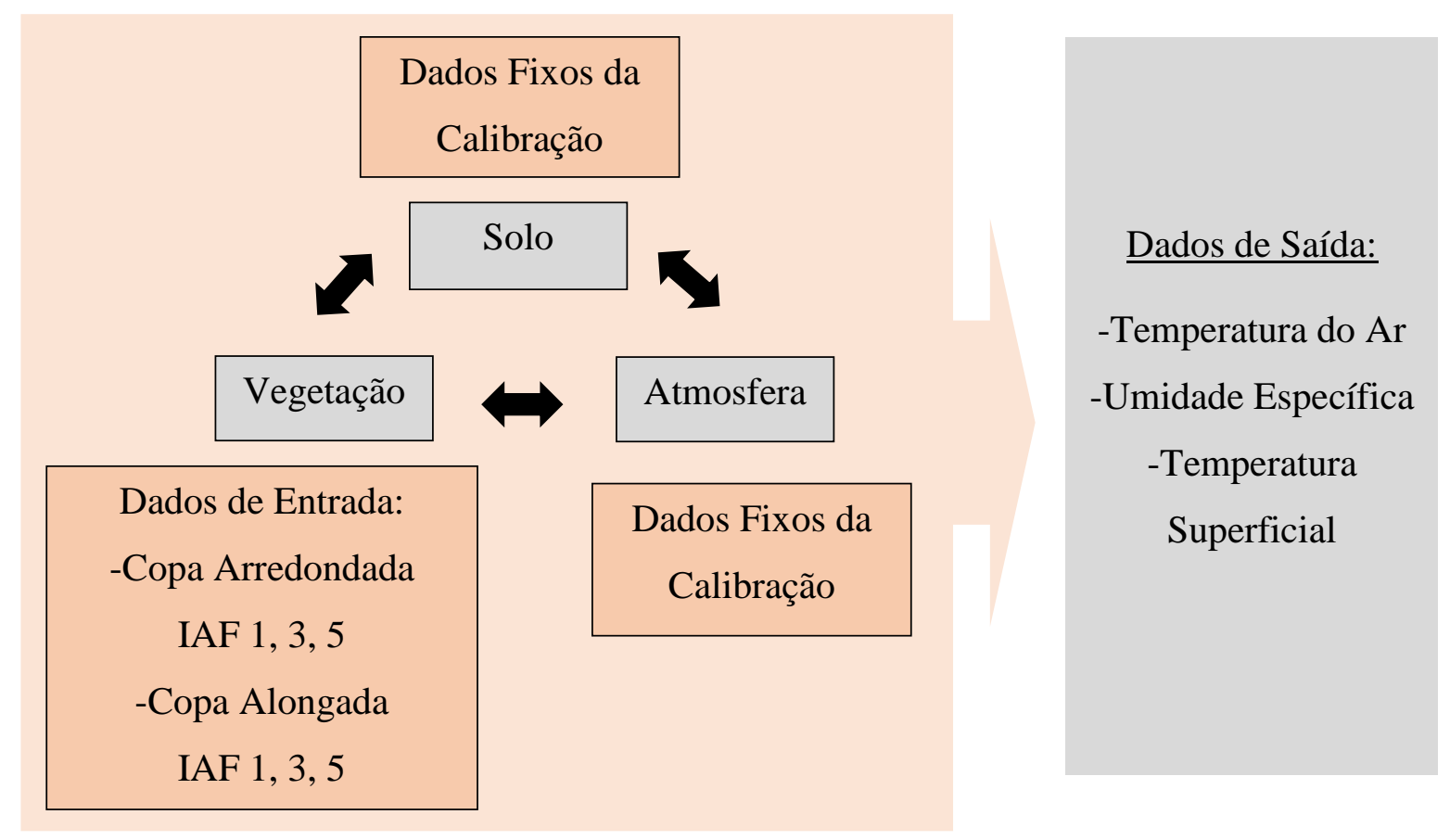

Figura 115: Estrutura geral do processo de simulação na primeira etapa das simulações paramétricas.

Na segunda etapa (Figura 116), foram geradas simulações em função das alterações da velocidade dos ventos na configuração dos dados de entrada. Durante a calibração do modelo foi considerada a velocidade de $1 \mathrm{~m} / \mathrm{s}$ para se evitar problemas de instabilidade e erros de convergência dos dados. 


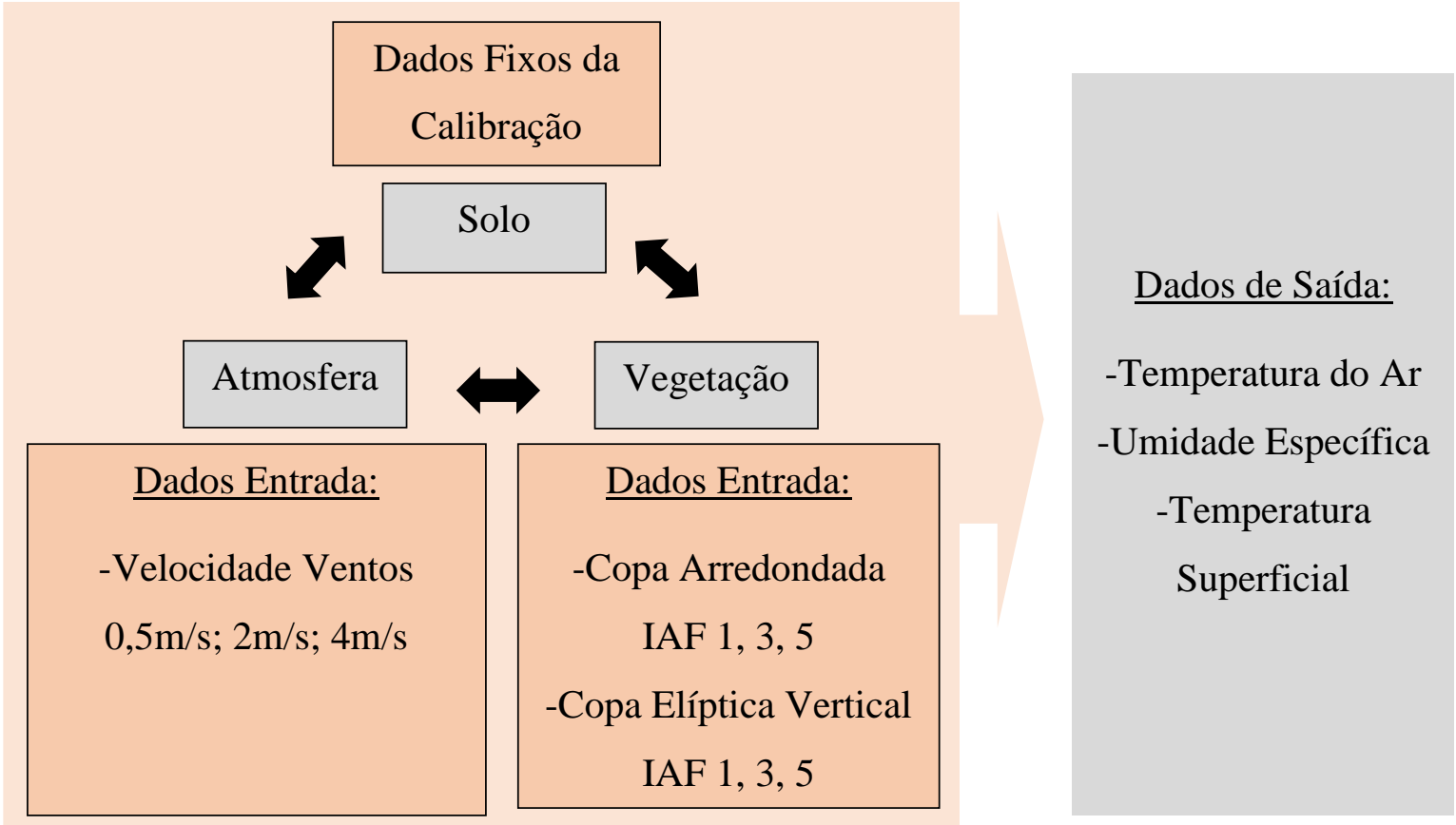

Figura 116: Estrutura geral do processo de simulação na segunda etapa das simulações paramétricas.

Nessa etapa, o objetivo foi de verificar o efeito de obstrução da copa em relação à velocidade dos ventos, desde uma condição de baixa velocidade $(0,5 \mathrm{~m} / \mathrm{s})$ a uma extrema de $4 \mathrm{~m} / \mathrm{s}$ na altura $13 \mathrm{~m}$. Foi calculado o percentual da redução da velocidade de acordo com o tipo da árvore (arredonda ou elíptica) com a análise do perfil do vento para diferentes alturas a partir do solo.

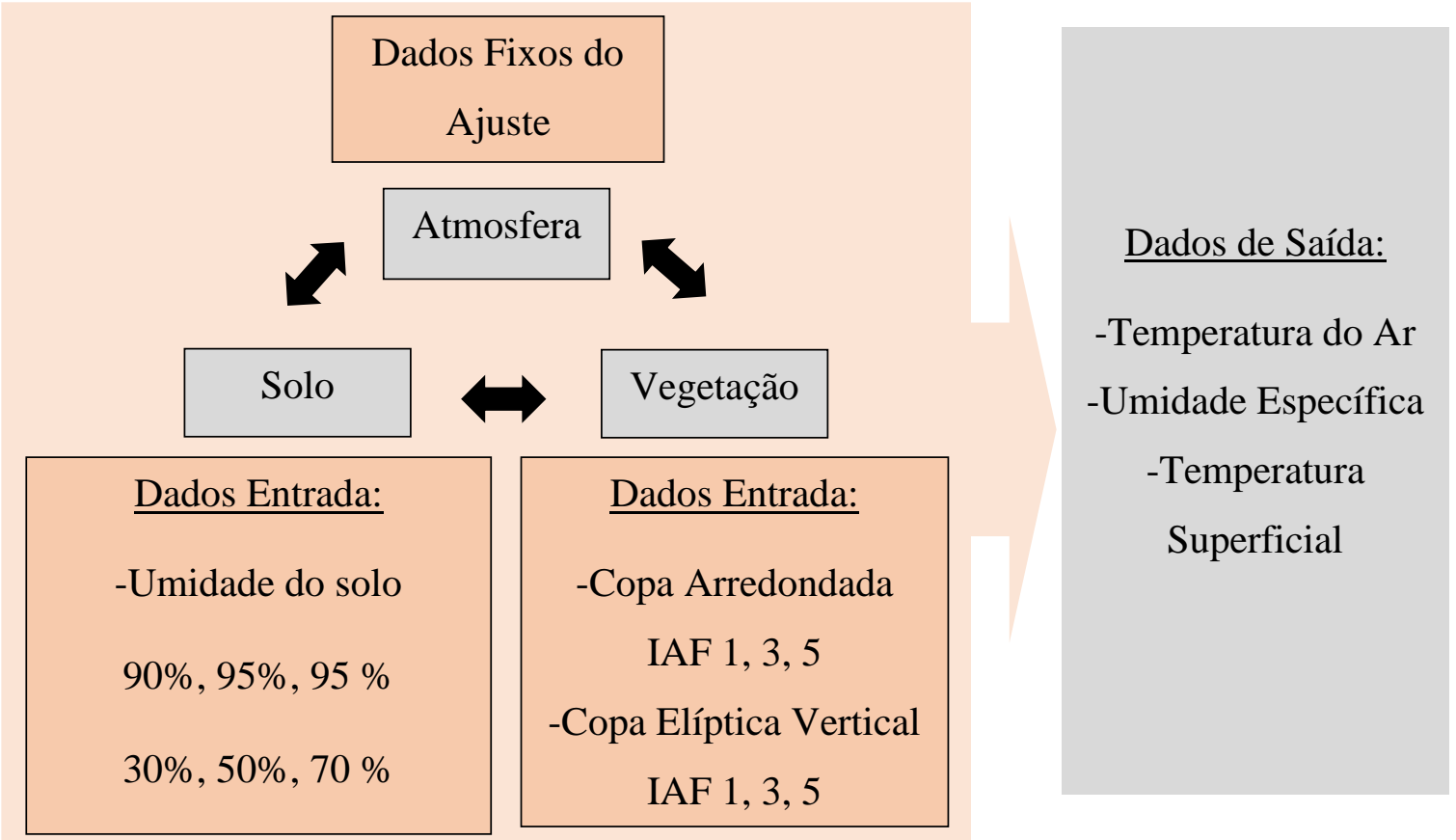

Figura 117: Estrutura geral do processo de simulação na terceira etapa das simulações paramétricas. 
A evapotranspiração é definida como sendo o processo simultâneo de transferência de água para a atmosfera por evaporação da água do solo e da vegetação úmida e por transpiração das plantas. Assim o conteúdo de água no solo colabora diretamente no aumento da umidade e redução da temperatura do ar próxima ao solo.

$\mathrm{Na}$ terceira etapa de simulação (Figura 117) foram consideradas as alterações nas características do solo em relação à umidade para três camadas. Na calibração final do modelo, a faixa superficial $(0-20 \mathrm{~cm}$ de profundidade) foi simulada com umidade relativa de $40 \%$; a faixa intermediária $(20 \mathrm{~cm}-50 \mathrm{~cm}), 50 \%$; e a última camada (mais de $50 \mathrm{~cm}), 60 \%$. Esses dados foram estimados para uma condição de primavera ou outono, com chuvas precedentes à data da medição de campo.

Assim foram definidos dois cenários: uma condição durante dias quentes (chuvoso) com valores de umidade relativa de 90\%, 95\%, $95 \%$ (camada superficial, intermediária, profunda) e outra para uma condição durante o período de dias frios (estiagem) com os valores de $30 \%, 50 \%, 70 \%$.

Nessa fase, o objetivo foi de se verificar a influência da umidade do solo, contribuindo no processo de evapotranspiração junto com a vegetação a fim de reduzir a temperatura do ar próxima ao solo. Além disso foram comparados dados de umidade específica logo acima do solo e temperatura das superfícies (solo x asfalto).

$\mathrm{Na}$ última etapa de simulações (Figura 118), o objetivo foi de se verificar a extensão do efeito da vegetação na temperatura do ar, a partir da borda do parque. Na fase de calibração do modelo, o tamanho das células compondo a malha ortogonal da modelagem foi de $10 \mathrm{~m} \times 10 \mathrm{~m}$ por $2 \mathrm{~m}$ de altura.

As simulações paramétricas permitiram um refinamento da malha, diminuindo-se o tamanho das células para $5 \mathrm{~m}$ x $5 \mathrm{~m}$ e $2 \mathrm{~m}$ x $2 \mathrm{~m}$ no eixo $\mathrm{x}$, y e mantendo a altura de $2 \mathrm{~m}$ no eixo z. A vegetação considerada no interior do parque foi a árvore de copa arredondada com três valores para o IAF. Os demais dados de entrada para a atmosfera e solo foram mantidos segundo as configurações finais da calibração. 


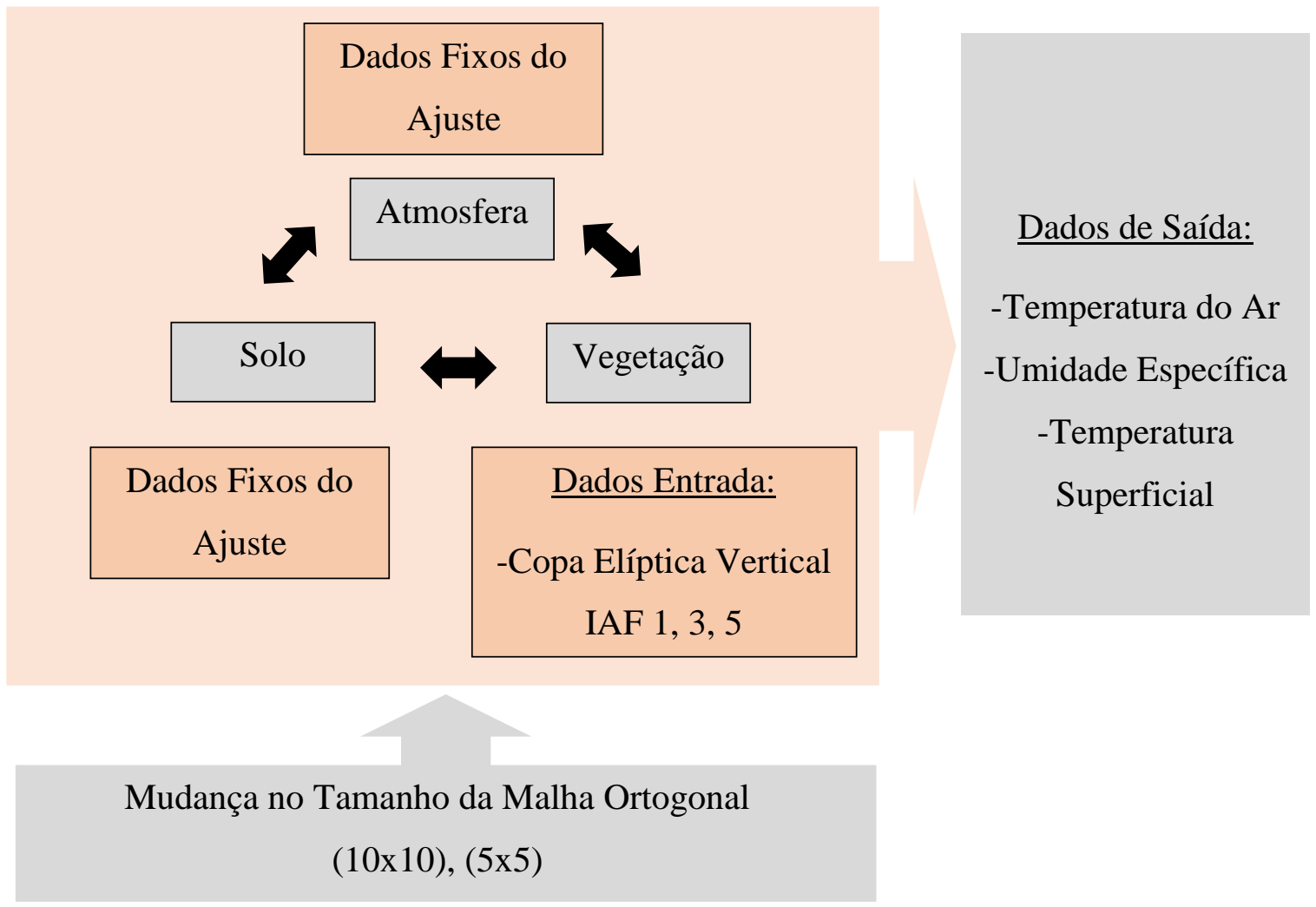

Figura 118: Estrutura geral do processo de simulação na quarta etapa das simulações paramétricas.

\subsubsection{MODELAGEM DAS ÁRVORES NO ENVI-MET}

O banco de dados de vegetação do ENVI-met (PLANTS.DAT) apresenta 27 tipos de vegetação e, a partir dos dados de altura e valores de DAF para a copa, foi possível calcular o IAF de cada indivíduo.

A Tabela 16 mostra dados calculados do IAF e DAF para árvores com altura de 10, $15 \mathrm{~m}, 16 \mathrm{~m}$ e $20 \mathrm{~m}$, a partir dos valores de DAF em 10 camadas, presentes no banco de dados do ENVI-met v.3.1. Observa-se a significativa variação do valor de IAF, podendo ter de 1,84 (MO) até 30,08 (Tb). Segundos os estudos de Caruzzo e Rocha (2000), os valores de IAF medidos para a floresta Amazônica, no Estado de Rondônia, foi de no máximo 5. Assim as tipologias presentes no banco de dados do modelo que apresentam valores de IAF para uma condição de parque urbano são: ds (4,73); L1 (2,70); TH $(2,68)$; MO $(0,92)$; DO $(4,68)$; w $(4,68)$; L2 $(1,84)$.

Por outro lado, apenas o valor total do IAF não possibilita saber com detalhes o formato da copa e a distribuição geométrica das aberturas (gap fraction). Assim, optou-se por 
construir duas tipologias de árvores baseados em medições de IAF feitas no Trianon e dados levantados sobre a vegetação existente no parque.

Tabela 16: Valores de DAF e IAF para os tipos de vegetação existentes no banco de dados do ENVI-met v. 3.1

\begin{tabular}{|c|c|c|}
\hline ÁRVORES 10M & DAF & IAF \\
\hline $\mathrm{ds}$ & 4,73 & 4,73 \\
\hline T1 & 16,98 & 16,98 \\
\hline ÁRVORES 15M & DAF & IAF \\
\hline L1 & 2,70 & 4,05 \\
\hline TH & 2,68 & 4,02 \\
\hline ÁRVORES 16M & DAF & IAF \\
\hline T2 & 14,80 & 23,68 \\
\hline Tb & 18,80 & 30,08 \\
\hline ÁRVORES 20M & DAF & IAF \\
\hline MO & 0,92 & 1,84 \\
\hline DO & 2,34 & 4,68 \\
\hline DM & 4,73 & 9,46 \\
\hline $\mathrm{dm}$ & 4,73 & 9,46 \\
\hline sm & 9,35 & 18,70 \\
\hline bs & 4,51 & 9,02 \\
\hline sc & 9,05 & 18,10 \\
\hline w & 2,34 & 4,68 \\
\hline ee & 0,92 & 1,84 \\
\hline SP & 11,84 & 23,68 \\
\hline & 1,26 & 2,50 \\
\hline
\end{tabular}

Nos estudos de Shinzato (2009), foi realizado um levantamento das principais espécies existentes na arborização de vias da cidade de São Paulo e, em geral, são árvores de copa média até $15 \mathrm{~m}$, a fim de se evitar problemas com a rede pública de energia.

No entanto, nos parques urbanos, existe uma maior diversidade de espécies que em sua fase adulta apresentam alturas maiores que $30 \mathrm{~m}$. No Trianon, foram elencadas as principais espécies nativas e exóticas com as características de altura total, formato e diâmetro da copa, conforme mostra a Tabela 17.

A forma geométrica da copa pode variar conforme a estrutura dos galhos principais, densidade das ramificações e tipos de folhas, assim encontram-se copas de formato arredondado, alongado; largo e arredondado; umbeliforme (formato de guarda-chuva); e piramidal (MASCARÓ, 2005).

Para este trabalho foram escolhidos dois tipos de copa: a arredondada e a alongada, com $20 \mathrm{~m}$ de altura e $6 \mathrm{~m}$ de diâmetro. O formato arredondado é o mais comum para as 
espécies brasileiras, sendo o formato alongado característico de espécies como Ipê amarelo (Tabeluia sp.), Ipê branco (Tabebuia roseoalba), Paineira (Chorisia speciosa) e Eucalipto (Eucalyptus sp.).

Tabela 17: Principais espécies de vegetação existente no Parque Trianon

\begin{tabular}{|c|l|c|c|c|c|}
\hline Nome cientifico & $\begin{array}{l}\text { Nome } \\
\text { popular }\end{array}$ & Local & $\begin{array}{c}\text { Formato da } \\
\text { Copa }\end{array}$ & $\begin{array}{c}\text { Diâmetro } \\
\text { (m) }\end{array}$ & $\begin{array}{c}\text { Altura } \\
\text { (m) }\end{array}$ \\
\hline $\begin{array}{c}\text { Caesalpinia ferrea } \\
\text { var. leiostachya }\end{array}$ & Pau Ferro & nativa & $\begin{array}{c}\text { Arredondada } \\
\text { larga }\end{array}$ & 12 & $20-30$ \\
\hline $\begin{array}{c}\text { Caesalpinia } \\
\text { echinata Lam. }\end{array}$ & Pau Brasil & nativa & arredondada & 12 & $20-30$ \\
\hline $\begin{array}{c}\text { Nectandra } \\
\text { megapotamica }\end{array}$ & Canela Preta & nativa & arredondada & $10-20$ & $15-25$ \\
\hline $\begin{array}{c}\text { Chorisia } \\
\text { speciosa }\end{array}$ & Paineira & nativa & alongada & 15 & $15-30$ \\
\hline $\begin{array}{c}\text { Cariniana } \\
\text { estrellensis }\end{array}$ & $\begin{array}{l}\text { Jequitiba } \\
\text { Branco }\end{array}$ & nativa & piramidal & $10-12$ & $10-50$ \\
\hline $\begin{array}{c}\text { Cerella } \\
\text { fissilis }\end{array}$ & Cedro & nativa & umbeliforme & 7 & $10-25$ \\
\hline $\begin{array}{c}\text { Phoenix } \\
\text { dactylifera }\end{array}$ & Tamareira & exótica & arredondada & $4-6$ & $15-25$ \\
\hline $\begin{array}{c}\text { Salix } \\
\text { babylonica }\end{array}$ & $\begin{array}{l}\text { Salgueiro } \\
\text { Chorão }\end{array}$ & exótica & arredondada & 6 & $8-20$ \\
\hline $\begin{array}{c}\text { Spathodea } \\
\text { campanulata }\end{array}$ & Espatodea & exótica & arredondada & 4 & $15-30$ \\
\hline \begin{tabular}{c} 
Ficus sp. \\
\hline
\end{tabular} & Figueira & exótica & arredondada & 4 & 8 \\
\hline
\end{tabular}

Fonte: Lorenzi (1998) e SVMA (2005)

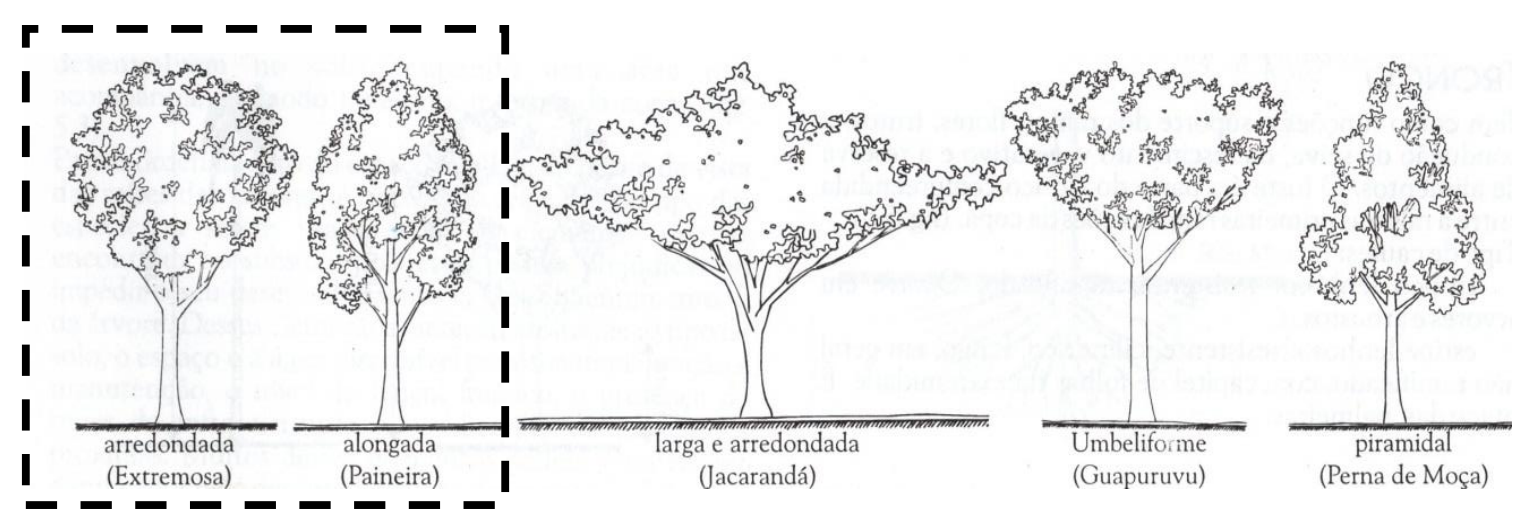

Figura 119: Diferentes formatos de copas das árvores.

Fonte: Mascaró (2005)

A partir da escolha dos tipos de copa, foi feito um modelo 3D no programa Autocad, em que as árvores foram cortadas em faixas de $2 \mathrm{~m}$, gerando 10 camadas a partir do solo. A copa arredondada tem $14 \mathrm{~m}$ de diâmetro e volume de $1767,15 \mathrm{~m}^{3}$, enquanto a copa alongada apresenta $10 \mathrm{~m}$ de diâmetro e $785,40 \mathrm{~m}^{3}$ de volume. 

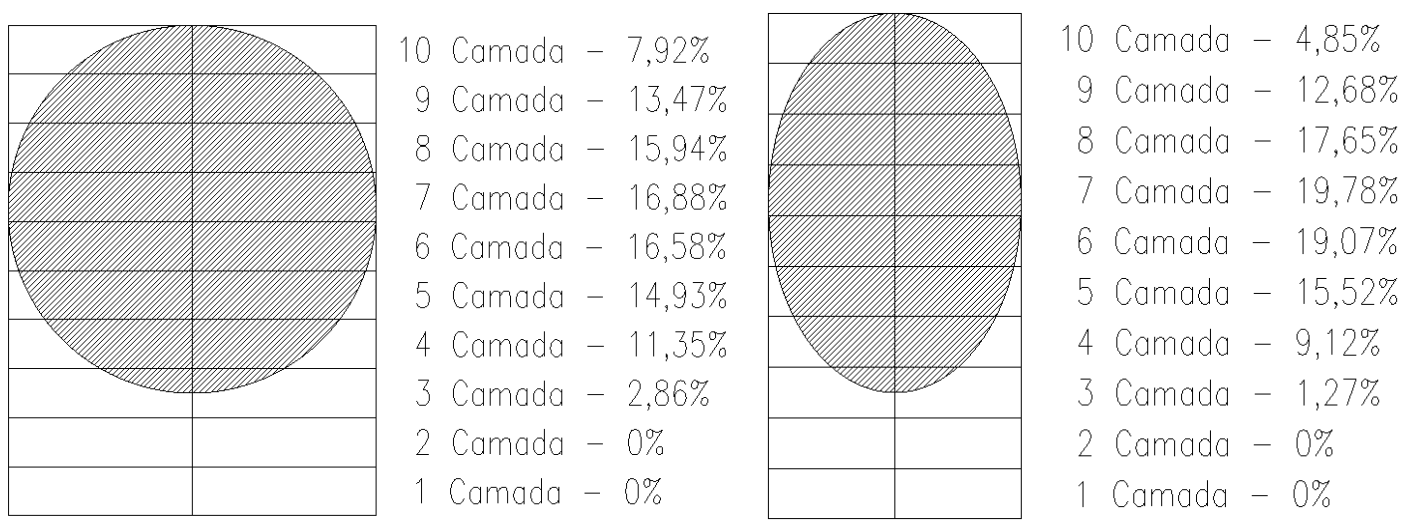

Figura 120: Porcentagem de volume para diferentes formatos de copa.

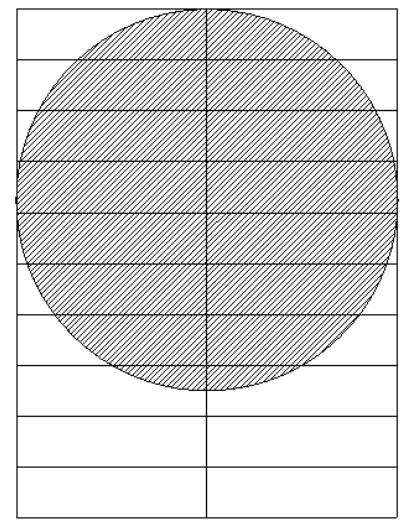

Valores de IAF
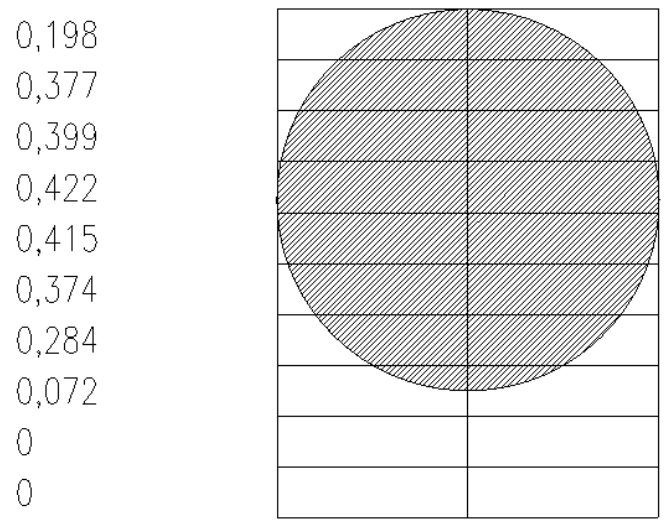

Valores de DAF

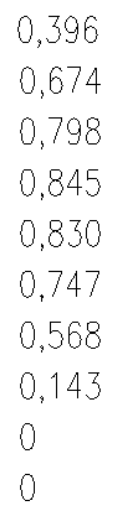

DAF Total $=2,50$

Figura 121: Distribuição dos valores de IAF e DAF para 10 camadas de uma copa arredondada.

Em seguida foi calculada a porcentagem do volume da copa em cada camada em relação ao volume total (Figura 120). Esses valores foram considerados no cálculo do IAF e DAF de cada árvore, a fim de se manter a mesma proporção na distribuição das folhas, conforme mostra a Figura 121, para a árvore arredondada com IAF de 5.

As Figuras 122, 123 e 124 mostram o perfil do DAF para a árvore com copa arredondada, sendo que o A1 é uma árvore com IAF de $1 \mathrm{~m}^{2} / \mathrm{m}^{2} \mathrm{O}$ A2 representa uma árvore com IAF de $3 \mathrm{~m}^{2} / \mathrm{m}^{2}$ e o A3, uma árvore com IAF de $5 \mathrm{~m}^{2} / \mathrm{m}^{2}$. As folhas que se iniciam a $5 \mathrm{~m}$ do solo e altura total de $20 \mathrm{~m}$.

As Figuras 125, 126 e 127 mostram o perfil do DAF para a árvore com copa elíptica, sendo que o B1 é uma árvore com IAF de $1 \mathrm{~m}^{2} / \mathrm{m}^{2} \mathrm{O}$ B2 representa uma árvore com IAF de $3 \mathrm{~m}^{2} / \mathrm{m}^{2}$ e o B3, uma árvore com IAF de $5 \mathrm{~m}^{2} / \mathrm{m}^{2}$. As folhas que se iniciam a $5 \mathrm{~m}$ do solo e altura total de $20 \mathrm{~m}$. No próximo capítulo serão apresentados os resultados para cada etapa das simulações, mostrando o efeito do sombreamento e processo de 
evapotranspiração das novas tipologias de árvores criadas, a partir dos dados de temperatura do ar, umidade específica e temperatura superficial.

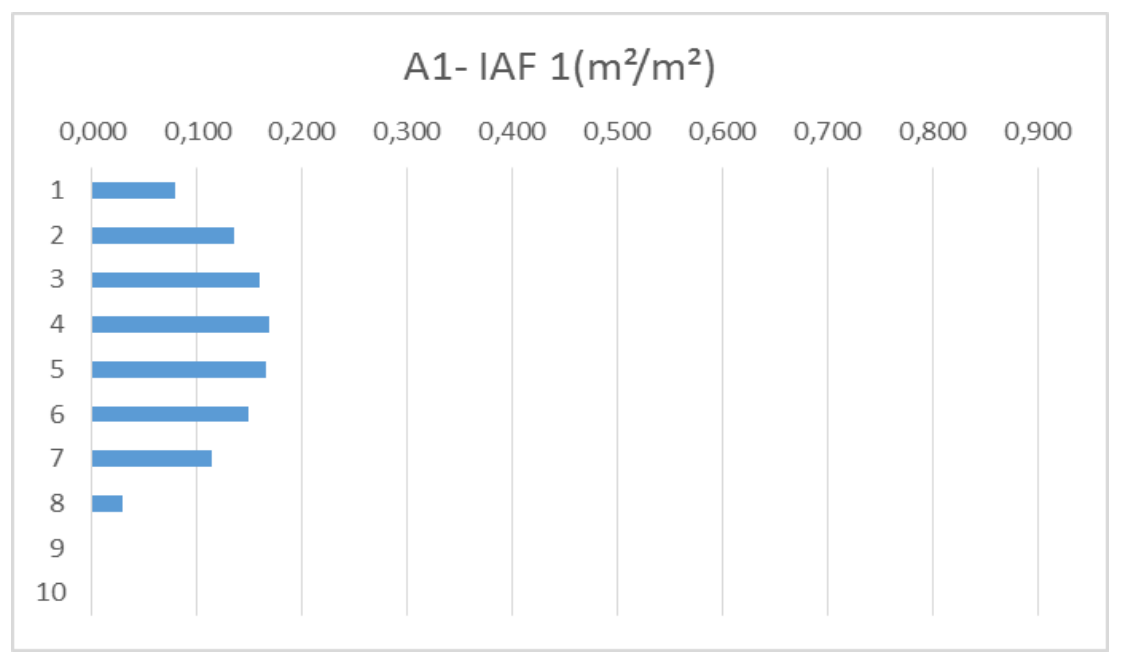

Figura 122: Perfil do valor de IAF=1 distribuído em 10 camadas para copa esférica.

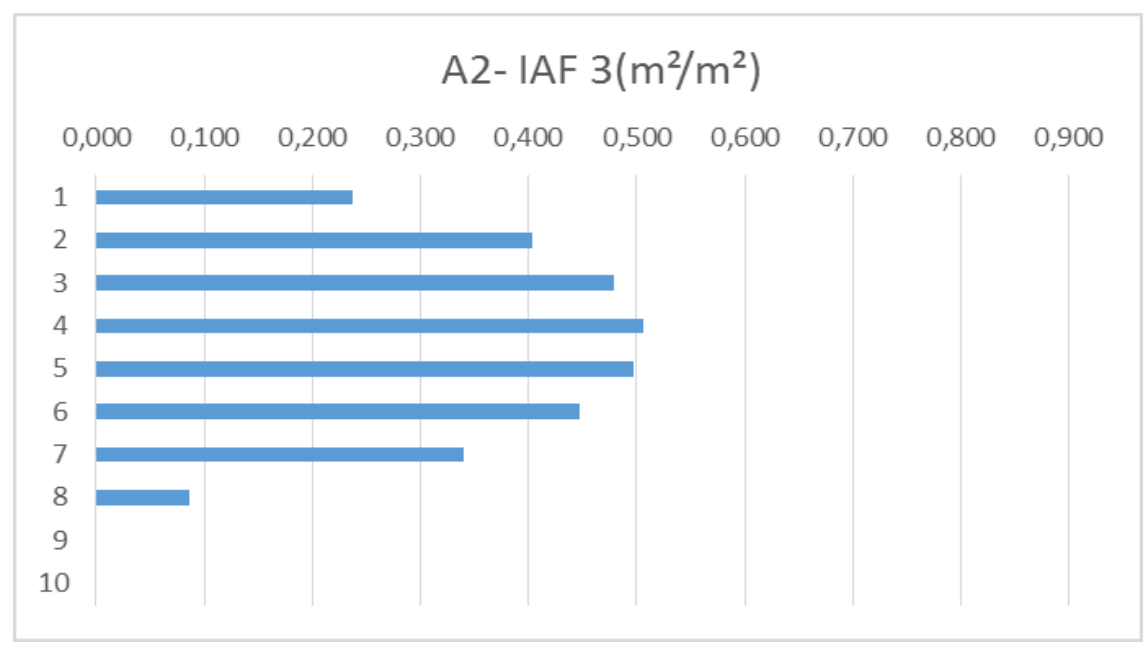

Figura 123: Perfil do valor de IAF=3 distribuído em 10 camadas para copa esférica.

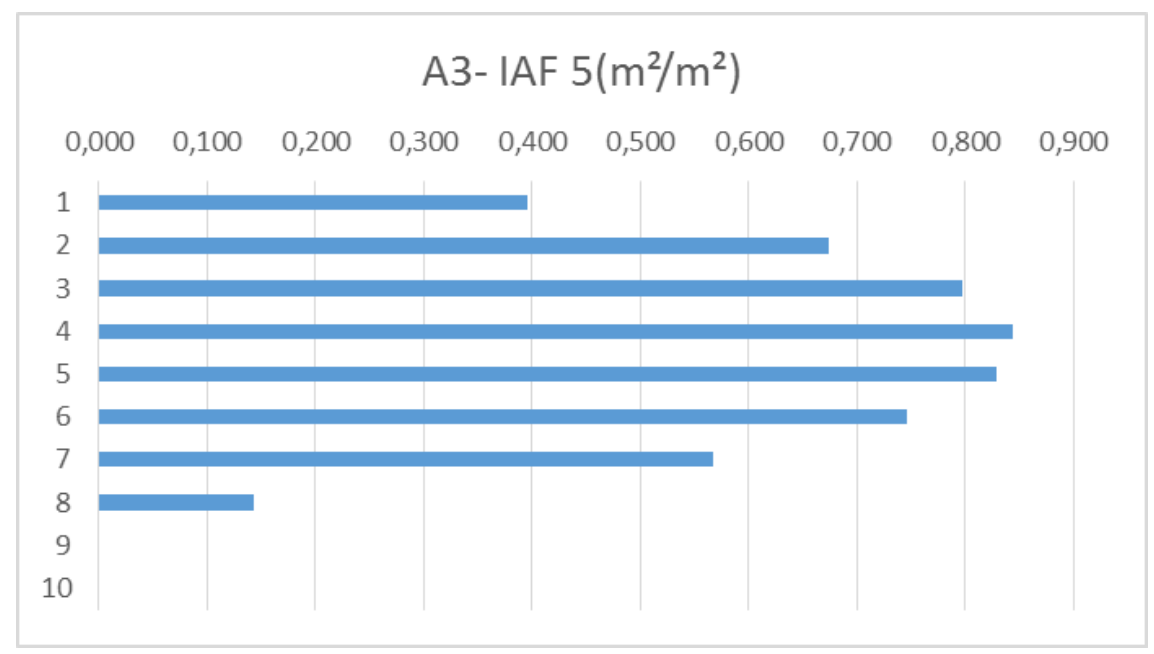

Figura 124: Perfil do valor de IAF=5 distribuído em 10 camadas para copa esférica. 


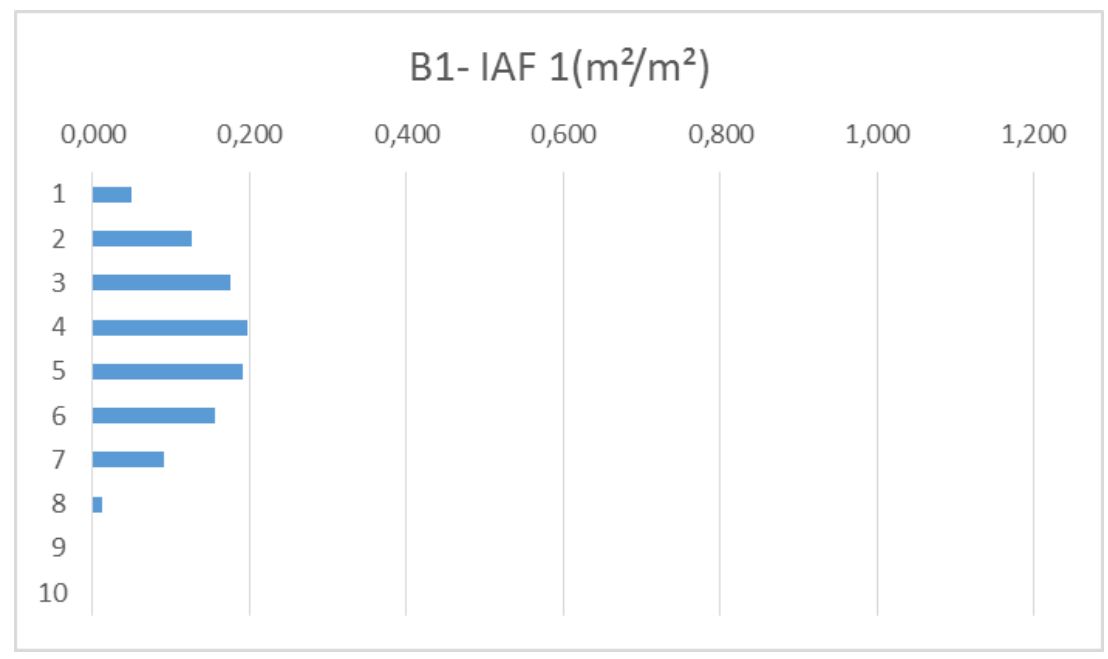

Figura 125: Perfil do valor de IAF=1 distribuído em 10 camadas para copa elíptica.

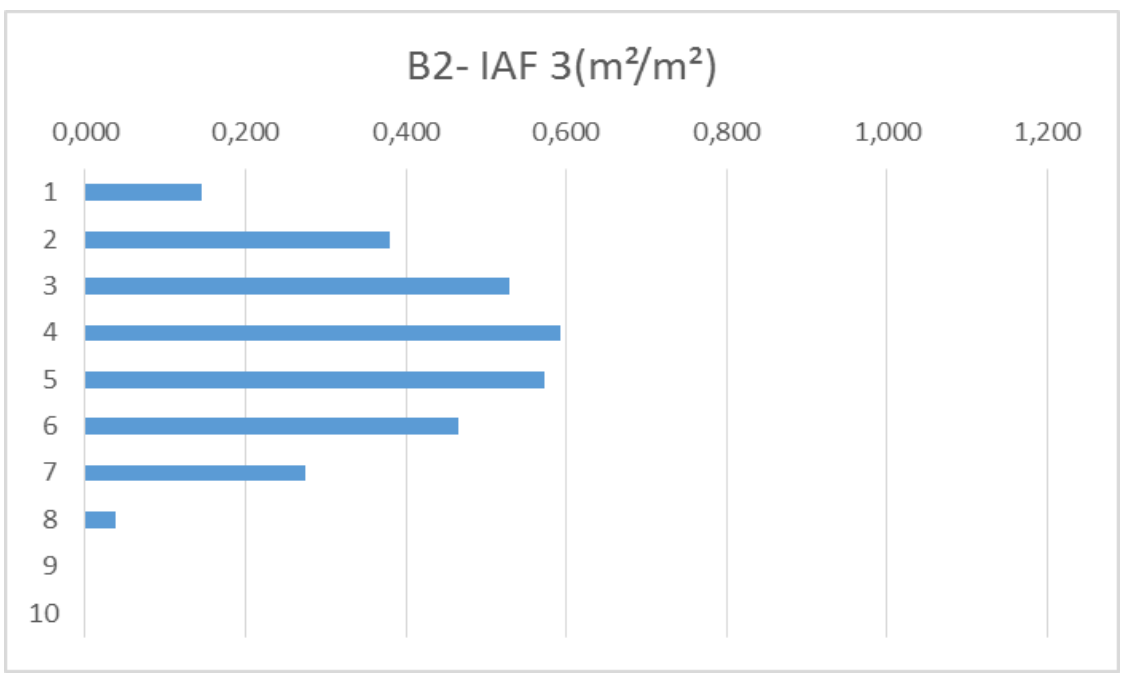

Figura 126: Perfil do valor de $\mathbf{I A F}=3$ distribuído em 10 camadas para copa elíptica.

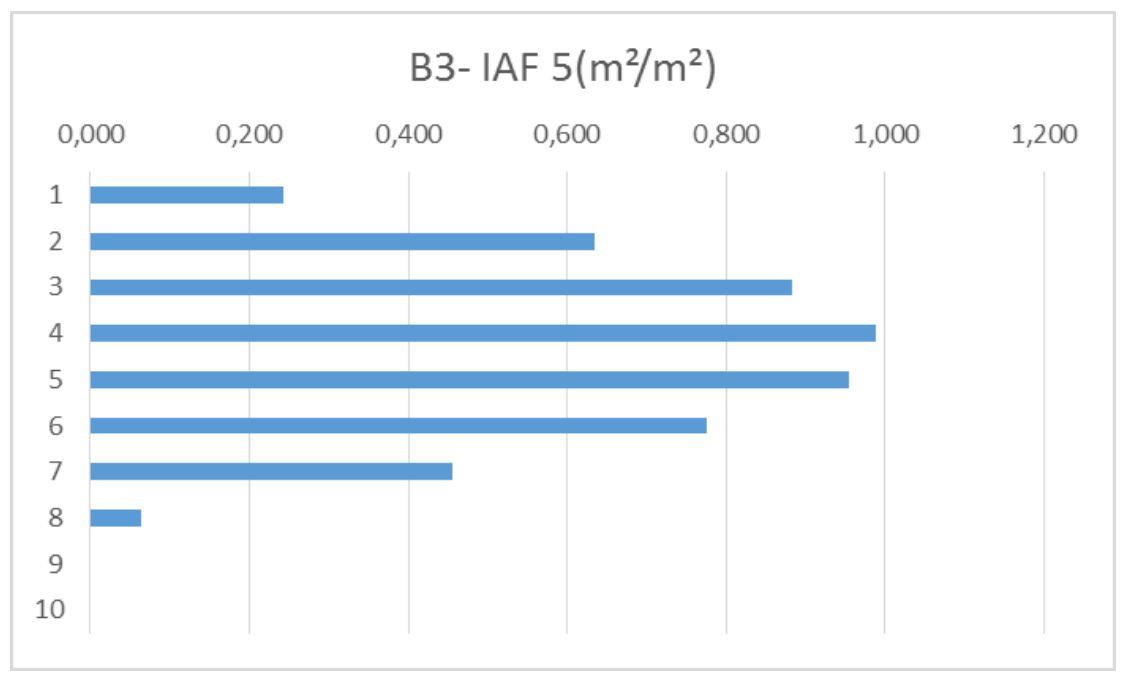

Figura 127: Perfil do valor de IAF=5 distribuído em 10 camadas para copa elíptica. 


\section{ANÁLISE DOS RESULTADOS E COMPROVAÇÃO DA TESE}

Conforme os cenários paramétricos apresentados no capítulo anterior, as simulações foram feitas utilizando o modelo ENVI-met e os resultados foram obtidos a partir dos dados específicos dos receptores e estão apresentados de acordo com as quatro etapas das simulações paramétricas propostas.

\subsection{RESULTADOS E ANÁLISES DAS SIMULAÇÕES PARAMÉTRICAS}

\subsubsection{RESULTADOS ETAPA 1}

A cobertura do dossel influencia no total de radiação solar que atinge a superfície abaixo deste. O IAF e a forma como estão distribuídas as aberturas geométrica na copa (gap fraction) é o que definirá o efeito de obstrução do dossel, calculado em função da radiação solar incidente acima e abaixo do dossel.

Objetivando avaliar o efeito das duas tipologias de árvores criadas (copa esférica e elíptica vertical), as simulações nessa etapa mantiveram os dados climáticos, assim como as características do solo, já definidos na fase de ajuste.

A Figura 128 mostra efeito de obstrução pelo dossel, indicando a porcentagem de radiação direta que chega na altura de $13 \mathrm{~m}$ (curva azul) e $0,2 \mathrm{~m}$ (curva vermelha) a partir do solo considerando diferentes valores de IAF, obtidos para o dia 15 de novembro de 2013 às $12 \mathrm{~h}$.

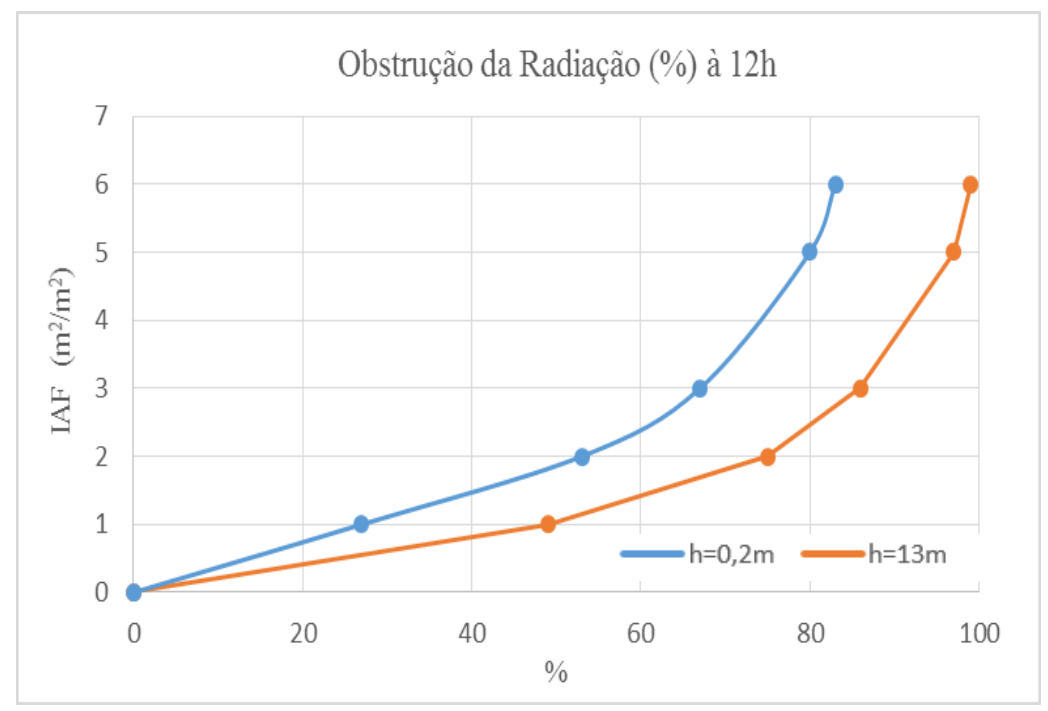

Figura 128: Efeito de obstrução da radiação direta para duas alturas (13m, 0,2m) 
Percebe-se pelo resultado das curvas de obstrução da radiação que ao aumentar o valor do IAF, a porcentagem de radiação chega no solo para IAF 5 é por volta de $5 \%$ da radiação solar que incide sob a copa. A curva hiperbólica na copa de formato elíptico apresenta valores maiores que a copa esférica, mostrando que o modelo ENVI-met calcula o coeficiente de extinção k e isso está ligado não apenas ao valor do IAF, mas no formato da copa.

As Figuras 129, 130 e 131 mostram os resultados da temperatura do ar, umidade específica e temperatura de superfície abaixo dossel, respectivamente. Os dados foram obtidos por simulações realizada no dia 15 de novembro de 2013 às 15 h. O horário foi escolhido devido à temperatura do ar máxima registrada pelas estações meteorológicas no parque Trianon. Foram comparados os resultados simulados para áreas com vegetação (IAF 1, 3 e 5) em relação à área da rua sem vegetação e com piso impermeável de asfalto. Além da variação no IAF, as árvores apresentaram diferenças no formato da copa (esférica e elíptica vertical).

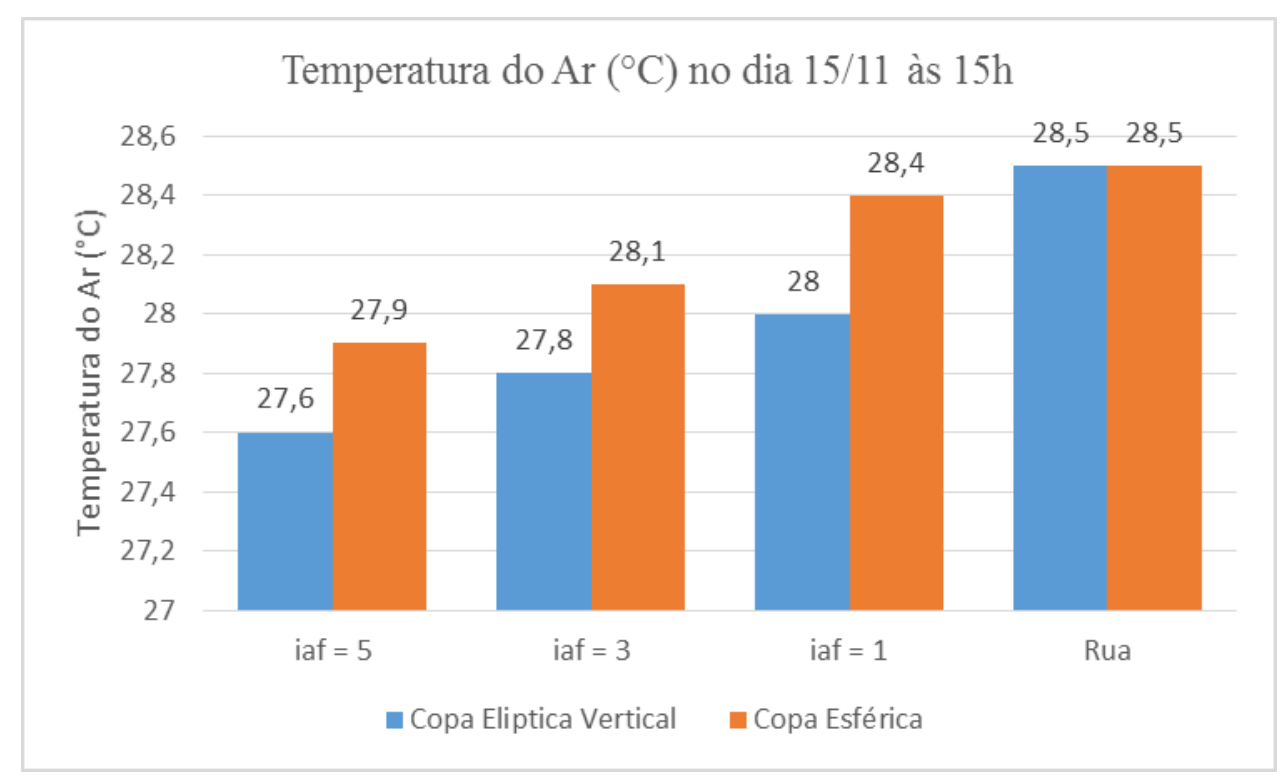

Figura 129: Temperatura do ar abaixo da copa esférica, elíptica vertical e na rua. 


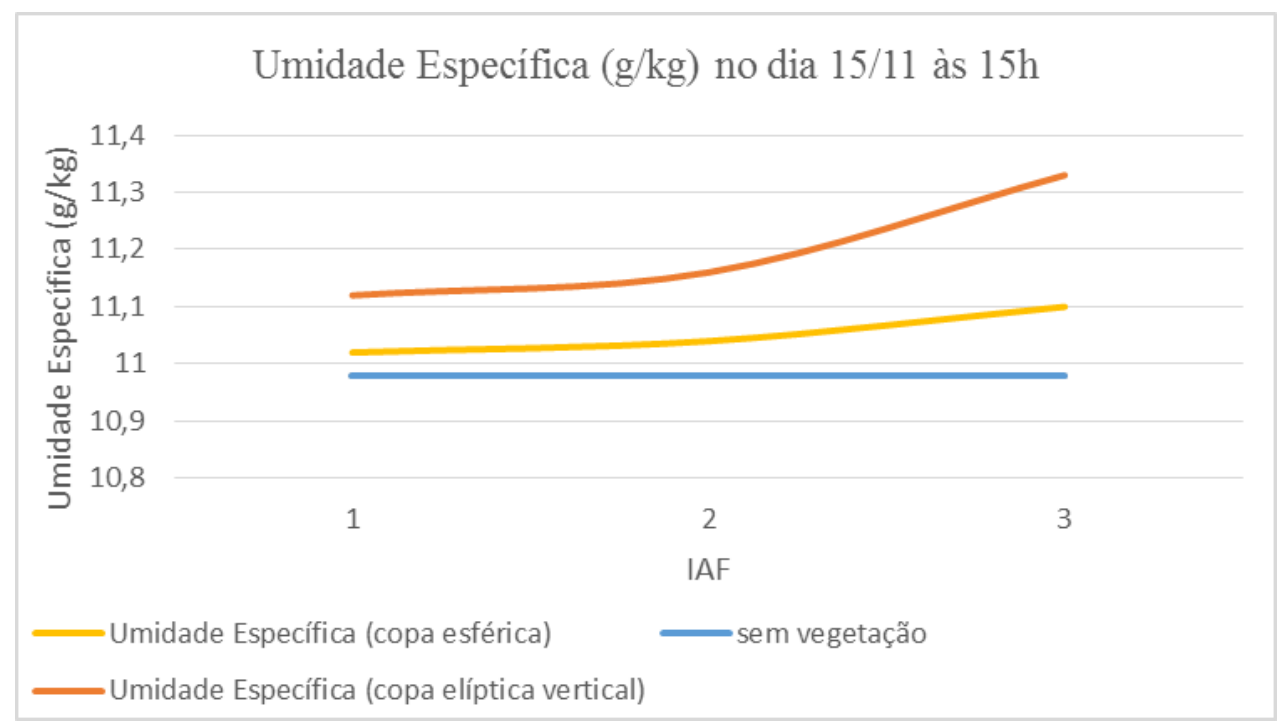

Figura 130: Umidade Específica abaixo da copa esférica, elíptica vertical e na rua.

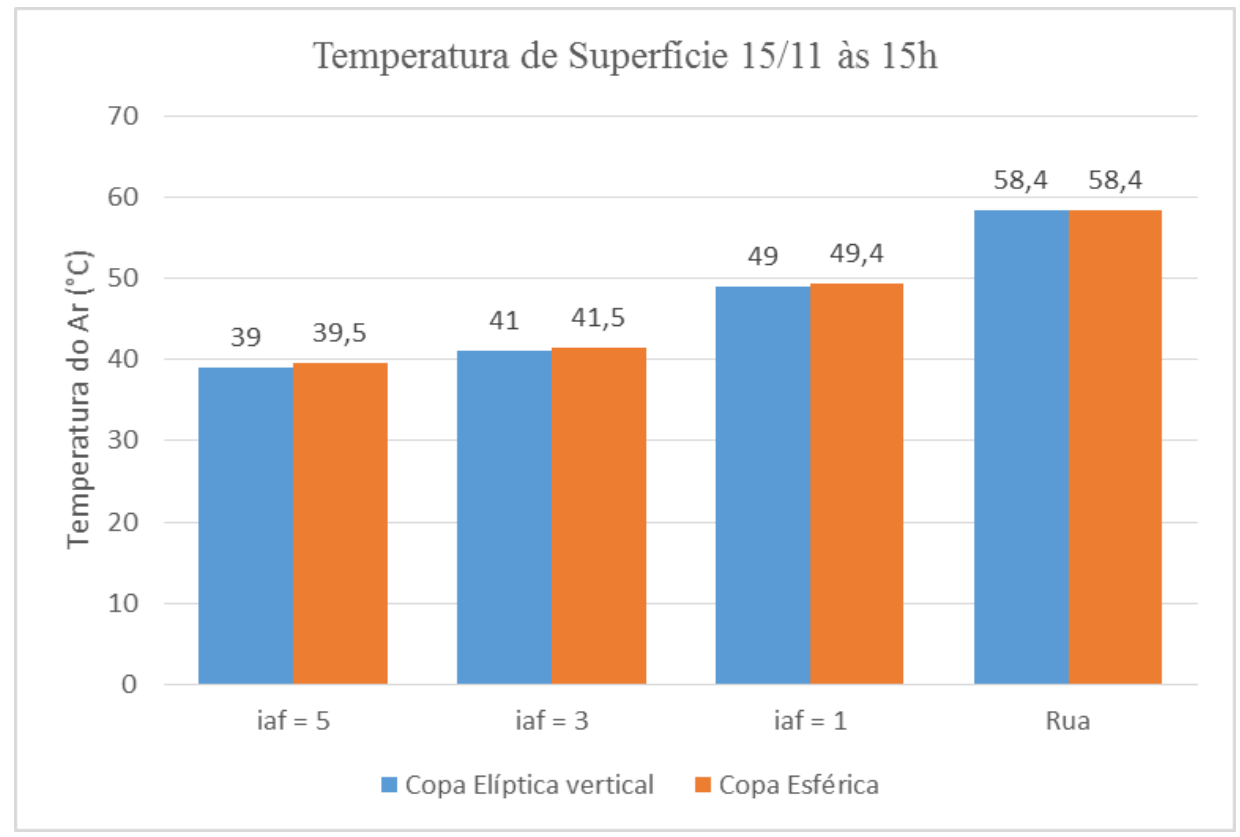

Figura 131: Temperatura de superfície para esférica, elíptica vertical e na rua.

A altura de $13 \mathrm{~m}$ corresponde ao meio da copa e de acordo com os resultados para um mesmo IAF de 2,5 (média do IAF para o parque Trianon), o meio da copa de formato elíptico vertical irá obstruir cerca de $60 \%$ da radiação total e a $2 \mathrm{~cm}$ de solo, chega cerca de $20 \%$ (copa inteira pode obstruir até $80 \%$ ) da radiação solar incidente. Esses valores ajudam a perceber o efeito do sombreamento provocada pela vegetação, ao mesmo tempo em que o modelo ENVI-met é capaz de perceber as variações do IAF em relação a distribuição geométrica das aberturas na copa (gap fraction).

Nos resultados para temperatura do ar, percebe-se que para um mesmo valor de IAF e apenas variando o formato da copa, a temperatura do ar para a copa elíptica vertical é 
em média $0,3^{\circ} \mathrm{C}$ menor que a copa esférica. Observa-se também uma redução máxima de $1^{\circ} \mathrm{C}$ ao comparar o valor obtido abaixo da copa elíptica de IAF 5 em relação à temperatura do ar na rua.

A Figura 130 mostra que a umidade específica para as simulações com copas elípticas apresentou valores de $11,1 \mathrm{~g} / \mathrm{kg}$ para IAF 1 à $11,4 \mathrm{~g} / \mathrm{kg}$ para IAF 5 . A curva para umidade específica simulada para copas esférica, ficou abaixo dos valores para copas alongadas (esféricas), com valores variando entre 11,0g/kg (IAF 1) e 11,1g/kg (IAF 5). Comparando-se os valores de umidade específica abaixo do dossel com a área da rua sem vegetação, os valores obtidos foram menores, sendo que na rua obtivemos uma umidade específica de $10,97 \mathrm{~g} / \mathrm{kg}$.

A Figura 131 mostra o resultado para as temperaturas superficiais na região de estudo que apresentou o mesmo comportamento da temperatura, ou seja, com o aumento do sombreamento pelas copas, houve uma variação da temperatura superficial abaixo do dossel das árvores elíptica entre $39^{\circ} \mathrm{C}$ (IAF 1) a $49^{\circ} \mathrm{C}$ (IAF 5), variação próxima dos resultados abaixo do dossel para árvores esféricas entre 39,5 (IAF 1) a 49, $4^{\circ} \mathrm{C}$ (IAF 5). Comparando-se a temperatura superficial na área da rua e com vegetação, percebemos uma diferença máxima de $19^{\circ} \mathrm{C}$ entre o piso de asfalto exposto e na superfície abaixo do dossel de IAF 5 para copa elíptica.

Dessa forma percebe-se que o efeito do sombreamento pela vegetação depende não só do valor para o IAF como o tipo copa também influencia nos resultados, pois esta indica a distribuição das folhas e aberturas na copa (gap fraction).

\subsubsection{RESULTADOS ETAPA 2}

Nessa etapa foram simulados os efeitos da velocidade do vento ao atravessar a copa de árvores com variações no valor do $\operatorname{IAF}(1,3$ e 5) e no formato do dossel (esférica, elíptica vertical). A Figura 132 mostra a comparação do perfil do vento do solo até $39 \mathrm{~m}$ de altura. Foram comparadas as seguintes tipologias de árvores: copas esféricas com IAF1 (A1), IAF 3 (A3) e IAF5 (A5); e copas elíptica com IAF 1 (B1), IAF 3 (B3) e IAF5 (B5).

A Figuras 133 e 134 mostram a comparação do perfil de vento ao se aumentar a velocidade do vento de $1 \mathrm{~m} / \mathrm{s}$ até $4 \mathrm{~m} / \mathrm{s}$. Nessa etapa, o objetivo foi de verificar o efeito de obstrução da copa em relação à velocidade dos ventos, desde uma condição de baixa velocidade $(0,5 \mathrm{~m} / \mathrm{s})$ a uma extrema de $4 \mathrm{~m} / \mathrm{s}$ na altura de $13 \mathrm{~m}$. A Figura 137 e 138 
mostram o percentual da redução da velocidade de acordo com o tipo da árvore (arredonda ou elíptica).

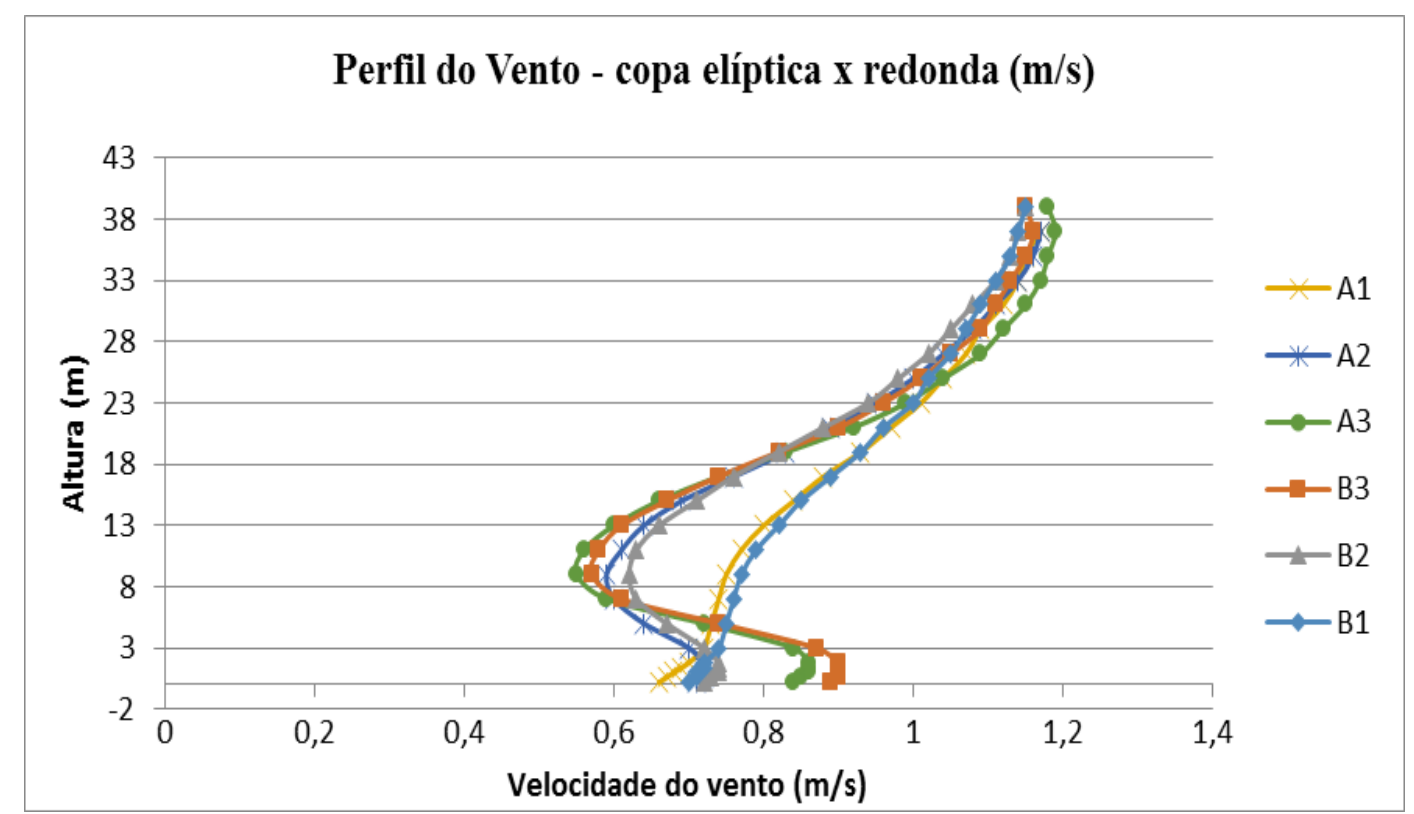

Figura 132: Perfil da velocidade do vento para copas esféricas e elípticas.

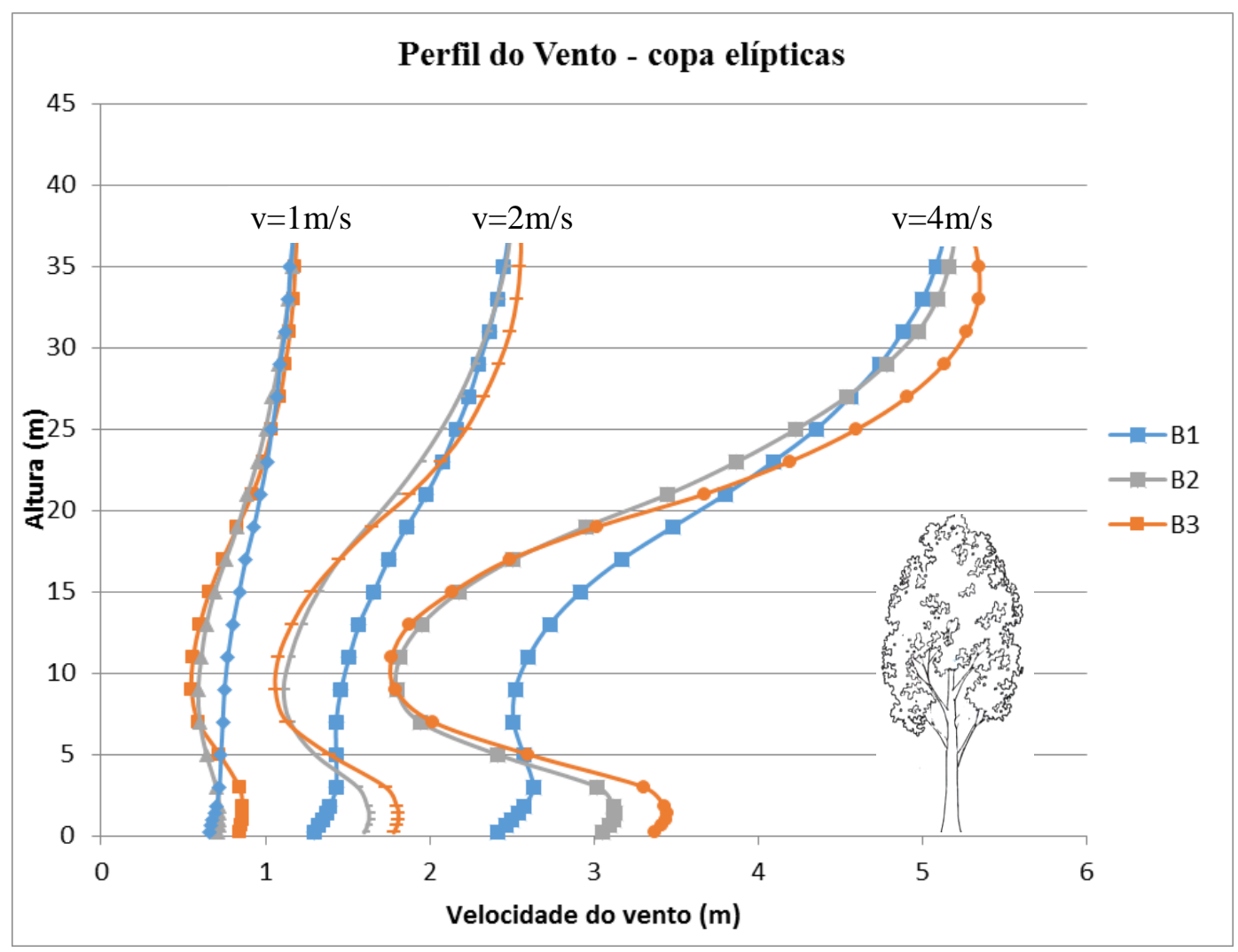

Figura 133: Perfil da velocidade do vento para copa elipsoide vertical. 


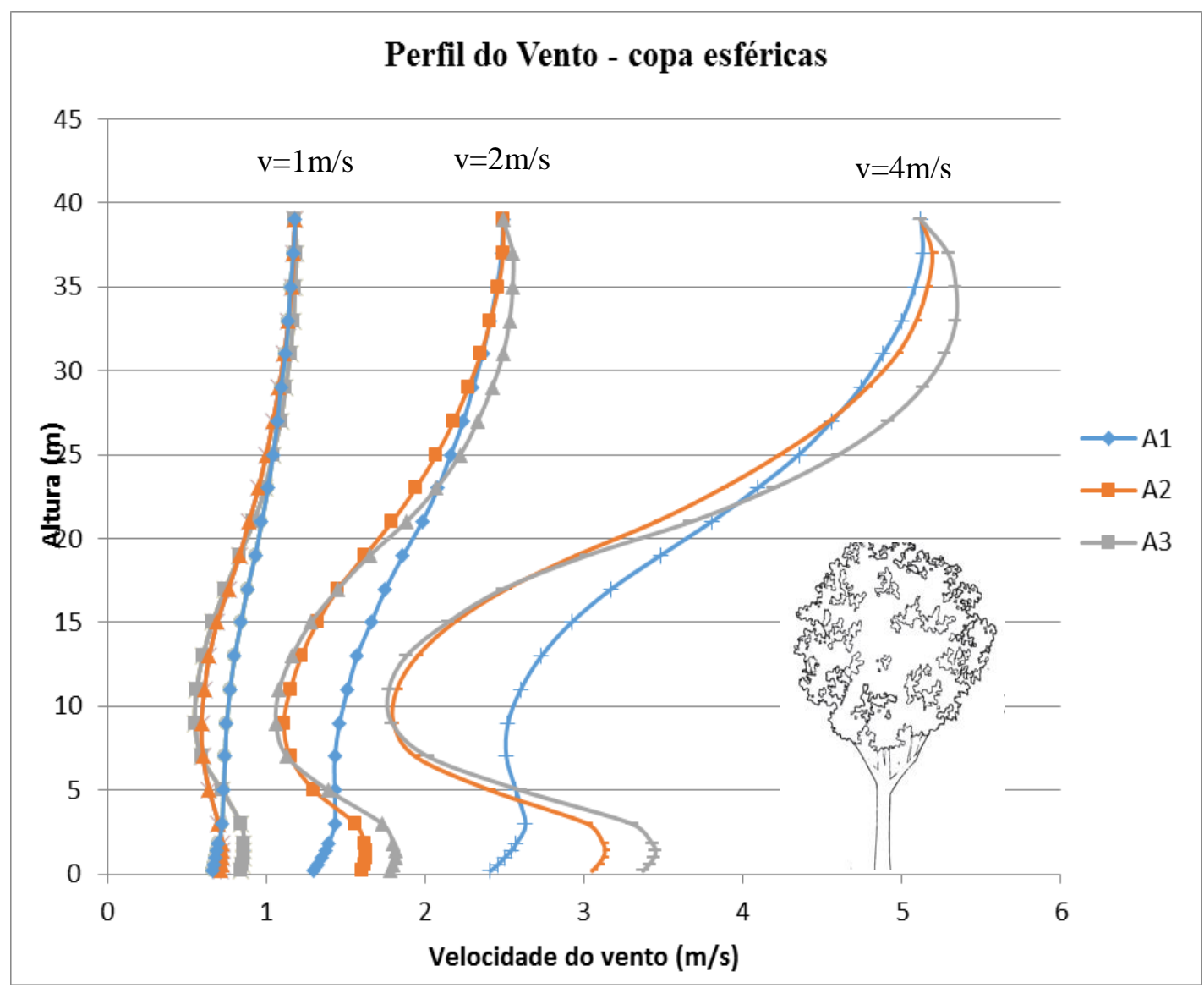

Figura 134: Perfil da velocidade do vento para copa esférica.

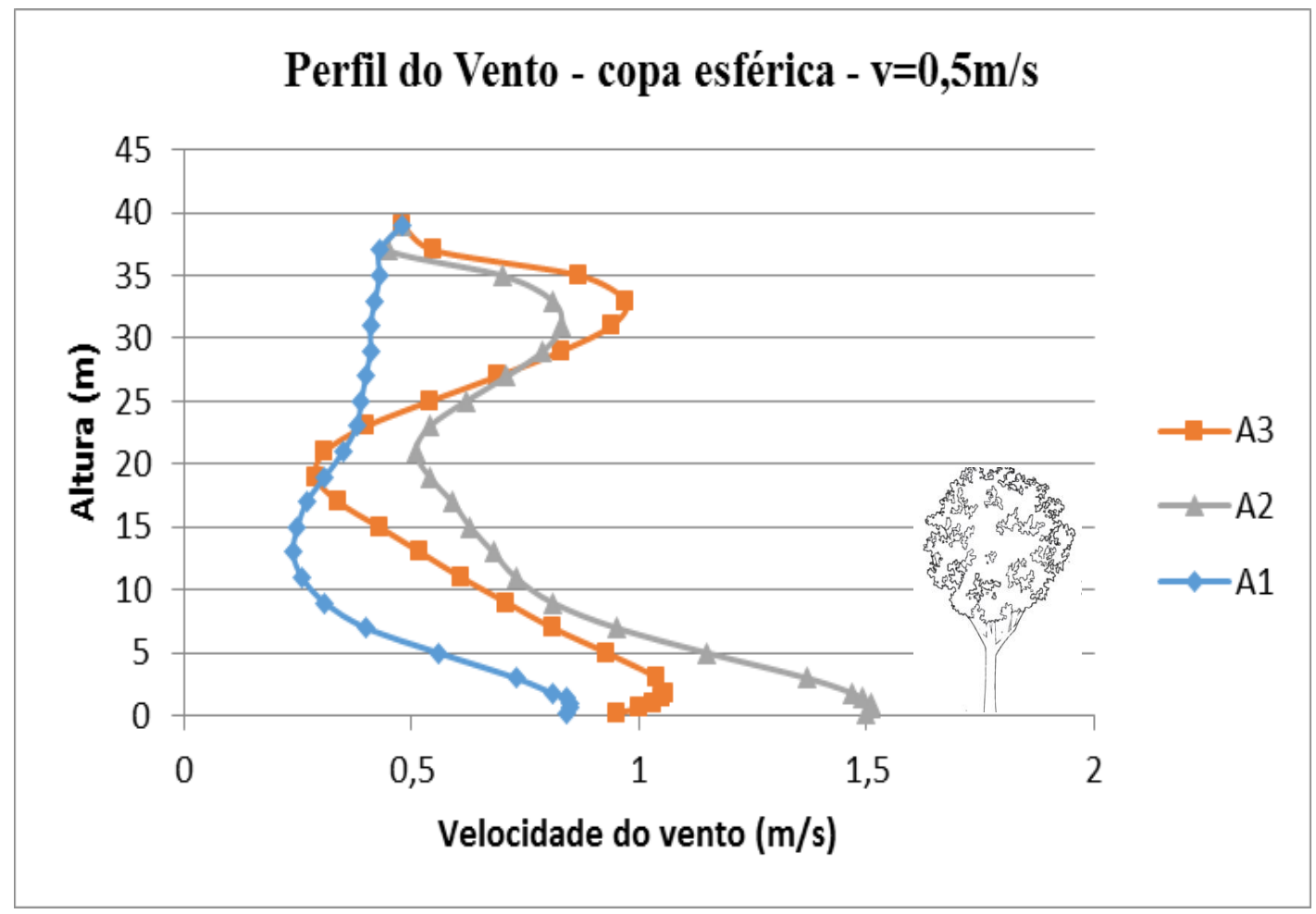

Figura 135: Perfil da velocidade do vento para copa esférica com $v=0,5 \mathrm{~m} / \mathrm{s}$ 


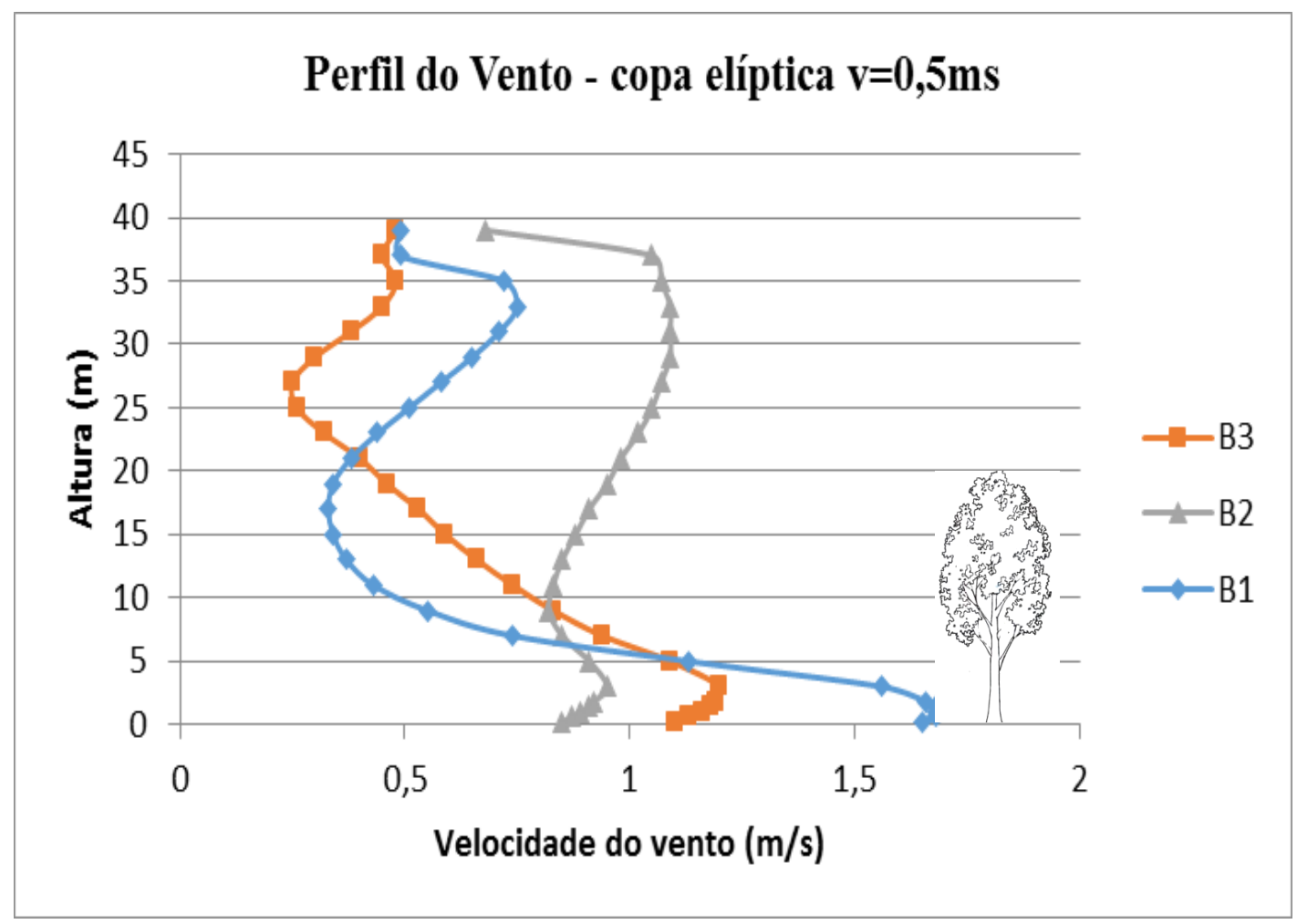

Figura 136: Perfil da velocidade do vento para copa elipsoide vertical com v=0,5m/s

O perfil do vento muda com a presença da vegetação. Assim as simulações feitas com as duas tipologias de árvores (esféricas e elípticas) tiveram os resultados apresentados na Figura 133, em que a redução máxima da velocidade inicial de $1 \mathrm{~m} / \mathrm{s}$ foi para $0,5 \mathrm{~m} / \mathrm{s}$ $(50 \%)$ ao passar pelo meio da copa esférica $(\mathrm{h}=13 \mathrm{~m})$. Percebe-se também que o efeito da copa redonda foi menor que a copa esférica, porque o diâmetro das copas é diferente com $15 \mathrm{~m}$ (copa redonda) e 10m (copa elíptica).

As Figuras 135 e 136 mostra o perfil do vento de 0,5m/s em relação à altura e observase que o desenho das curvas é diferente em relação aos resultados obtidos para ventos de $1 \mathrm{~m} / \mathrm{s}, 2 \mathrm{~m} / \mathrm{s}$ e $4 \mathrm{~m} / \mathrm{s}$. Assim mesmo rodando as simulações, percebe-se que o modelo apresentou erros na convergência dos dados, mostrando que na configuração dos dados de entrada, deve-se considerar a velocidade inicial sempre acima de $1 \mathrm{~m} / \mathrm{s}$.

As Figuras 137 e 138 mostram a porcentagem de redução do vento ao passar por diferentes tipologias de copa considerando uma velocidade do vento inicial de $1 \mathrm{~m} / \mathrm{s}$, $2 \mathrm{~m} / \mathrm{s}$ e $4 \mathrm{~m} / \mathrm{s}$. Dessa forma é possível constar que a maior redução do vento pela copa, acontecerá para a copa arredondada, resultando na diminuição de $54,8 \%$ da velocidade inicial de $4 \mathrm{~m} / \mathrm{s}$. 


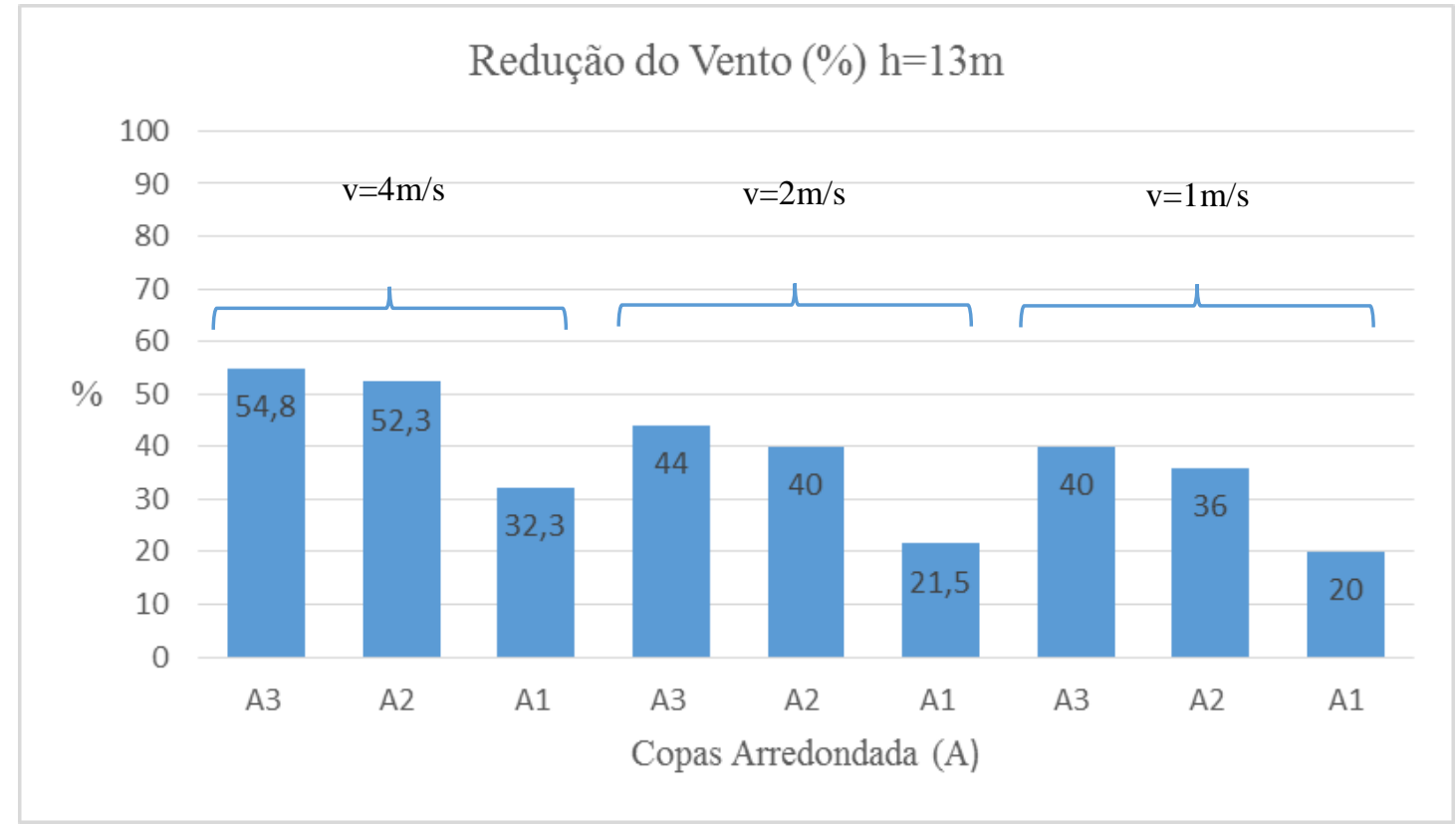

Figura 137:Porcentagem da redução do vento para copa esférica

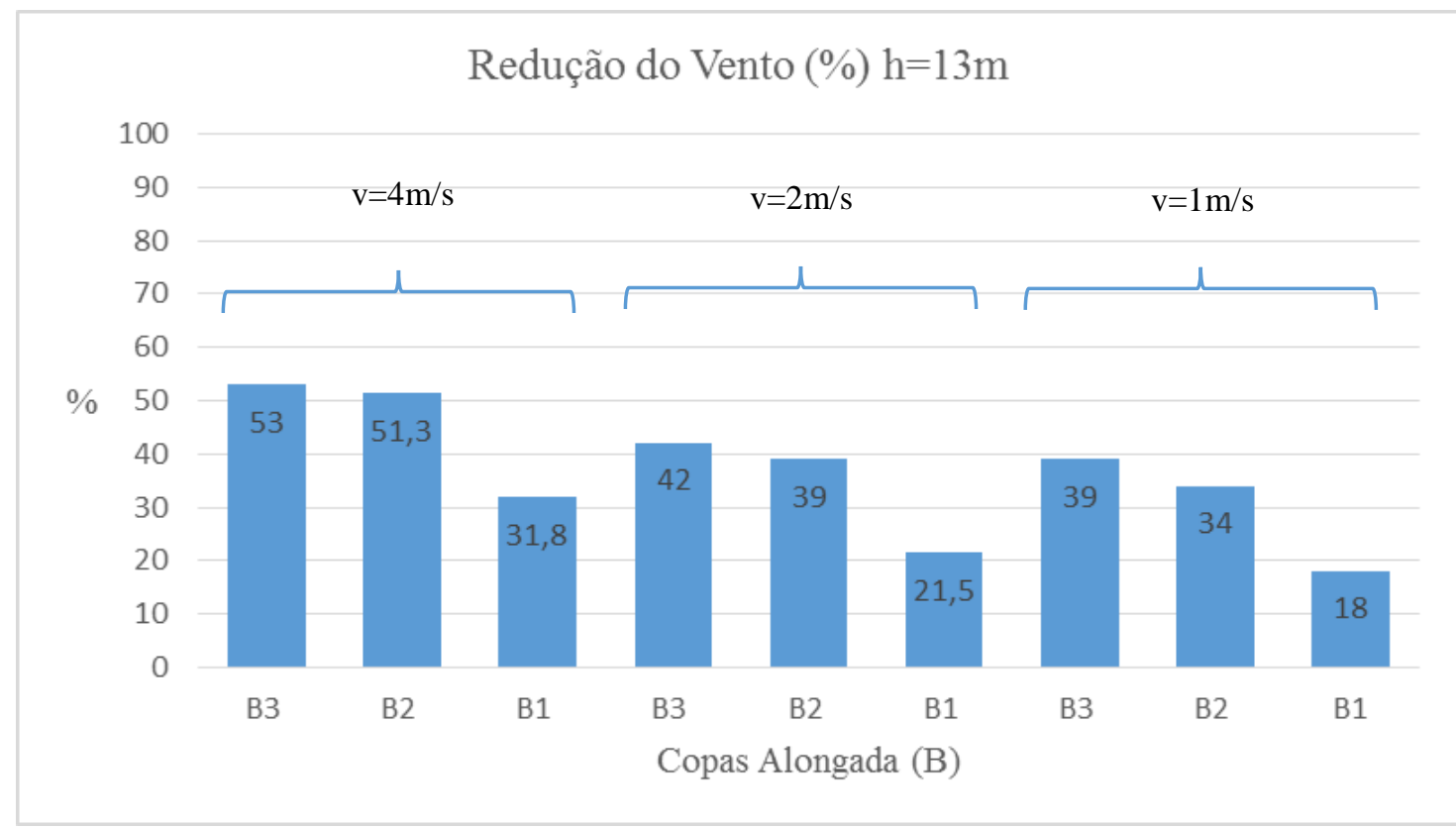

Figura 138: Porcentagem da redução do vento para copa elipsoide vertical.

As Figuras 139 e 140 mostram a influência dos ventos na redução da temperatura do ar. Assim, observa-se a velocidade do vento de $4 \mathrm{~m} / \mathrm{s}$ para uma copa elíptica de IAF 5 resulta numa temperatura do ar de $24,6^{\circ} \mathrm{C}$, uma diferença de $1,9^{\circ} \mathrm{C}$ em relação à temperatura do ar na rua de $26,5^{\circ} \mathrm{C}$. Isso mostra que além do efeito de evapotranspiração das plantas, o vento contribui na retirada do calor conforme aumenta a velocidade a partir de $1 \mathrm{~m} / \mathrm{s}$ 


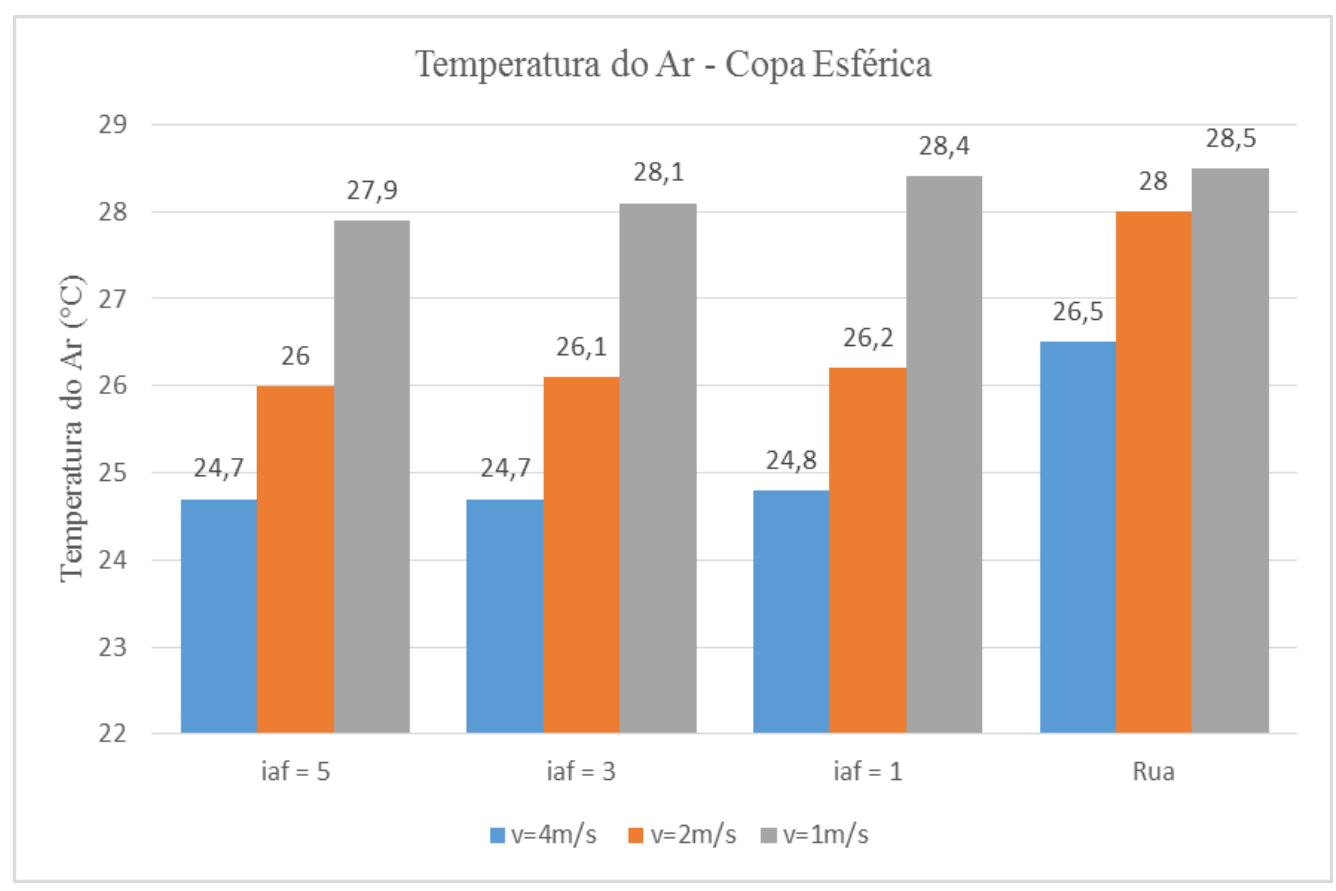

Figura 139: Temperatura do ar para diferentes velocidades do vento para copa esférica

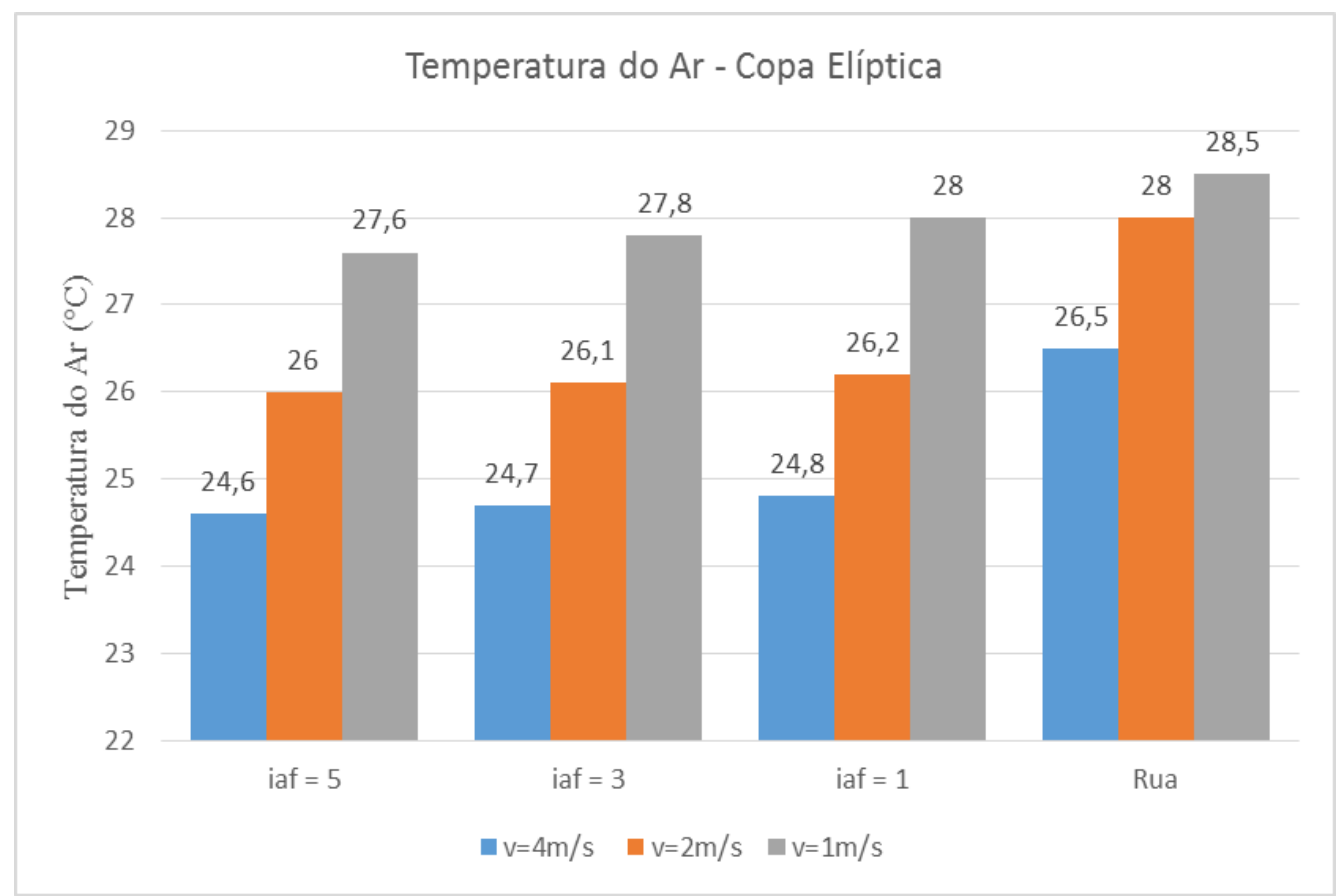

Figura 140: Temperatura do ar para diferentes velocidades do vento para copa elíptica

De acordo com as Figuras 141 e 142, a ação dos ventos também contribui na umidade específica, com valor máximo de $11,4 \mathrm{~g} / \mathrm{kg}$ para copa com IAF de 5 e velocidade do vento de $4 \mathrm{~m} / \mathrm{s}$. Enquanto numa área sem vegetação a umidade específica é de $11,3 \mathrm{~g} / \mathrm{kg}$. Ambas as tipologias apresentaram praticamente os mesmos resultados para os valores umidade específica e aumento da umidade do ar ocorreu nos cenários de maior velocidade do vento e índice de área foliar 


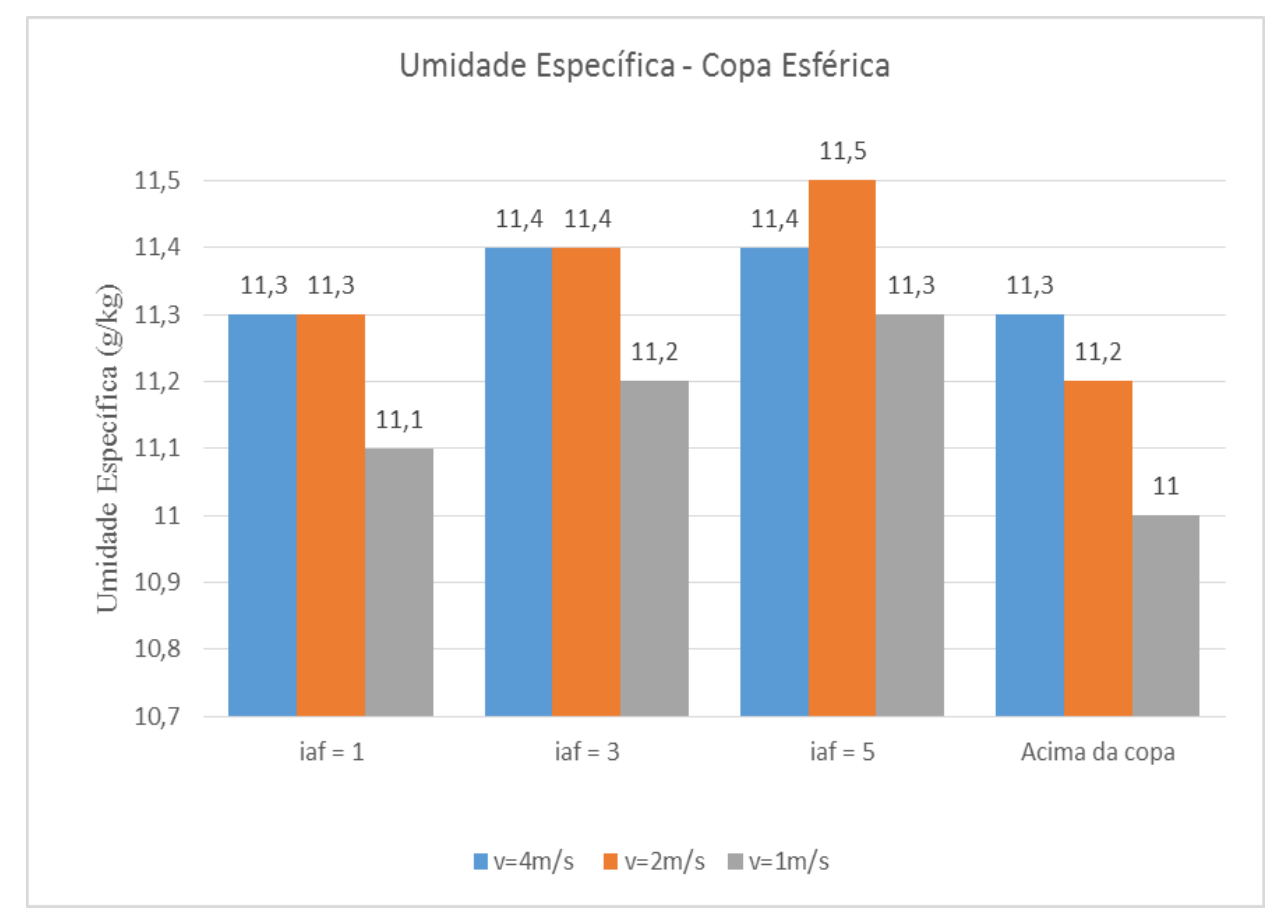

Figura 141: Umidade específica para diferentes velocidades do vento e valores de densidade para copa esférica

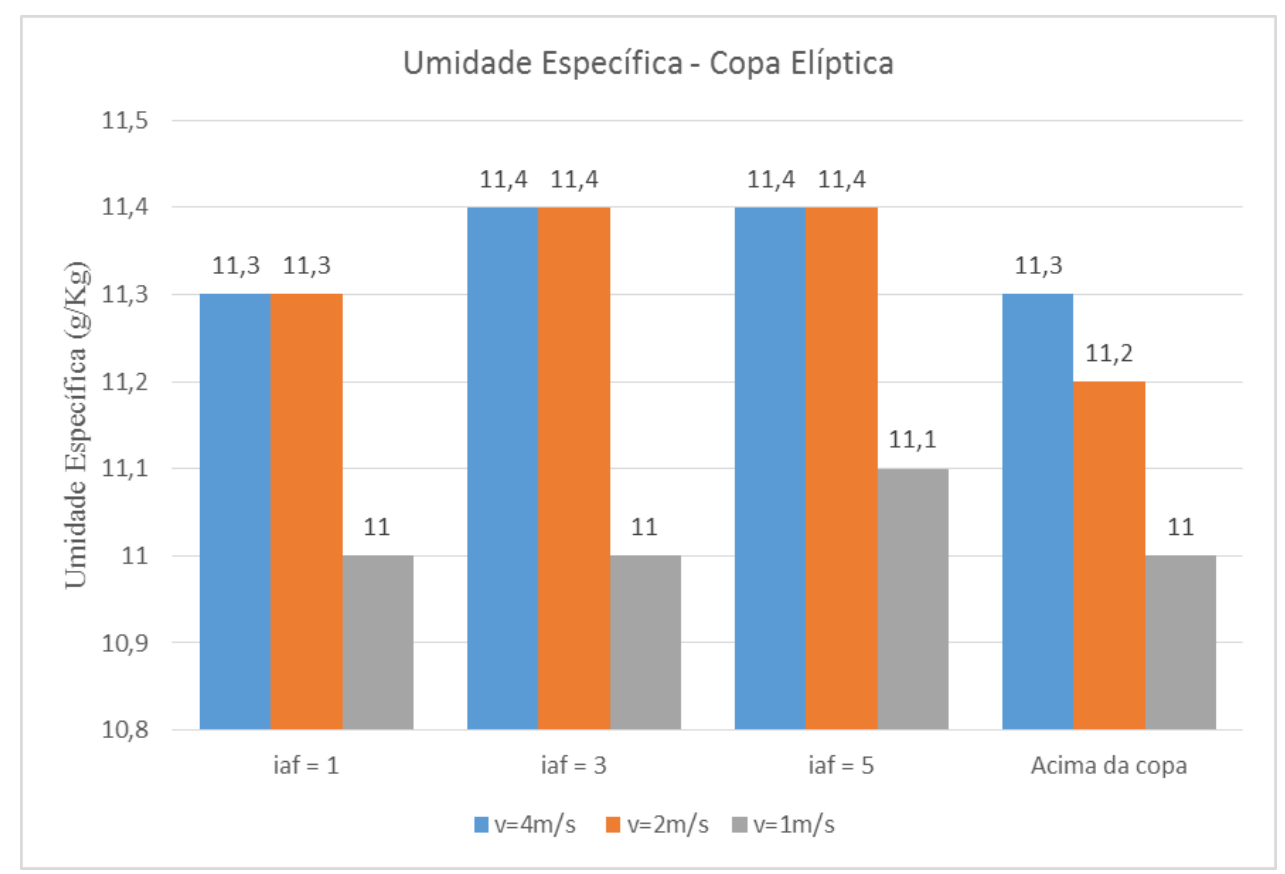

Figura 142: Umidade específica para diferentes velocidades do vento e valores de densidade para copa elíptica 
Nos resultados de temperatura de superfície, o menor valor foi de $34,8^{\circ} \mathrm{C}$ abaixo de um dossel de copa redonda com IAF 5 e velocidade de $4 \mathrm{~m} / \mathrm{s}$, enquanto na rua estava $53^{\circ} \mathrm{C}$, uma redução de $18,2^{\circ}$. Comparando o mesmo cenário para a copa elíptica, a temperatura de superfície ficou $0,5^{\circ} \mathrm{C}$ abaixo do resultado para copa redonda, chegando a temperatura do ar de $34,3^{\circ} \mathrm{C}$.

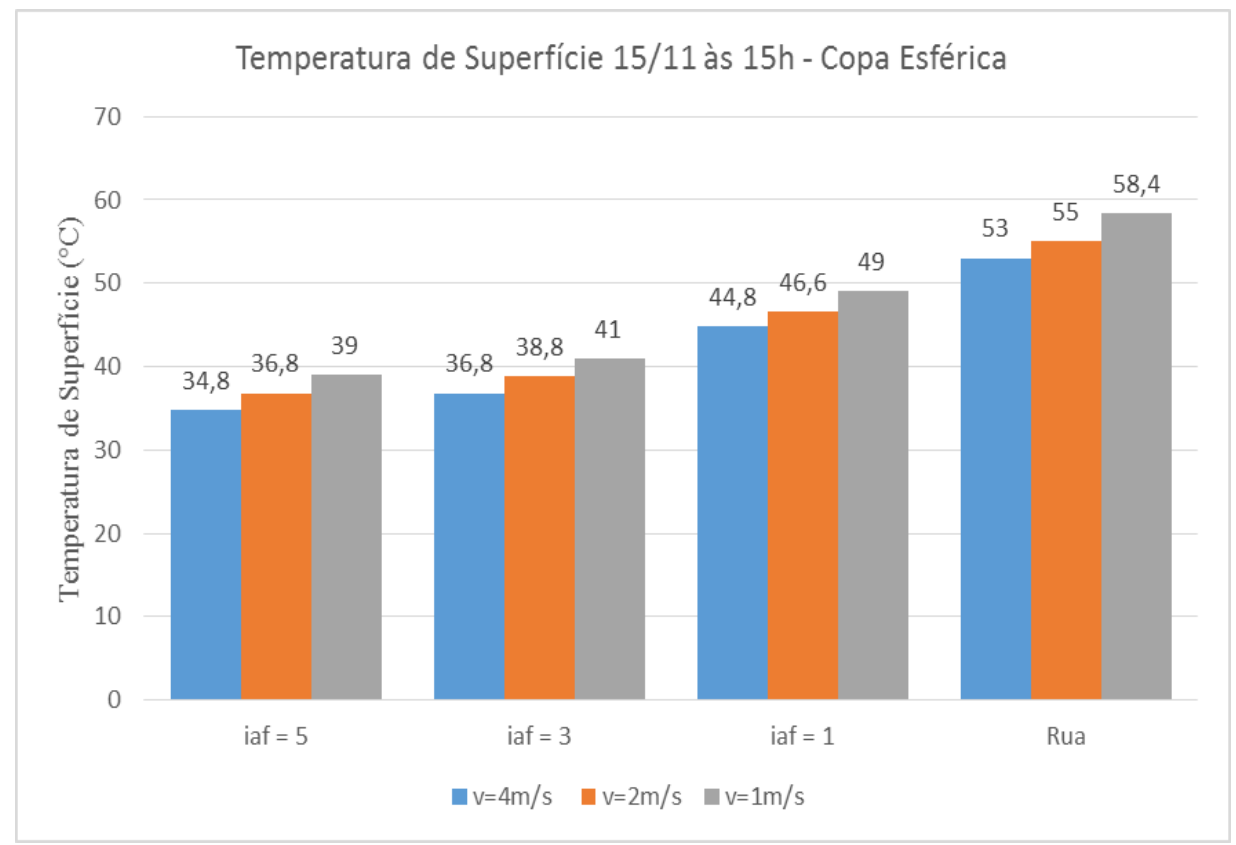

Figura 143: Temperatura de superfícies para diferentes velocidades do vento para copa esférica

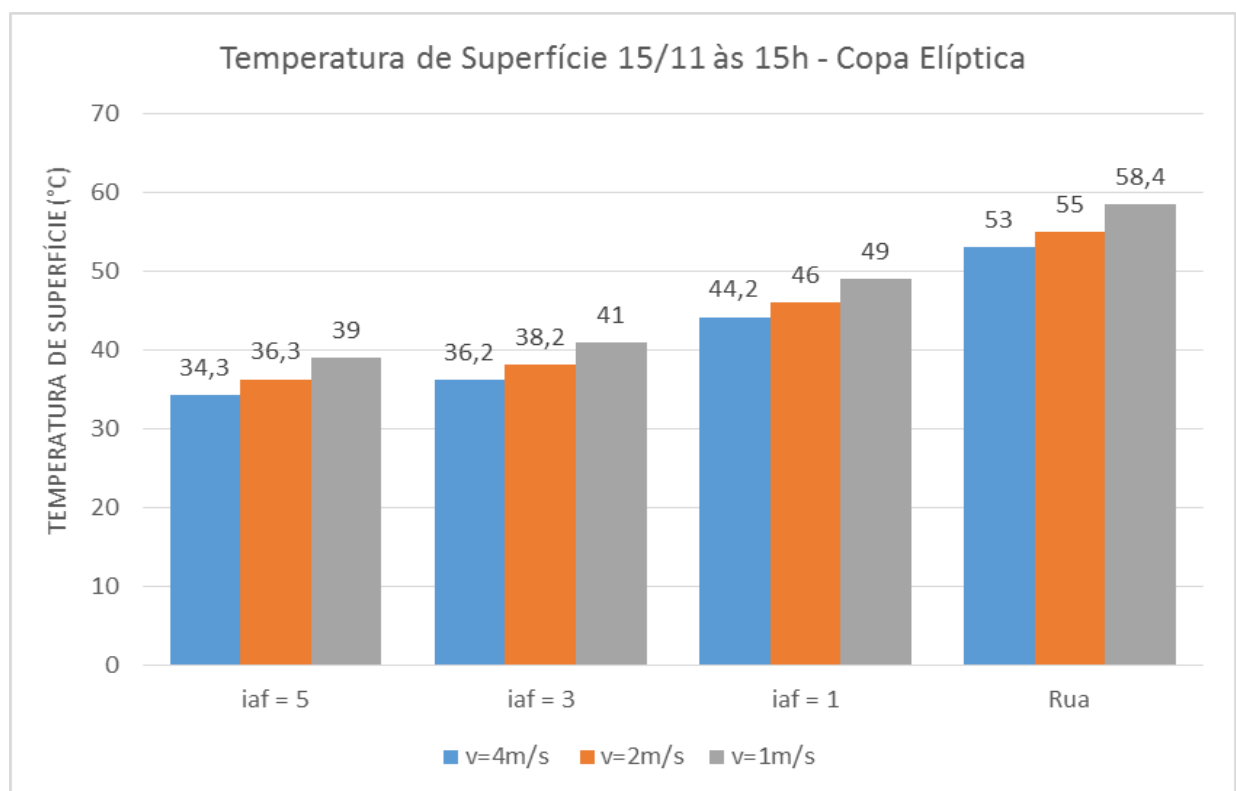

Figura 144: Temperatura de superfícies para diferentes velocidades do vento para copa elíptica 


\subsubsection{RESULTADOS ETAPA 3}

Nessa fase, o objetivo foi de se verificar a influência da umidade do solo, contribuindo no processo de evapotranspiração junto com a vegetação a fim de reduzir a temperatura do ar abaixo do dossel.

Nas Figuras 145 e 146 o resultado da temperatura do ar abaixo da copa é o efeito combinado da perda de água pelas folhas (transpiração) e pelo solo (evaporação). Assim, quanto maior for o teor de umidade do solo e densidade foliar, menor serão as temperaturas do ar. Observa-se que copa elíptica de IAF 5 em conjunto com um solo de alta umidade resulta numa temperatura do ar de $25,3^{\circ} \mathrm{C}$, uma diferença de $0,7^{\circ} \mathrm{C} \mathrm{em}$ relação à temperatura do ar na rua de $26^{\circ} \mathrm{C}$.

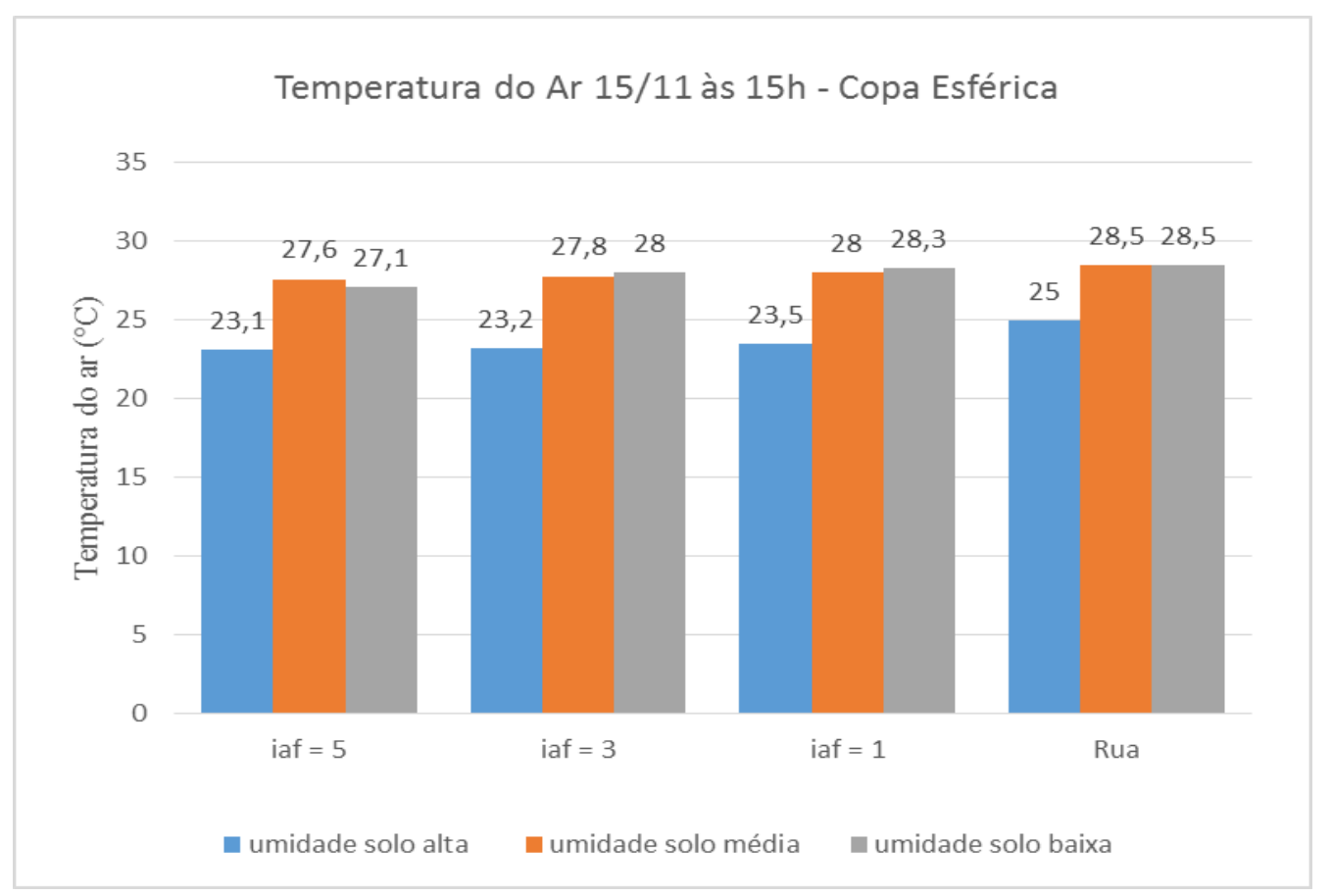

Figura 145: Temperatura do ar de acordo com variação da umidade do solo para copa esférica 


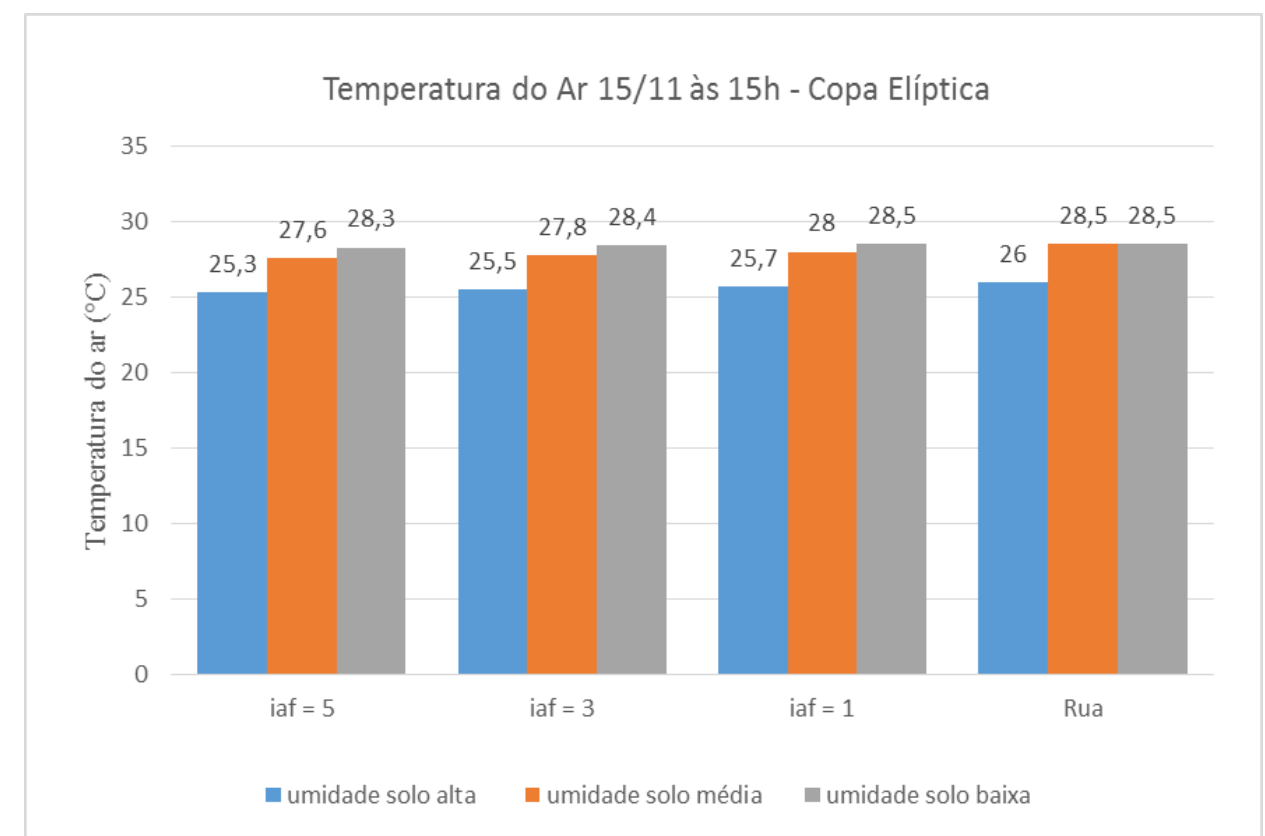

Figura 146: Temperatura do ar de acordo com variação da umidade do solo para copa elíptica

Conforme as Figuras 141 e 142, o processo de evapotranspiração contribui na umidade específica, com valor máximo de $14,5 \mathrm{~g} / \mathrm{kg}$ para copa com IAF de 5 e solo com alto teor de umidade. Enquanto que acima do dossel, a umidade específica é de 12,8g/kg. Ambas as tipologias apresentaram resultados semelhantes para os valores umidade específica e aumento da umidade do ar ocorreu nos cenários de maior umidade do solo e índice de área foliar.

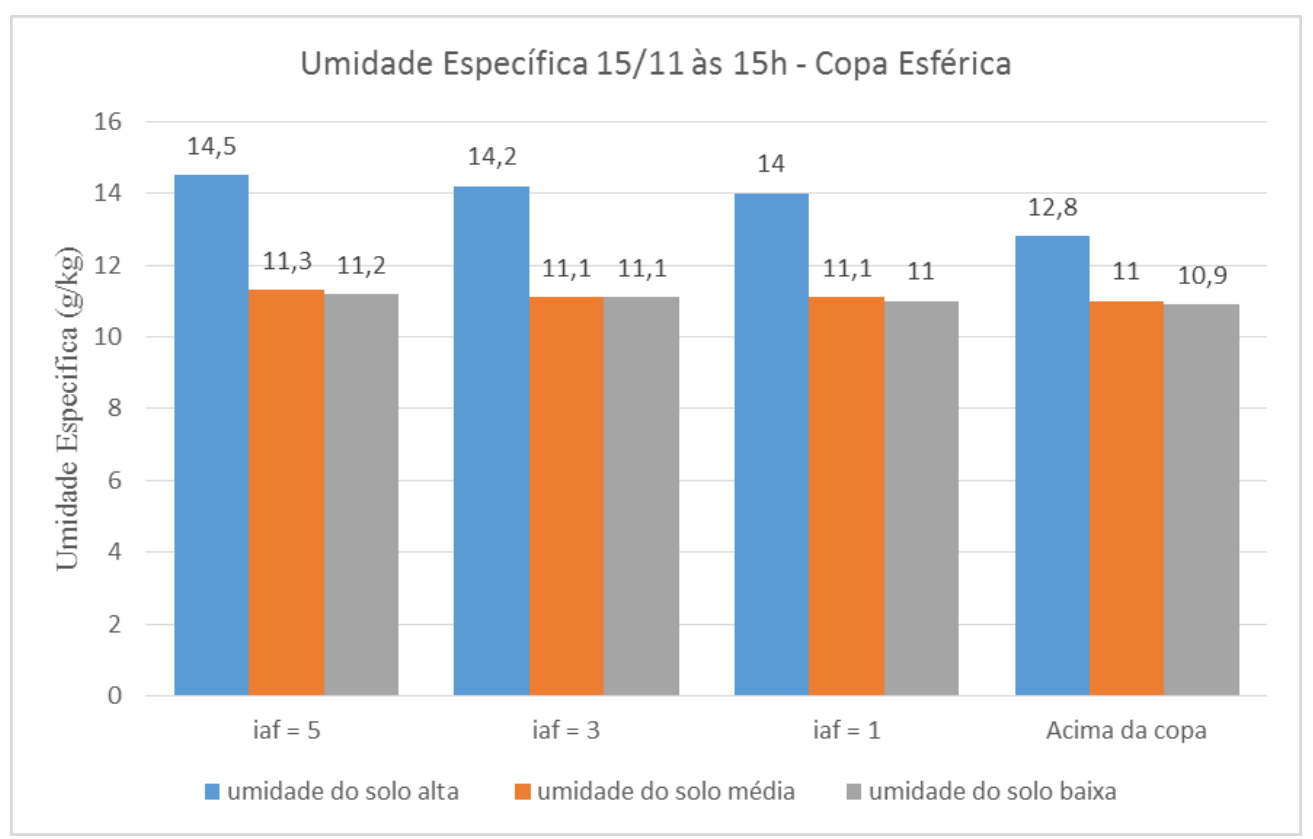

Figura 147: Umidade específica do ar de acordo com variação da umidade do solo para copa esférica 


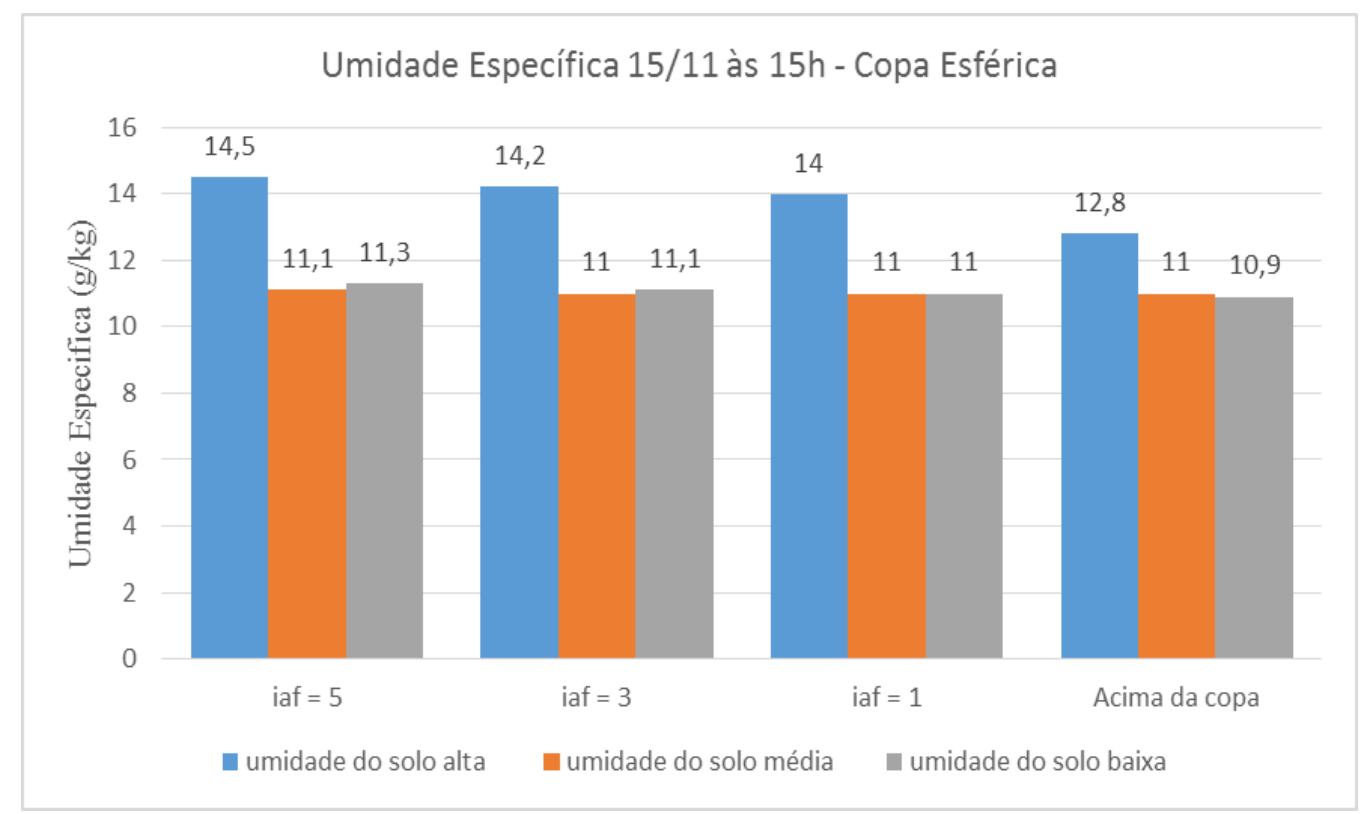

Figura 148: Umidade específica do ar de acordo com variação da umidade do solo para copa elíptica.

As Figura 147 e 148 mostram o resultado da temperatura de superfície em relação à variação do IAF. Nesse caso o efeito do sombreamento da copa junto com a perda de água na camada superior do solo, resultou em diferenças de até $23,8^{\circ} \mathrm{C}$ entre o asfalto descoberto e abaixo do dossel com IAF 5 e umidade relativa do solo de $90 \%, 95 \%, 95 \%$ (camada superficial, intermediária, profunda).

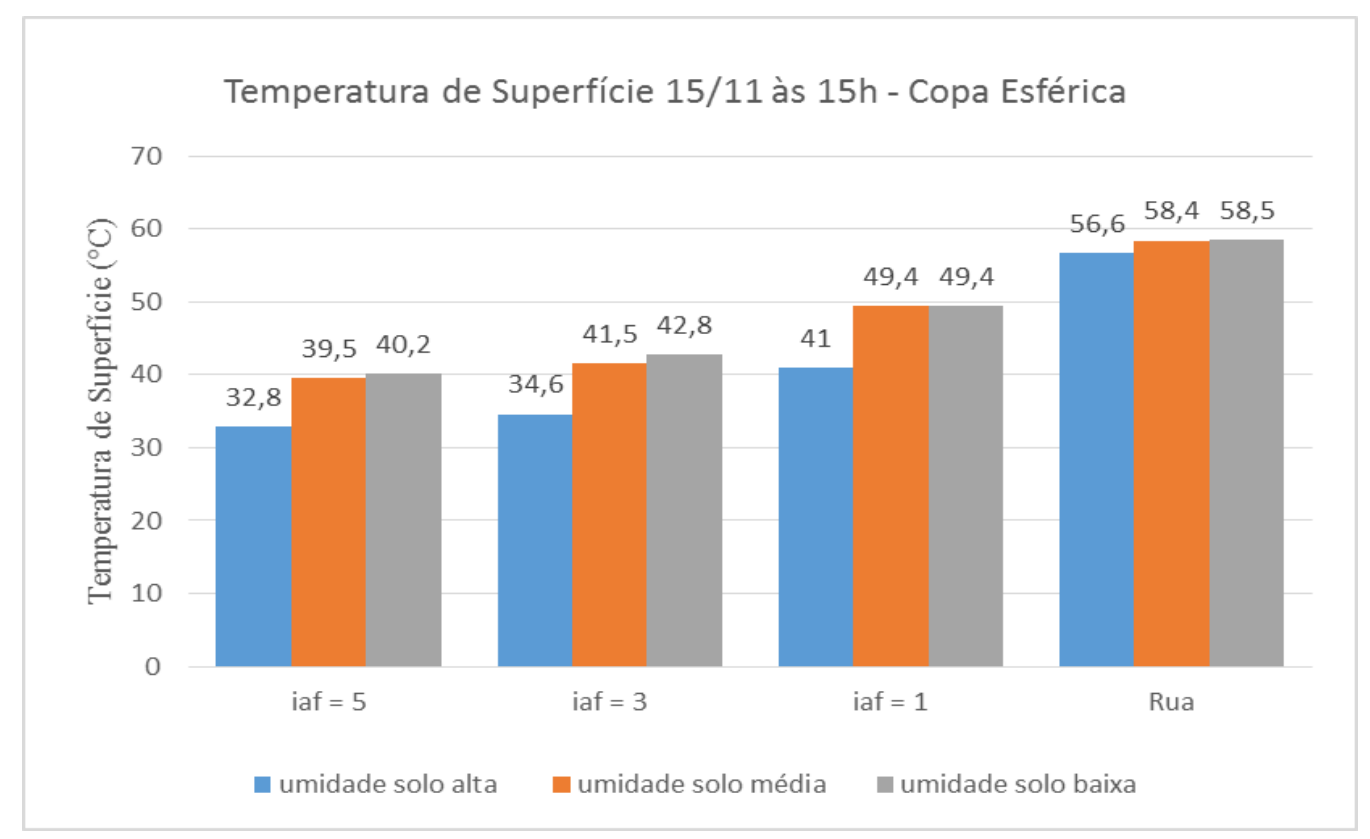

Figura 149: Temperatura de superfície de acordo com variação da umidade do solo para copa esférica 


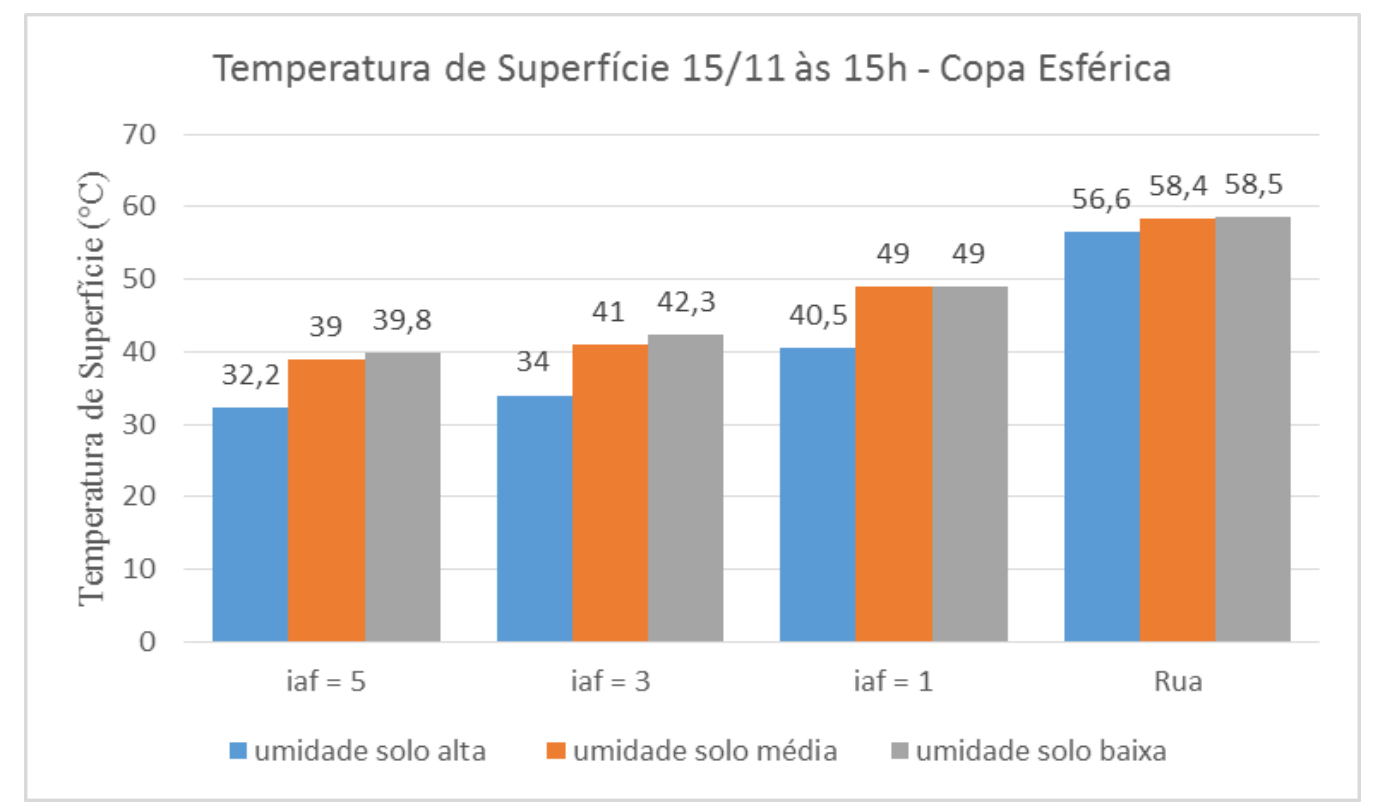

Figura 150: Temperatura de superfície de acordo com variação da umidade do solo para elipsoide vertical.

\subsubsection{RESULTADOS DA ETAPA 4}

Nessa etapa, foram feitas simulações no modelo ENVI-met considerando-se 2 tipos de malhas ortogonais: uma construída com células de $10 \mathrm{mx} 10 \mathrm{~m}$ e $2 \mathrm{~m}$ de altura e outra com $5 \mathrm{mx} 5 \mathrm{~m}$ e $2 \mathrm{~m}$ de altura, conforme mostra a Figura 144. O objetivo era verificar a extensão do efeito da vegetação a partir dos resultados da malha mais refinada $(5 \mathrm{mx} 5 \mathrm{~m})$.
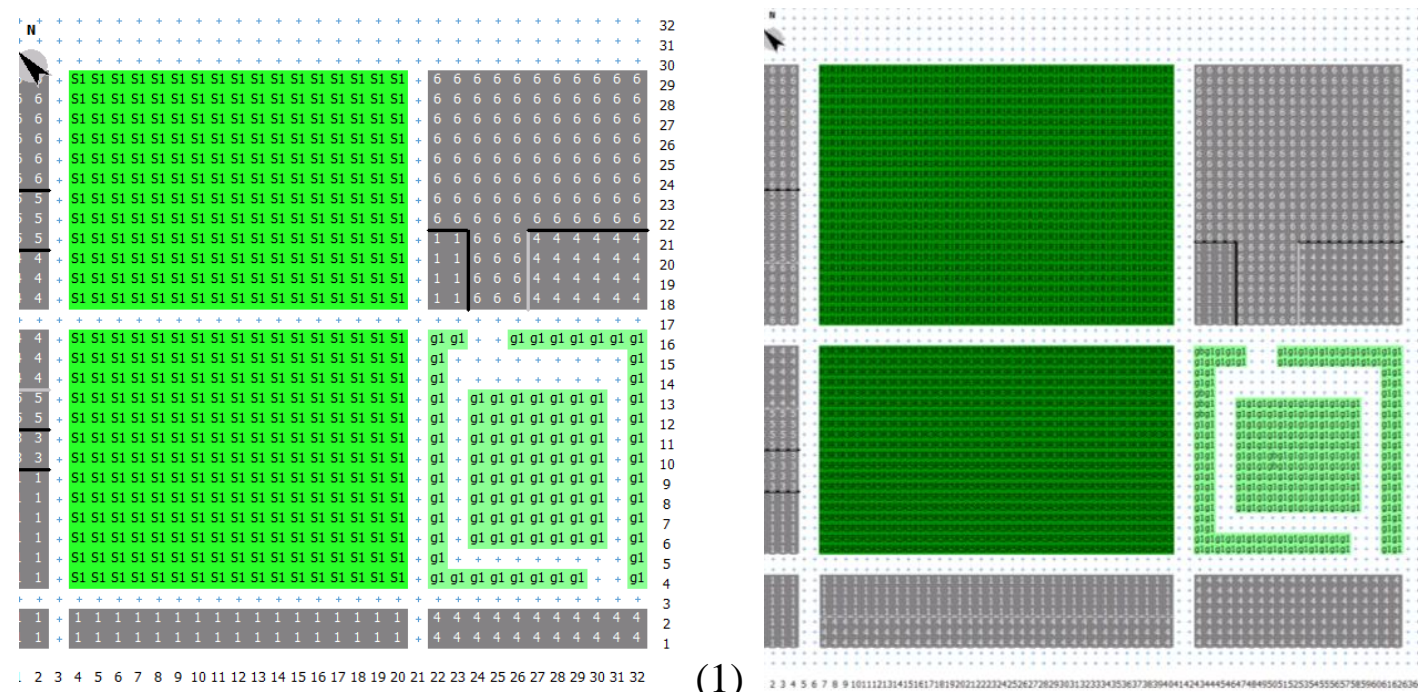

(1)

Figura 151: Tipos de malha ortogonal usada na modelagem: 10mx10m (1) e 5mx5m (2). 
A Figura 156 mostra o resultado para malha ortogonal 5mx5m utilizando o aplicativo Leonardo do modelo ENVI-met que ajuda na visualização 2D para a temperatura do ar no dia 15/11 às $15 \mathrm{~h}$. Os resultados consideraram apenas árvores de IAF 1 e copa elíptica.

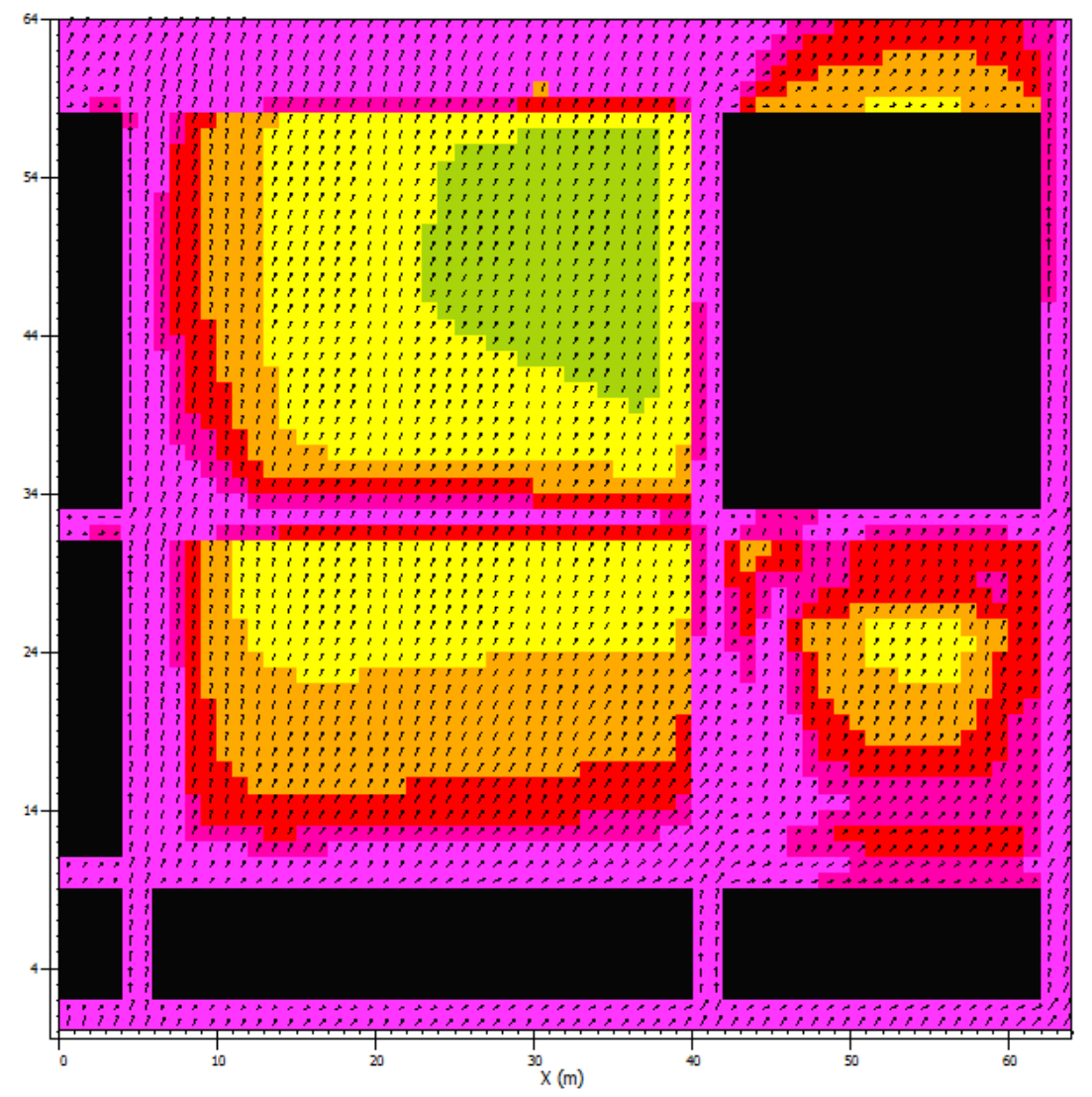

trianon13nov6 15:00:00 15.11 .2013 $x / y$ ost st: $x=0$

Temperatura do $\mathrm{Ar}$

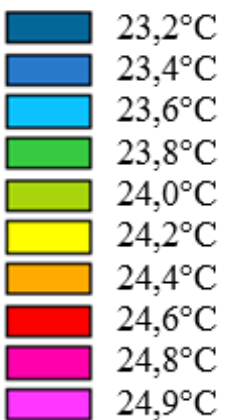

Figura 152: Projeção da sombra de uma copa esférica e elipsoide vertical.

Observa-se a temperatura do ar na área com árvores de IAF 1 que as temperaturas abaixo da copa variam de $24,0^{\circ} \mathrm{C}$ a $24,6^{\circ} \mathrm{C}$. Na área da via de carros, observa-se uma temperatura de $24,9^{\circ} \mathrm{C}$, gerando uma diferença máxima de até $0,88^{\circ} \mathrm{C}$. 
A Figura 157 mostra o resultado para malha ortogonal $5 \mathrm{mx} 5 \mathrm{~m}$ para a temperatura do ar no dia 15/11 às $15 \mathrm{~h}$. Os resultados consideraram apenas árvores de IAF 1 e copa elíptica.

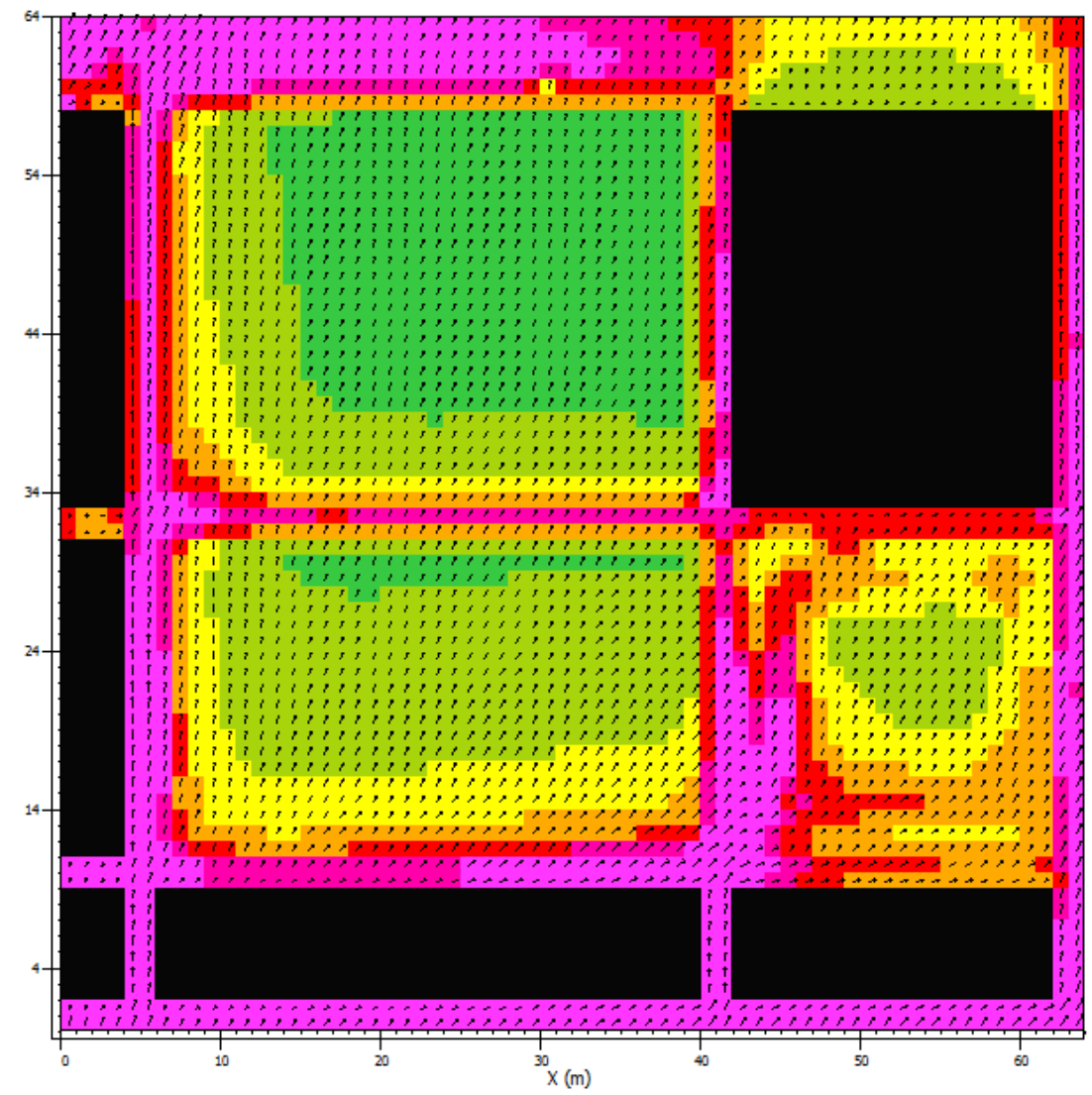

Figura 153: Projeção da sombra de uma copa esférica e elipsoide vertical.

Na Figura 155, observa-se que temperatura do ar na área com árvores de IAF 3 apresentam temperaturas abaixo da copa que variam de $23,8^{\circ} \mathrm{C}$ a $24,0,{ }^{\circ} \mathrm{C}$. $\mathrm{Na}$ área da via de carros, observa-se uma temperatura de $24,9^{\circ} \mathrm{C}$, gerando uma diferença máxima de até $1,0^{\circ} \mathrm{C}$.

Visualizando melhor a borda da fachada nordeste do parque, conforme mostra a Figura 164, percebe-se que a extensão do efeito na temperatura do ar avança $5 \mathrm{~m}$ em relação ao sentido do vento de $1 \mathrm{~m} / \mathrm{s}$. 

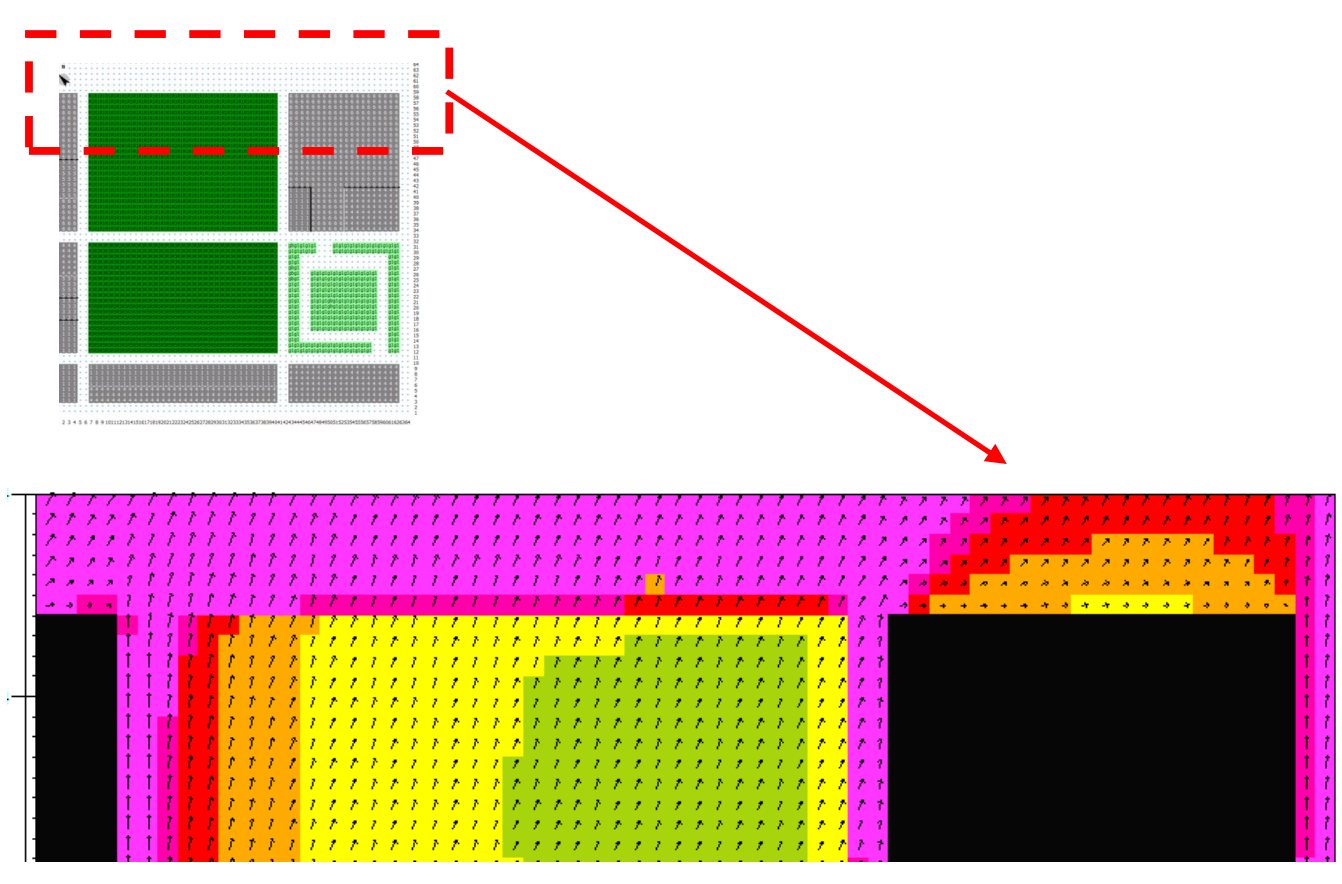

Temperatura do Ar

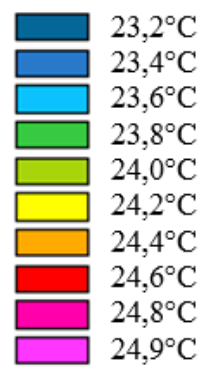

\section{Figura 154: Visualização da borda do parque}

Foi feito um corte transversal do parque para verificar com mais precisão, a localização e altura dos efeitos pela vegetação, conforme mostra os recortes AA, BB e CC.

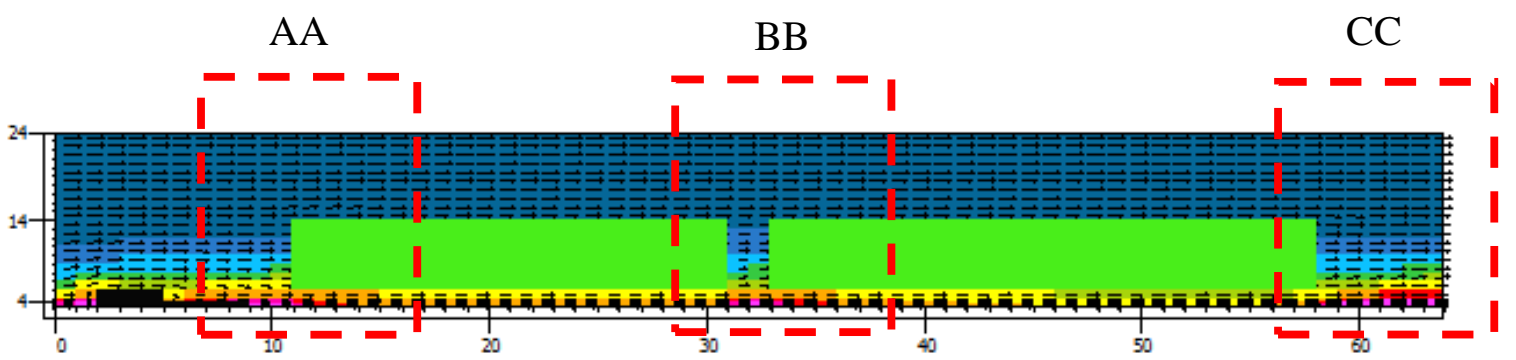

Figura 155: Corte Transversal do Parque

No corte AA, pode-se identificar que existe uma influência dos ventos, aumentando a temperatura do ar na borda do parque de $24,0^{\circ} \mathrm{C}$ para $24,2^{\circ} \mathrm{C}$.

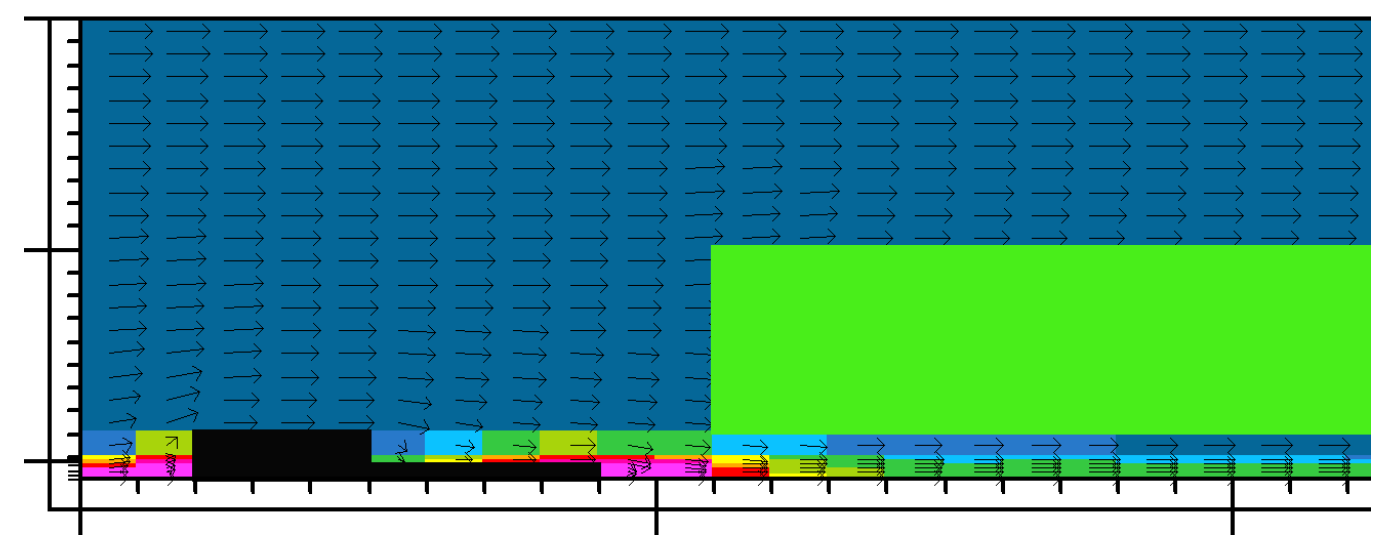

Temperatura do $\mathrm{Ar}$

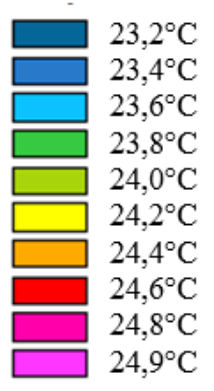

Figura 156: Corte transversal do parque AA 
O efeito da rua localizada entre as duas parte do parque, mostra que a temperatura embaixo do dossel, varia entre $23,4^{\circ} \mathrm{C}$ e $23,4^{\circ} \mathrm{C}$, e sob o asfalto a temperatura do ar sobre para $24,9^{\circ} \mathrm{C}$. Sendo que parte desse calor está sendo empurrado para dentro do parque pelo efeito do vento com velocidade de $1 \mathrm{~m} / \mathrm{s}$.

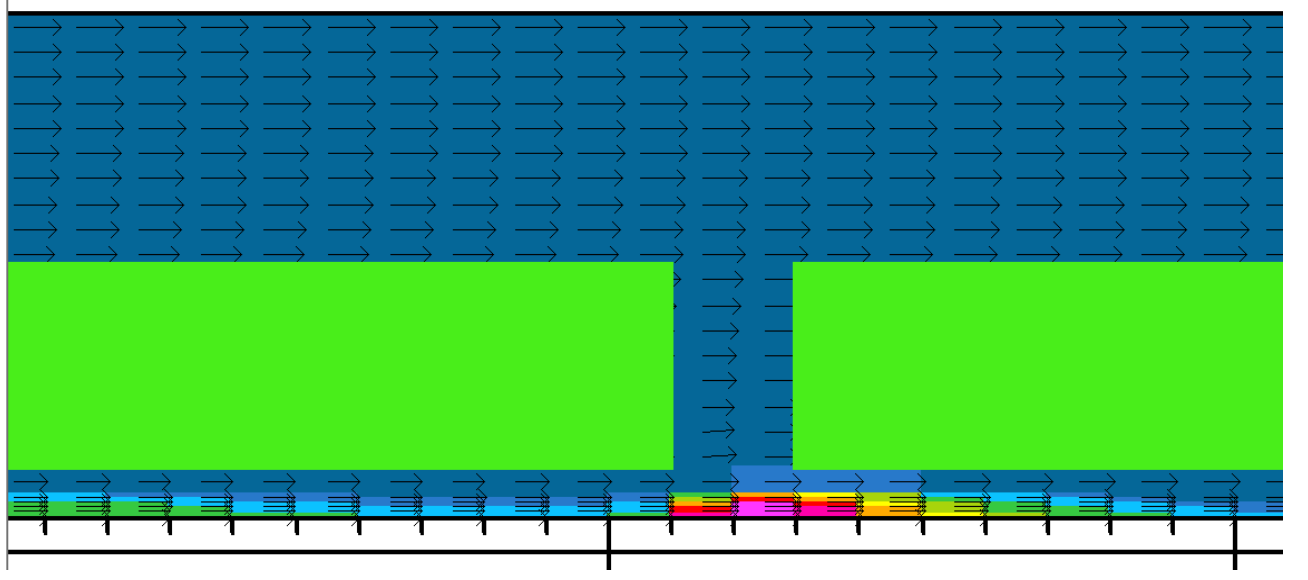

Temperatura do $\mathrm{Ar}$

Figura 157: Corte transversal do parque BB

No corte CC, observa-se o efeito da vegetação abaixo do dossel, com uma temperatura do ar mais homogênea de $24,4^{\circ} \mathrm{C}$. E a extensão do efeito é bem reduzida para árvores com copas de IAF 1 , até $5 \mathrm{~m}$ após a borda do parque é possível ver uma mudança na temperatura do ar acima do asfalto, reduzindo de $24,9^{\circ} \mathrm{C}$ para $24,8^{\circ} \mathrm{C}$.

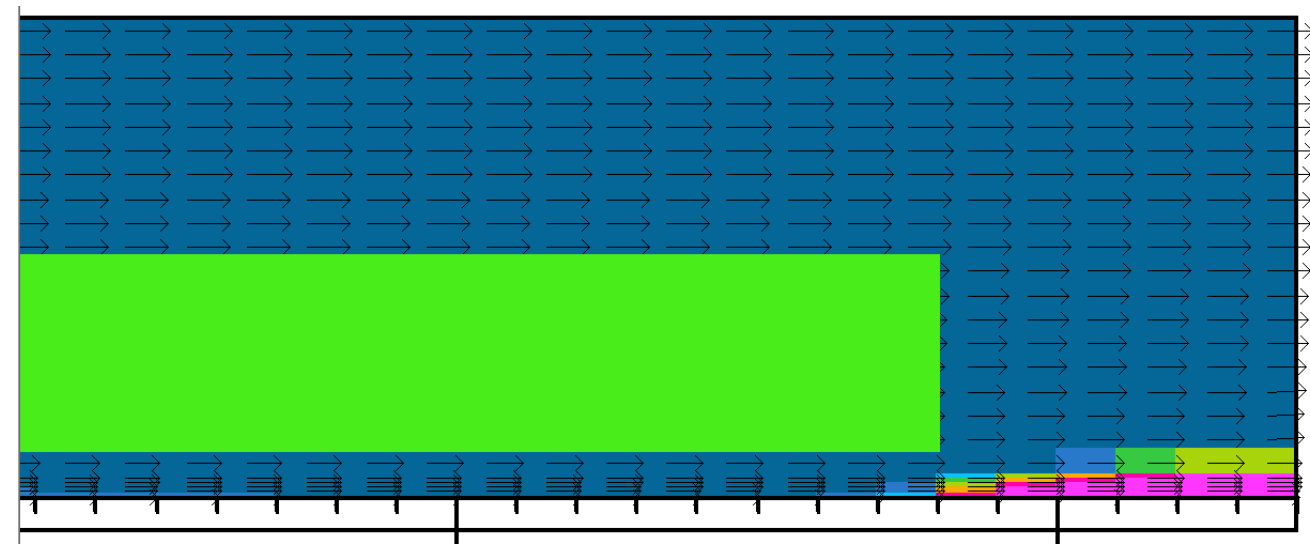

Temperatura do $\mathrm{Ar}$

$\square 23,2^{\circ} \mathrm{C}$ $23,4^{\circ} \mathrm{C}$ $23,6^{\circ} \mathrm{C}$ $23,8^{\circ} \mathrm{C}$ $24,0^{\circ} \mathrm{C}$ $24,2^{\circ} \mathrm{C}$ $24,4^{\circ} \mathrm{C}$ $24,6^{\circ} \mathrm{C}$ $24,8^{\circ} \mathrm{C}$ $24,9^{\circ} \mathrm{C}$

Figura 158: Corte transversal do parque CC 
Em seguida foi feito o mesmo tipo de visualização para o resultado obtido para o parque com IAF 5. A Figura 163 mostra que a extensão do efeito na borda do parque para a temperatura do ar, sendo que o efeito estende-se por $5 \mathrm{~m}$ reduzindo a temperatura do ar de $24,9^{\circ}$ (sob o asfalto) para $24,4^{\circ} \mathrm{C}$ e é possível ver uma faixa de $5 \mathrm{~m}$ a $10 \mathrm{~m}$ em que a temperatura ar fica por volta de $24,6^{\circ} \mathrm{C}$ (faixa na cor vermelha). Observa-se também que o efeito está no mesmo sentido do vento com velocidade de $1 \mathrm{~m} / \mathrm{s}$.

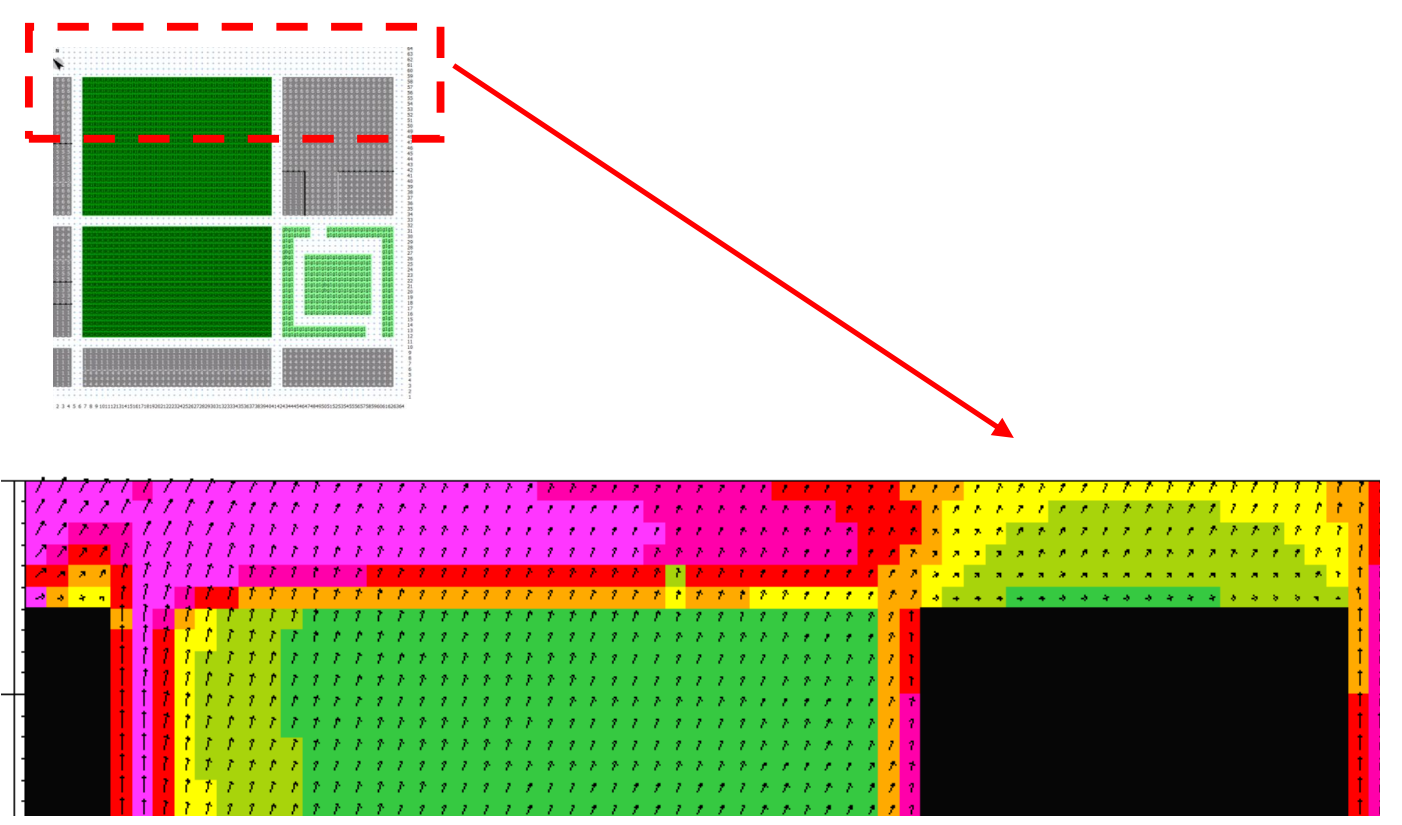

Figura 159: Projeção da sombra de uma copa esférica e elipsoide vertical.

Foi feito um corte transversal do parque para verificar com mais precisão, a localização e altura dos efeitos pela vegetação, conforme mostra os recortes DD, EE e FF.

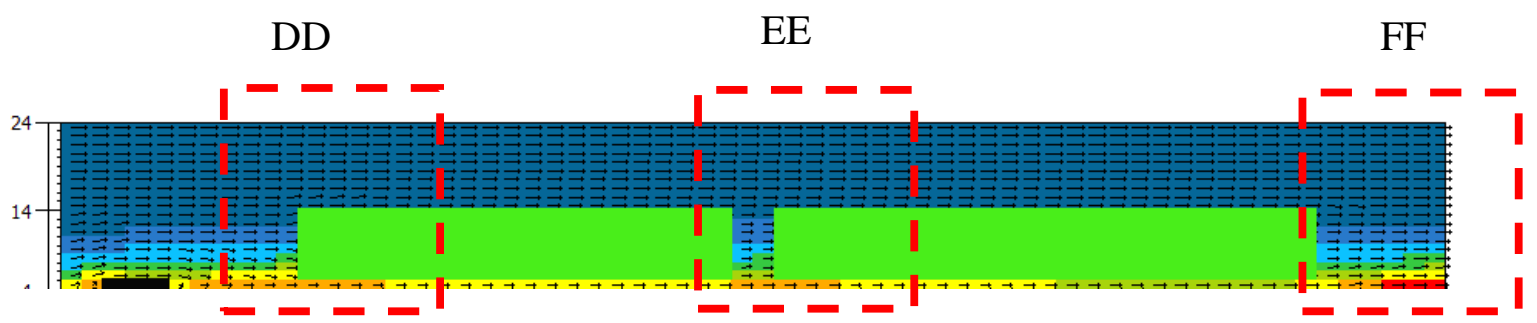

Figura 160: Corte transversal do parque DD

No corte DD, pode-se identificar que existe uma influência dos ventos, aumentando a temperatura do ar na borda do parque de $24,0^{\circ} \mathrm{C}$ para $24,2^{\circ} \mathrm{C}$, da mesmo foram que aconteceu na simulação anterior com IAF 1. 


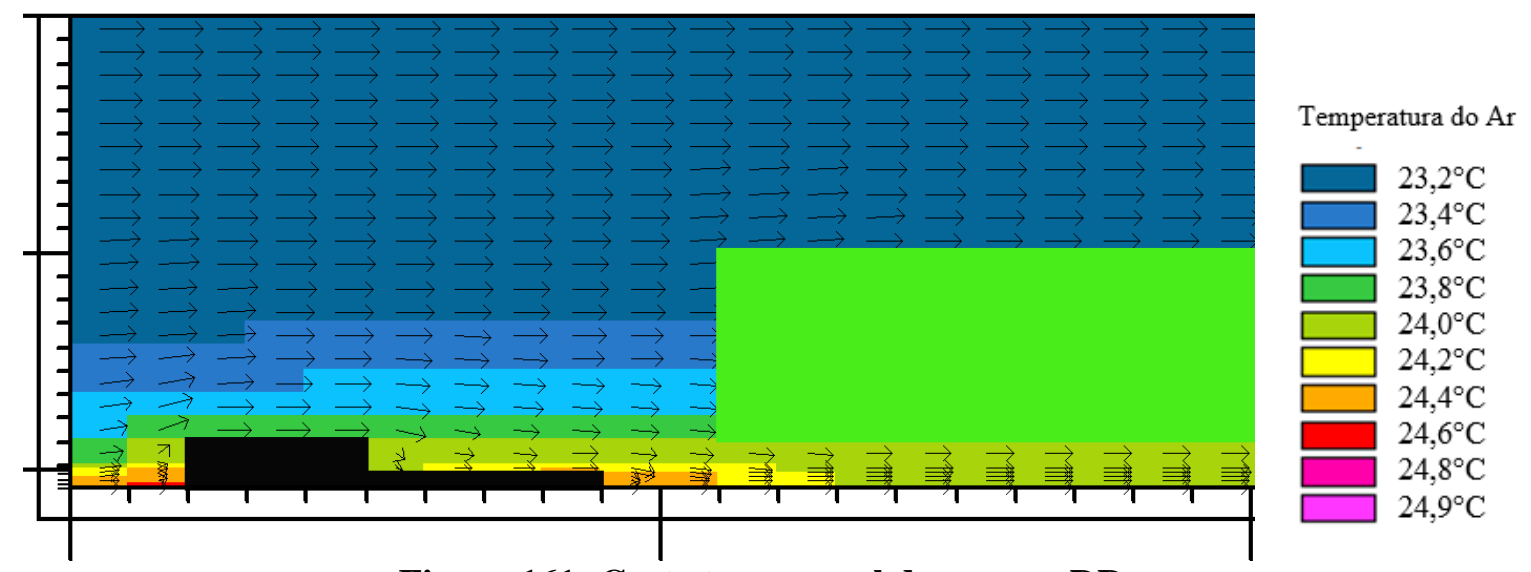

Figura 161: Corte transversal do parque DD

O efeito da rua localizada entre as duas partes do parque, mostra que a temperatura embaixo do dossel está por volta de $24,0^{\circ} \mathrm{C}$ e sob o asfalto a temperatura do ar é de $24,9^{\circ} \mathrm{C}$. Sendo que parte desse calor está sendo empurrado para dentro do parque pelo efeito do vento com velocidade de $1 \mathrm{~m} / \mathrm{s}$.

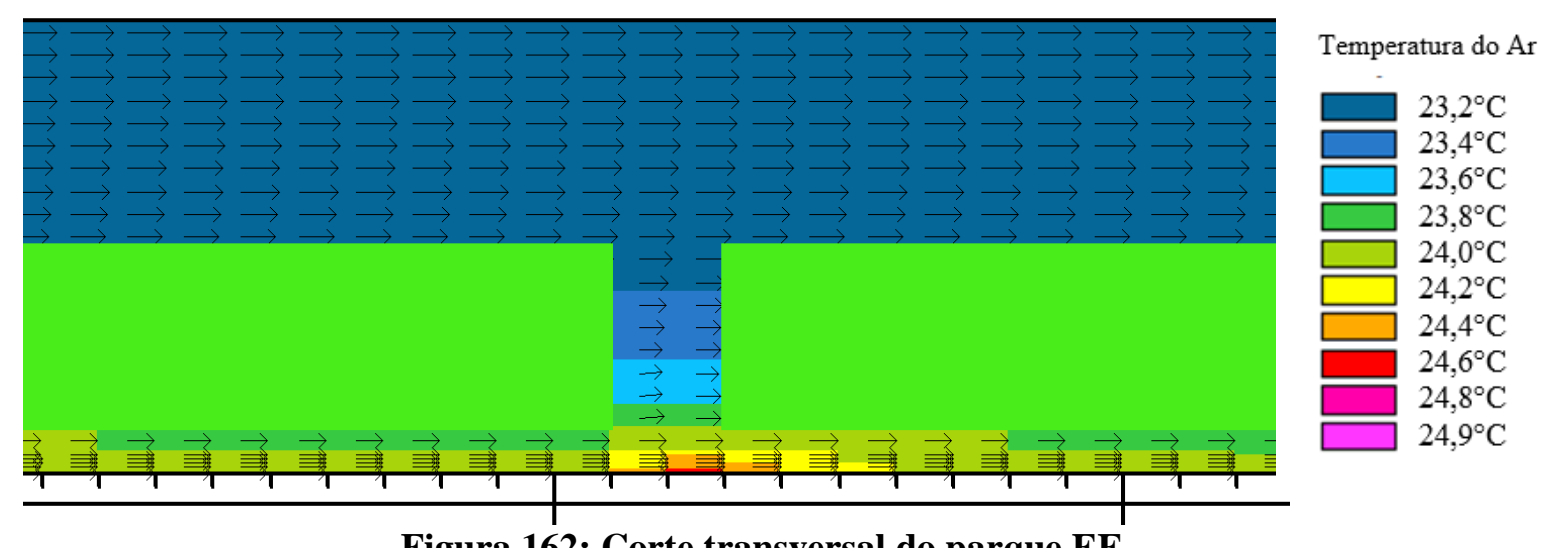

Figura 162: Corte transversal do parque EE

No corte CC, observa-se o efeito da vegetação abaixo do dossel, com uma temperatura do ar mais homogênea de $24,4^{\circ} \mathrm{C}$. Na extensão do efeito, existe uma redução da temperatura do ar na distância de $5 \mathrm{~m}$ após o limite do parque, entre $24,2^{\circ} \mathrm{C}$ e $24,4^{\circ} \mathrm{C}$, enquanto a temperatura do ar sob o asfalto é de $24,9^{\circ} \mathrm{C}$. Em seguida, verifica-se uma faixa de $5 \mathrm{~m}$ a $10 \mathrm{~m}$ em que a temperatura do ar próxima ao asfalto $24,8^{\circ} \mathrm{C}$. Dessa, considerando o efeito conjunto da evapotranspiração com a velocidade de $1 \mathrm{~m} / \mathrm{s}$, o efeito chega a se estender por $15 \mathrm{~m}$ a partir da borda do parque. 


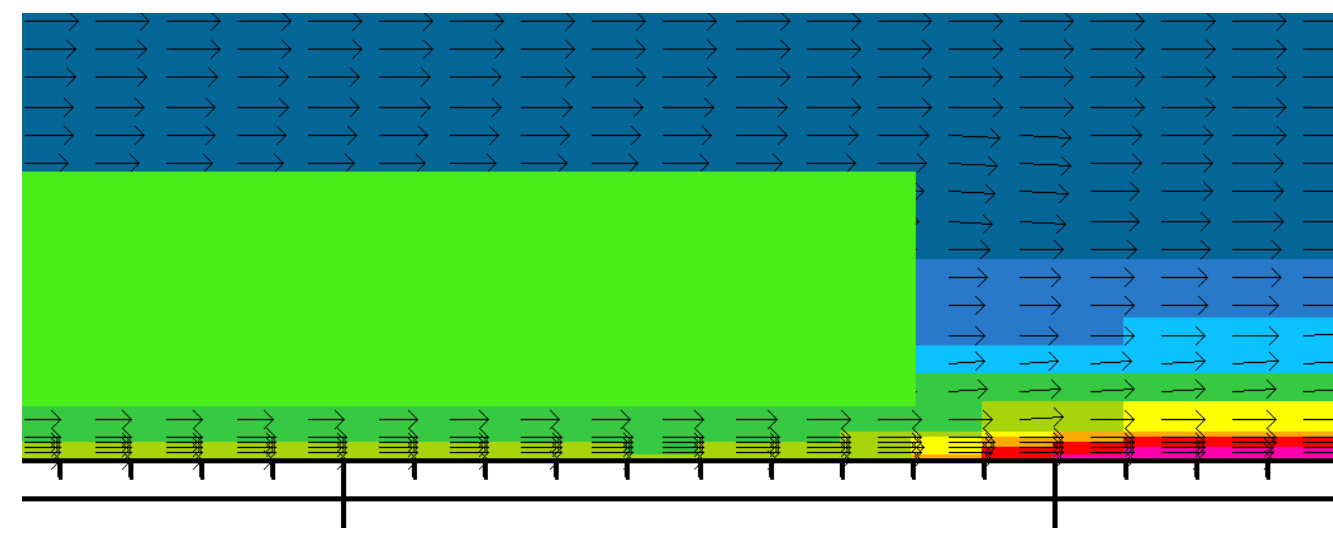

Temperatura do $\mathrm{Ar}$

Figura 163: Corte transversal do parque FF 


\section{CONSIDERAÇÕES FINAIS E CONCLUSÕES}

A partir das análises comparativas dos resultados das simulações paramétricas pelo modelo ENVI-met para o Parque Trianon, sob diferentes condições do solo-vegetaçãoatmosfera, pode-se concluir que:

- Em relação ao tipo de vegetação: ao se iniciar a pesquisa, acreditava-se que o principal elemento para definir o tipo da vegetação e sua influência seria o índice de área foliar. No entanto, utilizando-se o modelo ENVI-met, foi possível perceber, na fase de modelagem das tipologias das árvores com copa redonda (formato esférico) e alongada (formato elíptico vertical) que, além de definir a densidade do dossel pelas camadas de IAF e DAF, a distribuição geométrica das aberturas na copa (gap fraction) também se mostrou fundamental para definir a estrutura da copa.

Dessa forma, o gap fraction interfere na distribuição das folhas e isso está relacionado diretamente com o efeito do sombreamento. Assim, nos estudos com as copas elípticas e esféricas, foi possível se verificar que mesmo tendo o mesmo valor de IAF, os resultados foram diferentes para o efeito da temperatura do ar, superficial e umidade específica.

Foi importante verificar com as mudanças feitas no banco de dados de vegetação do modelo (PLANTS.DAT) que o ENVI-met considera o coeficiente de obstrução k nos cálculos e por isso que a radiação direta verificada logo abaixo do dossel, apresentou valores diferenciados nas duas tipologias simuladas. Os resultados mostraram que coeficiente de extinção k está ligado não apenas ao valor do IAF, mas no formato da copa.

- Em relação a variação nas condições climáticas: observou-se nos estudos que o aumento da velocidade do vento na área de estudo, teve uma grande influência nos efeitos finais para temperatura do ar e de superfície. Nos resultados apresentados no capítulo anterior, a velocidade do vento de $4 \mathrm{~m} / \mathrm{s}$ para uma copa elíptica de IAF 5 resulta numa temperatura do ar de $24,68^{\circ} \mathrm{C}$, uma diferença de $3,87^{\circ} \mathrm{C}$ em relação à temperatura do ar na rua de $28,55^{\circ} \mathrm{C}$.

Esses estudos foram importantes para se quantificar o percentual da obstrução das copas relacionando as características das copas (altura, largura, IAF, formato) com a variação da velocidade dos ventos. Os resultados indicaram que um vento de $4 \mathrm{~m} / \mathrm{s}$ passando pelo meio de uma copa densa (IAF 5), a redução da velocidade chega a 53\%. Para uma 
mesma velocidade e diminuindo-se o IAF, observa-se cerca de 51\% para IAF 3 e $30 \%$ de redução na velocidade inicial para IAF 1.

Em relação ao modelo, buscava-se nos estudos paramétricos de simular o mais próximo das condições reais medidas em campo. No entanto, ao se definir o vento inicial de 0,5 $\mathrm{m} / \mathrm{s}$, percebeu-se que os dados não estavam coerentes com os resultados obtidos para as demais velocidades dos ventos $(1 \mathrm{~m} / \mathrm{s} .2 \mathrm{~m} / \mathrm{s}$ e $4 \mathrm{~m} / \mathrm{s})$. Assim esses resultados foram desconsiderados e o efeito mais próximo da condição real do parque foi de ventos a $1 \mathrm{~m} / \mathrm{s}$.

- Em relação à variação nas condições do solo: verificou-se a importância da umidade do solo no processo de evapotranspiração da planta. O efeito conjunto do sombreamento das copas e a perda de água do solo por evaporação apresentou resultou em diferenças de até $23,8^{\circ} \mathrm{C}$ entre o asfalto descoberto e abaixo do dossel com IAF 5 e umidade relativa do solo de 90\%, 95\%, 95\% (camada superficial, intermediária, profunda).

O próprio modelo sugere como entrada padrão valores de 50\%,50\%,60\%\% (camada superficial, intermediária, profunda) para a realização das simulações com vegetação e pede para evitar valores de umidade no solo abaixo $10 \%$, para não comprometer o efeito de evapotranspiração.

- Em relação à extensão do efeito: reduzindo-se a malha ortogonal da modelagem para células de $5 \mathrm{mx} 5 \mathrm{~m}$ e $2 \mathrm{~m}$ de altura, foi possível verificar que nas áreas onde existe o vento a favor, e considerando as condições específicas do Parque Trianon, verificou-se uma extensão entre $5 \mathrm{~m}$ a $15 \mathrm{~m}$ partir da borda do parque até uma altura de $3,5 \mathrm{~m}$ acima da copa.

- Em relação à sensação térmica do efeito: A fim de verificar a relação das condições medidas abaixo do dossel com a sensação térmica das pessaoas, foi calculada a Temperatura Equivalente Percebida - TEP (MONTEIRO, 2008), conforme mostra a equação 52, para os dados medidos nos dois pontos no parque Trianon e os dados obtidos para estação no Aeroporto de Congonhas.

$\mathrm{TEP}=-3,777+0,4828 \cdot \operatorname{tar}+0,5172 \cdot \operatorname{trm}+0,0802 \cdot \mathrm{UR}-2,322 \cdot \operatorname{var}$

Onde,

$\operatorname{tar}=$ temperatura do $\operatorname{ar}\left[{ }^{\circ} \mathrm{C}\right]$

trm $=$ temperatura média radiante $\left[{ }^{\circ} \mathrm{C}\right]$

$\mathrm{UR}=$ umidade relativa [\%] 
var= velocidade do vento

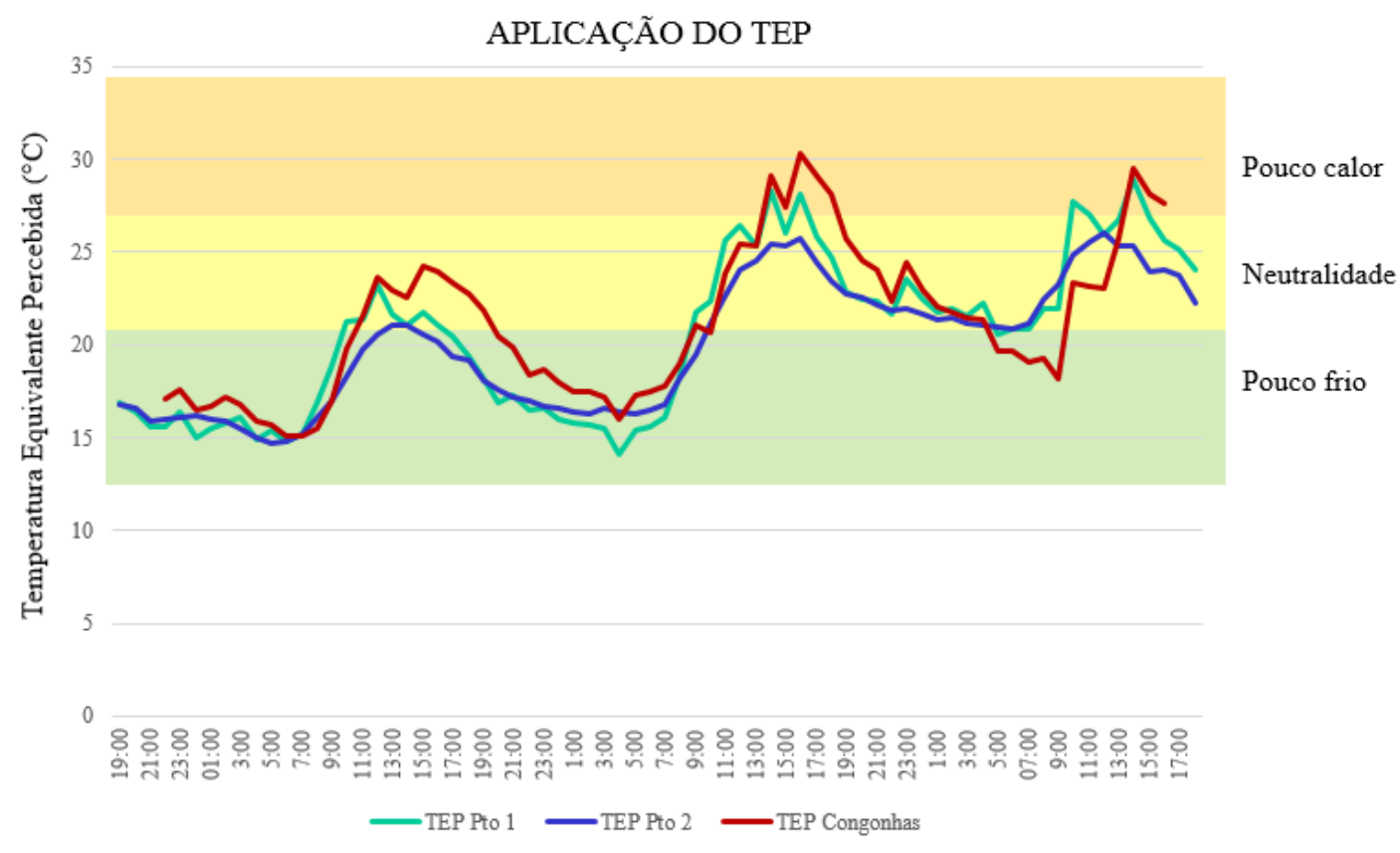

Figura 164: Resultados para TEP nos pontos 1 e 2 no Pq. Trianon.

A Figura 157 mostra que na maior parte do período as pessoas dentro do parque vão estar na condição de pouco frio e conforto. O ponto 1, localizado na entrada principal do parque, apresentou condições térmica agradável, apenas pouco de calor para os horários entre $13 \mathrm{~h}$ e $15 \mathrm{~h}$ no dia 15 de novembro de 2013.

No aeroporto de Congonhas os valores para o TEP são mais elevados do que os pontos 1 e 2 no parque, com um pico de $31^{\circ} \mathrm{C}$ às $15 \mathrm{~h}$ do dia 15 de novembro de 2013 . Nesse horário a diferença nos valores do TEP chegam a $3^{\circ} \mathrm{C}$ para o ponto 1 e $5^{\circ} \mathrm{C}$ em relação ao ponto 2 (centro do parque).

Conforme os estudos de Labaki et al. (2009), os agrupamentos arbóreos exercem influência numa escala maior do que uma única árvore. Ou seja, a disposição de elementos arbóreos pode aumentar a capacidade de redução da temperatura do ar e a atenuação da radiação incidente, bem como intensificar as sensações de conforto térmico ao usuário num determinado raio. Dessa forma é possível observar que mesmo a redução de $1{ }^{\circ} \mathrm{C}$ na temperatura do ar pode representar de $3^{\circ} \mathrm{C}$ na sensação percebida das pessoas e ser o suficiente para estar em conforto térmico. 
Este trabalho teve por objetivo quantificar o impacto da vegetação nos microclimas urbanos abaixo do dossel, em função das interações solo-vegetação-atmosfera. Essas interações consideram os efeitos:

1) do dossel propriamente dito, expressos pelas variáveis índice de área foliar - IAF (Leaf Area Index - LAI) e distribuição geométrica das aberturas na copa (gap fraction);

2) da cobertura do solo, expressa pela composição do solo, sua temperatura e teor de umidade,

3) e das variáveis microclimáticas locais (temperatura do ar, umidade do ar, radiação solar, temperatura radiante media, temperatura superficial, direção e velocidade dos ventos).

Considerando-se que o impacto da vegetação nos microclimas urbanos é função das interações solo-vegetação-atmosfera, e tendo em vista resultados de estudos anteriores, a hipótese deste trabalho é que, para o clima de São Paulo, em função dos processos de evapotranspiração e do sombreamento, a redução na temperatura do ar abaixo do dossel em parques urbanos será de cerca de $1^{\circ} \mathrm{C}$ e a redução da temperatura superficial será de cerca de $20^{\circ} \mathrm{C}$, ambas em relação às áreas não sombreadas pela vegetação, e que esses efeitos limitam-se à borda do parque sob condições de baixa velocidade do vento, de cerca de $1 \mathrm{~m} / \mathrm{s}$.

Em relação aos trabalhos já desenvolvidos sobre o efeito da vegetação no entorno, os resultados obtidos na pesquisa sobre a temperatura do ar estão de acordo a redução de até $3^{\circ} \mathrm{C}$ no entorno. No entanto, existe uma variação no que se refere aos resultados para a extensão do efeito.

Segundo os estudos de Ca, Asaeda e Abu (1998), um parque de 60 hectares chega a reduzir a temperatura do ar em $1,5^{\circ} \mathrm{C}$ embaixo da copa às $12 \mathrm{~h}$ com uma extensão do efeito de até $1 \mathrm{~km}$ no sentido do vento. Givoni (1998) verificou a mesma redução na temperatura do ar $\left(1,5^{\circ} \mathrm{C}\right)$ para o Parque Beijamin, em Haifa, Israel, sendo a extensão do efeito de no máximo 150m. Honjo e Takakura (1990), sugeriu que uma área de parque de comprimento $100 \mathrm{~m}$, pode influenciar o entorno a uma distância de $300 \mathrm{~m}$ a $400 \mathrm{~m}$ a partir do limite do parque e no sentido do vento.

Acredita-se que a extensão do efeito no entorno está muito relacionada com a velocidade e sentido dos ventos. Assim serão necessários mais estudos voltados para a variação do vento na borda do parque. 
Conforme com os resultados das simulações paramétricas, variando-se as caraterísticas do dossel, verificou-se uma redução máxima de $1^{\circ} \mathrm{C}$ na temperatura do ar e de $19^{\circ} \mathrm{C}$ na temperatura superficial, ao se comparar os valores obtidos abaixo de uma copa densa (forma elíptica e IAF $5 \mathrm{~m} 2 / \mathrm{m} 2$ ) em relação às condições do entorno, fora do parque. Esse efeito se estende por, no máximo, 5m de distância a partir dos limites do parque, com velocidade do ar de $1 \mathrm{~m} / \mathrm{s}$ e umidade de $40 \%$ na camada superficial do solo (0$20 \mathrm{~cm}$ ). Esses resultados comprovam a hipótese inicial e mostram não apenas a importância do tipo de vegetação escolhida (formato da copa, IAF e distribuição geométrica das aberturas na copa) como as características do meio em que ela está inserida (condições microclimáticas locais e de solo).

A pesquisa buscou contribuiu para a teoria existente com resultados que pela primeira vez incluem variáveis principalmente do dossel que não eram quantificadas adequadamente para estudos nessa área, como densidade e distribuição das folhas na copa. Assim como mostrar um processo de uso e refinamento das modelagens no ENVI-met para estudos do impacto da vegetação em micro-escala, abaixo do dossel. Os resultados podem contribuir para a formulação de políticas públicas visando à mitigação dos efeitos de aquecimento urbano, particularmente diurnos, em climas tropicais. 


\section{REFERÊNCIAS BIBLIOGRÁFICAS}

1. ABREU, L. V. ; LABAKI, L. C. Comparação de métodos de conforto térmico em ambientes externos para avaliação do raio de influência de espécie arbórea decídua. In: X Encontro Nacional e VI Encontro Latino Americano de Conforto no Ambiente Construído, 2009, Natal. X Encontro Nacional e VI Encontro Latino Americano de Conforto no Ambiente Construído, 2009. p. 1-10.

2. AKBARI, H. Energy Saving Potentials and Air Quality Benefits of Urban Heat Island Mitigation. Lawrence Berkeley National Laboratory. 2005. Disponível em: < http://www.osti.gov/bridge/servlets/purl/860475-UlHWIq/860475.PDF $>$. Acesso em maio de 2010.

3. AKBARI, H. Shade Trees Reduce building energy use and CO2 emission from power plants. Heat Island Group, 2001. Disponível em: <http://eetd.lbl.gov/HeatIsland/PUBS/PUBSLIST.html > Acesso em maio de 2010.

4. AKBARI, H.et. al. Paiting the town white and green. Heat Island Group, 1997. Disponível em: < http://eetd.lbl.gov/HeatIsland/PUBS/PAINTING/> Acesso em: 21 março de 2006.

5. ALLEN, R. G. Evaluation of procedures for estimating mean monthly solar radiation from air temperature. Rep., Food and Agricultural Organization of the United Nations FAO, Rome, 1995.

6. ALLEN, R. G. Assessing integrity of weather data for reference evapotranspiration estimation. Journa of. Irrigation and Drainage Engeneering, v.122, p. 97-106, 1996.

7. ALLEN, R. G. Self-calibrating method for estimating solar radiation from air temperature. Journal of Hydrology. Engeneering v.2, p.56-97, 1997.

8. ALLEN, R. G. et al. Crop evapotranspiration. Guidelines for computing crop water requirements. FAO Irrigation and Drainage Paper No. 56, Food and Agricultural Organization of the United Nations, Rome, 1998.

9. ALLEN, R. G., et al. The ASCE standardized reference evapotranspiration equation, American Society of Civil Engineers, 2005.

10. ALI- TOUDERT, F. Dependence of outdoor thermal comfort on street design in hot and dry climate. Berichte des Meteorologischen Institutes der Universität Freiburg n. 15, 2005.

11. AlvareZ DomingueZ, S. et al. Control Climático em Espacios Abiertos. El Proyecto EXPO'92. Sevilha: CIEMAT, 1992.

12. ALUCCI, M.P.; MONTEIRO, L. M. Climate and thermal Stress in outdoor spaces. In: Passive Low Energy Architecture, 21, Eindhoven, 2004. Proceedings. Built environments and environmental buildings. Eindhoven: PLEA, 2004 (CD-ROM). 
13. AMARAL, S.; SOARES, J.V.; ALVES, D.S.; MELLO, E.M.K.; ALMEIDA, S.A.S.; SILVA, O.F.; SILVEIRA, A.M. Relações entre índice de área foliar (LAI), área basal e índice de vegetação (NDVI) em relação a diferentes estágios de crescimento secundário na Floresta Amazônica em Rondônia. (Compact disc). In: SIMPÓSIO BRASILEIRO DE SENSORIAMENTO REMOTO, 8., Salvador, 1996. Anais. Salvador: INPE; SELPER, 1996.

14. ANDERSON, M.C. Studies of the woodland light climate I. The photographic computation of light condition. Journal of Ecology, v.52, 1964, p.27-41

15. ANDERSON, M.C. Radiation and crop structure. In: Z. Sestak, J. Catsky and P. G. Jarvis (eds). Plant Photosynthetic Production Manual of Methods. Junk. The Hague, 1971, p.77-90

16. ARAGÃO L. et al., Landscape patterns ad spatial variability of leaf area index in eastern Amazonia. Forest Ecology and Management, v. 211, 2005, p. 240-253.

17. ARES, A.; FOWNES, J. H. Productivity, nutrient and water-use efficiency of Eucalyptus saligna and Toona ciliata in Hawaii. Forest Ecology and Management, v. 139, p. 227-236, 2000.

18. ARTAXO, P. 2008. Mudanças climáticas globais: cenários para o planeta e a Amazônia. Artigo de internet. Endereço: www.mudancasclimaticas.andi.org.br. Acesso em: julho 2012.

19. ASNER, G. P. et al. Global synthesis of leaf area index observations: implications for ecological and remote sensing studies. Global Ecology and Biogeography, v.12, 2003, p.191-205.

20. ASSIS, E. S. Mecanismos de desenho urbano apropriado à atenuação da ilha de calor urbana: análise de desempenho de áreas verdes em clima tropical. Rio de Janeiro, 1990. Tese (Mestrado em Arquitetura) Faculdade de Arquitetura e Urbanismo, Universidade Federal do Rio de Janeiro, 1990.

21. ASSIS, E. S. Impacto da forma urbana na mudança climática: método para previsão do comportamento térmico e melhoria do desempenho do ambiente urbano. São Paulo, 2000. Tese (Doutorado em Arquitetura) Faculdade de Arquitetura e Urbanismo, Universidade de São Paulo, 2000.

22. ASSIS, E. S. Abordagem do Clima Urbano e Aplicações no Planejamento: Reflexões sobre uma trajetória. In: VIII Encontro Nacional sobre Conforto no Ambiente Construído, 2005, Maceió, Alagoas. Anais. Maceió, Alagoas: ENCAC -ELACAC, 2005 . 
23. AVIS, P.G; Stomata Control of Transpiration: Scaling Up from Pore to Paddock. In: C. Rosenzweig \& R. Dickinson (Eds), Climate Vegetation Ineteraction, Proceedings of a woakshop held at NASA/ Goddard Space Fight Center, Greenbelt, Maryland, 1986.

24. BARCLAY H. J.; TROFYMOW J. A.; LEACH R. I. Assessing bias from boles in calculating leaf area index in immature Douglas-fir with the LI-COR canopy analyzer. Agricultural and Forest Meteorology, v. 100, p. 255-260, 2000.

25. BARET, F.; GUYOT, G. Potential and limits of vegetation indices for LAI and APAR assessment. Remote Sensing of Environment, n.35, 1991, p.161-173.

26. BARTHOLOMEI, C. L. B. Estudo da Atenuação da Radiação Solar incidente por diferentes espécies arbóreas. 1998. Tese (Mestrado em Engenharia Civil). Universidade Estadual de Campinas, Fundação de Amparo à Pesquisa do Estado de São Paulo, 1998.

27. BARTHOLOMEI, C. L. B. Influência da vegetação no conforto térmico urbano e no ambiente construído. 2003. Tese (Doutorado em Engenharia Civil). Universidade Estadual de Campinas, Fundação de Amparo à Pesquisa do Estado de São Paulo, 2003.

28. BAtTAGLiA, M. et al. Prediction of leaf area index in eucalypt plantations: effects of water stress and temperature. Tree Physiology, v. 18, p. 521-528, 1998.

29. BEADLE, C.L. Growth analysis. Photosynthesis and production in a changing environment: a field and laboratory manual, ed. by D.O. Chapman \& Hall, London, 1993.

30. BECKER, M. Une technique nouvelle d'utilization des photographies hémisphériques pour la mesure du climat lumineux en forêt. Annales des Sciences Forestières v. 28, 1971, p. 425-442

31. BERBIGIER, P.; BONNEFOND, J.M. Measurements and modelling of radiation transmission within a stand of maritime pine (Pinus pinaster Ait). Annales des Sciences Forestières, $v .52,1995, P .23-42$.

32. BONAN, G. B. Ecologycal Climatology: Concepts and Aplications. Cambridge University Press, 2002.

33. BONHOMMER, R. Application de la technique des photographies hémisphériques in situ à la mesure de l'indice foliaire. In: Techniques d'étude des facteurs physiques de la biosphère. Paris, França,1970, p. 501-505.

34. BONHOMMER, R. et al. The use of hemispherical photographs for determining the leaf area index of young crops. Photosynthetica, v.8, 1974, p.299-301.

35. BONHOMME, R.; CHARTIER, P. The interpretation and automatic measurement of hemispherical photographs to obtain sun lit foliage and gap frequency. Israel Journal of Agricultural Research v.22, 1972, p. 53-61. 
36. BORCKE C. Landscape and nature in the city. In Sustainable Urban Design. R. Thomas, (Ed.), Spon Press, New York, 2003.

37. BREDA, N.J.J. Ground-based measurements of leaf área index: A review of methods, instruments and currentcontroversies. Journal of Experimental Botany, v. 54, p.24032417,2003

38. BRUSE, M. Simulating the Effects of Urban Environmental on Microclimate with a Three-Dimensional Numerical Model. In: Climate and Environmental Change, Conference Meeting of the Commission on climatology, Evora, 1998.

39. BRUSE, M.; Fleer, H. Simulating surface-plant-air interactions inside urban environments with a three dimensional numerical model. Environmental Modelling \& Software, 1998.

40. BRUSE, M. Modelling and Strategies for improved urban climates. In: Proceedings International Conference on Urban Climatology and International Congress of Biometeorology, Sydney, 1999.

41. BRUSE, M. ENVI-met 3.0 Manual. 2003. Disponível em: < http://envi-met.com > Acesso em abril 2010.

42. BRUSE, M. ENVI-met implementation of the Jacobs A-gs. Model to calculate the stomata conductance. Bochum, 2004. Disponível no site: <http://www.geographie.ruhruni-bochum.de/agklima/envimet/> Acesso em: maio de 2010.

43. BRUSE, M., Particle filtering capacity of urban vegetation: A microscale numerical approach. Berliner Geographische Arbeiten, 2007, p. 61-70.

44. CA, V. T.; ASAEDA, T., ABU, E. M. Reductions in air conditioning energy caused by a nearby park. Energy and Buildings. v. 29, pp. 83-92, 1998

45. CANNELL. M. G. R. et al. Radiation interception and productivity of willow. Journal of Applied Ecology, v. 24,1993, p.261-278.

46. CHATZIDIMITRIOU, A.; CHRISSOMALLIDOU, N. YANNAS, S. In: International Passive and Low Energy Architecture Conference, 22, Beirut, 2005. Proceedings. 2005. Beirut: PLEA, 2005.

47. CHEN, J. M.; BLACK, T. A.; ADAMS, R. S. Evaluation of hemispherical photography for determining plant area index and geometry of a forest stand. Agricultural and Forest Meteorology, v. 56, p. 129-143, 1991.

48. CHEN, J.M.; BLACK, T.A.. Defining leaf area index for non-flat leaves. Plant, Cell and Environment v. 15, 1992, p.421-429. 
49. CHEN, J. M.; CIHLAR, J..1995. Quantifying the effect of canopy architecture on optical measurements of leaf area index using two gap size analysis methods. IEEE Transactions on Geosciences and Remote Sensing 33,777-787, 1995a

50. CHEN, J. M.; CIHLAR, J. Retrieving leaf area index of boreal conifer forests using Landsat TM images. Remote Sensing of Environment, v. 55, p. 153-162, 1996.

51. CHEN, J. M. Optically-based methods for measuring seasonal variation in leaf area index of boreal conifer forests. Agricultural and Forest Meteorology, v.80, 1996a, p.135-163.

52. CHEN, J. M. et al. Leaf area index on boreal forests: theory, techniques and measurements. Journal of Geophysics Research 102,1997, p.429-444.

53. CHEN, J. M. et al. Derivation and validation of Canada-wide coarse-resolution leaf area index maps using high-resolution satellite imagery and ground measurements. Remote Sensing of Environment, v.80,2002, p.165-184.

54. CITY OF SEATTLE. Green Factor Overview. 2009. Disponível em: < http://www.seattle.gov/dpd/permits/greenfactor/Overview/ > Acesso em maio de 2010.

55. CLINE, R. G.; CAMPBELL, G. S. Seasonal and diaurnal water relation of selected forest species. Ecology, v. 56, 1976, p. 367-373.

56. YOK, T. P.; SIA, A. Leaf Area Index of Tropical Plants - A Guidebook on its Use in the Calculation of Green Plot Ratio. CUGE, 2010.

57. DAUGHTRY, C. S. T. Direct measurement of canopy structure. In: GOEL, N. S.; NORMAN, J. M. (Eds.) Instrumentation for studying vegetation canopies for remote sensing in optical and thermal infrared regions. London: Harwood, 1990. cap. 5, p. 4560.

58. DEARDORFF, J.W. Efficient Prediction of Ground Surface Temperature and Moisture with a Inclusion of a Layer of Vegetation. Journal of Geophysical Research, Colorado, v.83, n.C4, 1978.

59. DICKSON, R. E.; HANSON, B. Vegetation-albedo feedbacks. Climate processes and climate sensitivity. Geoghysical Monogragh 29, v.5, 1984, p. 180-186.

60. DIMOUDI, A; NIKOLOPOULOU, $\mathrm{M}$ Vegetation in the urban environment: microclimatic analysis and benefits. In: PLEA 2000 (17th International Conference on Passive and Low Energy Architecture), Cambridge, UK, 2000.

61. DIMOUDI, A; NIKOLOPOULOU, M. Vegetation in the Urban Environment: Microclimatic Analysis and Benefits. Energy and Buildings, vol.35, n.1, 2003. 
62. DUARTE, D. Padrões de Ocupação do solo e microclimas urbanos na região de clima tropical continental. 2000. Tese (Doutorado em Arquitetura e Urbanismo). Faculdade de Arquitetura e Urbanismo, Universidade de São Paulo, São Paulo, 2000.

63. DUARTE, Denise (coord). O Impacto da vegetação nos microclimas urbanos. Relatório técnico CNPq processo 400938/2007-3. São Paulo: FAUUSP, 2010.

64. DUARTE, D. H. S.; SERRA, Geraldo Gomes. Padrões de ocupação do solo e microclimas urbanos na região de clima tropical continental brasileira. Correlações e proposta de um indicador. Ambiente Construído (Online), Porto Alegre, v. 3, n. n.2, p. 7-20, 2003.

65. DUARTE, Denise; GONÇALVES, Joana Carla Soares. Environment and Urbanization: Microclimatic Variations in a Brownfield Site in Sao Paulo, Brazil. In: 23rd International Conference PLEA 2006 - Passive and Low Energy Architecture, 2006, Geneve. Proceedings...Clever Design, Affordable Comfort. A Challenge for Low Energy Architecture and Urban Planning. Fribourg: Université de Genève, 2006. v. 2. p. 497-503.

66. DUBOV, A. S. et al. Turbulence in the vegetation cover. L. Hydrometeoizdat. (In Russian), 1978.

67. DUCREY, M. Utilization des photographies hémisphériques pour le calcul de la perméabilité des couverts forestiers au rayonnement solaire. I. Analyse technique de l'interception. Annales des Sciences Forestières 32, 1975', p.73-92.

68. EAMUS, D. Identifying Groundwater Dependent Ecosystems: A Guide for Land and Water Managers. Australian Government Land and Water, 2009.

69. EVANS, G.D.; COOMBE, D. E. Hemispherical and woodland canopy photography and the light climate. Journal of Ecology, v. 47. 1959, p.103-113.

70. ELVIDGE, C.D.; LYON, R.J.P. Influence of rock-soil spectral variation on the assessment of green biomass. Remote Sensing of Environment, n.17, 1985, p.265-279.

71. FAHMY, M.; SHARPLES, S. On the development of an urban passive thermal comfort system in Cairo. Building and Environment, v.4, 2009, p.1907-1016.

72. FANGER, P. O. Thermal Comfort: Analysis and Applications in Environmental Engineering. New York: McGraw-Hill Book Company, 1982

73. FAZIA, A. Dependence of outdoor thermal comfort on street design in hot and dry climate, Tese (doutorado em Arquitetura), Université de Freiburg, Freiburg, 2005.

74. FRENCH, A. N. et. al. Discrimination of senescent vegetation using thermal emissivity contrast. Remote Sensing of Environment, v.74, 2000, p.249-254.

75. GIUNTI NETO, C. J. Calibração do uso de fotos hemisféricas, do LAI-2000 e do ceptômetro para estimativas do Índice Área Folia em plantações de Eucalyptus. 2007, 
p.61. Escola Superior de Agricultura "Luiz de Queiroz", Universidade de São Paulo, Piracicaba, 2007 (Relatório técnico de estágio profissonalizante).

76. GIVONI, B. Climate Considerations in Urban and Building Design. New York: John Wiley \& Sons, 1998.

77. GIVONI, B. Impact of Planted Areas on Urban Environmental Quality- A review. Atmosferic Environment, vol. 25, n.3, 1991, p.289-299.

78. GOMES, P. S.; LAMBERTS, R. O estudo do clima urbano e a interface com a legislação urbanística: considerações a partir do caso Montes Claros MG. Ambiente Construído (Online), v. 9, p. 73-91, 2009.

79. GOUDRIAAN, J. Crop Micrometeorology: A Simulation Study. Centre for Agricultural Publishing and Documentation, Wageningen, The Netherlands, 1977, p.249.

80. GUERRA MACHO, J. J. et al. Control Climático em Espacios Abiertos. Evaluacíon del Proyecto EXPO'92. Sevilha: CIEMAT, 1994.

81. GREEN, E. P; CLARK, C.D. Assessing Mangrove Leaf Area Index and Canopy Closure. In: Alasdair, J. Edwards (Ed.), Remote Sensing Handbook for Tropical Coastal Manegement Sourcebooks 3. Part 5. Quantitative Measurement of Ecological Parameteres and Marine Resource Assessment, CSI, UNESCO, 2000.

82. GRIMMOND, C.S.B; OKE, T. Variability of Evapotranspiration Rates in Urban Areas. In: Passive Low Energy Architecture, 17, Proceedings. International Passive and Low Energy Architecture Conference. Cambridge: PLEA, 2000.

83. GRIMMOUND, C. S. B., OKE, T.R. Turbulent heat fluxes in urban areas: Observations and Local-Scale Urban Meteorological Parameterization Scheme (LUMPS). Journal of Applied Meteorology.,vol. 41, p.792-810, 2002.

84. HARAZONO, Y, et. al. Effect of Rooftop Vegetation using Artificial Substrates on the Urban Climate and the Thermal Load of Buildings. Energy and Buildings, Netherlands, n.15-16, 1990/91, p. 443-446.

85. HEISLER, G.M. Energy savings with trees. Journal of Arboriculture, vol.12, n.5, p.113$125,1986$.

86. HEISERMAN, D. L. Exploring Chemical Elements and their Compounds. Tab Books, 1991.

87. HINGSTON, F. J.; GALBRAITH, J. H.; DIMMOCK, G. M. Application of the processbased model BIOMASS to Eucalyptus globulus ssp. globulus plantations on exfarmland in south western Australia - I. Water use by trees and assessing risk of losses due to drought. Forest Ecology and Management, v. 106, 1998, p. 141-156. 
88. HOLBEN, B.N.; TUCKER, C.J.; FAN, C.J. Spectral assessment of soybean leaf area and leaf biomass. Photogrammetric Engineering and Remote Sensing, n.46, 1980, p.651-656.

89. HONJO, T.; TAKAKURA, T. Simulation of thermal effects of urban green areas on the surroundings areas. Energy and Buildings, Netherlands, n.15-16, 1990/91, p. 435-442.

90. HOSOI, F. OMASA, K. Voxel-based 3-D modeling of individual trees for estimating leaf area density using high-resolution portable scanning lidar. IEEE Transactions on Geoscience and Remote Sensing, v. 44, 2006, p.3610-3618.

91. HUTTNER, S.; BRUSE, M. Numerical modelling of the urban climate- A preview on ENVI-met 4.0; Seventh International Conference on Urban Climate ICUC-7, Yokohama, Japão, 2009.

92. HUTTNER, S. Further development and application of the 3D microclimate simulation ENVI-met. Tese (doutorado em Arquitetura), Johannes Gutenberg-Universität Mainz, Mainz, Germany, 2012.

93. IPCC - Intergovernmental Panel on Climate Change. Climate Change 2007. The IPCC 4th Assessment Report, 2007.

94. IPCC - Intergovernmental Panel on Climate Change. Climate Change 2013. The IPCC 5th Assessment Report, 2013.

95. ISO 7726, Thermal Environments - Instruments and methods for measuring physical quantities, International Standard, 1985.

96. ISO 7730, Moderate thermal environments - Determination of the PMV and PPD indices and specification of the conditions for thermal comfort, International Standard, 1998.

97. JACOBS, C.M.J. Direct Impact of Atmospheric $\mathrm{CO}_{2}$ Enrichment on Regional Transpiration. Tese.Wageningen Agricultural University, Netherland, 1994.

98. JANSSON, P.E.; MOON, D. A Coupled model of water, heat and mass transfer using object orientation to improve flexibility and functionality. Environmental Modelling \& Software, v.16, 2001, p.37-46.

99. JANSSON, P. E. 2006 - Urban microclimate and surface hydrometeorological processes. Tese (doutorado em Arquitetura), Estocolmo, Suécia, 2006.

100. JARVIS, P. G.; LEVERENZ, J. W. Productivity of temperate, deciduous and evergreen forests. Encyclopedia of plant physiology, New York: Springer-Verlag, v.12, 1983, p.233-280.

101. JARVIS, P.G. The interpretation of the variations in leaf water potential and stomatal conductance found in canopies in the field. Philosophical Transactions of the Royal Society. Londres, v. 273, 1976, p.593-610. 
102. JENDRITZSKY, G. Perceived temperature: "Klima-Michel-model". In: The development of heat stress watch warning systems for European cities. Freiburg, 2003. Presentation of Conference The Development..., Friburgo, 2003.

103. JONCKHEERE, E. et al. Methods for Leaf Area Index Determination - Part I: Theories, Techniques and Instruments. 2003. Disponível em: < http://w3.avignon.inra.fr/valeri/fic htm/documents/main.ph>. Acesso em novembro de 2010.

104. JONCKHEERE, E.; FLECK, S.; NACKAERTS, K.; MUYS，B.; COPPIN，P.; WEISS, M.; BARET, F. Agricultural and Forest Meteorology, v.121, 2004, p.19-35.

105. JONES, H.G. Plant and Microclimates - A Quantitative approach to environmental plant physiology. Cambridge University Press. 2ed, 1992.

106. JANSSON, C. Urban Microclimate and Surface Hydrometeorological Processes. Tese (Doutorado em Arquitetura), KTH Architecture and Built Environment, Estocolmo, 2006.

107. JOHANSSON, Erik. Urban Design and Outdoor Thermal Comfort in Warm Climates.Int J. Biometorol. 2006.

108. JUSUF, S. K. et al. The Influence of Land Use on the Urban Heat Island in Singapore. Habitat International, n.31, 2007, p. 232-242

109. JUSUF, S. K.; WONG N.H. Development of empirical models for an estate level air temperature prediction in Singapore. In:Second International Conference on Countermeasures to Urban Heat Islands. Berkeley: LBNL Berkeley. Set. 2009. Anais...p. $21-23$.

110. KALLARACKAL, J.; SOMEN, C. K. An ecophysiological evaluation of the suitability of Eucalyptus grandis for planting in the tropics. Forest Ecology and Management, v. 95, p. 53-61, 1997.

111. KATZSCHNER, L. Urban climate studies as tools for urban planning and architecture. In: IV Encontro Nacional de Conforto no Ambiente Construído, 1997, Salvador. Anais. Salvador: FAUUUFBA/LACAM-ANTAC, 1997, p.49-58.

112. KIMBALL, B.A.; MAUREY, J.R.; NAKAYAMA, F. S., IDSO, S. W. Effects of increasing atmospheric CO2 on vegetation. Vegetatio, v.104/105, 1993, p.65-75.

113. KOLIC, B. Forest Ecoclimatology (in Serbian). University of Belgrade, Servia, 1978, p.295.

114. KONJINEDIJK, C.C., RANDRUP, T.B., NILSSON, K., Urban forestry research in Europe: an overview. Journal of Arboriculture, v.26, n.3, p. 152-161, 2000.

115. KONJINEDIJK, C.C. A decade of Urban Forestry in Europe. Forest Policies and Economics, v.5, p.173-186, 2003. 
116. KUCHARIK C. J. et al. Characterizing canopy nonrandomness with a Multiband Vegetation Imager MVI. Journal of Geophysical Research, v.102, 1997, p.455-473.

117. KUMAGAI, T. et al. Transpiration, canopy conductance and the decoupling coefficient of a lowland mixed dipterocarp forest in Sarawak, Borneo: Dry spell effects. Journal of Hydrology, v.287, 2004, p.237-251.

118. KUO, F. E.; SULLIVAN, W. C.; COLEY, R. L. ; BRUSON, L. Fertile ground for community: inner-city neighborhood common spaces. American Journal of Community Psychology, v. 26, n.6, 1998, p.823-851.

119. KUTTLER, W; STRASSBURGER A. Air Quality measurements in a urban green area - A Case Study. Atmospheric Environment. vol. 33, n. 24, 1999, p. 4101-4108.

120. LABAKI, L. C. ; RIGITANO, Roberta Zakia ; RODRIGUES, Michelle Santos . Conforto térmico no ambiente construído: contribuição da vegetação. In: COTEDI 2005 - Confort y eficiencia energética en la arquitectura, 2005, Cidade do México. Memórias del IV COTEDI - Confort y eficiencia energética en la arquitectura. Cidade do México : Universidad Autónoma Metropolitana, 2005. v. 1. p. 155-162.

121. LABAKI, L. C. ; SANTOS, R. F. ; BARThOlOMEI, C. L. B; ABREU, L. V. Vegetação e conforto térmico em espaços urbanos abertos. Fórum Patrimônio: Ambiente Construído e Patrimônio Sustentável (UFMG. Online), 2009.

122. LALIC, B; MIHAILOVIC, D. T. An empirical relation describing leaf-area density inside the forest for environmental modelling, J.Appl. Met., 2004

123. LANDSBERG, H. E. The Urban Climate. New York: Academic Press, 1981.

124. LANDSBERG, J.J.; WARING, R.H. A generalised model of forest productivity using simplified concepts of radiation-use efficiency, carbon balance and partitioning. Forest Ecology and Management, v.95, 1997, p.209-228.

125. LANG, A. Leaf area and average leaf angle from transmittance of direct sunlight. Australian Journal of Botany, v.34, 1986, p.349-355.

126. LANG, A. R. G.; MCMURTRIE, R. E. Total leaf areas of single trees of Eucalyptus grandis estimated from transmittances of the sun's beam. Agricultural and Forest Meteorology, v. 58, p. 79-92, 1992.

127. LARCHER, W. Ecofisiologia vegetal. São Carlos: RIMA Artes e Textos, 2006.p.532.

128. LAURIE, M. Clima y Microclima. Barcelona: Gustavi Gili, 1983.

129. LE DANTEC, V. et al. Interannual and spatial variation in maximum leaf area index of temperate deciduous stands. Forest Ecology and Management, v.34,2000, p.71-81.

130. LEDENT, J.F. Sur le calcul du coefficient d'extinction du rayonnement solaire incident direct dans un couvert végétal. Oecologia Plantarum, v.12, 1997, p.291-300. 
131. LEMEUR, R.; BLAD, B. L. A critical review of light models for estimating the shortwave radiation regime of plant canopies. Agricultural Meteorology, v.14, 1974, p.255-286.

132. LEVY, P. E; JARVIS, P. G. Direct and indirect measurements of LAI in millet and fallow vegetation in HAPEX-Sahel. Agricultural and Forest Meteorology, v. 97, 1999, P. 199-212.

133. LI-COR. LAI-2000 plant canopy analyser: Instruction manual. Li-cor Inc. Lincoln: 1992.

134. LILIEQUIST, G.; CEHAK, K. Allgemeine Meteorologie. Springer, Berlin, 2006.

135. LINHARES, C. A.; PONZONI, F. J.; SHIMABUKURO, Y. E. Relação entre volume de madeira e índice de área foliar em um povoamento de Pinus spp.: estudo de caso. Revista Árvore, v. 24, p. 47-54, 2000.

136. LOMBARDO, M. Ilha de calor nas metrópoles. São Paulo: Hucitec, 1985.

137. LÓPEZ-SERRANO, F.R. et al. Lai estimation of natural pine forest using a nonstandard sampling technique. Agricultural and Forest Meteorology, Amsterdam, v. 101, 2000, p. 95-111.

138. LORENZI, H. Árvores brasileiras: manual de identificação e cultivo de plantas arbóreas nativas do Brasil. Plantarum, Nova Odessa, v.2, 1998.

139. MANSSON, V. A Phisycally -Based Scheme for the Urban Energy Budget in Atmosferic Models. Atmospheric Models. Boundary-Layer Meteorology, v.9, 2000, p. 357-397.

140. MARKHAM, B. L.; BAKER, J. L. Landsat MSS and TM Post-Calibration Dynamic Rangers, Exoatmospheric Reflectance and At-Satellite Temperatures. EOSAT Landsat Tech, 1986.

141. MARTILLI et al. On the impact of urban surface exchange parameterisations on air quality simulations: the Athens case. Atmospheric Environment, vol. 37, n. 30, p. 4217-4231, 2002.

142. MASCARÓ, L; MASCARÓ, J. Vegetação urbana. 2.ed. Porto Alegre: Mais Quatro Editora, 2005.

143. MCPHERSON, E.G. et al. Desert Southwest Community Tree Guide: Benefits, Costs and Strategic Planting. Phoenix, AZ: Arizona Community Tree Council, 2004. Disponível em: <http://www.fs.fed.us/psw/programs/cufr/products/001 cufr542 72dpiDsrtSWComm TreeGd04.pdf >. Acesso em maio de 2007. 
144. MEIR, P; GRACE, J.; MIRANDA, A.C. Photographic method to measure the vertical distribution of leaf area density in forests. Agricultural \& Forest Meteorology. n.102. 2000. p.105-111

145. MENEZES, P. R.; ALMEIDA, T. Introdução ao Processamento de Imagens de Sensoriamento Remoto. Brasilía-DF. 2012

146. MONTEIRO, C. A. F.; MENDONÇA, F.Clima Urbano. São Paulo: Universidade de São Paulo, Série Teses e Monografias, n..25. 1976.

147. MONTEIRO, L. M. Modelos Preditivos de Conforto Térmico: quantificação de relações entre variáveis microclimáticas e de sensação térmica para avaliação e projeto de espaços abertos. 378 f. São Paulo, 2008. Tese (Doutorado em Engenharia Civil) Escola de Engenharia, Universidade de São Paulo, São Paulo, 2008.

148. MONTEITH, J.L. et al. The measurement and control of stomatal resistance in the field. Journal Appy. Ecology, v. 2, 1965, p. 345-355.

149. MONTEITH, J.L. Principles of environmental physics. Londres: Edward Arnold Ltd. 1973, p.241.

150. MONTEITH, J. L. Principal of Environmetal Physics. Edward Arnold, London, 1975, p.241.

151. MONTEITH J. L. Light and Crop Production.Field Crop Abstract, v. 18, 1965a, p.213-219.

152. MONTEITH J. L. Light Distribution and Photosynthesis. Annals of Botany, v. 29, 1965b, p.17-37.

153. MORELLI, D. D. O. ; LABAKI, L. C. Paredes verdes: vegetação como qualidade ambiental no espaço construído. In: X Encontro Nacional e VI Encontro Latino Americano de Conforto no Ambiente Construído, 2009, Natal. X Encontro Nacional e VI Encontro Latino Americano de Conforto no Ambiente Construído, 2009. p. 1-6.

154. MORISETTE, J. T.; ROY, D. The MODIS fire products. Remote Sensing of Environment, New York, v. 83, p. 244-262, 2002.

155. MÜLLER, N; WERNER, P; KELCEY, J. G. Urban Biodiversity and Design. Wiley Blackwell, Oxford, UK, 2010

156. NEWTON, A. C. Forest Ecology and Conservation. A Handbook of Techniques. Techniques in Ecology \& Conservation Series, Oxford University Press, Oxford, 2007.

157. NIELSEN, A. B.; NILSSON, K. Urban forestry for human health and wellbeing. Urban Forestry Urban Greening, v.6, 2007, p. 195-197.

158. NIKOLOPOULOU, M.. Designing open spaces in the urban environment: a Bioclimatic approach. Ruros: Rediscovering the Urban Realm and Open Spaces. CRES - Centre for Energy Resources, Department of Buildings, Greece, 2004. 
159. NIKOLOPOULOU, M. Vegetation in the Urban Environment. The Integration of Renewable Energy Sources in Buildings and the Urban Environment, (eds.) CRES, ALTENER, Atenas, 2003.

160. NIKOLOPOULOU, M; BRUSE, M. Urban Green Space in Europe: New approaches for practitioners. In: 3rd GREENCLUSTER International Conference, Utrecht, 2004.

161. NILSON, T. A theoretical analysis of the frequency of gaps in plant stands. Agricultural Meteorology, v.8,1971, p.25-38.

162. NILSON T.; KUUSK, A.; LANG, M.; PISEK, J. KODAR. A. Simulation of statistical characteristic of gap fraction in forest stands. Agricultural Forest Meteorology, 2011.

163. NILSSON, K.; RANDRUP, T. B. Urban and peri-urban forestry. In: XI World Forestry Congress, 1997, Antalya, Turkey, v.1

164. NORMAN, J. M.; CAMPBELL, G. S. Canopy structure. In:PEARCY, R. W.; EHLERINGER, J., MOONEY, H. A., RUNDEL, P. W. (Eds). Plant physiological ecology: field methods and instrumentation. London: Chapman and Hall, 1989. p. $301-326$

165. NORMAN, J. M. Radiative transfer in vegetation. In Neat and Mass Transfer iu the Biosphere (Il. A. DeVries and PI;. H. Afgan, Eds.), Saipto, Washington, DC, 1975.

166. NOWAK, D. J., The effect of Urban Trees on Air Quality. USDA Forest Service, Syracuse, NY. 2004. Disponível no site:

< http://www.fs.fed.us/ne/syracuse/TREE\%20Air\%20Qual.pdF> Acesso em maio de 2010.

167. NUCCI, J. C. Qualidade Ambiental e Adensamento Urbano. Um estudo de Ecologia e Planejamento da Paisagem aplicado ao distrito de Santa Cecília. UFPR, Curitiba, 2008.

168. OKE, Tim R. Evapotranspiration in urban areas and its implication for urban climate planning. In: Conference Teaching the Teachers on Building Climatology. Proceedings. The Nacional Swedish Institute for Building Research, v.2, 1973.

169. OKE, Tim R. Boundary Layer Climates. 2ed. Routledge and John Wiley \& Son; London, New York, 1978.

170. OKE, Tim R. The energetic basis of the urban heat island. Quartely Journal of the Royal Meteorology Society, vol..108, n.455, p.1-24, jan.1982.

171. OKE, Tim R. The Micrometeorology of the Urban Forest. J. Phil. R. Sec. Land. B324, 1989.

172. ONG, Boon Lay. Green Plot Ratio: An Ecological Measure for Architecture and Urban Planning. Landscape and Urban Planning, vol.63, p.197-211, 2002.

173. OMETO, J. C. Bioclimatologia Vegetal. Agronômica Ceres. São Paulo, SP. 1981. 
174. PARREIRA,, A. B. ; AZEVEDO, R. F. ; ZORNBERG, J. G. . Modelagem do comportamento do solo da cidade de São Paulo com vista à escavação do metrô Linha Paulista. In: VI congresso brasileiro de geologia de engenharia e IX congresso brasileiro de mecânica dos solos e engenharia de fundações, 1990, Salvador, 1990. v. 2. p. $45-52$.

175. PENMAM H.L. Natural evaporation from open water, bare soil and grass. In: Proceedings of the Royal Society of London, v.A193, p.120-146, 1948.

176. PEPER, P.J; MCPHERSON, E.G. Comparison of five methods for estimating leaf area index of open-grown deciduous trees. Journal Arboriculture, vol.24 , n.2, p.98111, 1998.

177. PIERCE, L. L.; RUNNING, S. W. Rapid estimation of coniferous forest leaf area using a portable integrating radiometer. Ecology, v.67, 1988, p.1762-1767.

178. PRATA, R. A. Impacto da altura de edifícios nas condições de ventilação natural no meio urbano. Tese (Doutorado em Arquitetura e Urbanismo). Faculdade de Arquitetura e Urbanismo, Universidade de São Paulo, São Paulo, 2005.

179. RAUPACH, M. R..; FINNINGAN, J. J. Single-Layer Models of Evaporation from Plant Canopies Are Incorrect but Useful, Whereas Multilayer Models Are Correct but Useless - Discuss, Australian Journal of Plant Physiology, v. 1, 1988, p. 705-716.

180. RICH, P.M. A manual for analysis of hemispherical canopy photography. Los Alamos National Laboratory Report, 1989.

181. RICH, P.M. Characterizing plant canopies with hemispherical photographs. In: N.S. Goel and J.M. Norman (eds), Instrumentation for studying vegetation canopies for remote sensing in optical and thermal infrared regions. Remote Sensing Reviews, v.5, 1990, p.13-29.

182. RICH, P.M., CLARK, D.A.; OBERBAUER, S.F. Long-term study of solar radiation regimes in a tropical wet forest using quantum sensors and hemispherical photography. Agricultural and Forest Meteorology, v. 65, 1993, p.107-127.

183. ROBINSON, D.; BRUSE, M. Pedestrian Comfort. In: Robinson D. (ed): Computer modelling for sustainable urban design, Earthscan, London, Washington DC, 2011.

184. ROSHEIDAT, A. et al. Visualizing pedestrian comfort using ENVI-met. Third National Conference of IBPSA-USA, 2008.

185. ROSS, J. Radiative transfer in plant communities. Vegetation and Atmosphere, Academic Press, London, 1975.

186. ROSS, J. The radiation regime and architecture of plant stands. The Hague, The Netherlands: Dr Junk W, 1981. 
187. ROWLAND-BAMFORD, A.J. et al. Changes in stomatal density in rice grown under various $\mathrm{CO}_{2}$ regimes with natural solar irradiance. Envir. Exp. Bot. v.30, 1990. p.175-180.

188. RUDORFF, B. Introdução ao Sensoriamento Remoto. $5^{\circ}$ Seminário de Sensoriamento Remoto, interpretação, e Processamento de Imagens de Satélites. São Paulo, 2008.

189. RUNNING, S. W.; COUGHLAN, J. C. A general model of forest ecosystem processes for regional applications: I. Hydrological balance, canopy gas exchange and primary production processes. Ecological Modelling, v. 42, p. 125-154, 1988

190. SAILOR, D. J. Simulated urban climate response to modifications in surface albedo and vegetative cover. Journal of Applied Meteorology, v.34, 1995.

191. SANCHES L. et al. Índice de área foliar em floresta de transição Amazônia cerrado em diferentes métodos de estimativa. Ciência e Natura, v. 30, n.1, p. 57-69, 2008.

192. SANTAMOURIS, M. Energy and Climate in the Built Environment. James and James, London, 2001.

193. SANTOS, R. M; ABREU, L.V; LABAKI, L. C. As árvores e a sensação de conforto térmico. Jornal da Unicamp, Campinas, SP, p.8-8, 29 set. 2008.

194. SÃO PAULO. Secretaria Municipal de Planejamento Urbano. Atlas Ambiental do Município de São Paulo. São Paulo, 2000: SEMPLA, 1985, 358p. Disponível em: $<$ http://atlasambiental.prefeitura.sp.gov.br/> Acesso em maio de 2010

195. SÃO PAULO. Secretaria do Verde e Meio Ambiente. Manual Técnico de Arborização Urbana, São Paulo, 2 ed, 2005.

196. SOCIEDADE BRASILEIRA DE ARBORIZAÇÃO URBANA - SBAU. "Carta a Londrina e Ibiporã". Boletim Informativo, v.3 , n.5, p.3, 1996

197. SHASHUA-BAR, L.; HOFFMAN, M. E. Quantitative Evaluation of trees effects on diurnal air temperatura cooling in urban streets. 2002.

198. SHAW, R. H.; SCHUMANN, U. Large-eddy simulation of turbulent flow above and within a forest. Boundary-Layer Meteorology, v.61, 1992, p.41-64.

199. SNYDER, W. C. et al. Classification-Based Emissivity for Land Surface Temperature Measurement from Space. International Journal of Remote Sensing, v.19, 1998, p.275-2774.

200. SHINZATO, P. ; SPANGENBERG, J. ; BOSCO, L. ; DUARTE, D. Impacto da vegetação nos micriclomas urbanos. In: ENCAC ELACAC 2007 - IX Encontro nacional e V Encontro latino-Americano de Conforto no Ambiente Construído, 2007, Ouro Preto. ENCAC ELACAC 2007 - IX Encontro nacional e V Encontro latino-Americano de Conforto no Ambiente Construído, 2007. 
201. SHINZATO, Paula. Impacto da vegetação nos microclimas urbanos. Dissertação (Mestrado em Arquitetura). Faculdade de Arquitetura e Urbanismo, Universidade de São Paulo, 2009.

202. SILVA FILHO, D.F. ; VEIGA, A.P.B. ; POLIZEL, J. L. ; COUTO, H.T.Z. ; BATISTA, J. L. F. . Efeito de borda no inventário dos maciços de eucalipto do Parque Ibirabuera por meio do uso de Sensoriamento Remoto e Geoprocessamento. Revista da Sociedade Brasileira de Arborização Urbana, v. 2, p. 81-100, 2007.

203. SILVA FILHO, D. F.; MEIRA, A.M; SETTE JÚNIOR, C.R; ALEXANDRINO, E.R; NOGUEIRA, C.L; GUARALDO, E; OLIVATTO, F.; ROLLO, F.M.A; PARRA, J; CHAGAS, M.P ; BIANCHI, M ; GABRIEL, M.V ; CELIDONIO, R.M.G.S ; FLORSHEIM, S.M.B ; COSTA, T.J . Levantamento do Potencial de arborização e proposta para três bairros no município de Piracicaba/SP, Brasil. Revista da Sociedade Brasileira de Arborização Urbana, v. 3, p. 20-39, 2008.

204. SILVA, L.; COSTA, J. F. F.; LIMA, E. R. V.; ALMEIDA, H. A. Análise do albedo $e$ do Índice de Vegetação da Diferença Normalizada (NDVI) em uma bacia hidrográfica, usando o SEBAL - Surface Energy Balance Algorithm for Land. XIII SBGFA, 054, UFV - Vicosa, MG, 2009.

205. SMITH, N. J. Estimating plant area index and light extinction coefficients in stands of Douglas-fir (Pseudotsuga Menziesii). Canadian Journal of Forest Research, v. 2, 1993, p.317-321.

206. SMITH, P. F. Architecture in Climate Change - A Guide to Sustainable Design. ed. 2. Architectural Press. 2005.

207. SPANGENBERG, Jörg. Improvement of urban microclimate in tropical metropolis A case study Maracanã. Rio de Janeiro, 2004. Dissertação (Mestrado de Arquitetura). Faculdade de Arquitetura e Urbanismo, Rio de Janeiro, 2004.

208. SPANGENBERG, J.; JOHANSSON, E.; SHINZATO, P; DUARTE, D. The Impact of Urban Vegetation on Microclimate in Hot Humid São Paulo. In: PLEA 2007 Passive and Low Energy Architecture, 2007, Singapore. PLEA 2007 - Passive and Low Energy Architecture. Singapore: PLEA International, 2007. SPIRN, A. W. $O$ jardim de granito. São Paulo: EDUSP, 1995.

209. SPANGENBERG, J.; JOHANSSON, E.; SHINZATO, P;. DUARTE, D. Simulation of the influence of Vegetation on Microclimate and Thermal Comfort in the city of São Paulo. Revista da Sociedade Brasileira de Arborização Urbana, v. 3, p. 1-19, 2008.

210. STEEMERS, K.; YANNAS, S. Architecture, City, Environment. In: Passive Low Energy Architecture, 17, Proceedings. International Passive and Low Energy Architecture Conference. Cambridge: PLEA, 2000. London: James\& James, 2000. 
211. STEWART, J. B. Modelling surface conductance of pine forest. Agricultural Forest Meteorology, v. 43, 1988, p. 19-35.

212. SOARES, J. V.; ALMEIDA A. C.; PENCHEL R. M. Balanço hídrico de plantações de eucalipto a partir da estimativa de transpiração pelo método de PenmanMonteith (Hydrological balance of eucalypt plantations through transpiration by the method of Penman-Monteith). In:INTERNATIONAL UNION OF FOREST RESEARCH ORGANIZATIONS (IUFRO) CONFERENCE ON SILVICULTURE AND IMPROVEMENT OF EUCALYPTS, 1997, Salvador. Anais... Salvador: v. 4, p. 52-61.

213. SOARES, J. V.; ALMEIDA, A. C. Modelling the water balance and soil water fluxes in a fast growing eucalypt plantation in Brazil. Journal of Hydrology, v. 253, p. 130-147, 2001.

214. SOUDANI, K. Comparaison de methodes optiques pour estimer l'ouverture de la canopée et l'indice foliaire en forêt feuillue. Comptes-Rendus de l'Académie des Sciences, Paris, Sciences de la vie, v.324, 2001, p.381-392.

215. SPANNER, M. A.; PIERCE, L. L.; RUNNING, S. W.; PETERSON, D. L. The seasonality of AVHRR data of temperate coniferous forests: Relationships with leaf area index. Remote Sensing of Environment, v.33, p.97-112, 1990.

216. STONE, B. The City and the Coming Climate: Climate Change in the Places We Live. New York: Cambridge University Press, 2012.

217. STEWART, J.B. Modelling surface conductance of pine forest. Agricultural and. Forest Meteorology, v.43, 1998, p. 19--35.

218. SUKOMINI, N. ; GIACOMELI, D.C ; SCHAMS, J. A ; SILVA FILHO, D.F. ; LIMA, A. M. L. P. ; SALES, A . Análise microclimática de uma área verde e de seu entorno imediato. In: II Simpósio de pós-graduação em Engenharia Urbana, 2009, Maringá. II Simpósio de pós-graduação em Engenharia Urbana. Maringá, 2009. v. 1. p. 1-10.

219. SZEICZ, G.; MONTEITH, J.L.; DOS SANTOS, J. M. Tube solarimetre to measure radiation amoung plants. Journal Applied Ecology, v.1, 1965, p. 169-174.

220. TAHA. H.; AKBARI, H.; ROSENFELD, A. H.; HUANG, Y.J. Residential cooling loads and the urban heat island--the effects of albedo. Building and Environment. v.23, 1988, p.271-283.

221. TAHA, H. et. al. (1992) The impact of trees and white surface on residential heating and cooling energy use in four canadian cities. Energy, v.17, n. 2, 1992, p.141-149. 
222. TAHA, H. Urban climates and heat islands: albedo, evapotranspiration, and anthropogenic heat. Energy and Buildings, n.25, 1997, p. 99-103.

223. TARIFA, J. R, A., TARIK, R.Os climas na cidade de São Paulo. Teoria e prática. São Paulo: Pró-reitoria de Cultura e Extensão. USP: laboratório de Climatologia. FFLCH, 2001. (GEOUSP - Coleção Novos Caminhos, 4).

224. TERJUNG, W. H.; O’ROUKE, P. A. Influences of physical structures on urban energy budgets. Boundary-Layer Meteorology, v.19, 1980, p.421-439.

225. TRICHON, V. et al. Identifying Spatial Patterns in the Tropical Rain Forest Structure using Hemispherical Photograghs. Plant Ecology, v. 137, 1998, p.227247.

226. TROWBRIDGE, P. J.; BASSUK, N. L. Trees in the Urban Landscape. John Wiley \& Sons. 2004.

227. TUCKER, C.J. Red and photographic infrared linear combinations for monitoring vegetation. Remote Sensing of Environment, n.8,1979, p.127-150.

228. TURNER D. P et al.Assessing alternative allometric algorithms for estimating leaf area index in Douglas-fir trees and stands. Ecological Management, in press, 1999.

229. ULRICH, R. et al. Stress recovery during exposure to natural and urban environments. Journal of Environmental Psychology, v.1, 1991, p.201-230.

230. ULRICH, R. Gardens Have The Potential To Improve Health. Science Daily, 2003. Disponível no site: <http://www.sciencedaily.com/releases/2003/11/031124071045.htm> Acesso em outubro 2007.

231. VERTESSY, R. A. et al. Relationships between stem diameter, sapwood area, leaf area and transpiration in a young mountain ash forest. Tree Physiology, v. 15, p. $559-567,1995$

232. VOOGT, J.A. Urban Heat Islands: Hotter Cities. 2004. Disponível no site: <http://www.actionbioscience.org/environment/voogt.html > Acesso em maio de 2010.

233. VOSE, J. M. et al. Vertical leaf area distribution, light transmittance, and the application of the Beer-Lambert Law in four mature hardwood stands in the southern Appalachians. Canadian Journal of Forest Research, v. 25,1995, p.10361043

234. WAGGONER, P. E.; REIFSNYDER, W. E. Simulation of the Temperature, Humidity and Evaporation Profiles in a Leaf Canopy', Journal Applied Meteorology, v. 7, 1968, p.400-409. 
235. WARREN-WILSON, J. Analysis of the spatial distribution of foliage by two-dimensional point quadrats. New Phytologist, v.58, 1959, p.92-101

236. WATSON, D. J. Comparative physiological studies on growth of field crops: I. Variation in net assimilation rate and leaf area between species and varieties, and within and between years. Annals of Botany, v. 11, p. 41-76, 1947.

237. WASSEIGE, C. et al. Seasonal variation of tropical forest LAI based on field measurements in Central African Republic. Agricultural and Forest Meteorology, v. 119, p. 181-194, 2003.

238. WEISS, M. et al. Review of methods for in situ leaf area index (LAI) determination Part II. Estimation of LAI, errors and sampling. Agricultural and Forest Meteorology, n.121, 2004, p. 37-53.

239. WELLES, J. M. Some indirect methods of estimating canopy structure. Remote Sensing Reviews, v. 5, p. 31-34, 1990.

240. WELLES, J.M., COHEN, S. Canopy structure measurement by gap fraction analysis using commercial instrumentation. Journal of Experimental Botany, v.47, 2003, p.1335-1342.

241. WHITFORD, K.R. et al. Measuring leaf area index in a sparse eucalypt forest: a comparison of estimates from direct measurement, hemispherical photography, sunlight transmittance and allometric regression. Agricultural Forest Meteorology, v.74, 1995, p.237-249.

242. WHITMORE T. C. et al. Use of hemisphere photographs in Forest ecology: measurement of gap size and radiation totals in a Bornean tropical rain forest. Journal of Tropical Ecology, v.9, 1993, p.131-151.

243. WILMERS, F. Effects of vegetation on urban climate and buildings, Energy and buildings, v. 15, 1991, p.507-514.

244. XAVIER, A. C. Estimativa de propriedades biofísicas de plantações de eucaliptos a partir de dados Landsat-TM. São José dos Campos, Instituto Nacional de Pesquisas Espaciais, 1998. 86 p. Dissertação (Mestrado em Sensoriamento Remoto) - Instituto Nacional de Pesquisas Espaciais, 1998.

245. XAVIER, A. C. et al. Variação do Índice de Área Foliar em Clones de Eucalipto ao longo do seu ciclo de crescimento. R. Árvore, v.26, n.4, 2002.

246. XAVIER, A. C. Estimativa de propriedades biofísicas de plantações de eucaliptos a partir de dados Landsat-TM. São José dos Campos, Instituto Nacional de Pesquisas Espaciais, 1998. 86 p. Dissertação (Mestrado em Sensoriamento Remoto) - Instituto Nacional de Pesquisas Espaciais, 1998. 
247. XAVIER, A. C. et al. Variação do Índice de Área Foliar em Clones de Eucalipto ao longo do seu ciclo de crescimento. R. Árvore, v.26, n.4, 2002.

248. YANNAS, S. Living with the city. Urban design and Environmental Sustainability. In: Environmentally Sustainability. In: Environmentally Friendly Cities. Proceedings of PLEA'98. Lisbon: James and James, 1998.

249. YEANG, K.. The Green Skyscraper: The Basis for Designing Sustainable Intensive Buildings. Prestel Verlag. 1999.

250. YIN, X. The albedo of vegetated land surfaces: systems analysis and mathematical modelling. Theoretical and Applied Climatology, v.60, 1998, p.121-140.

251. YU, C.; HIEN, W. N. Thermal benefits of the city parks. Energy and Buildings, n.38, 2006, p. 105-120.

252. ZHANG, L. et al. Modelling Hydrologic Processes Using a Biophysically based Model - Application of Waves to FIFE and HARPEX - MOBILHY. Journal of Hydrology, v. 185, 1996, p. 147-169

253. ZHENG, G. et al. Retrieving Leaf Area Index (LAI) Using Remote Sensing: Theories, Methods and Sensors. Sensors, n.9, 2009. 